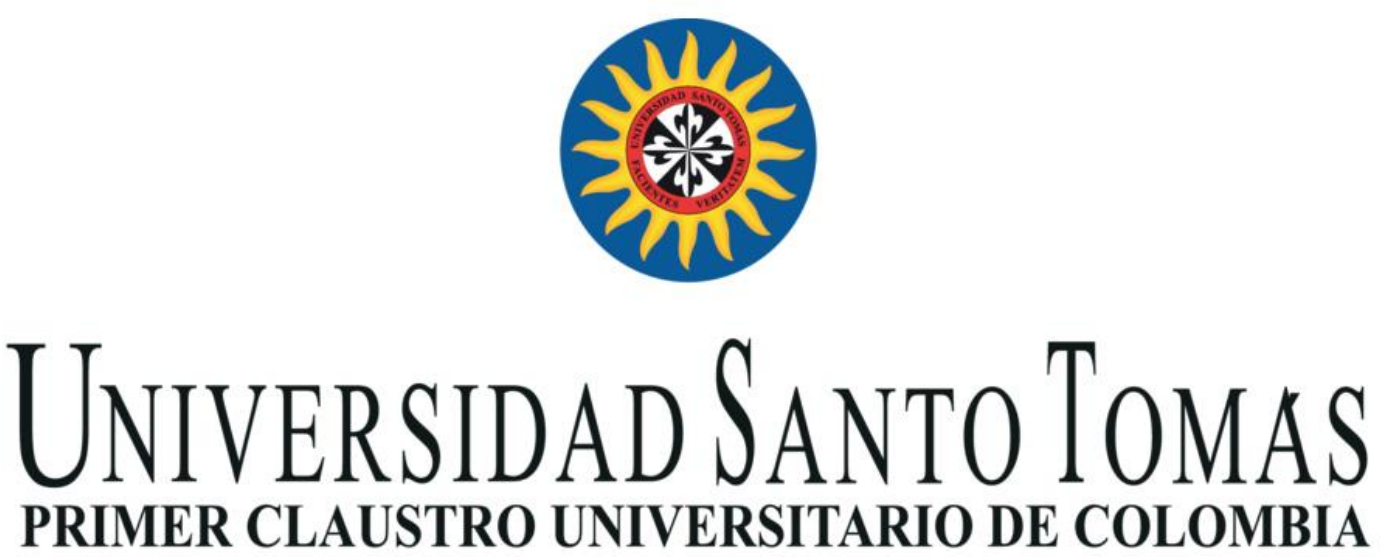

INCIDENCIA DE LA GARANTÍA DE COMPRA COMO HERRAMIENTA DE ESTÍMULO A LA PRODUCCIÓN CAFETERA EN ANTIOQUIA. UN ANÁLISIS EMPÍRICO PARA EL PERIODO 1999 A 2013.

EFRAIN SANTIAGO MENDOZA BETANCOURT

UNIVERSIDAD SANTO TOMÁS

FACULTAD DE ECONOMÍA

MAESTRÍA EN CIENCIAS ECONÓMICAS

Bogotá D.C., Colombia 2016 


\section{INCIDENCIA DE LA GARANTÍA DE COMPRA COMO HERRAMIENTA DE ESTÍMULO A LA PRODUCCIÓN CAFETERA EN ANTIOQUIA. UN ANÁLISIS EMPÍRICO PARA EL PERIODO 1999 A 2013.}

\section{EFRAIN SANTIAGO MENDOZA BETANCOURT}

Tesis presentada como requisito para optar al título de:

Magíster en Ciencias Económicas

Director: Gustavo Díaz

UNIVERSIDAD SANTO TOMÁS

FACULTAD DE ECONOMÍA

MAESTRÍA EN CIENCIAS ECONÓMICAS

Bogotá D.C., Colombia

2016 


\section{CONTENIDO}

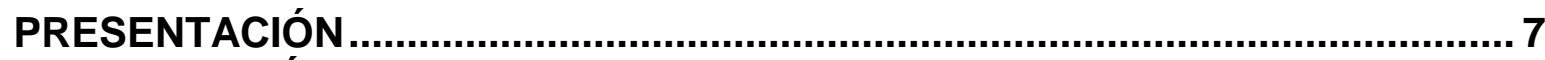

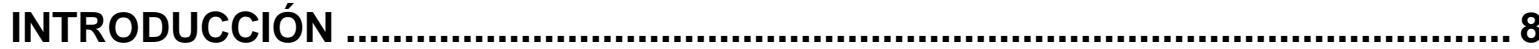

CAPÍTULO 1. ACERCAMIENTO TEÓRICO SOBRE LA ESTABILIZACIÓN DE

PRECIOS EN EL MERCADO CAFETERO..................................................... 12

1.1 Estructura oligopólica del mercado ..................................................... 12

1.2 Relación con el mercado cafetero ..................................................... 16

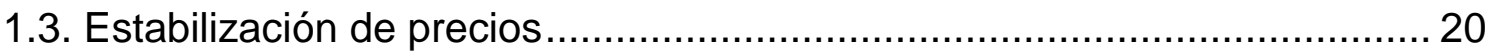

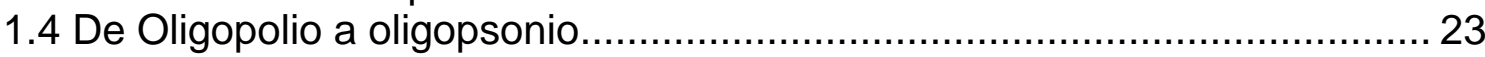

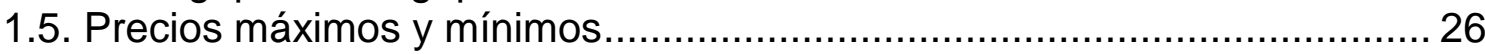

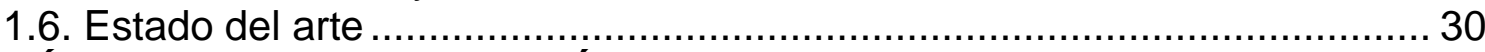

CAPÍTULO 2. CARACTERIZACIÓN DEL SECTOR CAFETERO.......................... 35

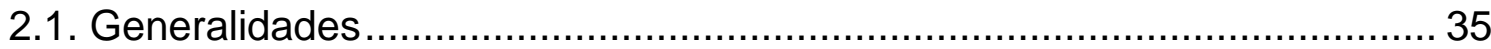

2.2. Garantía de Compra ................................................................................. 41

2.3. El Fondo Nacional del Café y la Garantía de Compra ............................. 46

2.4. El año en que cambió el negocio del café ............................................. 48

2.5 Los noventas y el 2000, el periodo de transición .................................... 50

2.6. La institución como respaldo .............................................................. 53

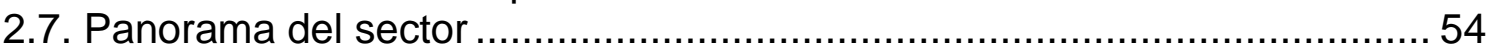

CAPÍTULO 3. INCIDENCIA DE LA GARANTÍA DE COMPRA COMO HERRAMIENTA DE ESTÍMULO A LA PRODUCCIÓN CAFETERA. UN ANÁLISIS EMPÍRICO PARA EL PERIODO 1999 A 2013 EN ANTIOQUIA. .......57

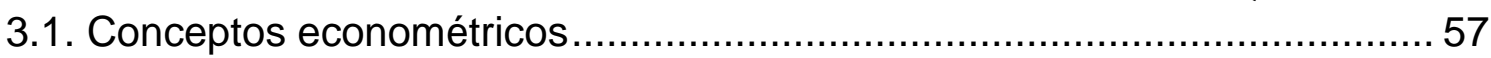

3.2. Descripción del entorno cafetero en Antioquia........................................ 59

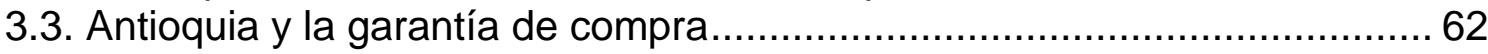

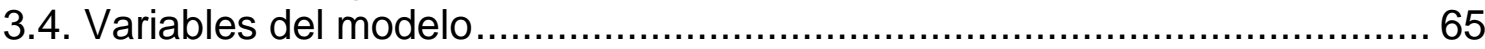

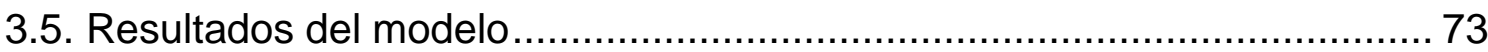

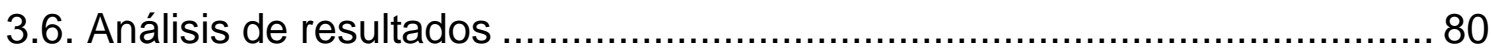

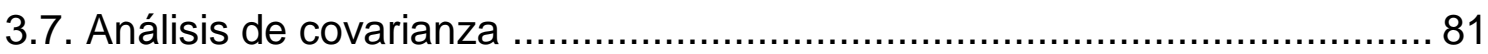

3.8. Respuesta de las variables estudiadas............................................... 85

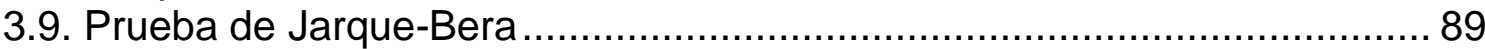

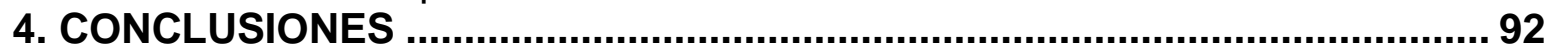

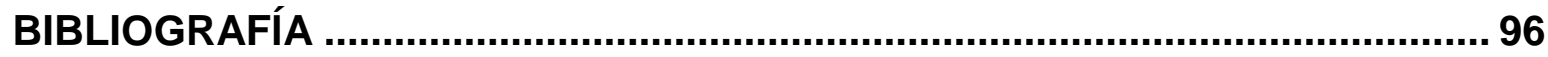

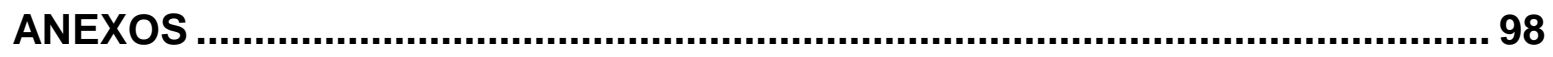




\section{ÍNDICE DE FIGURAS}

Figura 1. Equilibrio con curvas de oferta y demanda ...................................... 15

Figura 2. Política cafetera durante el Acuerdo Internacional del Café................... 18

Figura 3. El líder en la elección del precio ..................................................... 19

Figura 4. Política cafetera después del Acuerdo Internacional del Café.............. 24

Figura 5. Precios máximos como agente estabilizador de precios en el mercado.

Figura 6. Área (hectáreas) sembrada en café y número de cafeteros por

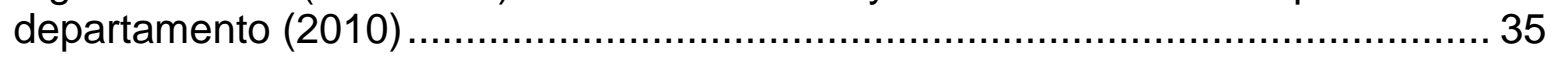

Figura 7. Distribución porcentual de los cafeteros según el tamaño de cultivo

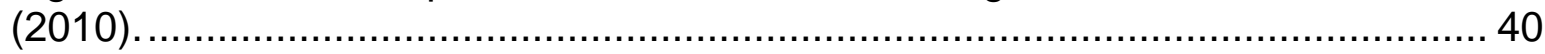

Figura 8. Distribución porcentual de la producción total según tamaño de cultivo

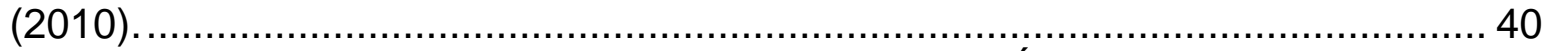

Figura 9. Garantía de compra deflactada ajustados al Índice de Precios del

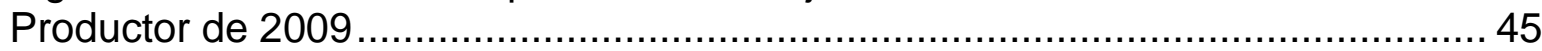

Figura 10. Promedio precio Mensual de la libra Café, convertido a TRM de Colombia y deflactado con el ITCRIP IPC de 2009 versus promedio mensual de la

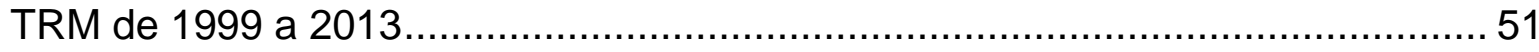

Figura 11. Producción registrada mensual en miles de sacos de $125 \mathrm{Kg}$ de café verde pergamino en Colombia ..................................................................... 52 Figura 12. Producción total de los principales países exportadores en miles de

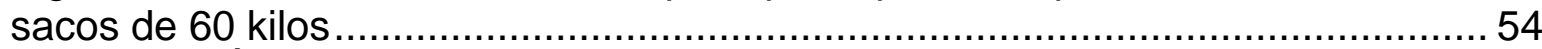

Figura 13. Área cultivada con café de Antioquia, Huila y Tolima......................... 60

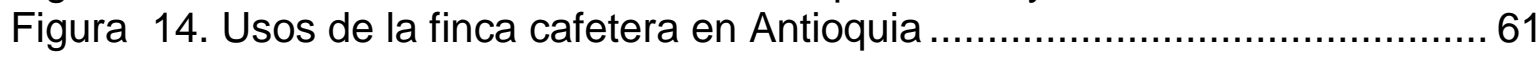

Figura 15. Variables que determinan el precio del café en Colombia ................. 63

Figura 16. Comportamiento entre los costos totales y beneficios para grandes productores de café de Antioquia.................................................................. 70 Figura 17. Comportamiento entre los costos totales y beneficios para productores medianos de café de Antioquia (variaciones porcentuales) ................................. 71 Figura 18. Comportamiento entre los costos totales y beneficios para productores pequeños de café de Antioquia (variaciones porcentuales) ............................... 72 Figura 19. Comportamiento entre el precio internacional de la libra de café y la garantía de compra (variaciones porcentuales) ….......................................... 73 Figura 20. Covarianzas en valores porcentuales con su coeficiente de correlación (paneles). 83

Figura 21. Análisis impulso-respuesta de la garantía de compra y distintas variables cafeteras (paneles) 87 


\section{LISTA DE TABLAS}

Tabla 1. Algunos autores que han abordado la problemática de la estabilización de

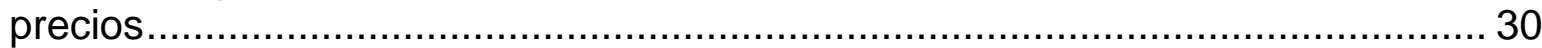

Tabla 2: Definiciones acerca de la industria del café ........................................ 37

Tabla 3. Área cultivada con café total a nivel departamental ............................. 39

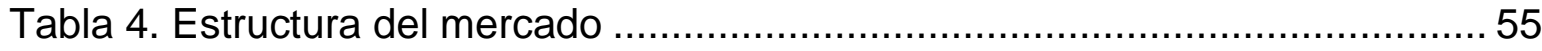

Tabla 5. Variables que conforman el modelo econométrico ................................. 68

Tabla 6. Regresión lineal múltiple con cultivadores pequeños ............................ 74

Tabla 7 Regresión lineal múltiple con cultivadores medianos ............................. 75

Tabla 8. Regresión lineal múltiple con cultivadores grandes............................... 76

Tabla 9 Regresión lineal múltiple con cultivadores pequeños simulando aumento de la garantía de compra al 10 \%........................................................... 77

Tabla 10 Regresión lineal múltiple con cultivadores medianos simulando aumento de la garantía de compra al $15 \%$ 78

Tabla 11. Regresión lineal múltiple con cultivadores grandes simulando aumento

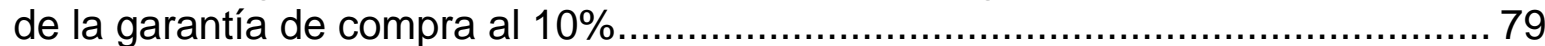

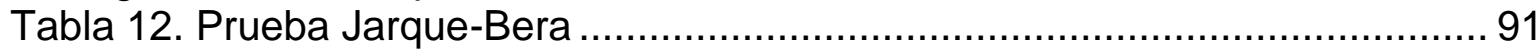




\section{LISTADO DE ANEXOS}

Anexo A. Índice de Precios al Productor y serie costos totales para productores grandes de Antioquia 98

Anexo B. Serie costos totales para productores medianos y pequeños de

Antioquia. 103

Anexo C. Garantía de compra deflactada con el Índice de Precios al Productor de 2009 y margen de beneficios de productores grandes de café 108

Anexo D. Margen de beneficios de productores medianos y pequeños de café. 113 Anexo E. Producción registrada y volumen de las exportaciones colombianas de café mensuales 118

Anexo F. Promedio mensual de la Tasa Representativa del Mercado de 1999 a 2013 en valores corrientes e Índice de tasa de cambio real. 123 Anexo G. Promedio mensual de la Tasa Representativa del Mercado de 1999 a 2013, deflactado Con ITCRIP IPC del Año 2009 y Promedio mensual de la Tasa Representativa del Mercado de 1999 a 2013 deflactado con el ITCRIP IPC de 1999. 128

Anexo H. Precio Mensual por de libra café arábica suave, precio mensual por libra de café, arábica suave convertido a TRM de Colombia deflactado con el ITCRIP IPC de 1999. Precio Mensual por libra de café arábica suave convertido a TRM y deflactado con el ITCRIP IPC de 2009 133

Anexo I. Costo de producción por hectárea (pequeños) 138

Anexo J. Costo de producción por hectárea (medianos) 139

Anexo K. Costo de producción por hectárea (grandes) 140 


\title{
PRESENTACIÓN
}

La garantía de compra en el sector cafetero surge en 1958 como uno de los bienes públicos más importantes en la generación de ingresos a los caficultores, y al mismo tiempo como una de las herramientas más visibles de la Federación Nacional de Cafeteros (FNC).

En vista que la política de la garantía de compra es uno de los recursos más importantes que ofrece el gremio para todos los caficultores, para asegurar su producción durante todo el año, la presente investigación busca evaluar a través de un análisis empírico la incidencia de la efectividad de esta herramienta en la producción del Departamento de Antioquia y en el ingreso de los caficultores en el período 1999 a 2013.

Palabras claves: Incidencia, garantía de compra, economía cafetera, ingresos caficultores, producción, institucionalidad cafetera, Departamento de Antioquia.

\begin{abstract}
The purchase guarantee in the coffee sector emerged in 1958 as one of the most important in generating income to growers public goods, and at the same time as one of the most visible tools of the National Federation of Coffee Growers (FNC).

Given that the policy purchase guarantee is one of the most important resources offered by the guild for all coffee producers to ensure their production throughout the year, this research seeks to assess through an empirical analysis of the incidence of effectiveness of this tool in the production of the Department of Antioquia and the income of farmers in the period 1999-2013.
\end{abstract}

Key words: Incidence, purchase guarantee, coffee economy, farmer's income, production, institutional coffee, Department of Antioquia 


\section{INTRODUCCIÓN}

Desde la creación de la Federación Nacional de Cafeteros (FNC) en 1927, por lo general siempre ha sido prioridad de este gremio la protección de los caficultores de los choques externos que tiene el precio del café. A lo largo del siglo pasado y el actual, siempre ha sido de gran atención hacer del caficultor un protagonista más activo en la cadena de producción del grano que involucra a todos los agentes que intervienen en la economía cafetera.

Sin embargo, un suceso que cambió el rumbo de la industria fue la culminación del Pacto de Cuotas en 1989, situación que expuso un nuevo escenario de liberalización de los mercados y un entorno global, en donde el precio del café estaría más sujeto a los vaivenes del mercado por cuenta de nuevos jugadores y que posteriormente ocasionó una crisis que afectó los ingresos de los caficultores y las finanzas de la FNC.

Si bien es cierto que el precio del café se ha enfrentado a escenarios como altas volatilidades a lo largo de su historia, la transformación de un mercado inmerso entre competidores directos como Brasil y Vietnam, la revaluación del peso, el clima, los excesos de inventario, y los costos de producción, estos factores no han influido para que los cafeteros no se queden abandonados.

Por tal motivo a nivel de política pública, y para el caso cafetero, el Gobierno ocasionalmente adopta políticas de otorgar subsidios para el sostenimiento del sector en época de precios bajos. Entretanto, existe otro mecanismo a nivel institucional, mediante el cual la Federación Nacional de Cafeteros (FNC), a través del Fondo Nacional del Café (FoNC), le garantiza al caficultor tener asegurada toda su producción durante todo el año en todos los municipios cafeteros al precio de referencia del día. Este mecanismo se denomina garantía de compra. 
Distintos autores coinciden en calificar este incentivo como un instrumento crucial de la política cafetera con la cual se garantiza la obtención del café sin tomar en cuenta la cantidad, se entrega en efectivo y al mejor precio posible, dadas las coyunturas sobre el cual se encuentra el precio internacional del grano.

Dicha garantía se aplica sobre un precio interno de referencia para la compra de café pergamino seco por carga de 125 kilos. Sin embargo al presenciar estos antecedentes el presente documento busca responder la siguiente pregunta de investigación: ¿La garantía de compra ha incentivado la producción cafetera y le ha generado beneficios a los cultivadores de Antioquia?

Es preciso mencionar que la presente investigación se sustenta bajo tres pilares teóricos como el institucionalismo, la estabilización de precios y la economía del libre mercado. Al evaluar la incidencia de este incentivo como herramienta de estímulo a la producción cafetera mediante un análisis empírico para el periodo 1999 a 2013, se vuelve ahora más imprescindible precisar cuáles pueden ser las nuevas decisiones de política que se deberán tomar para fortalecer la garantía de compra y mejorar el bienestar de las familias que viven de la producción cafetera.

Asimismo en vista de lo importante que se ha vuelto la garantía de compra en la historia de la caficultura, en el siguiente documento se propone cumplir tres objetivos primordiales; como objetivo general se propone analizar la incidencia de la garantía de compra como herramienta de estímulo a la producción cafetera entre los periodos de 1999 a 2013 en la región de Antioquia.

Adicionalmente se propone determinar la relación existente entre la garantía de compra, la producción y los beneficios para diferentes tipos de caficultores de Antioquia como objeto de estudio, así como también examinar qué políticas institucionales se han implementado en el periodo de referencia. Otro de los objetivos planteados va dirigido a plantear recomendaciones de intervención acerca del planteamiento del problema. 
El documento se desarrollará en cuatro capítulos. En el primero se dará a conocer al lector los aspectos que comprende el funcionamiento de la industria cafetera antes y después de 1989. Paralelo a ello el capítulo dos explica el funcionamiento de la comercialización del grano bajo el fundamento teórico de estabilización de precios.

El capítulo tres propone explicar dicha relación a partir de la identificación de un modelo econométrico, como instrumento metodológico que permitirá establecer la incidencia que genera la garantía de compra sobre la producción cafetera acudiendo a distintas variables que establezcan el cumplimiento de este apartado y concluir a partir de la evidencia si hubo un impacto positivo y responder a la pregunta de investigación. Parte del procedimiento involucra evidenciar qué tan significativa es la relación entre la producción cafetera con las exportaciones, el margen de beneficios entre otras variables.

Finalmente, el capítulo cuatro planteará las principales conclusiones sobre la incidencia del modelo analizado y valorado en la sección tres del documento y se proponen algunas recomendaciones de política de acuerdo a la pertinencia de los resultados estudiados anteriormente.

Aunque el trabajo deja como precedente el hecho de que se trata de medir qué tan relevante es la garantía de compra en la producción, la realización de la investigación mostró algunas dificultades como asimetrías al momento de conseguir la información, como es el caso de los costos de producción así como también identificar las variables con más significancia estadística ya que por cuestiones de habeas data, la FNC no facilitó la información solicitada dificultando el proceso de investigación. Prueba de lo anterior lo certifican autores especializados en economía cafetera, al asegurar que al momento de examinar las problemáticas en el eje cafetero colombiano, existen inconsistencias en la consecución de datos cuantitativos y cualitativos. 
“(...), en los estudios existentes la falta de información sobre el sector limita y dificulta tomar decisiones. La carencia estadística detallada a nivel microeconómico en Colombia, discriminada por tipo de productor cafetero, es un problema relevante que no permite evidenciar las debilidades del sector para formular políticas económicas cafeteras." (Perdomo \& Hueth, 2010, p. 7).

Por otra parte, los alcances del presente documento apuntan a dejar para futuras investigaciones, qué tan rentable se vuelve esta herramienta de política económica en otras regiones del país con la asociación de otras variables. Considerados los precedentes anteriores se sugiere la pertinencia de esta investigación para evaluar qué variables contempladas en esta investigación además, de la garantía de compra, contribuyen a la producción cafetera de otros departamentos. 


\section{CAPÍTULO 1. ACERCAMIENTO TEÓRICO SOBRE LA ESTABILIZACIÓN DE PRECIOS EN EL MERCADO CAFETERO}

En este primer capítulo se expone el fundamento teórico que permite entender el mecanismo de estabilización de precios que el mercado cafetero mantuvo durante los Acuerdos Internacionales de Café ${ }^{1}$ que se dio desde 1962 y se mantuvo hasta 1989, como consecuencia de la creación de la Organización Internacional del Café. También se explica la liberalización de los mercados que llevó a que después de dicho año se diera otra lógica económica.

\subsection{Estructura oligopólica del mercado}

Antes de 1989 el escenario de la industria cafetera estaba dado por la política de estabilización de precios. Esta medida estuvo muy marcada principalmente en los años sesenta en actividades muy dependientes de productos básicos para regular la oferta, controlar inventarios o establecer cuotas de exportación si la industria los veía necesario, aspecto que se traduce en mayores precios.

Reina et al, (2007, p. 51) exponen como el café obtuvo un comportamiento similar cuando se creó el Organismo Internacional del Café en 1962; a través de los Acuerdos Internacionales del Café se buscaba regular precios internacionales por medio de cuotas de exportación de obligatorio cumplimiento. Al ver que dichos acuerdos tuvieron interrupciones por aspectos como el auge de la cotización mundial por cuenta del incidente ocurrido en Brasil en 1975 conocido como la "Helada Negra" y que cambió abruptamente las condiciones de mercado, los acuerdos de referencia finalmente se cancelaron en 1989.

Previo a 1989 existía un esquema de mercado caracterizado por la política de estabilización de precios y posterior a su fecha se estructura otro esquema de

\footnotetext{
${ }^{1}$ Es pertinente advertir que el lector de este documento conozca de entrada que dicho Acuerdo difiere del Pacto de Cuotas que más adelante se explicará.
} 
mercado caracterizado por la liberalización económica. Antes de 1989 la dinámica de los productores estaba guiada por la restricción de la oferta hasta el punto de que la limitación en la comercialización del grano estaba restringida y generaba un punto de equilibrio dominado por una menor cantidad del grano y como consecuencia de esto se generaban mayores precios. Antes de pasar a explicar los mercados bajo el cual se sometió el sector cafetero antes y después de 1989, es pertinente realizar una comprensión del funcionamiento de los mercados a nivel general.

De acuerdo con Varian (2010, p. 293) "se supone que cada demandante y cada oferente consideran que dados los precios -es decir, fuera de control- y averiguan simplemente qué es lo mejor que pueden hacer dados esos precios de mercado. Un mercado en el que cada agente económico considere que el precio de mercado está fuera de su control se denomina mercado competitivo".

En este aspecto los agentes económicos involucrados en este escenario no tienen posibilidades de regir posición de mando entre la interacción de productores y consumidores. Este argumento es respaldado por Casas Pardo, (2007, p. 513) al afirmar que "(...) el que los vendedores individuales sean precio-aceptantes, es realmente la característica que define el mercado competitivo (...) No obstante, para cada empresa que actúa en competencia perfecta, su curva de demanda es perfectamente elástica".

En este orden de ideas Varian nuevamente expone a manera de supuesto que el mercado es competitivo porque tanto productores y consumidores conforman una porción pequeña del conjunto, la cual cada suma de dichas porciones ejercen una influencia inapreciable en el precio del mercado. "Aunque en un mercado competitivo el precio del mercado puede ser independiente de los actos de un agente, son los actos de todos los agentes los que lo determinan." (Varian, 2010 p. 294). 
En cuanto al precio de equilibrio de un bien el autor de referencia señala que dicha conducta se da cuando su oferta es igual a su demanda. "Si $D(p)$ es la curva de demanda del mercado y $S(p)$ la de la oferta, el precio de equilibrio es * $p$ ". (Varian, 2010, p. 294)". Lo anterior se explica en la siguiente ecuación 1:

$$
D(p *)=\mathrm{S}\left(p^{*}\right)
$$

1.

En donde Varian (2010, p. 294) expone que "las curvas de demanda y oferta representan las elecciones óptimas de los agentes implicados, y el hecho de que éstas coincidan al precio ${ }^{*} p$ indica que las conductas de los demandantes y los oferentes son compatibles".

Samuelson \& Nordhaus (2006, p. 177) complementan este concepto de Varian bajo la teoría de la oferta y la demanda, en donde se parte del supuesto de que por un lado, si el mercado funciona de forma autónoma, en el caso del primero, "un aumento de oferta de un bien (si la curva de demanda permanece constante) generalmente reducirá el precio y aumentará la cantidad que se compra y se vende. Una reducción de oferta tiene el efecto contrario".

Por el otro lado agregan que, "un aumento de demanda de un bien (sin que haya cambios en la curva de oferta) elevará el precio de la misma y asimismo para la mayoría de los bienes; un aumento de demanda también incrementará la utilidad demandada. Una reducción de demanda tendrá los efectos contrarios". (Samuelson \& Nordhaus, 2006, p. 177).

Aunque los autores insisten que estas dos reglas de la oferta y la demanda reflejan de manera cualitativa los efectos de las variaciones de ambas interacciones, los efectos cuantitativos en el precio y la cantidad dependen de las formas exactas de las curvas de oferta y demanda (Figura 1). 


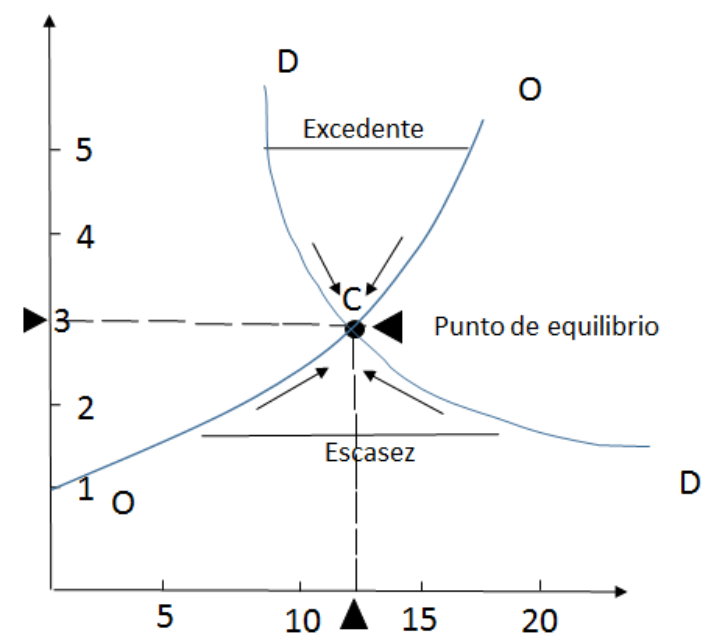

Figura 1. Equilibrio con curvas de oferta y demanda

Fuente: Elaboración propia con base en Samuelson y Nordhaus (2005, p. 177).

En la Figura 1 se observa como en este principio económico del equilibrio de mercado se encuentra en la intersección de las curvas de oferta y de demanda. Para Varian, en términos geométricos, es el precio al que la curva de demanda corta a la de su oferta. Adicional esto se hace pertinente explicar de una forma más procedimental las interacciones entre productores y vendedores. Casas Pardo (2007, p. 512) y Encinas (2010, p. 3) coinciden y al mismo tiempo explican esta situación a través del funcionamiento de competencia perfecta en donde se parten de los siguientes supuestos:

> Gran cantidad de productores (Oferta) y consumidores (Demanda), en los cuales ninguno de los dos agentes domina una parte significativa del mercado total del producto, esto es que ninguno de los oferentes produce una parte de la oferta tan grande que le permita determinar el precio, y tampoco ninguno de los consumidores consume una parte de la demanda tan grande que le permita controlar el precio.

$>$ Los productos no están diferenciados (o lo que es lo mismo, las mercancías que los productores ofrecen son exactamente iguales entre sí), aspecto importante cuando se trata de estudiar un commodity como el café. 
$>$ Tanto los productores como los consumidores tienen una información perfecta de los precios y condiciones del mercado.

$>$ De igual manera tanto la oferta como la demanda tendrán que dar por aceptado un precio socialmente determinado.

$>$ El precio será, por lo tanto, suficiente para que el productor cubra los costos de los factores invertidos en la producción (tierra, trabajo y capital) lo que implica tanto los costos explícitos, como los implícitos (los costos de oportunidad).

\subsection{Relación con el mercado cafetero}

Justamente, al introducir la teoría económica con el mercado cafetero, -en donde la política de estabilización de precios fue muy marcada principalmente en los años sesenta en actividades muy dependientes de productos básicos para regular la oferta con acuerdos para restringir la producción, controlar inventarios o establecer cuotas de exportación, aspecto que se traduce en mayores precios ${ }^{2}$-, los equilibrios en el mercado se evidenciaron bajo situaciones de oligopolio.

De acuerdo con Casas Pardo (2007, p. 551) el oligopolio comprende un mercado que se caracteriza por tener pocos vendedores. "Corresponde tanto a la situación en la que sólo existen unas pocas empresas grandes, como en la que se dan varias empresas pequeñas y una o pocas empresas grandes que producen la mayor parte del bien que elabora la industria."

En un mercado los distintos productores que realizan un determinado producto por regla propia, adoptan el comportamiento de obtener beneficios individuales sin seguir a sus semejantes, en el contexto de los mercados con oferentes reducidos

\footnotetext{
2 En el caso del petróleo Mankiw (2002, p. 67) expone como en la década de 1970, los miembros de la Organización de Países del Petróleo (OPEP) incrementaron el precio mundial del crudo con el fin de aumentar la renta: "Estos países lograron su objetivo reduciendo conjuntamente la cantidad ofrecida de petróleo. Entre 1973 y 1974, el precio del petróleo (...) subió más de un $50 \%$. Unos pocos años más tarde la OPEP volvió a hacer lo mismo. El precio subió un 14\% en 1979, un 34\% en 1980 y un $34 \%$ en 1981" (Mankiw, 2002 p. 67).
} 
también se corre con el supuesto de que la concertación de distintos productores debe dar también paso a la generación de beneficios colectivos.

Esta conjetura la expone de forma apropiada Casas (2007, p. 533) con la hipótesis de la maximización de los beneficios conjuntos, en donde se "afirma que existen fuerzas que empujan a la empresa a comportarse en ambas direcciones (la de la maximización de los beneficios conjuntos y la de la maximización de los beneficios individuales)".

El autor de referencia señala que a medida que las empresas (países productores de café $)^{3}$ que aprovechan más su categoría de interdependencia mutua podrán maximizar los beneficios de la industria. Asimismo Casas (2007, p. 554) resalta que "esta interdependencia mutua tenderá (céteris paribus) a ser mayor cuanto más reducido sea el número de empresas en la industria, cuanto más similares sean estas en volumen y métodos de producción y cuanto más parecidos (homogéneos) sean los productos que venden".

Transportando esta teoría al contexto de la industria cafetera el autor mencionado señala dentro de los tipos de oligopolio dos clases: el perfecto o concentrado (caracterizado porque pocas empresas producen un bien escasamente diferenciado) y el oligopolio imperfecto o diferenciado (cuando pocas compañías producen un bien heterogéneo o diferenciado), cumpliéndose más el primer caso para la industria de referencia.

Siguiendo con esta línea argumentativa del estudio del oligopolio en la industria cafetera ahora es esencial describir las condiciones por la cual se daba este tipo de mercado. Para Bohman \& Jarvis (1989, p. 3) durante el Acuerdo Internacional del Café $^{4}$ se establecería una cuota universal para las exportaciones de todos los

${ }^{3}$ Categorización hecha a cargo del autor de este documento.

4 De Acuerdo con Junguito Bonnet \& Pizano Salazar (1993, p. 250) en 1962 se celebró en Nueva York bajo los auspicios de Naciones Unidas, el primer Convenio Internacional del Café entre países productores y consumidores de café. Durante las sesiones se presentaron 36 países exportadores 
mercados, miembros y no miembros ${ }^{5}$, lo que resultaría en un solo precio mundial, siempre y cuando que no presentaran fraudes. Para los mismos autores esta situación implicaba que para mantener los ingresos constantes, los exportadores se propusieron ajustes apropiados para la asignación de una cuota global.

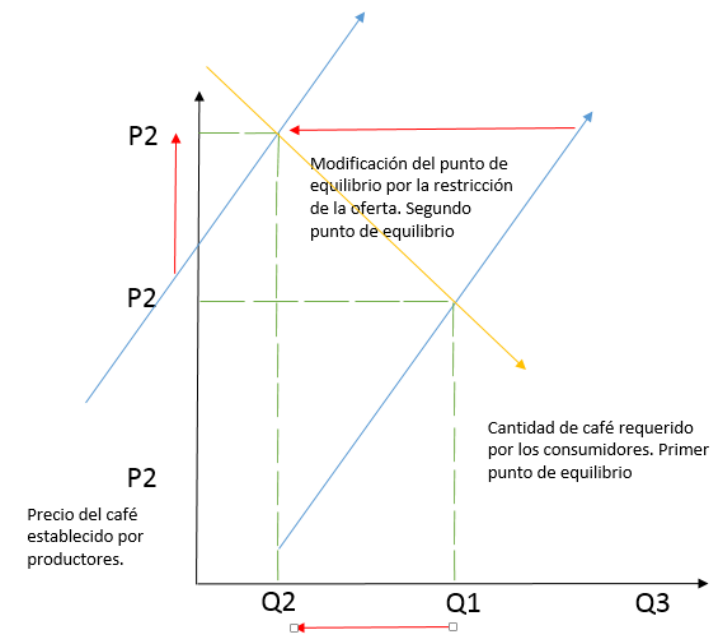

Figura 2. Política cafetera durante el Acuerdo Internacional del Café. Fuente: Elaboración propia con base en Varian (2010).

Para el caso de análisis se observa que en el Figura 2 se detallan los efectos en los precios vía un control de la cantidad de grano de café. En otras palabras el escenario de un mercado imperfecto causa que en el primer punto de equilibrio acerca de la cantidad de café requerido por los consumidores, se traslade hacia otro punto de equilibrio por cuenta de la restricción de la oferta y otras condiciones de mercado establecido por los productores de café ${ }^{6}$ haciendo que los compradores tengan que adquirir el grano a precios más altos.

que representaban más del $90 \%$ de la producción mundial y 24 consumidores netos, o sea, más del $80 \%$ del mercado de importación. En esa misa instancia se creó también la Organización Internacional del Café. Los temas a tratar comúnmente eran los relacionado con franja de precios, sistemas e cuotas básicas, cuota anual, sistemas de revisión de las cuotas anuales, mecanismos de ajustes de cuotas en función de la evolución de los precios, metas de producción y sistemas de regulación de importaciones.

${ }^{5}$ Antes de 1989 en el mercado cafetero el Acuerdo Internacional del Café (AIC) establecía una política de precios en forma de prebendas para aquellos grandes consumidores miembros de la AIC y aquellos que no formaban parte de este bloque de mercado.

6 Junguito Bonnet \& Pizano Salazar (1997, p. 84) mencionan que dentro de esas condiciones de mercado involucraba el cumplimiento de compromisos estipulados en el Decreto 080 de 1958 y la Ley $1^{a}$ de 1959. "el primero instituyó la llamada "retención cafetera" que era la obligación de entregar, sin compensación alguna un volumen dado de café pergamino por saco de exportación. Dicha 
Si antes había un precio de equilibrio, la política de bajar los volúmenes del grano para su comercialización ocasionó un incremento de los precios pasando de P1 a P2. Para este precedente es necesario establecer que la demanda tendría que darse de forma inelástica, en donde las cantidades demandadas no sufrirían un grado de sensibilidad notorio ante una variación en el precio.

En la teoría microeconómica Varian (2010, p. 505) anuncia que el líder en la prácticas de oligopolio, que en este caso se puede referir a los cafeteros, desea maximizar sus beneficios eligiendo un precio y un nivel de producción en los que el ingreso marginal sea igual al costo marginal. "Sin embargo, el ingreso marginal debe ser el ingreso marginal correspondiente a la demanda residual, es decir, la curva que mide de hecho el nivel de producción que podrá vender a cada uno de los precios dados". Varian (2010, p. 505).
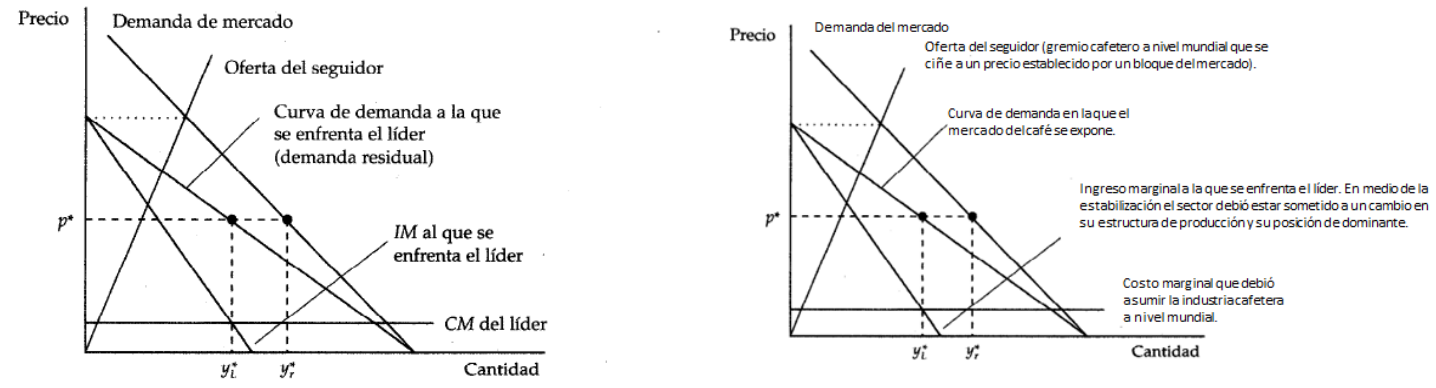

Figura 3. El líder en la elección del precio Fuente: Elaboración propia con base en Varian (2010).

retención que entraba al Fondo Nacional del Café, estaba encaminada -tal como se citan en los artículos de 1, 3 y 5 del Decreto-Ley 80 de 1958- a promover la estabilidad de los precios de café en el exterior y en el interior del país", así como también que los recursos transferidos al Fondo, fueran de gran ayuda a la financiación de sus compras de café en el mercado y al fortalecimiento de la política cafetera.

Por otra parte la Ley $1^{\text {a }}$ de 1959 citados por los autores de referencia se caracterizó por establecer importantes reformas al régimen cambiario y de comercio exterior, autorizó de paso a la Federación, como administradora del Fondo Nacional del Café para realizar diversas operaciones de crédito a favor de países extranjeros, y otras transacciones comerciales de crédito a favor de países extranjeros, y otras operaciones comerciales y cambiarias, con el fin de abrir nuevos mercados al café colombiano. 
Citando a Varian (2010, p. 503) nuevamente en la Figura 3, la curva de demanda a los que se enfrenta el líder es la curva de demanda del mercado menos la curva de oferta del seguidor, en donde el líder iguala el ingreso marginal para hallar la cantidad óptima que debe ofrecer, $y^{*} L$. La cantidad total ofrecida en el mercado es $y^{*} r$ y el precio de equilibrio $p^{*}$. En medio de este escenario, desde la óptica de la oferta el líder es quien dispone de todas las facultades para condicionar el mercado a nivel de demanda. Para estos efectos, el sector debió haber analizado qué tanto maniobraba con su estructura de producción y así establecer su posición dominante.

\subsection{Estabilización de precios}

Además de la estructura oligopólica sobre el cual estuvo sometido el mercado del café, también se hace necesario ofrecer la lógica económica sobre el cual operaban estos agentes tanto para la demanda como desde la oferta. Para esto la estabilización de precios obligaba a los productores de café estabilizar los precios del grano ya que según Thomas (1986 p. 104) "algunos observadores piensan que la incertidumbre sobre los precios lleva a los productores a tomar decisiones equivocadas, pues no sabiendo cómo se comportarán aquellos en el futuro, basan sus decisiones en los precios actuales, generando con ello alternativamente épocas de abundancia y de escasez".

Bajo esta situación, Thomas también señala que las preocupaciones relacionadas con los efectos macroeconómicos de la inestabilidad de los precios se basan en el supuesto de que consumidores y productores tienen distintas propensiones marginales a consumir, aspecto que causa un nivel de sensibilidad importante en la oferta y demanda de este producto. "De ahí el argumento de que, cuando las fluctuaciones en los precios agrícolas y en la producción generan un desplazamiento del ingreso entre los dos grupos, la demanda de productos individuales -lo mismo que la demanda agregada- también fluctúa, desestabilizando al resto de la economía". (Thomas 1986, p. 105). 
La anterior situación fue inevitable y es que tal como lo comprueban Reina et al (2007, p. 53), se mencionan tres requisitos indispensables para el funcionamiento de la estabilización de los precios en función de la restricción de la oferta:

$>$ Los bienes que son objeto de exportación no deben tener sustitutos en el mercado.

$>$ El acuerdo debe incluir a la gran cantidad de productores ya que puede vender volúmenes significativos a menores precios y,

$>$ Los productores deben cumplir las cuotas de exportación adoptando mecanismos para convencer a estos de tratar de adoptar las mayores cantidades a los precios superiores que resultan de haber restringido el mercado.

En esta instancia llega un punto que Casas (2007, p. 555) en la fijación de precios sostiene que los productos tienden a ser fácilmente almacenables, hasta el punto de que cuando hay excesos en la oferta, en vez adoptar la decisión de disminuir el precio, dicha decisión se traduce en el incremento de los stocks. "A la inversa, la presencia de stocks ya constituidos contribuyen a que la oferta sea aún más elástica ante repentinas presiones o variaciones de la demanda."

El punto óptimo se encuentra de la mano de los productores que por mayor precio buscaban vender a muy pocas cantidades. Por lo tanto una restricción de la oferta necesariamente genera una alteración en el funcionamiento de la economía.

Habría que examinar qué tanto esta decisión económica se tomó de forma consciente o si tal vez la implementación se hizo de forma indiscriminada, ya que la literatura deja entrever que en las frecuentes discusiones en este siglo y en el pasado sobre estabilización de precios, muy rara vez se esclarece si la meta de la política adoptada o propuesta fue disminuir la exposición al riesgo, estabilizar y de transferir el mayor porcentaje de los ingresos a los productores, o alguna otra variable que tuviera una incidencia importante en el sector. 
En el caso del café, Thomas (1986, p. 105) afirma que el programa de estabilización de precios regido por la Federación ha tenido un efecto significativo. Sin embargo en este trabajo se cuestiona más adelante qué tan eficaz han sido esta política en la producción cafetera en Colombia durante los años 1999 a 2013.

"No obstante al hablar de estos posibles efectos vía precio esta variable puede no ser un indicador tan bueno del riesgo y la incertidumbre como lo son el ingreso y la rentabilidad para el caso de los caficultores. Es bien sabido que estos últimos no se estabilizan necesariamente con las estabilizaciones de los precios. Por el contrario, si en este caso se estabiliza el precio por acción de una agencia externa, el ingreso de los productores fluctuará con la producción, y la estabilización del precio desestabiliza el ingreso" (Thomas, 1986 p. 106). Dado el anterior argumento se sugiere la pertinencia de esta investigación para evaluar qué variables contempladas en esta investigación además, de la garantía de compra contribuyen a la producción cafetera.

Entretanto Schultz ${ }^{7}$ (1967) complementa esta situación afirmando que cuando se garantizan en este caso por parte de una organización para estatal como la FNC los ingresos a los productores y se incentiva a ellos producir dentro de su industria, inevitablemente surgen programas destinados a estabilizar los precios agrícolas, bajo lo que el autor llama precios de sostenimientos o garantizados.

Continúa exponiendo Schultz (1967, p. 37) que los "apoyos han alterado notablemente los movimientos de corto plazo ocurridos en los precios agrícolas dentro de unos países determinados, pero los efectos surtidos por tales apoyos sobre los movimientos de plazo más largo y sobre la misma estructura de los precios agrícolas están lejos de ser evidentes".

\footnotetext{
${ }^{7}$ Reconocido economista que fue ganador del premio nobel en 1979.
} 


\subsection{De Oligopolio a oligopsonio}

Después de explicar el escenario la industria cafetera antes de 1989 la liberalización de los mercados después de este importante año, proporcionó unas nuevas reglas de juego a cargo de prácticas regidas por las economías de mercado en donde la interacción de múltiples agentes económicos traería un enorme cambio y retos por asumir por todos los sectores económicos.

Para Casilda Béjar (2004, p. 19), "el agotamiento del modelo vigente durante el periodo 1933-1980, conocido como «industrialización mediante la sustitución de importaciones» (ISI), promulgó las bases para emprender las reformas estructurales necesarias que permitiesen cambiar el rumbo económico de América Latina".

Como respuesta a esto el autor señala que para la solución de este problema y otros de orden sistémicos que tenían los países de América Latina, el Consenso de Washington surgió en 1989 con el propósito de instaurar un modelo más estable, abierto y liberalizado para los países de América Latina. "Se trata, sobre todo, de encontrar soluciones al problema de la deuda externa que atenaza el desarrollo económico de la zona latinoamericana y, al mismo tiempo, establecer un ambiente de transparencia y estabilidad económica". (Casilda Béjar 2004, p. 19).

Finalizado en 1989 el Acuerdo Internacional del Café que tenían los principales exportadores del grano en el mundo, las reglas del comercio cambian y en lugar de estar intervenido y condicionado por instituciones parafiscales y estatales, que tenían dentro sus objetivos procurar un terreno de estabilidad para la actividad cafetera y de paso imponer el control sobre la oferta del café, además de evitar grandes fluctuaciones y volatilidades en la transacción del grano, el libre mercado sería ahora el protagonista. Después de 1989 la dinámica de oferta y demanda del grano cambia drásticamente. Para estos efectos el punto óptimo estaba redirigido a favor de los grandes compradores en donde, un bajo precio por causa de una sobreoferta hizo que la demanda aumentara. 
Sergio \& Leibovich (1993 p. 13), citando a J. Friedman aducen que la "teoría económica denomina estos mercados como "monopsónicos" cuando se trata de un comprador u "oligopsónicos" cuando la compra de un determinado insumo o producto están dominados por unos pocos compradores". En vista de esto ambos autores fortalecen este argumento al afirmar que "la industria torrefactora ${ }^{9}$ del exterior se cataloga como oligopsónica, donde las firmas compran su insumo primordial (café) a un precio por debajo del que se observaría en un mercado competitivo". Justamente, este antecedente ocasionó que el Acuerdo Internacional del Café tuviera menos fundamento en el libre mercado.

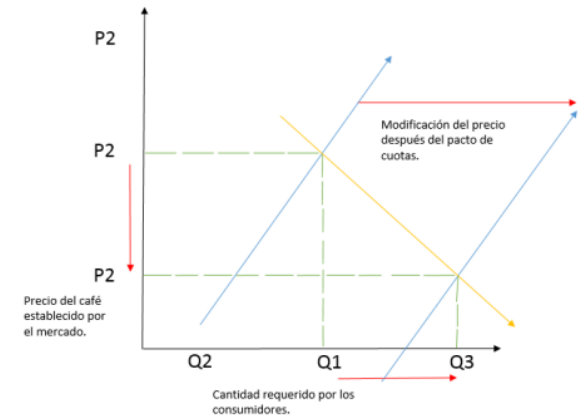

Figura 4. Política cafetera después del Acuerdo Internacional del Café. Fuente: Elaboración propia con base en Varian.

Con el panorama expuesto en la en la Figura 4 era evidente que la balanza se inclinara a favor de los compradores. Si bien es cierto que la concentración en las décadas de los sesentas y ochentas estuvo de lado en los productores, la economía de mercado se orientó a las redes de distribución, hasta el punto de que Reina et al afirma que (2007, p. 48) esa concentración dio un poder de negociación cada vez mayor a los tostadores, comercializadores y a los minoristas frente a los productores, lo que se ha traducido en una brecha creciente entre el precio final que paga el consumidor y la porción del mismo que logra capturar el productor, agregando que cuando se presenta una reducción de los precios internacionales

\footnotetext{
8 J. Friedman (1983) Oligopoly Theory (Cambridge University Press)

9 Según García y Olaya (2006 P. 202) la torrefacción es el proceso de tueste de café verde. Durante esta fase el grano pierde peso y se desarrolla el aroma y el gusto típico del café. Cada clase de grano tiene un tiempo y tipo de tostado óptimos, cuyas variaciones alteran el sabor final.
} 
del café no es completamente transferida al consumidor, generando mayores ganancias a la industria y retrasando el ajuste de la demanda a los cambios en el precio.

Un argumento que pone en evidencia el anterior planteamiento es el que expone Pérez (2013, p. 538), al afirmar que, citando cálculos efectuados de Cecafé ${ }^{10}$ estima que las ventas del café procesado (tostado y soluble) se sitúan en un aproximado de US $\$ 35$ billones anuales mientras que el valor de las cosecha que mide el ingreso que reciben los productores mundiales es próxima a los US $\$ 17$ billones.

De igual manera el autor de referencia asegura que "si el cálculo del precio al detal del café vendido por taza al consumidor final se hace sobre la base de la calidad "Costa Coffee y Starbucks ${ }^{11}$ ", que representa entre un $20 \%$ y $30 \%$ de consumo mundial, se puede usar este indicador para multiplicarlo por el número de tazas consumidas en el mundo, y con base en este indicador se estima el valor total de la industria mundial del café. Siguiendo esta metodología se estima que esta cifra asciende a la nada despreciable suma de US\$120 billones anuales, cifra que contrasta con el nivel de ingreso que reciben los países exportadores que es de unos US $\$ 17$ billones anuales por concepto de la cosecha”. (Pérez, 2013. p. 538).

Por otra parte tal como señala Echavarría \& Robayo et al (2014. p, 14), el mercado mundial del café se ha caracterizado históricamente por la concentración existente a nivel de empresas comercializadoras y tostadoras. "En esta última década han ocurrido aún más fusiones y adquisiciones de estas empresas a nivel global, aunque también han surgido nuevos competidores. Desde los años noventa esta gran concentración ha operado como una barrera de entrada, y lo sigue siendo, sobretodo en el mercado del café estándar" (Echavarría \& Robayo et al 2013. p. 14).

\footnotetext{
10 Consejo de Exportadores de Brasil.

11 Dos de las tiendas especializadas de café preparado en distintas presentaciones
} 
El mismo autor plantea que en la comercialización mundial, compañías que tenían poca presencia como Louis Dreyfus, Olam o Noble han crecido y hoy disputan los primeros lugares frente a jugadores más tradicionales como Neumann Kaffe Gruppe, Ecom y Volcafe. Sin embargo, pocas firmas siguen dominando como lo muestra la reciente adquisición de Armajaro Trading por parte de Ecom. (Echavarría et al 2014. p. 14).

En este orden de ideas el poder de los grandes consumidores del grano nombrados anteriormente ejercen gran poder en el mercado adoptando lo que Encinas (2010, p. 12) señala como la doble personalidad del intermediario monopsonistamonopolista en la cual tiene un doble impacto negativo sobre el mercado ya que por un lado reduce la demanda a productores que enfrentan un mercado competitivo, logrando con esta lógica precios más bajos como compradores, y por el otro lado reducen su oferta elevando los precios como vendedores. "De esta manera, sus beneficios se ven incrementados al comprar barato y vender caro, afectando la demanda efectiva del consumidor final y la oferta efectiva del productor inicial" (Encinas, 2010, p. 12).

\subsection{Precios máximos y mínimos}

Después de abordar de forma teórica el funcionamiento del mercado cafetero antes y después de 1989, año en que finalizó el Pacto de Cuotas y se dio paso a una liberalización paulatina de los mercados, que terminó afectando de forma negativa a los productores de café a nivel internacional y de paso se establecieron nuevas reglas de juego por cuenta de los grandes consumidores, ahora conviene destacar

qué papel desempeña el Estado y la institucionalidad a nivel económico al momento de generar beneficios a los productores y le permiten a éstos, tal como asegura el autor Silva et al (2012, p 112), participar en un mayor número de eslabones dentro de la cadena que conforma la industria cafetera y que es considerado un mercado altamente concentrado por la literatura especializada en este producto. 
Uno de esos beneficios se traduce en el precio que ofrecen los caficultores del grano en unas condiciones determinadas de mercado. Al ver esta situación la literatura explica estas condiciones ante el hecho de que si bien es cierto que los compradores desean pagar un precio bajo, los vendedores tienden a reaccionar ante el deseo de cobrar un precio mucho más alto.

Sin embargo parte de la teoría que apoya el beneficio que se otorga en la garantía de compra para los caficultores se apoya en la teoría del institucionalismo desarrollada por North, (1995, p.16) al afirmar que las instituciones, en este caso la Federación Nacional de Cafeteros, impactan en el desempeño de la economía debido a su efecto sobre los costos del cambio de la producción. "Junto con la tecnología empleada determinan los costos de transacción y transformación (producción) que constituyen los costos totales" (North 1995, p.16).

Como en este documento se trata de ver la incidencia del incentivo de la garantía de compra en la producción cafetera de 1999 a 2013 un zona específica como lo es Antioquia, es pertinente establecer cómo funciona la garantía de compra dentro de la lógica económica. De acuerdo con Silva (2010, p. 12), la Garantía de Compra es el derecho de todo cafetero, federado o no federado, de vender su café sin límite de cantidad, con pago en efectivo y al mejor precio posible, dadas las condiciones de mercado, a saber, precio internacional del café, diferencial del café colombiano y tasa de cambio.

Aunque la Federación no fija del precio de forma obligatoria y el caficultor puede escoger de manera facultativa entre un precio de compra ofrecido por el gremio cafetero los exportadores los precios máximos y mínimos explican la situación presentada anteriormente. De acuerdo con Mankiw (2004. p, 74), el precio máximo constituye el precio legal más alto al que puede venderse un bien, en tanto que el mínimo corresponde al precio legal más bajo al que puede venderse un bien. A partir de lo explicado por el autor de referencia se puede hacer un acercamiento de cómo se comporta la garantía de compra para el beneficio de los caficultores. 
Figura 5. Precios máximos como agente estabilizador de precios en el mercado.

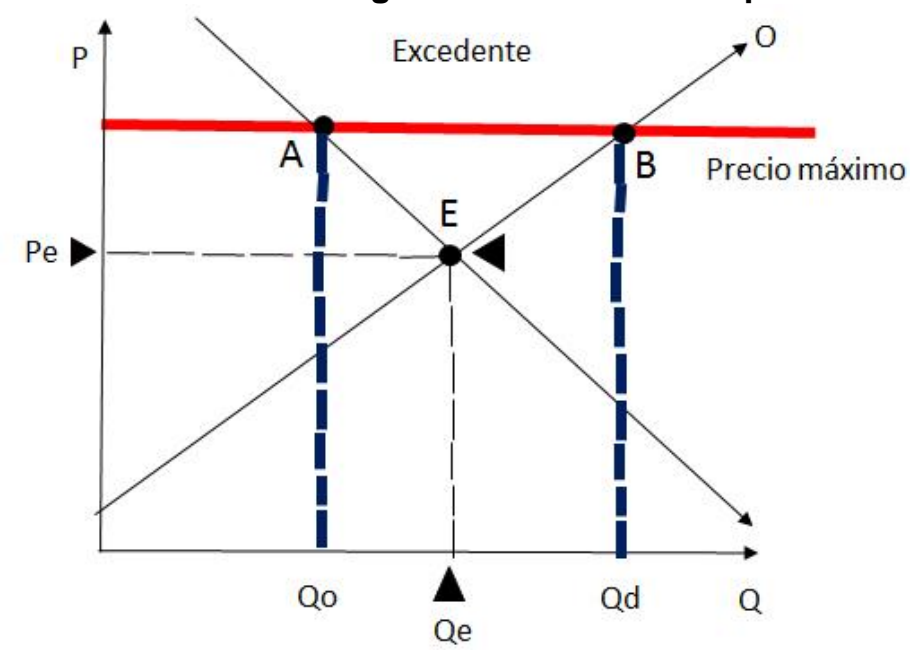

Fuente: Elaboración propia con base en Mankiw (2004).

La Figura 5 expone el hecho de que para Mankiw (2004. p, 75) "cuando el gobierno establece un precio máximo que impone una restricción activa en un mercado competitivo -en este caso el cafetero, surge una escasez del bien, por lo que los vendedores deben racionar los bienes escasos entre el gran número de posibles compradores. Los mecanismos de racionamiento que surgen cuando hay un precio máximo son raras veces deseables".

Siguiendo con esta línea argumentativa y al relacionarlo con el objeto de estudio que aborda el autor de referencia, en la misma figura cuando la entidad que agremia a los caficultores impone un precio de referencia que se identifica con la línea que crea los nuevos puntos $A$ y $B$, este precio supera el de equilibrio $(\mathrm{Pe})$, creando con ella unas nuevas cantidades demandas $(Q d)$ y unas nuevas cantidades ofrecidas (Qo).

En otras palabras el precio que es fijado por la FNC se vuelve en un importante mecanismo para la producción del grano generándoles un excedente a los cultivadores del grano. Al ver que la teoría económica busca para sus agentes el mejor bienestar, autores como Pindyck \& Rubinfeld (2009 p, 358) argumentan que para efectos de descartar la regulación en los precios cabría pensar que si el único 
objetivo fuera lograr la eficiencia económica, sería mejor dejar actuar al mercado competitivo. Sin embargo en el escenario de la industria cafetera no suele suceder.

"A veces es así, pero no siempre. En algunas situaciones, hay fallos del mercado: como los precios no trasmiten las señales correctas a los consumidores y a los productores, el mercado competitivo no regulado es ineficiente, es decir, no maximiza el excedente agregado del consumidor y del productor" Pindyck y Rubberfield (2009. p, 358). Cuando el precio de mercado no compensa los costos de los productores el Gobierno o la Federación Nacional de Cafeteros fija un precio que se estima por encima del precio de mercado para generarle excedentes a los productores y puedan cubrir los costos.

En este caso como es el excedente del productor el que interesa estudiar en el documento, ajustándolo a los términos de Mankiw (2004, p. 93), se refiere a la cantidad que es recibida por un vendedor menos el coste de producción. Es oportuno mencionar que se parte del supuesto de que los precios mínimos de compra solamente alcanzan a cubrir los costos de los productores y no generan unos cuantiosos beneficios a los productores. 


\subsection{Estado del arte}

En la Tabla 1 se presentan los principales autores que han desarrollado trabajos relacionados con la estabilización de precios y el institucionalismo.

Tabla 1. Algunos autores que han abordado la problemática de la estabilización de precios

\begin{tabular}{|l|l|l|l|}
\hline \multicolumn{1}{|c|}{ AUTOR } & $\begin{array}{l}\text { TÍTULO DEL } \\
\text { TRABAJO }\end{array}$ & \multicolumn{1}{|c|}{ RESUMEN } & AÑO \\
\hline $\begin{array}{l}\text { Santiago Silva } \\
\text { Restrepo }\end{array}$ & $\begin{array}{l}\text { Instituciones, } \\
\text { Garantía de } \\
\text { Compra y } \\
\text { beneficios para } \\
\text { el } \\
\text { caficultor en } \\
\text { Colombia }\end{array}$ & $\begin{array}{l}\text { Este documento se convierte en un análisis econométrico en donde el autor } \\
\text { de referencia desea comprobar si el inventario de reglas y normas que } \\
\text { conforman el marco institucional del sector cafetero en Colombia transmite } \\
\text { beneficios al caficultor, utilizando para ello la serie de producción registrada } \\
\text { de café. }\end{array}$ & 2010 \\
& & $\begin{array}{l}\text { Silva señala que "en primer lugar se modela la Garantía de Compra como } \\
\text { política institucional y la forma en que beneficia al cafetero. En segundo } \\
\text { lugar, se busca evidencia empírica que soporte dicha regla institucional a } \\
\text { través de la búsqueda de quiebres estructurales en la serie de producción } \\
\text { registrada. Con lo anterior, se busca determinar la existencia de una } \\
\text { relación positiva entre los arreglos institucionales que permiten la } \\
\text { intervención del mercado interno de café por parte de la Federación } \\
\text { Nacional de Cafeteros de Colombia -FNC, y los menores costos de } \\
\text { producción que los caficultores obtienen, situación que permiten un mayor } \\
\text { nivel de producción" (Silva, 2011, p. 1). }\end{array}$ \\
& $\begin{array}{l}\text { El autor concluye que en los resultados se exponen beneficios significativos } \\
\text { para la expansión de un sector agrícola, como el café, en una política de } \\
\text { Garantía de Compra del producto, así como también el hecho de que al tener } \\
\text { presente la teoría neoinstitucionalista en el que las reglas claras de juego } \\
\text { disminuyen la incertidumbre en las relaciones de los agentes y permiten el } \\
\text { desarrollo de un sector productivo, región o país. En este aparte se hace un }\end{array}$ & \\
& &
\end{tabular}




\begin{tabular}{|c|c|c|c|}
\hline & & $\begin{array}{l}\text { reparo como es el hecho de que si bien es cierto que el autor demuestra la } \\
\text { evidencia empírica de manera general sobre el impacto positivo en la garantía } \\
\text { de compra, omite el hecho ver cuál es la efectividad de esta herramienta } \\
\text { institucional en alquna zona puntual de la industria cafetera. }\end{array}$ & \\
\hline $\begin{array}{l}\text { Pérez Toro } \\
\text { José Alberto. }\end{array}$ & $\begin{array}{l}\text { Economía } \\
\text { Cafetera y } \\
\text { Desarrollo } \\
\text { Económico en } \\
\text { Colombia. } \\
\text { Universidad } \\
\text { Jorge Tadeo } \\
\text { Lozano. }\end{array}$ & $\begin{array}{l}\text { Muestra un documento completo sobre la problemática del café. Contribuye } \\
\text { con gráficas de estadísticas sobre el impacto de la producción con distintas } \\
\text { variables. } 1934 \text { es un antecedente notorio de que los subsidios se usaban en } \\
\text { función de ayudar a los productores. } \\
\text { Al ver que el autor hace una recopilación de varios ensayos de literatura } \\
\text { económica, recoge el documento llamado la "Evolución histórica de las series } \\
\text { de tiempo de los agregados cafeteros y de comercio exterior, 1945-2000. Una } \\
\text { interpretación metodológica. En este documento señala Pérez que se realiza } \\
\text { una recopilación y análisis estadístico de los agregados más importantes de } \\
\text { la actividad cafetera como el costo y el valor de la cosecha cafetera, la tasa } \\
\text { de cambio, las exportaciones y el ahorro cafetero. } \\
\text { Después de la interacción de estas variables el autor llega concluir que "las } \\
\text { referencias empíricas confirman la tendencia hacia el deterioro de los } \\
\text { agregados cafeteros frente al retiro que ha hecho la industria nacional del } \\
\text { café del negocio mundial de la actividad internacional de la distribución y } \\
\text { venta del café en taza." (Pérez, p. 336). Agrega el autor también que si bien } \\
\text { es cierto que en el periodo de referencia y el ingreso y el costo de la cosecha } \\
\text { exponen una tendencia ascendente la evolución del ahorro muestran una } \\
\text { tendencia declinante. }\end{array}$ & 2013 \\
\hline $\begin{array}{l}\text { Jorge Andrés } \\
\text { Perdomo y } \\
\text { Darrell Lee } \\
\text { Hueth }\end{array}$ & $\begin{array}{l}\text { Funciones de } \\
\text { producción, } \\
\text { análisis de } \\
\text { economías a } \\
\text { escala } \\
\text { eficiencia } \\
\text { técnica en el } \\
\text { eje cafetero }\end{array}$ & $\begin{array}{l}\text { Es una publicación especializada en donde su objetivo principal consiste en } \\
\text { estimar distintas formas (convencionales y flexibles) funcionales de } \\
\text { producción cafetera en Colombia. Durante la investigación los autores } \\
\text { procuran calcular y analizar las economías a escala por unidad cafetera que } \\
\text { comprenden tanto productores pequeños, medianos, grandes y sector } \\
\text { general cafetero. } \\
\text { "De esta forma, las instituciones encargadas de prestar asesoría de eficiencia } \\
\text { técnica a los productores de café en Colombia deben fortalecerse y apoyar }\end{array}$ & 2011 \\
\hline
\end{tabular}




\begin{tabular}{|c|c|c|c|}
\hline & $\begin{array}{l}\text { colombiano: } \\
\text { una } \\
\text { aproximación } \\
\text { con frontera } \\
\text { estocástica. }\end{array}$ & $\begin{array}{l}\text { principalmente a los pequeños y medianos productores. Debido a que estos } \\
\text { grupos son la mayor parte de caficultores del país y son los sectores más } \\
\text { vulnerables a cambios estructurales del mercado internacional por la } \\
\text { ineficiencia técnica y estocástica presentada en su actividad." (Perdomo \& } \\
\text { Hueth, } 2010, \text { p. } 21 \text { ). El anterior estudio no tiene en cuenta como sería la } \\
\text { influencia de un incentivo institucional en el mejoramiento de esa producción. }\end{array}$ & \\
\hline $\begin{array}{l}\text { Departamento } \\
\text { Nacional de } \\
\text { Planeación } \\
\text { DNP }\end{array}$ & $\begin{array}{l}\text { (Consejo } \\
\text { Nacional de } \\
\text { Política } \\
\text { Económica y } \\
\text { Social, 2013) } \\
\text { Conpes 3763: } \\
\text { Una estrategia } \\
\text { para la } \\
\text { competitividad } \\
\text { de la } \\
\text { caficultura } \\
\text { colombiana } \\
\text { comisión de } \\
\text { expertos }\end{array}$ & $\begin{array}{l}\text { Desde el punto teórico de la institucionalidad, en este documento se pone a } \\
\text { consideración del CONPES la conformación de una Comisión de Expertos } \\
\text { para analizar la actual situación del sector cafetero. Ésta tendrá la misión de } \\
\text { realizar un análisis profundo e integral de diferentes aspectos del sector a } \\
\text { nivel mundial y nacional, y a partir de ello, diseñar un conjunto de políticas } \\
\text { públicas y estrategias que permitan enfrentar los problemas estructurales del } \\
\text { sector en el ámbito de la producción, comercialización, innovación, } \\
\text { generación de valor agregado, gestión de riesgos, aspectos sociales como la } \\
\text { generación de empleo e ingresos y por último, el marco institucional del } \\
\text { sector. En dicho documento se muestra también incentivos económicos } \\
\text { otorgados al sector desde } 2001 \text { hasta } 2013 \text {, pero sin ninguna medición de } \\
\text { impacto. }\end{array}$ & 2013 \\
\hline $\begin{array}{l}\text { Cano, Vallejo, } \\
\text { Caicedo, } \\
\text { Amador, \& } \\
\text { Tique, } 2012\end{array}$ & $\begin{array}{l}\text { El mercado } \\
\text { mundial del } \\
\text { café y su } \\
\text { impacto en } \\
\text { Colombia. }\end{array}$ & $\begin{array}{l}\text { Según el autor se elaboran recomendaciones, en relación con el cultivo, la } \\
\text { comercialización y las instituciones del sector, para fortalecer su capacidad } \\
\text { de enfrentar futuros choques de precios y contribuir a atenuar sus efectos } \\
\text { sobre la Economía. A partir de los resultados de la ineficacia en algunas Se } \\
\text { plantea como posibilidad revaluar la institucionalidad cafetera y la política de } \\
\text { subsidios. } \\
\text { Para Cano et al (2012) la caficultura, después de un serio diagnóstico de } \\
\text { cómo se convierte en una industria débil y por no estar preparada ante las } \\
\text { volatilidades del mercado hace que "su arreglo institucional actual no ofrece } \\
\text { la flexibilidad necesaria en la producción y comercialización para actuar en } \\
\text { un mercado libre. La productividad y rentabilidad de los cultivos son bajas y }\end{array}$ & 2012 \\
\hline
\end{tabular}




\begin{tabular}{|c|c|c|c|}
\hline & & $\begin{array}{l}\text { declinantes, a pesar de que Cenicafé dispone de paquetes tecnológicos } \\
\text { avanzados. En la medida en que se supere la tendencia declinante de la } \\
\text { productividad se podrá dar término a los subsidios con cargo al presupuesto } \\
\text { nacional" (Cano et al, } 2012, \text { p. } 54 \text { ). }\end{array}$ & \\
\hline $\begin{array}{l}\text { Diego } \\
\text { Escobar } \\
\text { Felipe Castro } \\
\text { Beatriz } \\
\text { Cuervo } \\
\text { Maritza } \\
\text { Rodríguez } \\
\text { José Ignacio } \\
\text { Vargas }\end{array}$ & $\begin{array}{l}\text { Costos de } \\
\text { Producción de } \\
\text { Doce } \\
\text { Productos } \\
\text { Agropecuarios } \\
\text { Fedesarrollo }\end{array}$ & $\begin{array}{l}\text { A partir de un estudio realizado hace } 15 \text { años, Fedesarrollo realiza una } \\
\text { proyección de los costos y se comparan los costos de producción de café por } \\
\text { actividades para las dos zonas. Según esta tabla, los costos laborales de los } \\
\text { empleados es el concepto que tiene mayor peso, en ambas regiones, en el } \\
\text { costo total. Así, en la zona Centro su participación es del } 49,5 \% \text { y en la Sur } \\
\text { del } 34,27 \% \text {. (Perfetti, y otros, } 2012) \\
\text { En la zona Centro las otras actividades que más pesan en los costos totales } \\
\text { son, en su orden: cosecha (14,8\%), labores de cultivo (12,6\%) y fertilización } \\
(10,3 \%) \text {. Por su parte, en la zona Sur las participaciones de las actividades } \\
\text { en el costo total son, en orden descendente, la cosecha (22,1\%), la } \\
\text { fertilización (17,3\%) y las otras labores }(6,5 \%) \text {. Las otras actividades tienen, } \\
\text { en ambas zonas, bajos niveles de participación en el costo total. }\end{array}$ & \\
\hline $\begin{array}{l}\text { Juan José } \\
\text { Echavarría, } \\
\text { Pilar } \\
\text { Esguerra, } \\
\text { Daniela } \\
\text { McAllister, } \\
\text { Carlos Felipe } \\
\text { Robayo }\end{array}$ & $\begin{array}{l}\text { Informe de la } \\
\text { misión de } \\
\text { estudios para } \\
\text { la } \\
\text { competitividad } \\
\text { de la } \\
\text { caficultura en } \\
\text { Colombia }\end{array}$ & $\begin{array}{l}\text { Además de realizar un diagnóstico de la industria cafetera en donde visibiliza } \\
\text { la crisis del sector, el documento en uno de los partes también muestra la } \\
\text { evolución de los costos de producción, en peso colombianos constantes de } \\
2012 \text { por carga, en diferentes países, tanto en arábiga como en robusta, para } \\
\text { los períodos } 1987 / 88-1992 / 93 \text { y } 2007 / 08-2011 / 12 \text {. } \\
\text { De acuerdo a la evidencia empírica se observa que los costos han } \\
\text { descendido en todos los países productores incluidos en la investigación } \\
\text { hasta el punto de que han descendido países que también son productores } \\
\text { menso en Colombia, excepto por el caso del café arábiga en Brasil. } \\
\text { Así, mientras en Colombia descendieron a una tasa anual de }-2.87 \% \text { y - } \\
1.86 \% \text {, respectivamente, en café robusta en Brasil y Vietnam (también } \\
\text { robusta) descendieron }-3.11 \% \text { y }-3,31 \% \text {, y }-3.24 \% \text { y }-3.34 \% \text { y en café arábiga } \\
\text { en Honduras y Nicaragua descendieron }-4.08 \% \text { y }-4.02 \% \text { y }-3.03 \% \text { y }-3.01 \% \text {. }\end{array}$ & 2014 \\
\hline
\end{tabular}


Como ya se mencionó, solo fue menor la caída en costos en arábiga en Brasil $(-1.72 \%$ y $-1.89 \%)$. Los costos de producción de Colombia en 2011/12 (\$ 585,402 pesos de 2012 por carga) fueron mucho mayores que aquellos para robusta en Vietnam $(\$ 232,151)$ y en Brasil $(\$ 256,576)$, y para arábiga en Honduras $(\$ 420,386)$, Perú $(\$ 451,355)$, Nicaragua $(\$ 472,641)$ y Brasil $(\$$ $503,415)$.

Fuente: Elaboración propio con base en los autores de referencia. 


\section{CAPÍTULO 2. CARACTERIZACIÓN DEL SECTOR CAFETERO}

Después de exponer el fundamento teórico sobre el cual funciona el mercado del café antes y después de 1989 en el primer capítulo, ahora se explicará en este aparte del documento las características del sector relacionados con la estabilización de precios presentado en un mercado tanto oligopólico como oligópsonico, así como también la descripción de algunos momentos importantes de la industria relacionado con el objeto de estudio del documento que pretende analizar la efectividad de la garantía de compra como herramienta de estímulo a la producción cafetera, a través un análisis empírico para el periodo 1999 a 2013 para grandes, medianos y pequeños cultivadores del grano.

\subsection{Generalidades}

Según Gómez et al (2011, p. 11), a corte del año 2010, existía en Colombia 553 mil familias productoras de café, y cerca de cuatro millones de colombianos dependen de este cultivo. "Ninguna otra actividad agrícola ha generado el ingreso y el desarrollo social asociado al café en las zonas rurales de Colombia" (Ver Figura 6).

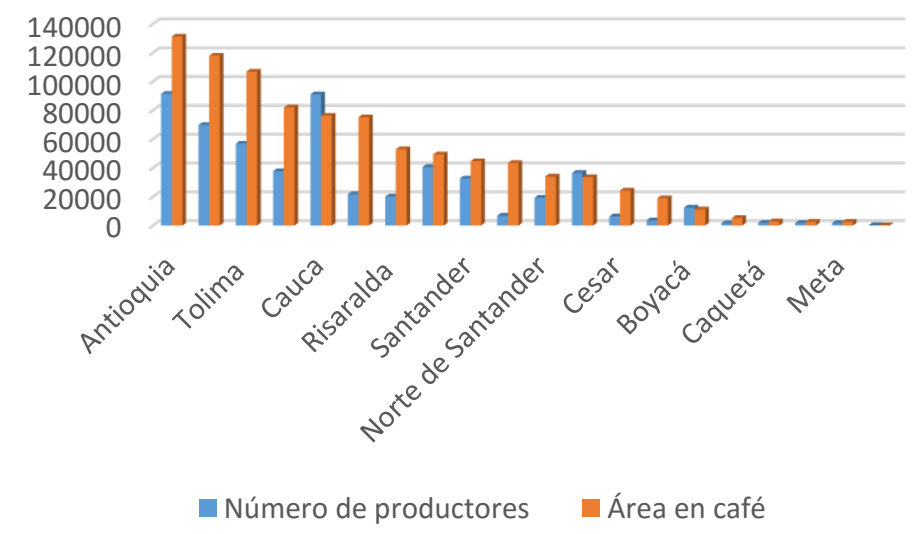

Figura 6. Área (hectáreas) sembrada en café y número de cafeteros por departamento (2010) Fuente: Elaboración propia con base en Gómez et al, (2011, p. 11) 
Haciendo un inventario de las áreas sembradas por departamento y el número de productores, se puede apreciar que al cierre de 2010 Antioquia es el mayor departamento con 131.123 hectáreas (has) que se destinan a la producción del grano y 91.355 productores. Haciendo la descripción solo por departamentos se puede apreciar como el Huila tiene 117.842 has.

De igual forma le siguen otras subdivisiones geográficas como el Tolima, Caldas, Cauca, Valle y Risaralda con 106.792, 81.918, 76.189, 75.093 y 52.884 has, respectivamente. Aunque históricamente departamentos como Caldas, Risaralda y Quindío se destacaron por ser protagonistas en la producción cafetera, la disminución de su área cultivada cultivable ha adoptado desde el año 2009 una tendencia decreciente, por situaciones como el impacto negativo el Fenómeno del Niño que afectó negativamente entre el 2008 y el 2011 así como también el hecho que otras regiones como Huila y Cundinamarca hayan ganado terreno en la industria.

En este mismo orden de ideas de acuerdo con la Organización Internacional del Café (por sus siglas en inglés) Colombia es el tercer productor cafetero y principal agricultor de café arábica lavado, hasta el punto que para Pérez (2013, p. 15) el café se considera el segundo producto básico más valioso del mundo, siendo el petróleo el primero. Dentro de sus características existen en el mundo más de 20 millones de productores ubicados en 50 países; en cuanto área cultivada se estima que en el mundo existen 11 millones de hectáreas dedicadas al cultivo del grano.

En la producción de este commodity los cultivadores locales del grano se clasifican en minifundistas, medianos campesinos y los grandes productores. "La principal región cafetera colombiana está conformada por Antioquia, Quindío, Risaralda y Caldas. Esos departamentos cuentan con características ideales para cultivar café, porque el grano se cosecha principalmente en zonas templadas a 1.200 metros sobre el nivel del mar" Pérez (2013, p. 15). Sin embargo en las últimas décadas otras zonas se han sumado aparte de las tradicionales como Bolívar, Putumayo, 
Caquetá, Casanare, Chocó y Meta. En medio de este inventario que realiza Federación Nacional de Cafeteros, al término de 2014 cerca 948.540 hectáreas son destinadas al cultivo de café (ver Tabla 3).

\author{
Para ofrecer una claridad sobre qué tipo de análisis que se va realizar más adelante \\ en las subdivisiones de este capítulo en el diseño metodológico (Capítulo 3), es \\ necesario establecer algunas características básicas del grano a través de la \\ siguiente Tabla 2:
}

Tabla 2: Definiciones acerca de la industria del café

\begin{tabular}{|c|c|}
\hline Tipo de café & Características \\
\hline Café & $\begin{array}{l}\text { Significa el grano y la cereza del cafeto, ya sea en pergamino, verde o tostado, e incluye } \\
\text { el café molido, descafeinado, líquido y soluble. }\end{array}$ \\
\hline Café verde & $\begin{array}{l}\text { Todo café en forma de grano pelado, antes de tostarse y es el que suele exportarse. Es el } \\
\text { grano o almendra de café libre de las capas que lo recubren; es el producto que se obtiene } \\
\text { del proceso de trillado, mediante el cual se descascara el café pergamino, se limpia o } \\
\text { eliminan impurezas, se clasifica el grano (por tamaño, densidad y color) y se pule para } \\
\text { eliminar el episperma o película plateada. }\end{array}$ \\
\hline Café en cereza seca & $\begin{array}{l}\text { El fruto seco del cafeto. Para encontrar el equivalente de la cereza seca en café verde, } \\
\text { se multiplica el peso neto de la cereza seca por } 0,50 \text {. }\end{array}$ \\
\hline Café pergamino & $\begin{array}{l}\text { Es el grano de café verde contenido dentro de la cubierta de pergamino, después de } \\
\text { recolectado los granos maduros en donde se someten a un proceso de despulpado } \\
\text { fermentación (desmucilaginado), lavado y secado. Debe alcanzar una humedad del } 10 \% \\
\text { al } 12 \% \text { para obtener el café pergamino que el productor vende a intermediarios, } \\
\text { cooperativas, compañías exportadoras o la FNC. Estos agentes se encargan de la trilla, } \\
\text { en donde se obtiene el café verde según su tamaño y densidad. Se comprueba también } \\
\text { la existencia de posibles imperfecciones en color y otros defectos visuales. Con base en } \\
\text { este proceso se determina si el café es de exportación o de consumo doméstico (los } \\
\text { llamados coproductos uno de los cuales se conoce como café pasilla). Para encontrar el } \\
\text { equivalente del café pergamino en café verde, se multiplica el peso neto del café } \\
\text { pergamino por } 0,80 \text {. }\end{array}$ \\
\hline Café tostado & $\begin{array}{l}\text { Café verde tostado en cualquier grado, e incluye el café molido. El café verde es } \\
\text { sometido al proceso de torrefacción para que sea apto en la preparación de la infusión y } \\
\text { desarrolle su aroma y sabor. Cada clase de grano tiene un tiempo y tipo de tostado } \\
\text { óptimos, cuyas variaciones alteran el sabor final. Se pueden distinguir tres tostados } \\
\text { distintos: claro (de delicado sabor), mediano (de sabor fuerte) y oscuro (elimina la acidez } \\
\text { y confiere un sabor amargo). }\end{array}$ \\
\hline Café descafeinado & $\begin{array}{l}\text { Café verde, tostado o soluble del cual se ha extraído la cafeína. Es el producto al que le } \\
\text { ha removido la cafeína en una proporción que varía entre } 97 \% \text { y } 98 \% \text {. El descafeinado } \\
\text { se obtiene con la adición de agua, dióxido de carbono o solventes orgánicos al café } \\
\text { verde, antes de ser tostado y molido. }\end{array}$ \\
\hline Café Líquido & $\begin{array}{l}\text { Las partículas sólidas, solubles en agua, obtenidas del café: tostado y puestas en forma } \\
\text { líquida. }\end{array}$ \\
\hline Café soluble & $\begin{array}{l}\text { Las partículas sólidas, secas, solubles en agua, obtenidas del café tostado. Esta } \\
\text { denominación se reserva al producto seco que resulta de la extracción del café tostado } \\
\text { por medio de agua potable y que contiene exclusivamente los principios solubles, } \\
\text { sápidos y aromáticos del café. Este polvo de café no deja borra, pues se diluye } \\
\text { completamente en el agua. }\end{array}$ \\
\hline Cafés Robustas & $\begin{array}{l}\text { Se caracteriza por ser una variedad de la especie Coffea Canephora más resistente a } \\
\text { muchas de las enfermedades del café, especialmente a la roya, así como también por } \\
\text { producir una bebida fuerte y amarga con mayor concentración de cafeína. Según la } \\
\text { literatura especializada en este producto, este grano se cultiva generalmente en altitudes } \\
\text { por debajo de } 1.000 \mathrm{~m} \text {, en países como Brasil, Vietnam, Indonesia y Uganda. }\end{array}$ \\
\hline
\end{tabular}




\begin{tabular}{|l|l|}
\hline \multicolumn{1}{|l|}{ Cafetales Tecnificados } & $\begin{array}{l}\text { Tienen el atributo de ser plantaciones con trazo y densidad mayor o igual a } 2.500 \\
\text { árboles, de variedades: Caturra y Castillo. A plena exposición solar con edades menores } \\
\text { o iguales a nueve años y a la sombra y semi-sombra menores o iguales a } 12 \text { años. }\end{array}$ \\
\hline \multicolumn{1}{|c|}{ Distintas clases de café arábica sembradas en Colombia } \\
\hline Típica & $\begin{array}{l}\text { También es definido como arábigo, pajarito o nacional. Se caracteriza por ser susceptible a la roya y se } \\
\text { siembran hasta 2.500 árboles por hectárea }\end{array}$ \\
\hline Borbón & $\begin{array}{l}\text { Como atributo fundamental esta derivación del grano tiene mayor número de ramas que la variedad Típica. } \\
\text { El árbol de Borbón produce 30\% más que una Típica, así como también el hecho de que es susceptible a } \\
\text { la roya y comparte de común con la típica de que se siembran hasta 2.500 árboles por hectárea. }\end{array}$ \\
\hline Tabi & $\begin{array}{l}\text { Proviene de la variedad derivada de cruzamientos del Híbrido de Timor con las variedades Típica y Borbón. } \\
\text { Se caracteriza por ser de una variedad de grano grande, superior al } 80 \% \text { de café supremo, así como } \\
\text { también por ser de excelente calidad, es ideal para obtención de cafés especiales. De igual manera se } \\
\text { siembran hasta 3.000 plantas por hectárea y es resistente a la roya. }\end{array}$ \\
\hline $\begin{array}{l}\text { Variedad } \\
\text { Colombia }\end{array}$ & $\begin{array}{l}\text { Debido a su variedad genética, posee una resistencia durable al ataque de la roya del cafeto. De igual } \\
\text { manera la producción es igual o superior a la Caturra. Por sus propiedades, este grano y la calidad de la } \\
\text { bebida son similares a las otras variedades de café arábigo. }\end{array}$ \\
\hline Caturra & $\begin{array}{l}\text { La literatura técnica que es un árbol produce menos que Borbón y más que Típica. Asimismo se comporta } \\
\text { muy bien en toda la zona cafetera y es susceptible a la roya. }\end{array}$ \\
\hline $\begin{array}{l}\text { El café que es enviado al exterior tiene las siguientes características: Saco de } 60 \text { kilogramos ó 132,276 libras de café } \\
\text { verde; tonelada significa una masa de 1.000 kilogramos ó 2.204,6 libras, y libra significa 453,597 gramos. }\end{array}$ \\
\hline
\end{tabular}

\section{Fuente: Elaboración propia con base en Reina et al (2007, p. 48, 83, 84), Convenio} Internacional del Café (2001, p. 25, 26) y Cáceres \& Escobar (2006, p, 206). 
Tabla 3. Área cultivada con café total a nivel departamental

\begin{tabular}{|c|c|c|c|c|c|c|c|c|c|c|c|c|c|}
\hline Departamentos & 2002 & 2003 & 2004 & 2005 & 2006 & 2007 & 2008 & 2009 & $2010^{*}$ & 2011* & $2012^{*}$ & $2013^{*}$ & $2014^{*}$ \\
\hline Antioquia & 127,99 & 128,05 & 129,30 & 129,82 & 126,30 & 126,90 & 129,10 & 130,57 & 131,12 & 131,17 & 133,61 & 137,13 & 130,99 \\
\hline Bolívar & $n / d$ & $n / d$ & $n / d$ & $n / d$ & $n / d$ & $n / d$ & $n / d$ & $n / d$ & $n / d$ & $n / d$ & $n / d$ & 1,00 & 1,12 \\
\hline Boyacá & 11,36 & 11,23 & 11,09 & 10,96 & 10,80 & 11,10 & 10,70 & 10,95 & 11,14 & 11,27 & 10,35 & 11,49 & 11,41 \\
\hline Caldas & 88,82 & 88,51 & 90,87 & 89,52 & 89,10 & 87,70 & 85,00 & 83,88 & 81,92 & 80,52 & 78,58 & 77,56 & 74,53 \\
\hline Caquetá & $n / d$ & $n / d$ & $n / d$ & $n / d$ & $n / d$ & 2,80 & 2,80 & 2,78 & 2,85 & 3,43 & 3,68 & 4,08 & 3,99 \\
\hline Casanare & $n / d$ & $n / d$ & $n / d$ & $n / d$ & $n / d$ & 2,60 & 2,60 & 2,56 & 2,61 & 2,74 & 2,92 & 3,20 & 3,25 \\
\hline Cauca & 65,68 & 68,50 & 69,85 & 68,92 & 68,00 & 67,80 & 69,80 & 73,34 & 76,19 & 81,17 & 84,06 & 91,61 & 88,83 \\
\hline Cesar & 22,43 & 22,19 & 21,84 & 21,49 & 21,10 & 21,50 & 21,90 & 22,45 & 24,23 & 26,19 & 28,69 & 30,77 & 30,28 \\
\hline Chocó & $n / d$ & $n / d$ & $n / d$ & $n / d$ & $n / d$ & 0,18 & 0,19 & 0,20 & 0,19 & 0,21 & 0,17 & 0,17 & 0,16 \\
\hline Cundinamarca & 55,44 & 54,31 & 53,17 & 52,04 & 50,90 & 48,20 & 48,90 & 48,92 & 49,36 & 43,85 & 40,79 & 41,99 & 38,00 \\
\hline Guajira & 4,57 & 4,72 & 4,85 & 5,02 & 4,40 & 5,07 & 5,08 & 5,18 & 5,28 & 5,79 & 6,21 & 6,77 & 6,79 \\
\hline Huila & 78,23 & 82,20 & 93,91 & 95,92 & 95,10 & 98,10 & 102,50 & 104,99 & 117,84 & 129,15 & 139,14 & 154,49 & 154,98 \\
\hline Magdalena & 17,45 & 17,58 & 17,73 & 18,04 & 18,30 & 17,10 & 17,60 & 18,45 & 18,87 & 19,76 & 20,56 & 21,26 & 21,27 \\
\hline Meta & $n / d$ & $n / d$ & $n / d$ & $n / d$ & $n / d$ & 2,40 & 2,40 & 2,29 & 2,59 & 3,01 & 3,23 & 3,60 & 3,44 \\
\hline Nariño & 23,00 & 24,47 & 26,15 & 26,45 & 26,80 & 27,40 & 29,00 & 31,00 & 33,54 & 35,37 & 37,12 & 39,29 & 38,86 \\
\hline N. Santander & 32,05 & 32,08 & 32,10 & 32,12 & 32,10 & 32,10 & 32,60 & 33,63 & 33,98 & 32,90 & 30,01 & 30,39 & 26,73 \\
\hline Putumayo & $n / d$ & $n / d$ & $n / d$ & $n / d$ & $n / d$ & $n / d$ & $n / d$ & $n / d$ & $n / d$ & $n / d$ & $n / d$ & 0,04 & 0,13 \\
\hline Quindío & 44,52 & 44,71 & 44,59 & 42,95 & 44,00 & 43,30 & 42,40 & 39,78 & 43,37 & 31,07 & 30,18 & 28,88 & 27,67 \\
\hline Risaralda & 59,38 & 58,55 & 57,78 & 56,85 & 56,20 & 55,40 & 54,40 & 54,27 & 52,88 & 52,56 & 52,32 & 52,27 & 51,03 \\
\hline Santander & 42,09 & 42,36 & 42,75 & 43,28 & 41,20 & 41,10 & 41,50 & 42,75 & 44,58 & 45,23 & 46,83 & 50,27 & 50,32 \\
\hline Tolima & 105,56 & 105,44 & 105,33 & 105,21 & 105,10 & 104,30 & 102,80 & 103,91 & 106,79 & 109,86 & 113,15 & 119,33 & 117,18 \\
\hline Valle & 86,55 & 85,94 & 85,34 & 84,73 & 84,10 & 82,50 & 77,50 & 75,78 & 75,09 & 75,80 & 69,44 & 68,39 & 67,57 \\
\hline TOTAL & 865,14 & 870,83 & 886,65 & 883,33 & 873,50 & 877,55 & 878,77 & 887,66 & 914,41 & 921,06 & 931,06 & 974,01 & 948,53 \\
\hline
\end{tabular}

* Corte a diciembre

Fuente: Federación Nacional de Cafeteros. 
Una lectura sobre los inventarios de la producción colombiana cafetera, según cálculos de Naciones Unidas (2011, p. 70), señalan que en Colombia el 95\% de los cafeteros tienen menos de 5 hectáreas (has) sembradas en café y responden por el $69 \%$ de la producción nacional. Por otra parte los productores medianos poseen de 5,1 a 10 has, mientras que los grandes tienen 10,1 has en adelante, respondiendo ellos al $13 \%$ y $18 \%$ de la producción nacional, respectivamente, lo cual se encuentran ilustradas en las Figuras 7 y 8 :
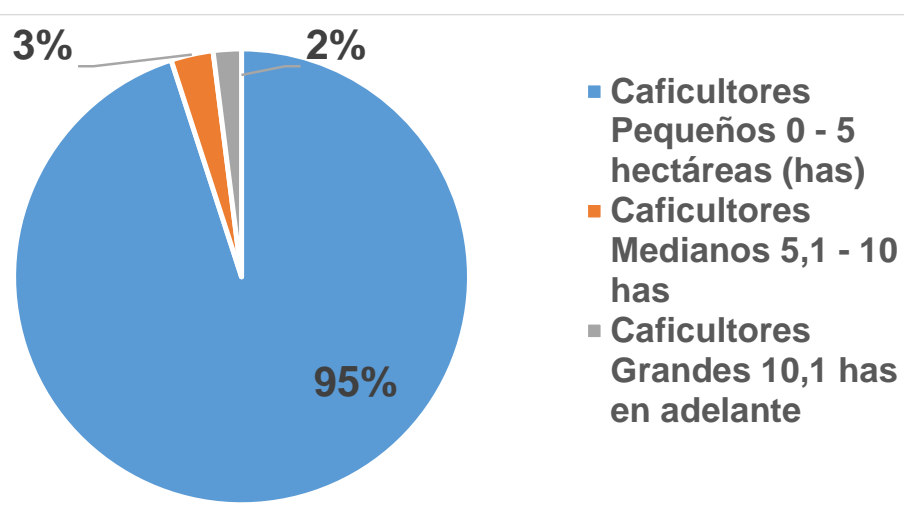

Figura 7. Distribución porcentual de los cafeteros según el tamaño de cultivo (2010). Fuente: Elaboración propia con base en Naciones Unidas (2011, p. 70)

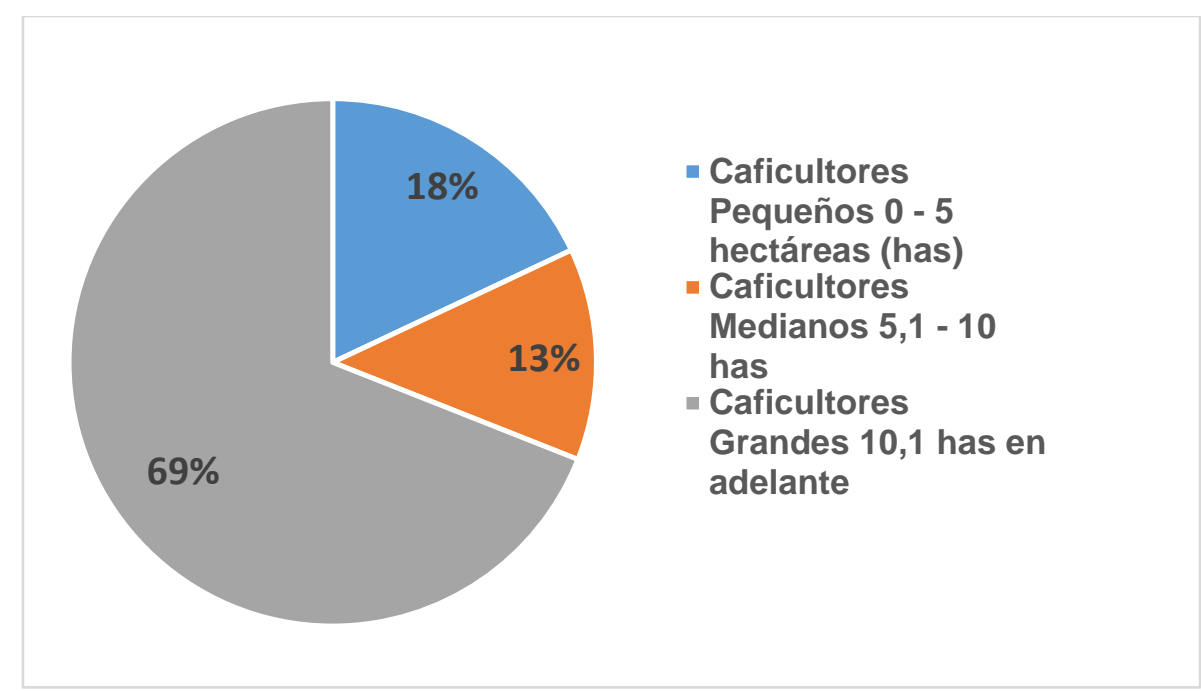

Figura 8. Distribución porcentual de la producción total según tamaño de cultivo (2010). Fuente: Elaboración propia con base en Naciones Unidas (2011, p. 70) 


\subsection{Garantía de Compra}

El Gobierno ocasionalmente adopta políticas de otorgar subsidios para el sostenimiento del sector y el bienestar de sus agentes para elevar la competitividad. Como consecuencia de lo anterior "en los últimos años la producción ha crecido a un ritmo superior al del consumo, presentándose para el año 2002 un exceso de oferta de café por quinto año consecutivo, lo que llevó a que los inventarios se incrementaran a niveles equivalentes a 8 meses de consumo global. Lo anterior significa que la industria cafetera mundial está atravesando una de las peores crisis, que se refleja en los precios reales del grano que llegaron a los niveles más bajos de la historia" (FNC. 2002. p, 3).

Bajo esta coyuntura el Gobierno Nacional y la FNC firmaron un acuerdo para dar a los caficultores el Apoyo del Gobierno a la Caficultura Nacional (AGC). "En el marco de la Ley 101 de $1993^{12}$, el Gobierno otorgó un apoyo directo a los caficultores como complemento al precio interno (AGC), programa que como se recordará comenzó el 28 de septiembre de 2001. Este incentivo se manejó en función del precio externo y la tasa de cambio, teniendo en cuenta la disponibilidad fiscal de la Nación" (FNC, 2002. p, 10).

Dicho programa se activaba cuando el precio interno estaba por debajo del precio mínimo de sustentación de la carga. Mientras en 2002 dicha ayuda representó $\$ 22.800$ por carga, en 2003 fue de $\$ 10.250$ y en 2005 fue de $\$ 3.701$ por carga. Luego de estos años de otorgamiento de subsidios se suspendieron.

Sin embargo hubo otras ayudas que se reactivaron posteriormente para garantizar la sostenibilidad del ingreso de las familias cafeteras. Ésta se denominó el Apoyo al

\footnotetext{
12 Legislación aperturista del mercado que se expidió con el fin de hacer énfasis en objetivos puntales como: a. otorgar especial protección a la producción de alimentos; b. adecuar el sector agropecuario y pesquero a la internacionalización de la economía, sobre bases de equidad, reciprocidad y conveniencia nacional; c. promover el desarrollo del sistema agroalimentario nacional y; d. elevar la eficiencia y la competitividad de los productos agrícolas, pecuarios y pesqueros mediante la creación de condiciones especiales.
} 
Ingreso al Caficultor (AIC), en donde según la FNC (2014) se entregaba un apoyo por carga de café cuando los niveles de precio se encontraban por debajo de los $\$ 650.000$. Entre octubre 24 del 2012 y el primero de marzo del 2013 el AIC fue de 60 mil pesos por carga de 125 kilos o $\$ 6.000$ por arroba de café pergamino seco, o su equivalente en café húmedo o cereza.

Seguido de esto la contribución cambió. Entre el 3 de marzo y el 14 de marzo los niveles de apoyo se incrementaron a $\$ 95.000$ o $\$ 115.000$, dependiendo si el tamaño de la finca cafetera es de más o menos de 20 hectáreas; luego se trasformó en el Programa de Protección del Ingreso Cafetero (PIC) que reemplazó al AIC y está vigente a partir de marzo 15 del $2013^{13}$. El PIC tiene un monto equivalente a $\$ 145.000$ por carga de 125 kilos o 14,500 por arroba de café pergamino seco, o su equivalente en café húmedo o cereza ${ }^{14}$.

Mucho se ha cuestionado sobre el camino que ha tomado la caficultura en torno a la comercialización del grano en Colombia. En vista de que el mercado exige productores competitivos, y estar más involucrado con las nuevas formas de ventas para enfrentar diversificación de la industria así como la entrada de nuevos competidores Cano et al (2012, p. 53) asegura también que "la caficultura, sin embargo, presenta serias vulnerabilidades ante sus posibilidades de aprovechar las fases expansivas de esos ciclos y sortear con éxito las negativas". Los autores también señalan que su arreglo institucional actual no ofrece la flexibilidad necesaria en la producción y comercialización para actuar en un mercado libre.

"La productividad y rentabilidad de los cultivos son bajas y declinantes, a pesar de que Cenicafé ${ }^{15}$ dispone de paquetes tecnológicos avanzados. En la medida en que

\footnotetext{
${ }^{13} \mathrm{http}: / /$ www.federaciondecafeteros.org/static/files/PreguntasAIC-PIC.pdf

${ }^{14}$ Según el informe de gestión de 2014 de la FNC, el programa tuvo vigencia hasta el 31 de diciembre de 2014. Al corte del año de referencia se ejecutaron recursos por más de $\$ 154$ mil millones, mediante el trámite de cerca de tres millones de facturas por concepto de la compraventa de cuatro millones de cargas de $125 \mathrm{~kg}$ café pergamino seco.

${ }^{15}$ Es una extensión institucional de la FNC. Fue creada en 1938 con el propósito de estudiar los aspectos relacionados con la producción en las fincas, la cosecha, el beneficio, la calidad del grano,
} 
se supere la tendencia declinante de la productividad se podrá dar término a los subsidios con cargo al presupuesto nacional Cano et al" (2012. p, 52).

Echavarría et al (2014, p, 173), citando a Junguito, Perfetti, y Becerra considera que Colombia aparece como el país más intensivo en subsidios - regalos, mientras que Brasil, conjuntamente con Costa Rica, Nicaragua y Uruguay, se encuentra en el extremo opuesto. Entretanto existe otro mecanismo a nivel institucional, mediante el cual la Federación Nacional de Cafeteros (FNC), a través del Fondo Nacional del Café (FoNC) $)^{16}$, garantiza al caficultor tener asegurada toda su producción durante todo el año en todos los municipios cafeteros al precio de referencia del día. Este mecanismo se denomina garantía de compra.

Silva Restrepo (2001, p. 113, 114), citando a Citando a Junguito \& Pizano (1997) explica que la garantía de compra es una medida de política cafetera con la cual se

el manejo y la utilización de los subproductos de la explotación cafetera, y la conservación de los recursos naturales de la zona cafetera colombiana.

${ }^{16}$ De acuerdo con Junguito y Pizano et al (1997, p. 75) tras las secuelas originadas por la Segunda Guerra Mundial se dificultó de forma significativa la logística de transporte de café a Europa afectando el consumo. Lo anterior implicaba doblegar esfuerzos para concentrarse en un mercado como el de los Estados Unidos. Con base en esto se crea el Convenio Interamericano de Café -o Pacto de Cuotas- que fue suscrito en Washington el 28 de noviembre de 1940, "que en razón del desequilibrio existente en el mercado internacional del café, hacía conveniente, la adopción de medidas para promover la venta ordenada del grano mediante cuotas de exportación acordadas para cada país productor que suscribiera el Pacto" (Junguito y Pizano et al (1997, p. 75).

Los autores señalan que "conforme a las autorizaciones otorgadas por el Congreso de la República, en materia cambiaria, de comercio exterior, tributaria y crediticia, diseñaron un esquema de política cafetera para atender lo convenido en el Pacto de Cuotas. Dado que uno de los elementos fundamentales de este Pacto era el compromiso de cada país latinoamericano de no exportar los Estados Unidos más café que la cuota previamente acordada, se imponía la necesidad de crear un mecanismo para retener en el país el café de exportación producido y que excediese dicha cuota. El mecanismo escogido por Colombia tuvo como fin fundamental la constitución de un fondo (el Fondo Nacional del Café), con cuyos recursos se podían comprar los aludidos excedentes de café. (Junguito y Pizano et al 1997, p. 75)".

De acuerdo con los analistas de referencia el Fondo Nacional del Café fue constituido el 22 de noviembre de 1940 con los aportes de dos impuestos creados expresa y exclusivamente para este fin (...) "de los dos impuestos, uno grava los giros al exterior y el otro, en la forma de un diferencial cambiario, recae sobre los ingresos en divisas por las exportaciones del café cuando el precio de éstas exceda el precio básico fijado por el Gobierno".

De igual forma, para mayor información se sugiere al lector ver el Decreto-Ley 2078 de noviembre de 1940 que fue según (Junguito y Pizano et al 1997, p. 77), "fue promulgado a instancias de la Ley 45 de noviembre 21 de 1940 que preveía una adecuada aplicación de la convención sobre cuotas cafeteras, o sea el Pacto Interamericano de Cuotas, en caso de que fuese adoptado por los países suscribientes." 
garantiza la obtención del café sin límite de cantidad, en efectivo y al mejor precio posible, dadas las condiciones de precio internacional. Dicha garantía se aplica sobre un precio interno de referencia para la compra de café pergamino seco por carga de 125 kilos $^{17}$. La FNC asegura que el incentivo económico ofrecido a todos los cafeteros se hace mediante la publicación de un precio base de mercado que se calcula de acuerdo con la cotización de cierre en la Bolsa de Nueva York del día, el precio del dólar del día y el diferencial o prima de referencia para el café colombiano.

Al ver la importancia que tiene esta herramienta la desde la teoría institucional Silva et al (2002. p, 29), recalca como es de importante defender al productor con la garantía de compra. "Además de ser la clave para defender el ingreso cafetero, dicha garantía permite instaurar políticas de calidad mínima, ofrecer garantía de suministro, a los compradores internacionales, controlar el impacto de las tendencias oligopsónicas de los actores nacionales e internacionales del mercado, y preservar una infraestructura comercial que es indispensable económica y socialmente para el sector".

Según las Naciones Unidas (2011 , p. 69) por razones de interacción con el mercado la FNC no puede garantizar precios pero a través del precio de la garantía de compra puede asegurar que alguien le compre su café al cultivador, sin importar la cantidad y el periodo del año.

"Para estas compras se utiliza el precio de mercado del café, esto es, el precio internacional. Con ello se logra transferir al productor el $95 \%$ del precio internacional, evitando que la mayor parte de éste quede en manos de los grandes traders internacionales, como es el caso de otros países. Esta herramienta ocupa un rol relevante en la estrategia global implementada por la FNC". (Naciones Unidas 2011, p. 69).

${ }^{17}$ Explicado en la página 19. 


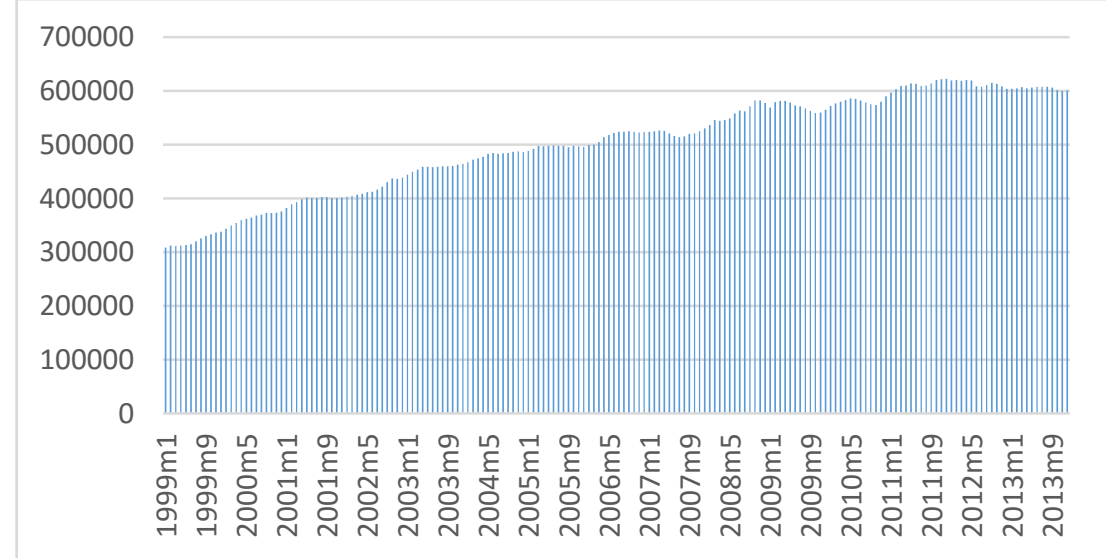

Figura 9. Garantía de compra deflactada ajustados al Índice de Precios del Productor de 2009

Fuente: Elaboración propia del autor con datos de la FNC

En la Figura 9 se muestra una evolución de los precios mínimos de compra deflactado con el Índices de Precios al Productor del año 2009 desde 1999 hasta 2013, en donde se muestra una tendencia creciente por cuenta de los precios bajos que estaban afectando a los cafeteros de forma notoria en el periodo de referencia. Este no era el único factor que incidía ya que el país cafetero padece los efectos negativos del Fenómeno del Niño. En el periodo de 1999 hasta el 2013 se observa una tendencia de pago al caficultor de por parte de la FNC un precio por cada saco de café pergamino de 125 kilos que oscila entre los $\$ 310.000$ hasta los $\$ 600.000$.

Complementando las características de esta herramienta la presencia en el mercado cafetero, como efecto de la garantía de compra, la Federación señala que cuenta con 513 puntos de compra en el territorio nacional, que son manejados por 34 cooperativas de caficultores, a las que se reconoce un margen de intermediación por la compra del café ${ }^{18}$. A nivel histórico Silva (2011, p. 14), citando a Junguito \& Pizano, expone que esta política inició en 1958, cuando el Comité Nacional de

\footnotetext{
18 "Esas cooperativas patrocinadas por la FNC compiten en los mercados locales con otros compradores, que pueden ser otros intermediarios locales o trilladoras de propiedad de los grandes comercializadores internacionales privados (cuando éstas están presentes en esos mercados) o el mismo Almacafé, el operador logístico de la FNC, que administra 9 plantas industriales especializadas en trilla de café de exportación. Las cooperativas entregan a Almacafé el café que compran para la FNC, y Almacafé trilla el café y lo lleva a su destino: los puertos donde se embarca el café que la FNC vende en los mercados internacionales".
} 
Cafeteros estableció las características del café de exportación como tipo único de pergamino y su garantía de compra.

La Garantía de Compra dependía también del precio interno del grano en donde además de ser garantizado con los recursos del Fondo Nacional del Café (FoNC) administrado por la FNC sería fijado por un comité integrado por los Ministros de Agricultura y Hacienda y el Gerente de la FNC.

\subsection{El Fondo Nacional del Café y la Garantía de Compra}

Desde la teoría institucional no se puede hablar de la intervención de precios sin la influencia de una estructura administrativa que lo implemente. Justamente en este aparte se explicarán las acciones más importantes de la injerencia administrativa en la política de precios.

Para Junguito \& Pizano (1993, p. 76) al crearse la Federación Nacional de Cafeteros en 1927 se empezaron a evidenciar los primeros indicios de que un órgano paraestatal contribuyera a la ordenación del mercado como lo fue las calidades del café en cada departamento productor, los atributos de cada clase y las marcas que debía llevar de acuerdo a su lugar de origen.

Como segunda fase de un mercado estructurado en medio de la formación de la Federación, se dio vía libre a la creación y operación de los almacenes de depósito que ofrecían a los productores el servicio de consignación del café con el fin de esperar mejores precios a fin de contrarrestar el poder de influencia ejercida por los compradores particulares.

A través de lo expuesto en el Decreto 444 de 1967 "Sobre régimen de cambios internacionales y de comercio exterior", dicho comité adoptaría las medidas pertinentes para la compra del grano a los pequeños productores de forma directa a por la Federación, con el fin de que en esta operación se haga manifiesto el beneficio mutuo. 
El Decreto 444 de 1967 tenía dentro de sus lineamentos estimular el desarrollo económico social el fomento de las ventas externas, exportaciones; aprovechamiento adecuado de las divisas disponibles, así como el control sobre la demanda de cambio exterior, particularmente para prevenir la fuga de capitales y las operaciones especulativas. Todo lo anterior tenía como fin erradicar las asimetrías de la información y hacer al Estado un controlador del flujo de divisas. Todo lo anterior se hacía a través de la Junta Monetaria ${ }^{19}$.

En vista de lo anterior las actividades económicas a través del Estado estaban sujetos a cumplir el Acuerdo Monetario de Bretton Woods, aprobado por la Ley 96 de $1945^{20}$. En el Decreto 444 de 1967 los ingresos en moneda extranjera se venderán al Banco de la República o se canjearán en esta institución por "Certificados de Cambio", según el caso. Bajo este precedente las divisas solo podrían adquirirse para los fines económica o socialmente útiles como mercancías y fletes de importaciones que debían cubrirse en moneda extranjera.

Para el caso de la actividad cafetera la norma menciona que la actividad de vender café al exterior estaba ligada a la presentación de un registro de exportación reglamentado por la FNC. En este escenario habría que destacar lo siguiente: Mientras los bienes que se exportaban y se importaban estaban regidos bajo regulaciones y dictámenes estatales, el café estaba, en cierta medida, amparado bajo las decisiones del mercado internacional del grano y las determinaciones de la $\mathrm{FNC}^{21}$.

\footnotetext{
${ }^{19}$ Formada tras el inventario de reformas que se le hizo al Banco de la República desde 1930, ésta Junta Monetaria se creó en 1963 y se conformó por los siguientes miembros el Ministro de Hacienda y Crédito Público, quien la presidía, el Ministro de Desarrollo, el Ministro de Agricultura, el jefe del Departamento Nacional de Planeación y el Gerente del Banco de la República. En 1976 se incorporó al Director del Instituto Colombiano de Comercio Exterior - INCOMEX. De acuerdo con información del Banco de la República se retornaron al Estado las funciones que antes eran de responsabilidad exclusiva de la Junta Directiva del Banco, de carácter privado. De esta forma, se asignó al Estado el estudio y la adopción de las políticas cambiaria, monetaria y crediticia, dejando a la Junta del Banco sólo la ejecución de dichas políticas.

20 Artículo 3ํㅡㄹ Decreto 444 de 1967.

21 Según el Decreto 444 de 1967 la Superintendencia de Comercio Exterior. Establecía un registro de exportación. En el caso de exportadores de café dicho documento se efectuará con el visto bueno de la Federación Nacional de Cafeteros de Colombia.
} 
Así mismo, el decreto también establece que "los contratos de venta de café deberán registrarse en la Superintendencia de Comercio Exterior, la cual queda facultada para que, a solicitud de la Federación Nacional de Cafeteros de Colombia, pueda suspender o limitar transitoriamente el registro de dichos contratos" (Presidencia de la República, Decreto 444 de 1967, p. 12).

Aunque el control de las actividades externas relacionadas con el Acuerdo Internacional del Café y otras coyunturas eran gestionados por la FNC, la Junta Monetaria era un regulador de todas las actividades que involucraban el manejo de divisas. En este orden de ideas el Decreto de referencia establecía que para efectos de hacerse responsable de sus gastos y de otras obligaciones extranjeras, los presupuestos que eran elaborados por la FNC de forma periódica y que incluían estos ítems debían pasar por la lupa de la Junta Monetaria.

En cuanto al comportamiento del precio del café en el entorno internacional, si bien es cierto que a nivel interno existía el decreto 444 de 1967 que servía para controlar el flujo de divisas al momento de exportarse (entre ellas el grano debía cumplir algunas de esas regulaciones), el café estaba sujeto a otras condiciones de mercado.

\subsection{El año en que cambió el negocio del café}

1989 fue un año en el que la caída del muro de Berlín cambió al mundo en todas sus dimensiones. Así como se empezaba a ver un nuevo entorno en la arena geopolítica por cuenta de la desintegración de la Unión Soviética, los mercados también se vieron impactados tras la liberalización de la economía. América Latina no fue ajeno este proceso.

Al ver que la región debía seguir unos parámetros para aprovechar el panorama aperturista y desprenderse de la tendencia proteccionista y la regulación, en 1989 el Consenso de Washington sería el derrotero que según Casilda Béjar (2004 p. 19) 
debían seguir los países en América Latina para "orientar a los Gobiernos de países en desarrollo y a los organismos internacionales (Fondo Monetario Internacional, Banco Mundial y Banco Interamericano de Desarrollo (FMI, BM y BID) a la hora de valorar los avances en materia económica de los primeros al pedir ayuda a los segundos. El Consenso, se elaboró para encontrar soluciones útiles sobre la forma de afrontar en la región la crisis de la deuda externa, y establecer un ambiente de transparencia y estabilidad económica".

Entre las reformas que se pedían a dichas economías se consideraban la modificación de reformas fiscales, los tipo de interés, el tipo de cambio, la privatización para liberar al país de una gran carga presupuestal proveniente del gasto público, desregulaciones para fomentar la competencia entre empresas y la liberalización de las importaciones.

Con este escenario la industria del café se vio permeado por esta dinámica. Pese a que la liberalización plena de las economías en teoría representaba el acceso a nuevos mercados el grano colombiano no se vio beneficiado. Para Silva et al, (2002, p. 15) la crisis tiene su origen en los procesos de ajuste de la caficultura mundial desatados por la ruptura del Acuerdo Internacional de Café en 1989.

Un suceso que cambió el rumbo de la industria del café a nivel mundial fue la finalización del Pacto de Cuotas en 1989, situación que aseguraba un nuevo escenario en donde el precio del café estaría más sujeto a los vaivenes del mercado por cuenta de nuevos jugadores y de una inminente crisis que afectó severamente los ingresos de los caficultores y las finanzas de la FNC.

Describen los autores que este entorno desencadenó una expansión de la producción, principalmente en Vietnam y Brasil, creándose un exceso crónico de producción mundial que ha llevado los precios reales del grano a los niveles más bajos de su historia hasta el punto de que los tostadores han aprovechado esa situación para sustituir cafés suaves por robustas de menor calidad en las mezclas 
que llegan al consumidor final, con la consiguiente caída en la demanda por cafés suaves.

De acuerdo con Bohman \& Jarvis (1990, p. 11) el Acuerdo Internacional del Café (AIC) es una organización de países exportadores e importadores de café. EI AIC se creó inicialmente en 1962 por un periodo de seis años y luego se renovó en 1968, en 1976 y en 1983. Las negociaciones para renovar el AIC de 1983 que expiraría en octubre de 1989, se suspendieron en julio de 1989 como resultado de los graves desacuerdos que se presentaron dentro de la AIC. Señalan los autores que el objetivo de dicho acuerdo era elevar los precios y al mismo tiempo estabilizarlos ${ }^{22}$.

Dado lo anterior, en el siglo XX la política de estabilización de precios fue marcada principalmente en los años sesenta en actividades muy dependientes de productos básicos para regular la oferta con acuerdos para restringir la producción, controlar inventarios o establecer cuotas de exportación, aspecto que se traduce en mayores precios $^{23}$.

\subsection{Los noventas y el 2000 , el periodo de transición}

Después de 1989 si bien es cierto que Colombia registró la mayor producción de sacos de 60 kilos, no contaba con el mejor panorama para destinar gran parte de este inventario en exportaciones. Para Silva et al (2002. p, 17) "desde 1997 se ha dado una reducción significativa en los precios externos del café. El precio en bolsa del Contrato $\mathrm{C}^{24}$ en términos nominales es el más bajo en 33 años, y el precio del

\footnotetext{
22. "Lo que resulta en que los consumidores en los países miembros importantes pagan por el café precios más altos que los precios del mercado libre. (...) las disposiciones del AIC que elevan los precios benefician a los miembros exportadores a expensas de los consumidores en los países importadores miembros." Bohman \& Jarvis (1990, p. 12)

${ }^{23}$ En el caso del petróleo Mankiw (2002, p. 67) expone como en la década de 1970, los miembros de la Organización de Países del Petróleo OPEP incrementar el precio mundial con el fin de aumentar la renta: "Estos países lograron su objetivo reduciendo su objetivo reduciendo conjuntamente la cantidad ofrecida de petróleo. Entre 1973 y 1974, el precio del petróleo (ajustado para tener en cuenta la inflación general) subió más de un $50 \%$. Unos pocos años más tarde la OPEP volvió a hacer lo mismo. El precio subió un $14 \%$ en 1979 , un $34 \%$ en 1980 y un $34 \%$ en 1981 " (Mankiw, 2002 p. 67).

24 Los autores del "El café capital social y estratégico" (2002 P. 17) explicaron en un aparte que el Contrato $\mathrm{C}$ es el Contrato de futuros de café transado en la bolsa de Nueva Cork para cafés arábicos
} 
café colombiano es, en términos reales, el más bajo en la historia documentada" (ver Figura 10).

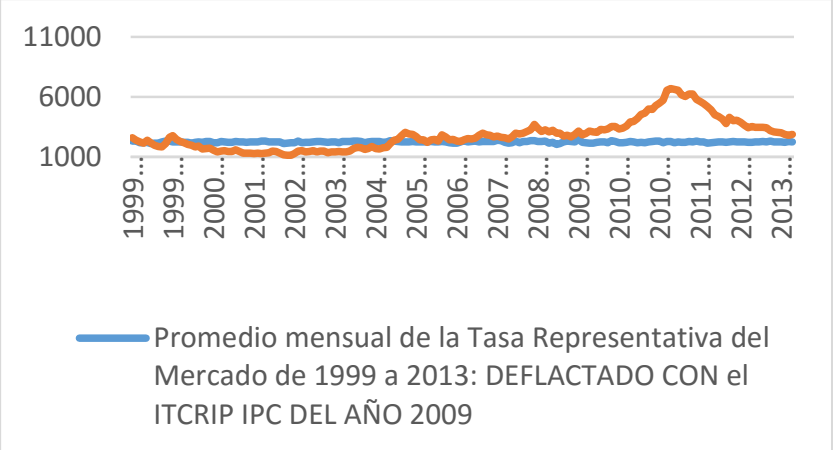

Figura 10. Promedio precio Mensual de la libra Café, convertido a TRM de Colombia y deflactado con el ITCRIP IPC de 2009 versus promedio mensual de la TRM de 1999 a 2013 Fuente: Elaboración propia del autor con datos de la FNC.

Después de 1989, año en que el mundo se enmarcó hacia la liberalización de la economía y la interacción cada vez más frecuente de los mercados, actores importantes dentro de la industria cafetera aprovechan este escenario en donde la guerra por tener el producto con el mejor valor agregado se apodera de un nicho estratégico en el mercado.

Lo anterior se convierte en un argumento bastante útil para explicar como una industria que ha sufrido por el fenómeno de la estandarización, debe tener como reto hacia el futuro fortalecerse e innovar dentro de su estructura de funcionamiento. El café, por ser un producto básico se ha sometido a las volatilidades del mercado. Citando nuevamente a Reina et al (2007, p. 22), el mercado del café comparte con otros productos agrícolas y mineros ciertas características que han dado lugar a la denominada maldición de los productos básicos, los cuales registran las siguientes características:

> Los precios internacionales de estos bienes registran una tendencia descendente en el largo plazo, lo que erosiona el ingreso de sus productores.

lavados producidos en Centro América, Asia y África. Este precio más una prima o descuento, determina los precios para diferentes tipos de café, entre ellos el colombiano. 
Dsos mismos precios tienden a oscilar considerablemente en periodos cortos de tiempo, lo que trae consigo ganancias inesperadas, pero también grandes colapsos que tienden a mantenerse por periodos prolongados.

$>$ Adicional a esto el comercio masivo y la ausencia de rasgos distintivos frente al consumidor fenómenos conocidos como estandarización, explican en gran medida por qué los precios de los productos básicos tienden a descender con el tiempo Reina et al (2007, p. 26).

Prueba de lo anterior es que en la Figura 10 se refleja como la misma oscilación de los precios no garantiza un ingreso constante para uno de los principales eslabones en la producción del café como lo son los caficultores. En ella se refleja como la libra de café desde 1999 se valora en la Bolsa de Nueva York en \$2.596 a valores de 2009, mostrando en noviembre de 1999 un descenso de hasta \$1837, pronunciándose aún más entre los años 2000 hasta mediados del año 2002, cuando pasa de $\$ 1.666$ hasta $\$ 1.134$, respectivamente.

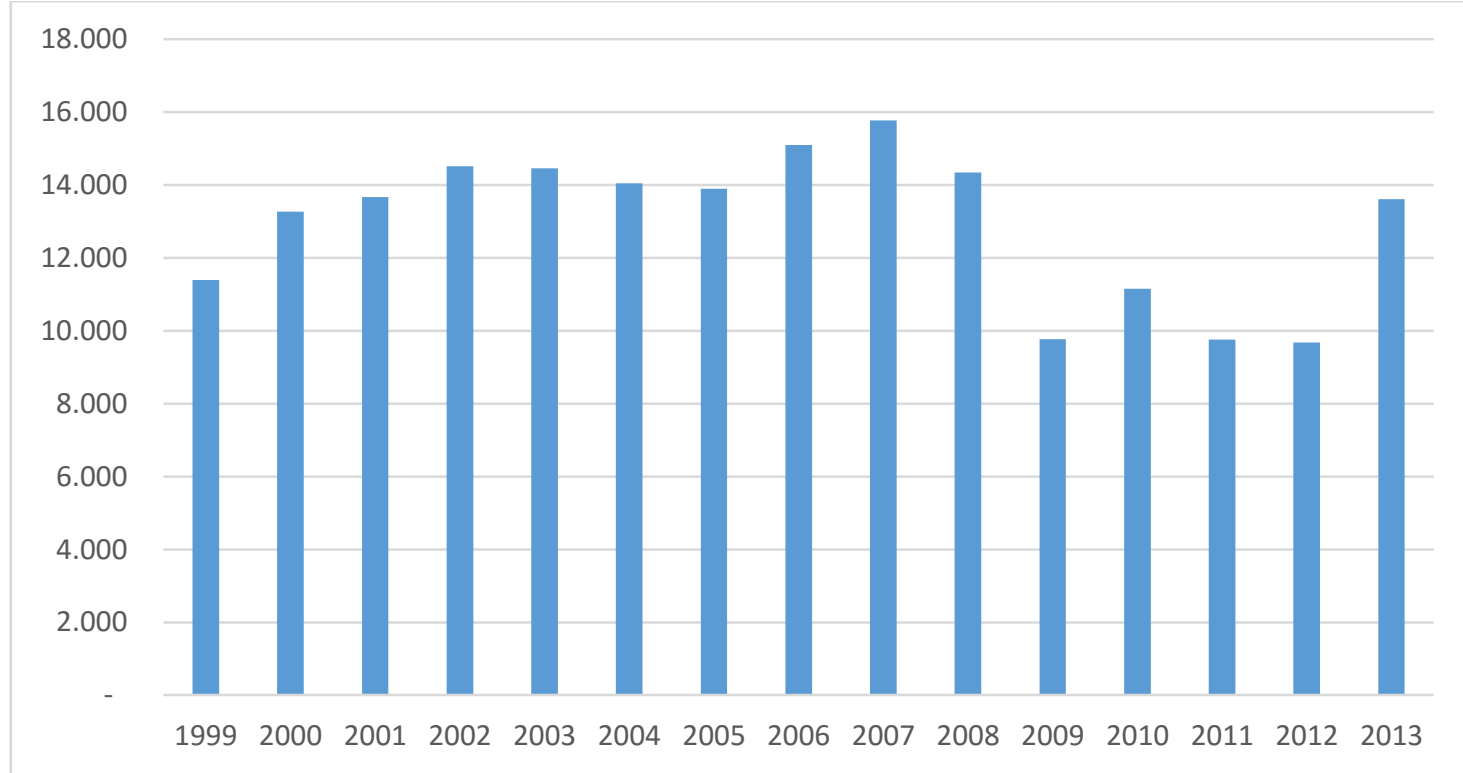

Figura 11. Producción registrada mensual en miles de sacos de $125 \mathrm{Kg}$ de café verde pergamino en Colombia

Fuente: Elaboración propia con datos de la FNC. 
Por otra parte en la Figura 11 se muestra la producción registrada mensual en miles de sacos de $125 \mathrm{Kg}$ de café verde pergamino. Al tomar de referencia el año 1999 se refleja un descenso en la producción hasta el punto de que la producción total de esos 12 meses llega a los 11.390 .000 millones de sacos. Sin embargo el periodo que refleja otro descenso significativo en la producción se da en el 2009, principalmente atribuido a lo que la FNC explica como la "combinación de una serie de factores excepcionales tales como niveles de lluvia $40 \%$ superiores al promedio histórico, la menor aplicación de fertilizantes como consecuencia del aumento de los precios del petróleo, el fósforo y el potasio durante 2008 y el incremento en los niveles de roya". (FNC, 2009, p. 4).

\subsection{La institución como respaldo}

Al ver que la producción anual fue de 11,3 millones de sacos de $60 \mathrm{~kg}$ en 1999, el precio internacional de cotización de café baja a aún más situándose en US\$53 centavos, la Federación Nacional de Cafeteros (FNC, 2002 p. 5) afirmaba que la prolongada situación de un mercado con precios deprimidos y exceso de oferta, modificaron de forma dramática las condiciones del negocio cafetero mundial y las reglas de juego con las que operó la caficultura colombiana durante décadas.

Prueba de lo anterior es lo expuesto en la Figura 12, en donde el inminente ascenso en la producción del grano de agentes competidores como (descartando a Brasil por ser el mayor productor de café en el mundo) Vietnam e Indonesia le ha generado a la caficultura colombiana una disminución notable en su producción y una pérdida significativa del mercado por cuenta de otros países que ofrecen otras condiciones a los grandes consumidores.

En el periodo de estudio se observa como Colombia registró una producción aproximada de 9,6 millones de sacos, en tanto que Vietnam e Indonesia comenzaron el milenio con una oferta de 11,6 y 6,9 millones, respectivamente. Aunque Indonesia obtuvo producciones por debajo de los que tenía Colombia a comienzos de la primera década del 2000, no fue hasta los años 2007 y 2008 que 
el país asiático supera a Colombia obteniendo la capacidad de producir en promedio entre 9 y 11,5 millones de sacos, mientras que el país experimentó una tendencia decreciente pasando de producir alrededor de 12 millones a un mínimo de 7 millones entre el 2011 y 2012 y retornando a la producción anual de los 12 millones de sacos entre 2013-2014.

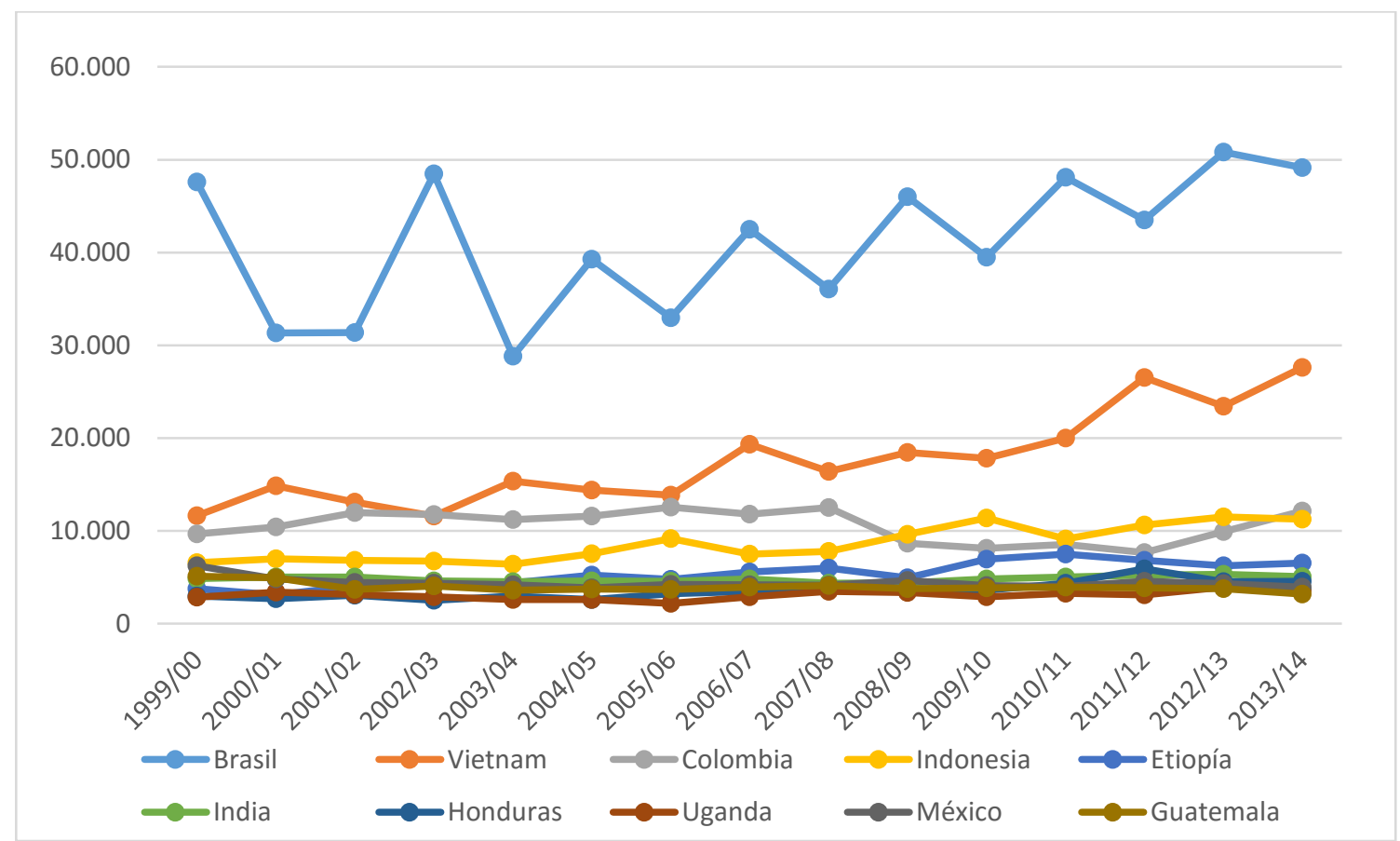

Figura 12. Producción total de los principales países exportadores en miles de sacos de 60 kilos

Fuente: Elaboración propia con datos de la Organización Internacional del Café

\subsection{Panorama del sector}

A lo largo de este capítulo se ha ilustrado un panorama de los principales sucesos que marcaron los rumbos del mercado del café, lo cual se complementó con otros aspectos que dieron lugar en los años noventa así como también algunas de las políticas implementadas por la Federación Nacional de Cafeteros para afrontar la crisis antes descrita. Ahora se brindará una panorámica de esta industria.

Silva et al (2007, p. 33) señala que Coffea arabica y Coffea robusta son las dos principales especies de café de importancia comercial en el mundo con 
aproximadamente el $65 \%$ y $35 \%$ del mercado respectivamente. Sin embargo Echevarría et al (2014, p. 15), citando a la OIC señala que la producción de café robusta ha sido la que exhibe mayor dinamismo durante la década, incrementando su participación en la producción mundial hasta representar un 49\% en 2012/1, con una tendencia creciente en la producción de esta variedad en Vietnam y Brasil.

La literatura especializada en temas de café señalan que dichas especies se diferencian por su forma, condiciones de crecimiento y desarrollo, número de cromosomas, composición química, gusto, sabor y aroma, así como el hecho de que las bebidas preparadas con café arábico se destaca por tener más suavidad, cuerpo medio y un aroma afrutado, mientras que el de café robusta es más fuerte y amargo y posee cafeína. En la Tabla 4 se muestran los actores que corresponden a la industria torrefactora internacional, y Comercializadoras internacionales de café procesado

Tabla 4. Estructura del mercado

\begin{tabular}{|c|c|}
\hline & $\begin{array}{l}\text { omercializadoras internac } \\
\text { café procesado }\end{array}$ \\
\hline $\begin{array}{l}\text { Se encarga de las actividades } \\
\text { industriales de la transformación del } \\
\text { café verde en café procesado en sus } \\
\text { diferentes estados. KRAFT (Estados } \\
\text { Unidos), Procter and Gamble (Estados } \\
\text { Unidos), Nestlé (Suiza) y Sara Lee } \\
\text { (Estados Unidos), son las empresas } \\
\text { multinacionales que controlan el } \\
\text { proceso de tostado y venta del café } \\
\text { procesado. En estas actividades se le } \\
\text { da mayor valor agregado al producto y, } \\
\text { por ende, se logra una mayor utilidad. }\end{array}$ & $\begin{array}{l}\text { Es desarrollada por grandes cadenas } \\
\text { en el exterior, que se encargan de } \\
\text { distribuir el café en diferentes } \\
\text { presentaciones. Las mayores empresas } \\
\text { comercializadoras de café en el mundo } \\
\text { son: Neuman Kaffe (Alemania), Volcafe } \\
\text { (Suiza), Cargill (Estados Unidos), } \\
\text { Esteve (Brasil-Suiza), Aron (Estados } \\
\text { Unidos), Ed\&Man (Reino Unido), } \\
\text { Dreyffus (Francia), Mitsubishi (Japón), } \\
\text { Nestlé (Suiza) y Sara Lee (Estados } \\
\text { Unidos). }\end{array}$ \\
\hline
\end{tabular}

Fuente: Elaboración propia con base en García y Olaya (2006, p. 211). 
Esta anatomía de la industria se mueve bajo una realidad en donde aquellos agentes que ofrezcan el café de la forma más especializada, será quien ponga las reglas en el mercado. Según Echavarría et al (2014, p. 14) el mercado mundial del café se ha caracterizado históricamente por la concentración existente a nivel de empresas comercializadoras y tostadoras. "(...) los grandes volúmenes de café siguen siendo comercializados por las multinacionales que tradicionalmente han dominado esas actividades. En esta última década han ocurrido aún más fusiones y adquisiciones de estas empresas a nivel global, aunque también han surgido nuevos competidores" Echavarría et al (2014, p. 14).

Justamente los autores de referencia señalan que en el mercado de la comercialización mundial, compañías que tenían poca presencia como Louis Dreyfus, Olam o Noble han crecido y hoy disputan los primeros lugares frente a jugadores más tradicionales como Neumann Kaffe Gruppe, Ecom y Volcafe.

En este orden de ideas en el eslabón de la industria tostadora también han surgido algunos nuevos actores como Starbucks, Dunkin Donuts, Mc Donalds y, en general, todos los que atienden el consumo fuera de casa. "Así mismo hay nuevas formas de preparación cuyas ventas vienen creciendo como los cafés single serve o de consumo individual cuyo mejor ejemplo son las cápsulas de Nespresso". (Echavarría et al 2014, p. 14). 


\section{CAPÍTULO 3. INCIDENCIA DE LA GARANTÍA DE COMPRA COMO HERRAMIENTA DE ESTÍMULO A LA PRODUCCIÓN CAFETERA. UN ANÁLISIS EMPÍRICO PARA EL PERIODO 1999 A 2013 EN ANTIOQUIA.}

Después de haber elaborado un acercamiento teórico acerca del panorama de la industria cafetera antes y después de 1989, así como una contextualización sobre cómo se ha estructurado el sector desde un ámbito descriptivo, la finalidad de este capítulo es realizar un acercamiento cuantitativo al problema de investigación.

Para este capítulo se busca a través de un modelo econométrico una interrelación de las variables que responderán a la pregunta de investigación que se formuló al comienzo: ¿La garantía de compra ha incentivado la producción cafetera y le ha generado beneficios a los cultivadores?

Con base en lo anterior la resolución de este interrogante será respaldado con evidencia empírica mediante el análisis de diferentes variables relacionadas con la industria cafetera, planteando como hipótesis el hecho de que la garantía de compra tiene una incidencia negativa en la producción cafetera y para los productores del grano en Colombia.

\subsection{Conceptos econométricos}

La literatura estadística permite establecer a las regresiones como una herramienta econométrica de gran utilidad que establecer en gran medida la estimación y la predicción de la media de la (población) o valor promedio de la variable dependiente con base en los valores conocidos fijos de las variables explicativas. Con base en esto Gujarati 1997) señala que el valor esperado, expectativa media poblacional de una variable aleatoria $Y$ se denota mediante $E(Y)$.

De acuerdo con Wooldridge (2001, p. 66) el análisis de regresión múltiple se vuelve indispensable "porque nos permite controlar explícitamente muchos otros factores que influyen de manera simultánea en la variable dependiente. Esto es importante 
para tanto para probar teorías económicas como para evaluar efectos de las medidas políticas cuando tenemos que confiar en datos que no son experimentales."

El autor agrega que las regresiones se vuelven útiles para abarcar muchos factores observables que influyen en la variable dependiente. En la ecuación 2 se puede explicar el anterior enunciado:

$$
\mathrm{Y}: \mathrm{B0}+\mathrm{B} 1 \mathrm{x} 1+\mathrm{B} 2 \mathrm{X} 2+\mathrm{B} 3 \mathrm{X} 2+\mathrm{B} 4 \mathrm{X} 4+\mathrm{B} 5 \mathrm{X} 5+u
$$

En donde $\mathrm{B}_{0}$ corresponde a la intercepción, $\mathrm{B}_{1}$ es el parámetro asociado con $\mathrm{x}_{1}, \mathrm{~B}_{2}$ es el parámetro asociado con $\mathrm{x} 2 \mathrm{y}$ así sucesivamente. Por otra parte la variable u es el término de error o perturbación.

Para estos efectos, así como las teorías cumplen una serie de especificaciones para tratar de explicar una realidad determinada, los modelos econométricos deben atender a una serie de condiciones que sustente la robustez de su herramienta. Señala Gujarati \& Porter (2010, p. 189) el modelo de regresión múltiple se ampara en las siguientes condiciones que son:

1. En el modelo de regresión lineal se debe presentar linealidad en los parámetros.

2. Valores fijos de $X$ o valores de $X$ independientes del término de error. En este caso, esto significa que se requiere covarianza cero entre ui y cada variable $X$.

$$
\operatorname{Cov}(\mathrm{ui}, \mathrm{X} 2 \mathrm{i})=\operatorname{Cov}(\mathrm{ui}, \mathrm{X} 3 \mathbf{i})=0
$$

3.

3. Valor medio de la perturbación ui igual a cero.

$$
E(\mathrm{ui}, \mathrm{X} 2 \mathrm{i}, \mathrm{X3i})=0 \text { por cada } i
$$

4.

4. Homoscedasticidad o varianza constante de ui.

5.

$$
\operatorname{var}\left(\mathrm{ui}_{\mathrm{i}}\right)=\sigma 2
$$

5. No autocorrelación, o correlación serial, entre las perturbaciones: 


$$
\operatorname{Cov}\left(\mathrm{u}_{\mathrm{i}} \mathrm{u}_{\mathrm{j}}\right)=0 i \neq j
$$

6. El número de observaciones $n$ debe ser mayor que el de parámetros por estimar, que en el presente caso son 3.

7. Debe haber variación en los valores de las variables $X$.

8. No debe haber colinealidad exacta entre las variables $\mathrm{X}$

No hay relación lineal exacta entre $\mathrm{X}_{2}, \mathrm{X}_{3}$

9. No hay sesgo de especificación.

\subsection{Descripción del entorno cafetero en Antioquia}

Antes de referenciar las variables que conformarán al modelo econométrico, en esta sección del capítulo se hará una explicación sobre la caficultura de Antioquia y su relación con la garantía de compra. Aunque el departamento de Antioquia se ha caracterizado por ser uno de los testigos del florecimiento de la industria cafetera, actualmente otras zonas no tradicionales de Colombia se han metido en la puja por ser protagonista en la industria del grano.

En el caso del Huila, gracias al impacto positivo que ha tenido el grado de tecnificación de su caficultura que se manifiesta en el manejo de la edad y densidad del cultivo, este departamento pasa a ser el más productor de café del país tal como como los refleja la Figura 13 con los datos rescatados en la Tabla 3.

La Figura 13 que corresponde al Área cultivada con café de Antioquia, Huila y Tolima muestra como ha sido la evolución de tres importantes lugares de siembra y cosecha del café, en donde Huila muestra el ascenso más significativo; mientras la región de Antioquia incrementó en promedio su área en 3.000 hectáreas en los últimos 14 años (lo que representa una variación de 3\%) pasando de 127.900 a 130.900 hectáreas la unidad geográfica localizada en la parte suroccidental del país, la región andina mostró un marcado crecimiento de área de 76.230 has a 154.980 has, situación que le significó un aumento del 50,47\%. 


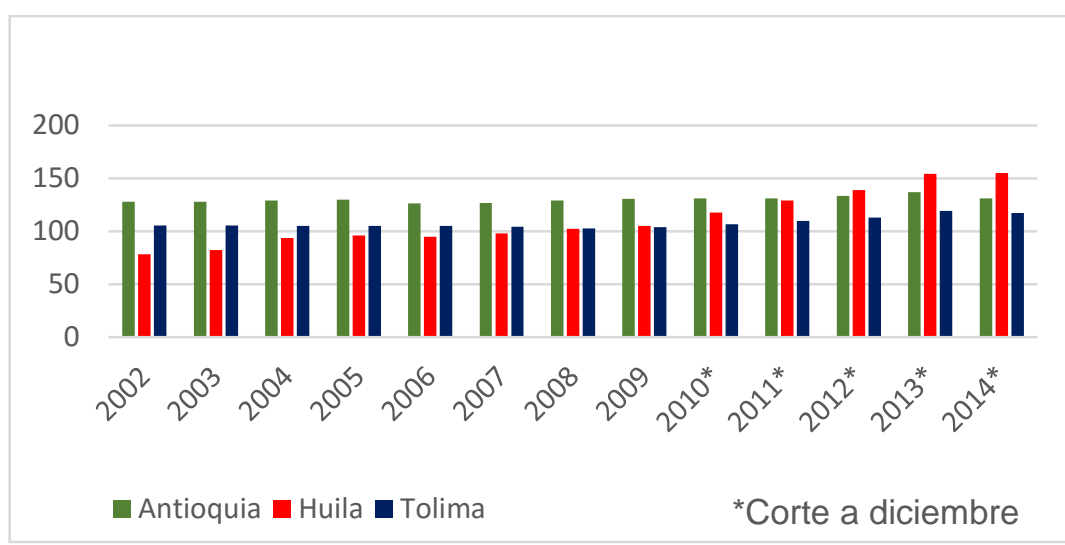

Figura 13. Área cultivada con café de Antioquia, Huila y Tolima

Fuente: Elaboración propia con base en datos de la Federación Nacional de Cafeteros

Siguiendo con este inventario Escobar (2013, p. 3) señala que "Antioquia cuenta actualmente con 94 municipios productores, alrededor de 120.000 fincas cafeteras donde se produce el $15.8 \%$ de la producción nacional". Señala también el autor referenciado anteriormente que en esta región se destaca el suroeste antioqueño como productor del $60 \%$ del total del departamento que cuenta con un área de producción disponible de $54.204,5$ hasta el punto de que "cerca de $12 \%$ del café que exporta Colombia sale de los municipios del suroeste antioqueño." (Escobar 2013, p. 3).

A manera de caracterización Escobar Henao relata como en el departamento que se encuentra ubicado en el noroeste de Colombia, la manipulación del grano para su producción y su comercialización representa uno de los primeros lugares en generación de entre 1'200.000 a 1'400.000 empleos directos e indirectos. "El aporte al valor agregado por la agricultura fue de 416 mil millones de pesos, en el 2012, lo que representó el $0.1 \%$ del PIB y es además el motor básico del desarrollo rural, especialmente en la zona sur y centro del departamento cuyas alternativas económicas son reducidas en el corto plazo" (Escobar, 2013, p. 4).

En cuanto a la caracterización de esta importante región cafetera, el autor de referencia comenta que los predios cafeteros conservan el atributo de ser 
predominantemente pequeños, ya que la mayor parte de ellos está dedicada a la explotación cafetera, mientras que es muy poca el área vinculada otras actividades productivas. "Del tamaño total de la finca un $76.4 \%$ está sembrado con café, el $9.7 \%$ se dedican a otras actividades agropecuarias y un $13.9 \%$ corresponde a áreas no explotadas o recursos naturales" (Escobar, 2013, p. 4). Tras lo afirmado por Escobar Henao los terrenos dedicados al cultivo del grano poseen características como topografía predominante quebrada y ondulada, atributo que se convierte en un factor preponderante en el empleo de cualquier innovación tecnológica.

A corte de 2010 existía 91.355 caficultores en esta región, según datos de Gómez, Ruiz, \& Castro (2011 p, 11). Sin embargo como no existen cifras oficiales de la clasificación por tamaño de productor en este documento se retoman los porcentajes de la Figura 7 de la siguiente manera; de esos 91.355 el $95 \%$ equivale a 86.787 caficultores pequeños con cultivos que van de 0 a 5 hectáreas (Has), el $3 \%$ son 2.740 productores medianos con cultivos de 5,1 a 10 Has y los grandes equivalen a 1.827 cultivadores del grano con cultivos de 10,1 has en adelante. Por medio de la Figura 14 se explica las dimensiones y características de las fincas cafeteras en Antioquia.

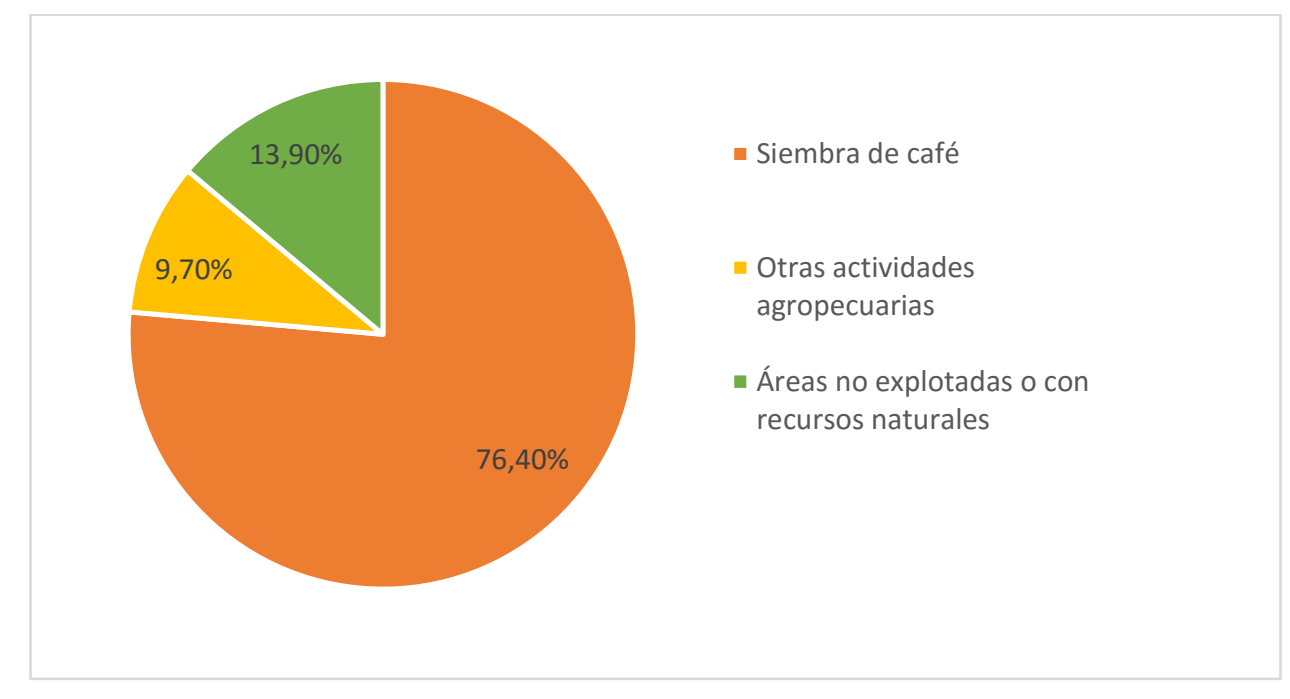

Figura 14. Usos de la finca cafetera en Antioquia Fuente: Elaboración propia con datos de Escobar Henao (2013). 


\subsection{Antioquia y la garantía de compra}

Ya se había descrito en el capítulo dos que la garantía de compra se realiza mediante la publicación de un precio base de mercado que se calcula de acuerdo con la cotización de cierre en la Bolsa de Nueva York del día, el precio del dólar del día y el diferencial o prima de referencia para el café colombiano, situación que se ve detallada en la Figura 15: 
Figura 15. Variables que determinan el precio del café en Colombia

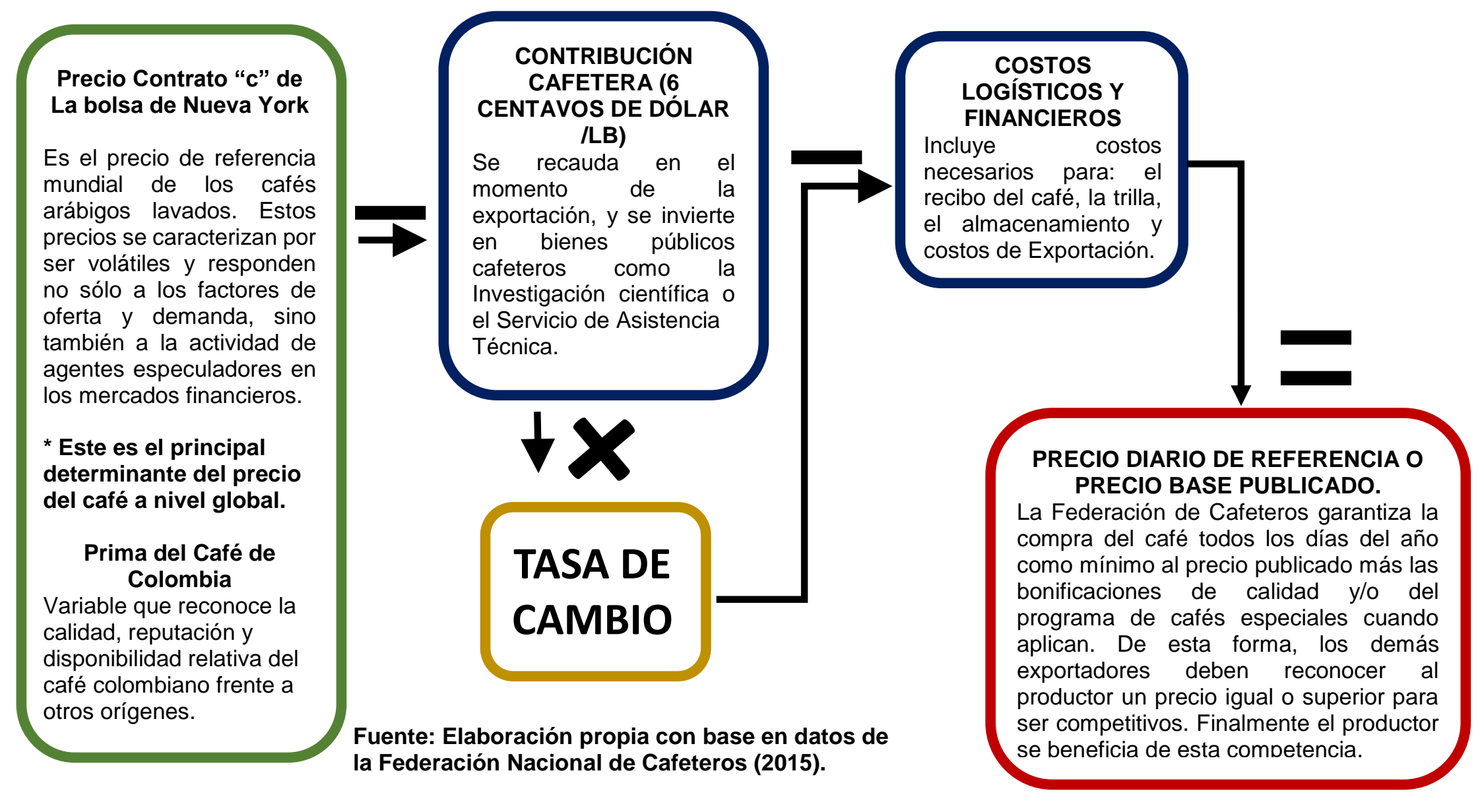


Desde el punto de vista del precio interno la misma Federación Nacional de Cafeteros (FNC), justifica que esta fijación de esta variable se realiza ya que los mismos caficultores del grano son susceptibles y sufren de manera directa dos clases de riesgos que se asocian con el precio del café en la Bolsa de New York o también denominado "Contrato C" y el segundo está relacionado con las fluctuaciones del tipo de cambio en la relación dólar-peso (ver anexo H).

Entretanto, a manera de logística, el funcionamiento de la garantía de compra se da cuando una vez el café pergamino resulta de un procedimiento y luego se lleva para ser comercializado. Señala Escobar (2013, p. 4), que el respaldo a aquellos que cultivan el grano se ve plasmado mediante 4 cooperativas que hasta el corte de 2012 contaban con 21.072 asociados en 72 comités locales que disponen 94 puntos de servicio de atención para compras de café y el Comité Departamental ${ }^{25}$ presta el servicio de extensión con cerca de 200 profesionales.

"Una vez que culmina el proceso productivo en la finca, el cafetero antioqueño tiene la opción de vender su café en el punto de compra de la cooperativa de caficultores más cercano a su finca o a otros comercializadores, intermediarios o exportadores". (Escobar 2013, p. 4). De aquí surge la importancia de la garantía de compra porque el caficultor tiene la posibilidad de hacer dos elecciones; si el agente privado le ofrece un precio de compra más bajo que el incentivo entregado por la FNC, probablemente acuda a la garantía de compra para protegerse de los embates que sufren los commodities por cuenta de la volatilidad de sus precios.

\footnotetext{
25 Es una extensión administrativa de la FNC que según rigen los estatutos de este órgano paraestatal, tiene como principal tarea cumplir y al mismo tiempo hacer cumplir los Estatutos, las políticas del Congreso Nacional de Cafeteros, así como también las decisiones del Comité Directivo, de la Gerencia General y de los Comités Departamentales. De igual manera está dentro de sus atribuciones gestionar con el Comité Departamental, campañas para el mejoramiento del cultivo, el control de situaciones como plagas y enfermedades, la renovación de los cafetales, el correcto beneficio del café, y todas las que redunden en el mejoramiento de las condiciones sociales y económicas de los productores de café.
} 


\subsection{Variables del modelo}

Con una regresión lineal multivariable se busca establecer de manera práctica si es la garantía de compra la que incide de manera significativa en la producción, o de lo contrario es otra variable la que ejerce una mayor fuerza de asociación con la variable dependiente.

A continuación las variables tomadas en cuenta fueron las siguientes:

\section{Variable dependiente:}

- ProdCafe125kgOKconver: Producción registrada - mensual Miles de sacos de $125 \mathrm{Kg}$ de café verde pergamino transformado (Producción de sacos $60 \mathrm{~kg}$ kilos de café verde * factor de conversión $(0,80) / 125)$. Datos dados en variaciones porcentuales intermensuales. La garantía de compra se les entrega a los cafeteros por la producción de este tipo de café. En este documento se parte del supuesto de que todos los cafeteros reciben este incentivo (ver Anexo E).

\section{Variables predictivas:}

- GarCompraAdjustIPPmensual: Garantía de compra del café. Este valor se encuentra deflactado con el Índice de Precios al Productor del año 2009. Como se mencionaba anteriormente este incentivo está conformado por el precio contrato "C" de la bolsa de Nueva York, la prima del café de Colombia, la tasa de cambio y los costos de comercialización que se derivan de este producto. Datos dados en variaciones porcentuales intermensuales (ver Anexo C).

- TotCostBigAntIPP: Serie costos totales por hectárea para grandes productores de la región de Antioquia. El tipo de cultivo es Café Tecnificado con un ciclo de duración de 5 años. Las características del productor grande 
se dan porque posee cultivos mayores a 20 hectáreas (Has). El dato suministrado proviene de la central de datos Agronet (ver Anexo K). A septiembre 2009 se da el valor de los costos de producción por hectárea, que posteriormente son ajustados mensualmente a los valores del Índice de Precios del Productor (IPP) de 2009. Los datos están dados en variaciones porcentuales intermensuales y se encentran en el Anexo A.

Los valores que se ajustaron al Índice de Precios al Productor del año de referencia se realizó con base la serie histórica de la sección "Agricultura, Ganadería, Caza, Silvicultura Y Pesca" en oferta interna que es construida agregando las antiguas secciones "Agricultura, Silvicultura y Ganadería" y "Pesca", que se encuentra reposada en las bases de datos del Banco de la República (Base: Diciembre 2014=100). El mismo ajuste de valores se realiza tanto para los productores medianos y pequeños.

- TotCostMedAntIPP_01: Serie de costos totales por hectárea para productores medianos de la región de Antioquia. El tipo de cultivo es Café Tecnificado con una duración de ciclo de 5 años. El tipo de productor se caracteriza por tener de 5 a 20 Has para producir. El dato es suministrado por la central de datos Agronet (véase Anexo J). A septiembre 2009 se da el valor de los costos de producción por hectárea, que posteriormente son ajustados mensualmente a los valores del IPP de 2009. Datos dados en variaciones porcentuales intermensuales. Los ítems que conforman los costos para este tipo de productor se encuentran en el Anexo B de este documento.

- TotCostSmallAntIPP: Serie costos totales por hectárea para productores pequeños de la región de Antioquia. El tipo de cultivo es Café Tecnificado con un ciclo de duración de 5 años. El tipo de productor es pequeño ya que posee menos de $5 \mathrm{Has}$. El dato suministrado por la central de datos Agronet (véase Anexo I). A septiembre 2009 se da el valor de los costos de 
producción por hectárea, que posteriormente son ajustados a los valores IPP de 2009. Datos dados en variaciones porcentuales intermensuales.

- BenPGCCosBigAntIPP: Margen de beneficios de los grandes productores de Antioquia deflactada con e IPP de 2009. Datos dados en variaciones porcentuales intermensuales. Este dato se calculó con base en la diferencia entre la garantía de compra que entrega la FNC a los cafeteros (ajustados a precios de 2009) y los costos de producción por hectárea de este tipo de caficultor explicados anteriormente (véase Anexo C).

- BenPGCCosMedAntIPP: Margen de beneficios de los productores medianos de Antioquia deflactada con el IPP de 2009. Datos dados en variaciones porcentuales intermensuales. La información se calculó con base en la diferencia entre la garantía de compra que entrega la FNC a los cafeteros (ajustados a precios de 2009) y los costos de producción por hectárea de este tipo de caficultor (véase Anexo D).

- BenPGCCosSmallAntIPP: Margen de beneficios de los pequeños productores de Antioquia deflactada con e IPP de 2009. Datos dados en variaciones porcentuales intermensuales. Este dato se calculó con base en la diferencia entre la garantía de compra que entrega la FNC a los cafeteros (ajustados a precios de 2009) y los costos de producción por hectárea de este tipo de caficultor (véase Anexo D).

- ExpCafe125kgOKconver: Volumen de las exportaciones colombianas de café (Miles de sacos de $60 \mathrm{Kg}$ de café verde equivalente) Producción de sacos $60 \mathrm{~kg}$ *kilos de café verde * factor de conversión $(0,80) / 125$. Datos dados en variaciones porcentuales intermensuales (véase Anexo E).

- PrommenTRMCorriente: Promedio mensual de la Tasa Representativa del Mercado de 1999 a 2013. Datos dados en Valores corrientes. Aunque la TRM 
es una variable fundamental en la determinación de la garantía de compra, la razón del por qué se contempla esta variable en términos corrientes es porque que la decisión del caficultor de obtener este incentivo se dio bajo las condiciones de la variabilidad del dólar en el periodo de estudio. Datos dados en variaciones porcentuales intermensuales (véase Anexo F).

- PrecLibraCafConvCoITRMCon: Promedio del Precio mensual dados en centavos de dólar americano por libra Café, arábica suave y convertido a la Tasa Representativa del Mercado y deflactado con el Índice de la tasa de Cambio Real empleando las ponderaciones totales y el IPC como deflactor (ITCRIP-IPC) con el dólar de 2009. Datos dados en variaciones porcentuales intermensuales (véase Anexo H).

Para una mayor comprensión de las variables a continuación se resumen en la Tabla 5:

Tabla 5. Variables que conforman el modelo econométrico

\begin{tabular}{|l|l|l|}
\hline VARIABLES & DESCRIPCIÓN & MEDICIÓN \\
\hline ProdCafe125kgOKconver & $\begin{array}{l}\text { Producción registrada } \\
- \text { mensual Miles de } \\
\text { sacos de 125 Kg de } \\
\text { café verde pergamino } \\
\text { transformado. }\end{array}$ & Porcentual \\
\hline GarCompraAdjustIPPmensual & $\begin{array}{l}\text { Garantía de compra } \\
\text { del café ajustado al } \\
\text { IPP de 2009. }\end{array}$ & Porcentual \\
\hline TotCostBigAntIPP & $\begin{array}{l}\text { Serie costos totales } \\
\text { para grandes } \\
\text { productores de la } \\
\text { región de Antioquia. }\end{array}$ & Porcentual \\
\hline TotCostMedAntIPP_01 & $\begin{array}{l}\text { Serie de costos totales } \\
\text { para productores } \\
\text { medianos de la región } \\
\text { de Antioquia. }\end{array}$ & Porcentual \\
\hline TotCostSmallAntIPP & $\begin{array}{l}\text { Serie costos totales } \\
\text { para productores } \\
\text { pequeños de la región } \\
\text { de Antioquia. }\end{array}$ & Porcentual \\
\hline
\end{tabular}




\begin{tabular}{|l|l|l|}
\hline BenPGCCosBigAntIPP & $\begin{array}{l}\text { Margen de beneficios } \\
\text { de los grandes } \\
\text { productores de } \\
\text { Antioquia. }\end{array}$ & Porcentual \\
\hline BenPGCCosMedAntIPP & $\begin{array}{l}\text { Margen de beneficios } \\
\text { de los medianos } \\
\text { productores de } \\
\text { Antioquia. }\end{array}$ & Porcentual \\
\hline BenPGCCosSmallAntIPP & $\begin{array}{l}\text { Margen de beneficios } \\
\text { de los pequeños } \\
\text { productores de } \\
\text { Antioquia. }\end{array}$ & Porcentual \\
\hline ExpCafe125kgOKconver: & $\begin{array}{l}\text { Volumen de las } \\
\text { exportaciones } \\
\text { colombianas de café - } \\
\text { mensual. mensual de }\end{array}$ & Porcentual \\
\hline PromMenTRMCorriente & $\begin{array}{l}\text { Promedio mensentual } \\
\text { la Tasa Representativa } \\
\text { del Mercado de 1999 a } \\
\text { 2013. }\end{array}$ & \\
\hline PrecLibraCafConvColTRMCon & $\begin{array}{l}\text { Promedio del Precio } \\
\text { mensual dados en } \\
\text { centavos de dólar } \\
\text { americano por libra } \\
\text { Café, arábica suave. }\end{array}$ & \\
\hline
\end{tabular}

Fuente: Elaboración propia

Antes de continuar con la evaluación del modelo econométrico se vuelve de gran relevancia mostrar cómo se han comportado porcentualmente las variables del estudio a lo largo del periodo analizado. Para esta situación en la Figura 16, se ilustran los promedios de las variaciones anuales del margen de beneficios de los grandes productores de Antioquia deflactada con el IPP de 2009 (Anexo A), así como también los costos totales para grandes productores de la región de Antioquia.

Al observar la variable costos para este tipo de productores se puede evidenciar que a lo largo del tiempo adopta una tendencia estable, en donde entre 2009 y el 2011 es el periodo por el cual los cultivadores sufren altos incrementos en su cadena de costos. Según el informe de gestión de 2010 de la Federación Nacional de Cafeteros (FNC, 2010), lo anterior se explica porque si bien es cierto que la industria cafetera reforzó su apuesta por la competitividad centrada en la renovación de 
cafetales y el mejoramiento de los ingresos del caficultor, inevitablemente debió seguir enfrentándose a un panorama como el aumento de sus insumos como fertilizantes edáficos, fertilizantes foliares, fungicidas, insecticidas, herbicidas, entre otros y la volatilidad del precio internacional del grano.

Por otra parte al examinar el caso de los beneficios entre 1999 y 2001 el cafetero de esta categoría dejó de recibir un $0.0354 \%$ menos de beneficio, situación que se recrudece aún más entre los años 2004 y 2007, época en la que sus beneficios no alcanzaron a cubrir los costos. Del mismo modo entre el 2011 y 2012 los cafeteros percibieron beneficios gracias a que según datos de la Federación Nacional de Cafeteros (FNC, 2012, p. 4), se han gestionado recurso "para la puesta en marcha del Apoyo al Ingreso del Caficultor (AIC) que destinó recursos por $\$ 78.800$ millones para reconocer hasta enero de 2013 un incentivo equivalente a $\$ 60.000$ por carga cuando el precio interno del café estuviera por debajo de $\$ 650.000$ por carga de café pergamino seco". Pese a que en 2011 el precio de la libra se cotizó entre US\$2 y US\$3, los productores de café tuvieron que asumir altos costos en insumos tal como se muestra en la Figura 16.

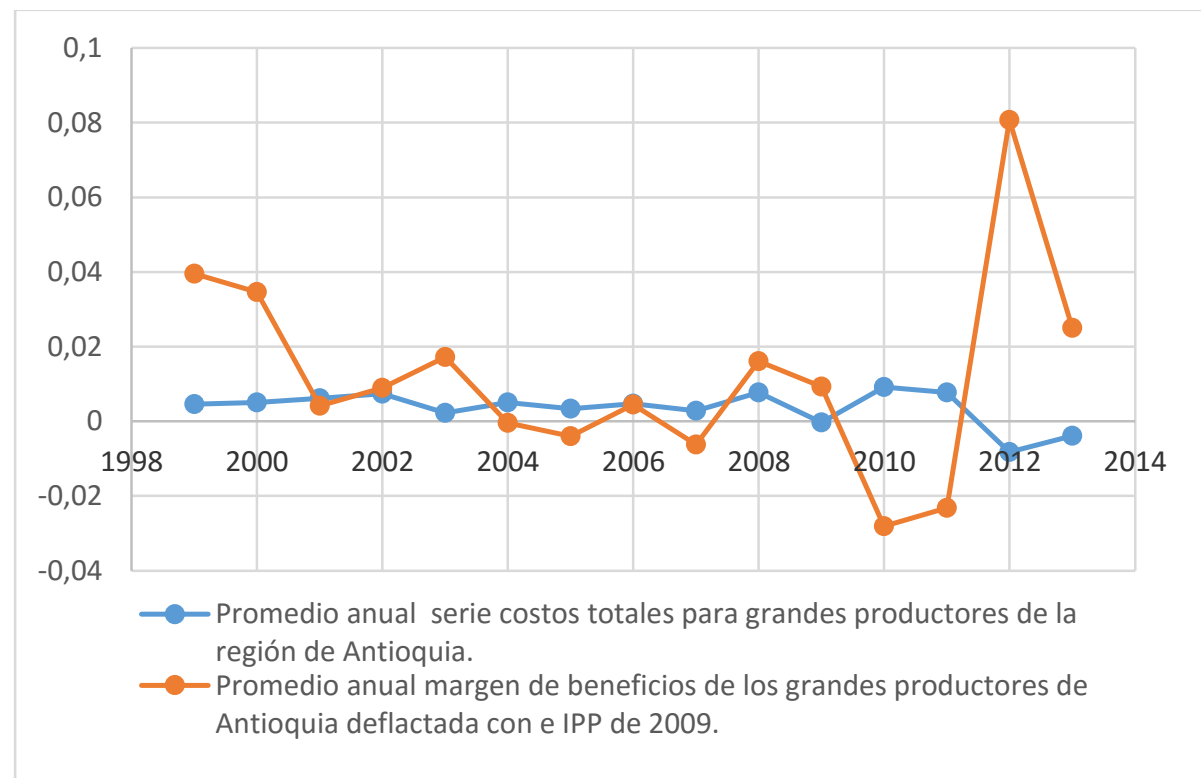

Figura 16. Comportamiento entre los costos totales y beneficios para grandes productores de café de Antioquia

Fuente: Elaboración propia con base en datos de la Federación Nacional de Cafeteros 
En la Figura 17, al relacionar el Promedio anual serie de costos totales para productores medianos de la región de Antioquia (eje vertical izquierdo) y el promedio anual margen de beneficios deflactada con e IPP de 2009 (eje vertical derecho color naranja), se puede apreciar como los costos para este tipo de caficultores sufrió un fuerte incremento entre el 2009 y el 2011, causando un efecto negativo en los ingresos de los caficultores. Justamente entre los años 1999 a 2013 los beneficios de aquellos no sufrieron variaciones significativas exceptuando los periodos que oscilan entre el 2005 y el 2007, en donde la industria cafetera obtuvo un comportamiento positivo gracias a una situación que derivó de la escasez del grano a nivel mundial, y que tuvo como consecuencia un mayor nivel de precios.

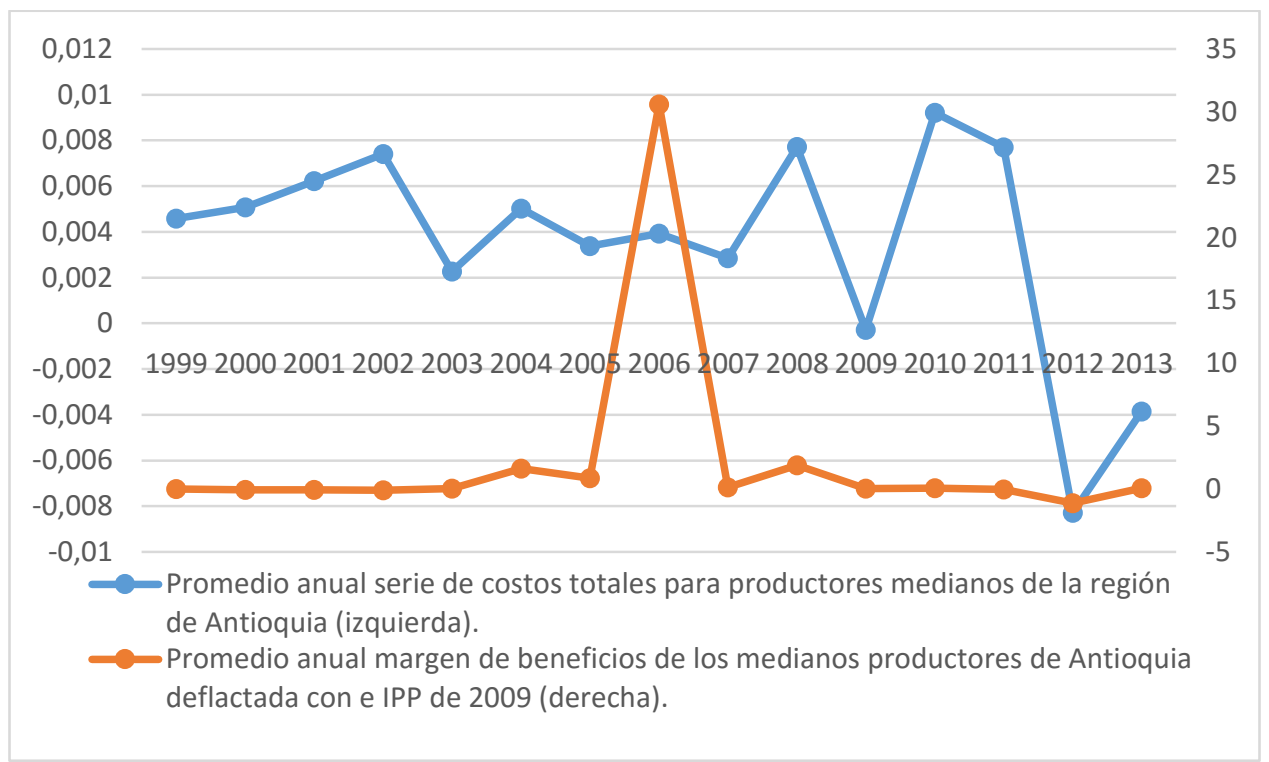

Figura 17. Comportamiento entre los costos totales y beneficios para productores medianos de café de Antioquia (variaciones porcentuales)

Fuente: Elaboración propia con base en datos de la Federación Nacional de Cafeteros.

Entretanto al ver el comportamiento de las mismas variables para el caso de los productores pequeños de café se puede observar en la Figura 18 que los costos tienen una tendencia decreciente aunque con variaciones positivas entre el 2008 y 2009. Esta situación también se acentúa en entre los años 2009 y 2011 con aumentos entre $0,2 \%$ y $0,9 \%$. 


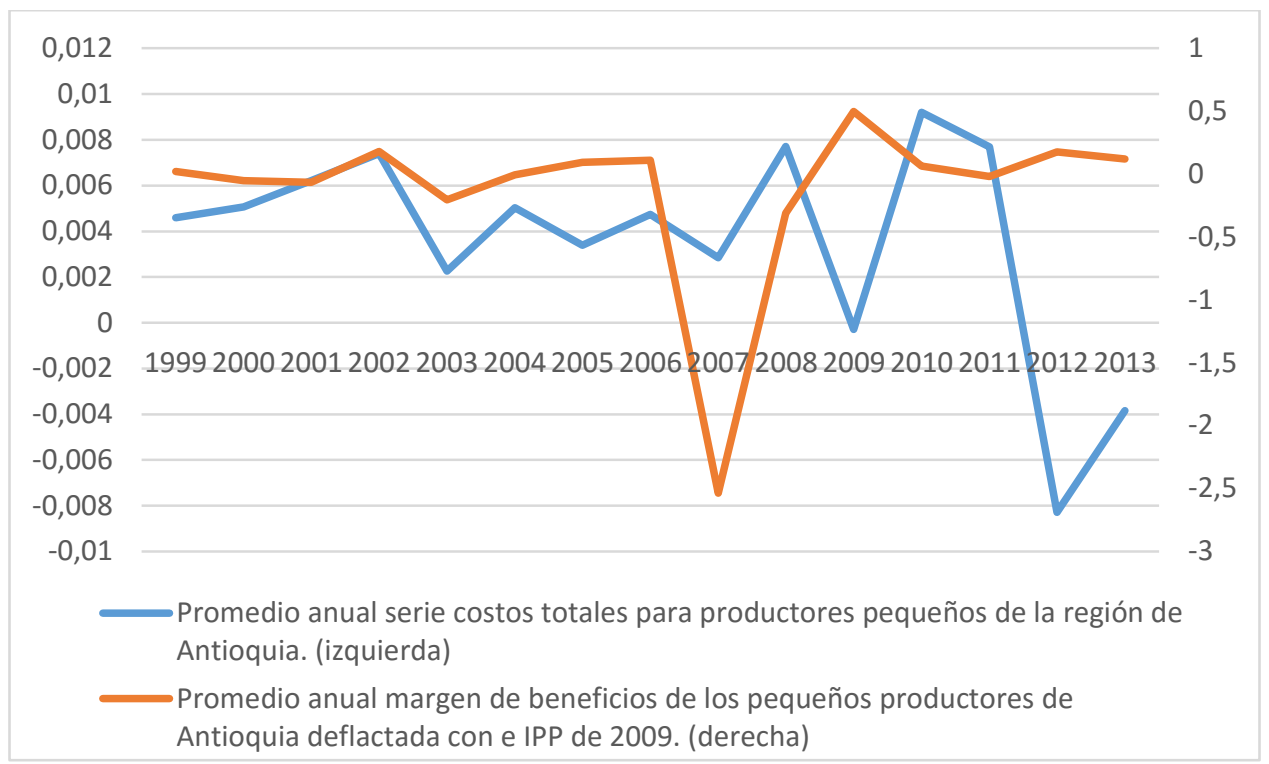

Figura 18. Comportamiento entre los costos totales y beneficios para productores pequeños de café de Antioquia (variaciones porcentuales)

Fuente: Elaboración propia con base en datos de la Federación Nacional de Cafeteros.

Para el caso de los beneficios su comportamiento ha sido estable; sin embargo ha tenido conductas negativas bastantes sensibles, sobre todo entre los años 2007 y 2008 en donde la FNC en sus informes de gestión argumenta que "la masiva entrada de flujos de inversión extranjera directa, combinada con el debilitamiento del dólar, profundizó a lo largo de 2007 el proceso revaluacionista del peso colombiano, ubicando la tasa de cambio en niveles de 1999". (FNC, 2007, p. 3).

Otras variables que se vuelven importantes al momento de analizar su comportamiento, a través del periodo estudiado en el documento de investigación, es el precio internacional de la libra de café y la garantía de compra referenciadas en la Figura 19. Al confrontar estos dos ítems se puede inferir que entre los años 1999 a 2003 y 2011 a 2013 los bajos precios internacionales dieron pie para que la garantía de compra fuera el incentivo económico que respaldara a los cafeteros. Sin embargo la confrontación de ambas variables refleja como en dicho periodo la garantía de compra no compensa los descensos del precio internacional, haciendo que los beneficios obtenidos por el caficultor disminuyan y al mismo tiempo este incentivo se vuelva insuficiente para los cultivadores del grano. 


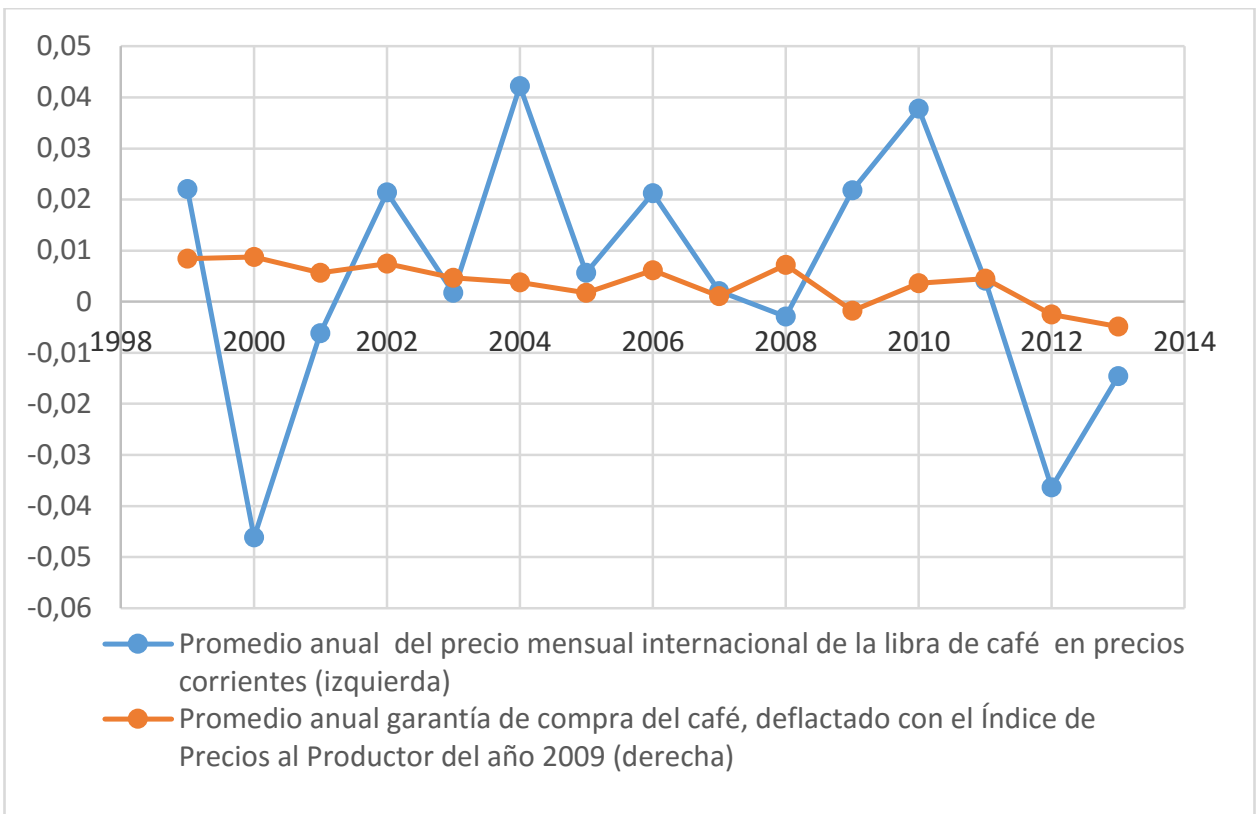

Figura 19. Comportamiento entre el precio internacional de la libra de café y la garantía de compra (variaciones porcentuales)

Fuente: Elaboración propia con base en datos de la Federación Nacional de Cafeteros.

\subsection{Resultados del modelo}

Para el documento se decidió acoger a través de la regresión lineal las variables mencionadas en la parte inicial del capítulo simbolizadas en las siguientes ecuaciones:

$$
\begin{aligned}
& \text { ProdCafe125kgOKconver = B0 + B1ExpCafe125kgOKconver + B2 } \\
& \text { BenPGCCosSmallAntIPP + B3GarCompraAdjustIPPmensual + B4 } \\
& \text { PrecLibraCafConvColTRMCon + B5 PromMenTRMCorriente + } u \\
& \text { ProdCafe125kgOKconver = B0 + B1ExpCafe125kgOKconver + B2 } \\
& \text { BenPGCCosMedAntIPP + B3GarCompraAdjustIPPmensual + B4 } \\
& \text { PrecLibraCafConvColTRMCon + B5 PromMenTRMCorriente + } u \\
& \text { ProdCafe125kgOKconver = B0 + B1ExpCafe125kgOKconver + B2 } \\
& \text { BenPGCCosBigAntIPP + B3GarCompraAdjustIPPmensual + B4 } \\
& \text { PrecLibraCafConvColTRMCon + B5 PromMenTRMCorriente + } u
\end{aligned}
$$

Las tres ecuaciones anteriores reflejan la modelación econométrica de los tres tipos de caficultores de Antioquia con las variables que inciden en la producción cafetera: 
Tabla 6. Regresión lineal múltiple con cultivadores pequeños

\begin{tabular}{|c|c|c|c|c|c|c|}
\hline Source & SS & df & MS & & $\begin{array}{l}F(5, \\
173)= \\
15,23\end{array}$ & $\begin{array}{l}\text { Number } \\
\text { of obs = } \\
179\end{array}$ \\
\hline Model & 4,230622 & 5 & .84612451 & & $\begin{array}{l}\text { Prob > F } \\
= \\
0.0000\end{array}$ & $\begin{array}{l}\text { R- } \\
\text { squared } \\
= \\
0.3056\end{array}$ \\
\hline Residual & 9,610885 & 173 & .05555425 & & $\begin{array}{l}\text { Adj R- } \\
\text { squared } \\
= \\
0.2856\end{array}$ & $\begin{array}{l}\text { Root } \\
\text { MSE } \\
=.2357\end{array}$ \\
\hline Total & 13,84150 & 178 & .07776128 & & & \\
\hline ProdCafe125kgOKconver & Coef. & Std. Err. & $\mathbf{T}$ & $P>t$ & $\begin{array}{l}{[95 \%} \\
\text { Conf. }\end{array}$ & Interval] \\
\hline ExpCafe125kgOKconver & .6880786 & .081256 & 8.47 & 0.000 & .527697 & .848459 \\
\hline BenPGCCosSmallAntIPP & $4.92 \mathrm{e}-11$ & $2.35 \mathrm{e}-11$ & 2.09 & 0.038 & $2.81 \mathrm{e}-1$ & $9.56 \mathrm{e}-1$ \\
\hline GarCompraAdjustIPPmensual & .874588 & .4287703 & 2.04 & 0.043 & .028293 & 1.72088 \\
\hline PrecLibraCafConvColTRMCon & -.529043 & .4448374 & -1.19 & 0.236 & -1.4070 & .348964 \\
\hline PromMenTRMCorriente & -.490595 & .6726189 & -0.73 & 0.467 & -1.8181 & .837000 \\
\hline cons & .019259 & .0179958 & 1.07 & 0.286 & -.01626 & .054779 \\
\hline
\end{tabular}

Fuente: Cálculo del investigador

Durbin-Watson d-statistic $(6,179)=2.332121$. La literatura evidencia que se necesita de un examen de autocorrelación o correlación serial, para saber si existe una relación del error con el tiempo, situación que invalida algunas propiedades de los mínimos cuadrados ordinarios. En otras palabras lo anterior causa que los estimadores se vuelvan ineficientes en el modelo econométrico. "Por consiguiente, como regla práctica, si en una aplicación vemos que d es igual a 2, podemos suponer que no hay autocorrelación de primer orden, positiva o negativa" Gujarati \& Porter (2010, p. 436). Como en este caso es de 2.3321 no se presentan este fenómeno.

En la Tabla 6 se refleja que por cada unidad que aumentan las exportaciones la producción se incrementa en $0,68 \%$. Asimismo por cada unidad en que aumenta el margen de beneficio la producción sube un $0.00000000000498 \%$, situación que se hace inelástico para los agricultores y que se traduce en que los beneficios 
económicos son muy pocos ante la evidencia expuesta; asimismo por cada unidad que aumente la garantía de compra la producción se aumenta en $0,87 \%$

Tabla 7 Regresión lineal múltiple con cultivadores medianos

\begin{tabular}{|c|c|c|c|c|c|c|}
\hline Source & SS & df & MS & & $\begin{array}{l}F(5,173) \\
=14.75\end{array}$ & $\begin{array}{l}\text { Number } \\
\text { of obs = } \\
179\end{array}$ \\
\hline Model & 4.1368752 & 5 & .82737505 & & $\begin{array}{l}\text { Prob > F } \\
=0.0000\end{array}$ & $\begin{array}{l}\text { R- } \\
\text { squared } \\
=0.2989\end{array}$ \\
\hline Residual & 9.7046329 & 173 & .05609614 & & $\begin{array}{l}\text { Adj R- } \\
\text { squared } \\
=0.2786\end{array}$ & $\begin{array}{l}\text { Root } \\
\text { MSE } \\
=.23685\end{array}$ \\
\hline Total & 13,841508 & 178 & .07776128 & & & \\
\hline ProdCafe125kgOKconver & Coef. & Std. Err. & $\mathbf{t}$ & $P>t$ & $\begin{array}{l}\text { [95\% } \\
\text { Conf. }\end{array}$ & Interval] \\
\hline ExpCafe125kgOKconver & .6624115 & .0824458 & 8.03 & 0.000 & .4996824 & .8251407 \\
\hline BenPGCCosMedAntIPP & $-2.04 \mathrm{e}-11$ & $1.25 e-11$ & -1.63 & 0.104 & $-4.50 e-11$ & $4.24 \mathrm{e}-12$ \\
\hline GarCompraAdjustIPPmensual & .9373738 & .434805 & 2.16 & 0.032 & .0791681 & 1.79558 \\
\hline PrecLibraCafConvColTRMCon & -.6643921 & .4529659 & -1.47 & 0.144 & -1.55844 & .229659 \\
\hline PromMenTRMCorriente & -.5947414 & .6753656 & -0.88 & 0.380 & -1.92775 & .7382759 \\
\hline _cons & .0208811 & .0180439 & 1.16 & 0.249 & -.014733 & .0564956 \\
\hline
\end{tabular}

Fuente: Cálculo del investigador

Durbin-Watson d-statistic $(6,179)=2.343873$. En este caso no se presenta la situación de autocorrelacción ya que es mayor que 2. Al interpretar las regresiones de la Tabla 7 se muestra que por cada unidad que aumentan las exportaciones la producción se incrementa en $0,66 \%$. Asimismo por cada unidad en que se amplía el margen de beneficio la producción sube un 0.00000000000204 . En este modelo el margen de beneficios se vuelve inelástico para los agricultores, lo que se traduce que sus utilidades económicos son muy pocas ante la evidencia expuesta haciendo que se convierta en una variable poco significativa para la efectividad de la producción. De igual manera por cada unidad que aumente la garantía de compra la producción se aumenta en un 0,93\%. 
Tabla 8. Regresión lineal múltiple con cultivadores grandes

\begin{tabular}{|l|l|l|l|l|l|l|}
\hline Source & SS & df & MS & & $\begin{array}{l}\text { F(5,173) } \\
=14.18\end{array}$ & $\begin{array}{l}\text { Number } \\
\text { of obs }= \\
179\end{array}$ \\
\hline Model & 4.024548 & 5 & .80490977 & & $\begin{array}{l}\text { Prob > F } \\
=0.0000\end{array}$ & $\begin{array}{l}\text { R- } \\
\text { squared } \\
=0.2908\end{array}$ \\
\hline Residual & 9.816959 & 173 & .05674542 & & $\begin{array}{l}\text { Adj R- } \\
\text { squared } \\
=0.2703\end{array}$ & $\begin{array}{l}\text { Root } \\
\text { MSE } \\
=.23821\end{array}$ \\
\hline Total & & & & & & \\
\hline & 13.84150 & 178 & .07776128 & & & \\
\hline ProdCafe125kgOKconver & Coef. & Std. Err. & $\mathbf{t}$ & P>t & $\begin{array}{l}{[95 \%} \\
\text { Conf. }\end{array}$ & Interval] \\
\hline ExpCafe125kgOKconver & .6839815 & .082112 & 8.33 & 0.00 & .521910 & .846052 \\
\hline BenPGCCosBigAntIPP & .1412234 & .173970 & 0.81 & 0.41 & -.202155 & .484602 \\
\hline GarCompraAdjustIPPmensual & .930463 & .447850 & 2.08 & 0.03 & .0465085 & 1.81441 \\
\hline PrecLibraCafConvCoITRMCon & -.543412 & .449523 & -1.21 & 0.22 & -1.43066 & .343843 \\
\hline PromMenTRMCorriente & -.632635 & .684668 & -0.92 & 0.35 & -1.98401 & .718743 \\
\hline cons & .0208943 & .018224 & 1.15 & 0.25 & -.015076 & .056865 \\
\hline
\end{tabular}

Fuente: Cálculo del investigador

Durbin-Watson d-statistic $(6,179)=2.353382$. Para esta situación no se presenta autocorrelación ya que es mayor que 2 . En la tabla 8 se refleja que por cada unidad que aumentan las exportaciones la producción se incrementa en $0,68 \%$. Asimismo por cada unidad en que aumenta el margen de beneficio la producción sube un $0.14 \%$. Lo anterior se traduce en que los beneficios generan un nivel de sensibilidad importante para los grandes caficultores. En cuanto a la garantía de compra se muestra que por cada unidad que aumente la producción se aumenta en un $0,9304 \%$.

De igual manera, se simuló otro modelo en donde se realizaron cálculos sobre cuál sería el margen de beneficio de los tres tipos de caficultores estudiados si la garantía de compra se aumenta al $5 \%, 10 \%, 15 \%$ y $20 \%$, que se encuentran en los anexos de este documento. Dichos valores se hallaron multiplicando las variaciones porcentuales de GarCompraAdjustIPPmensual por los porcentajes mencionados. Aunque es preciso mencionar que la garantía de compra sigue teniendo más incidencia en la producción que en los beneficios para los cultivadores del grano, los resultados estadísticamente más significativos favorecieron a un aumento de la 
garantía de compra del 10\% para los pequeños y grandes caficultores, mientras que para los medianos los resultados obtienen significancia con aumento del $15 \%$, demostradas en la evidencia que se expone a continuación. Las ecuaciones 7, 8 y 9 se replican con el reemplazo de la variable GarCompraAdjustIPPmensual por GC10percent y GC15percent para el caso de los medianos.

Tabla 9 Regresión lineal múltiple con cultivadores pequeños simulando aumento de la garantía de compra al $10 \%$

\begin{tabular}{|c|c|c|c|c|c|c|}
\hline Source & SS & df & MS & & & $\begin{array}{l}\text { Number of } \\
\text { obs }=\quad 179\end{array}$ \\
\hline & & & & & & $\begin{array}{l}F(5,173)= \\
15,54\end{array}$ \\
\hline Model & 4,29084 & 5 & .85816 & & & $\begin{array}{l}\text { Prob }>F= \\
0.0000\end{array}$ \\
\hline Residual & 9,55066 & 173 & .05520 & & & $\begin{array}{l}\text { R-squared = } \\
0.3100\end{array}$ \\
\hline & & & & & & $\begin{array}{l}\text { Adj R- } \\
\text { squared = } \\
0.2901\end{array}$ \\
\hline Total & 13,8415 & 178 & .07776 & & & $\begin{array}{l}\text { Root MSE = } \\
.23496 \\
\end{array}$ \\
\hline ProdCafe125kgOKconver & Coef. & Std. Err. & $\mathbf{T}$ & $P>t$ & $\begin{array}{l}{[95 \%} \\
\text { Conf. }\end{array}$ & Interval] \\
\hline ExpCafe125kgOKconver & .687904 & .080898 & 8.50 & 0.000 & .5282 & .847579 \\
\hline BenPGCCosSmallAntIPP & $4.84 \mathrm{e}-11$ & $2.34 \mathrm{e}-11$ & 2.07 & 0.040 & $2.15 e-$ & $9.46 \mathrm{e}-11$ \\
\hline GC10percent & .001002 & .000436 & 2.30 & 0.023 & .0001 & .001864 \\
\hline PrecLibraCafConvColTRMCon & -.20219 & .324222 & -0.62 & 0.534 & -.8421 & .437750 \\
\hline PromMenTRMCorriente & -.332746 & .647279 & -0.51 & 0.608 & -1.610 & .944834 \\
\hline cons & .012758 & .017877 & 0.71 & 0.476 & -.0225 & .048045 \\
\hline
\end{tabular}

Fuente: Cálculo del investigador

En la Tabla 9 se puede observar como el valor "t" de la garantía de compra (GC10percent), aumenta su significancia estadística de 2.04 a 2.30 y conserva su $p$ valor de 0.023 generando más incidencia de esta variable en la producción. Sin embargo los beneficios de este tipo de cultivadores, sugieren que por cada unidad en que aumenta el margen de beneficio la producción sube un $0.00000000000484 \%$, lo que significa que sigue siendo bajo el beneficio para los caficultores de esta categoría. 
Tabla 10 Regresión lineal múltiple con cultivadores medianos simulando aumento de la garantía de compra al $15 \%$

\begin{tabular}{|c|c|c|c|c|c|c|}
\hline Source & SS & df & MS & & & $\begin{array}{l}\text { Number of } \\
\text { obs }=\quad 179\end{array}$ \\
\hline & & & & & & $\begin{array}{l}F(5,173)= \\
14.94\end{array}$ \\
\hline Model & 4.173907 & 5 & .83478 & & & $\begin{array}{l}\text { Prob > F = } \\
0.3049\end{array}$ \\
\hline Residual & 9.667600 & 173 & ,05588 & & & $\begin{array}{l}\text { R-squared = } \\
0.3016\end{array}$ \\
\hline & & & & & & $\begin{array}{l}\text { Adj R- } \\
\text { squared = } \\
0.2814\end{array}$ \\
\hline Total & 13,841 & 178 & .07776 & & & $\begin{array}{l}\text { Root MSE }= \\
.23639\end{array}$ \\
\hline ProdCafe125kgOKconver & Coef. & $\begin{array}{l}\text { Std. } \\
\text { Err. }\end{array}$ & $T$ & $P>t$ & $\begin{array}{l}{[95 \%} \\
\text { Conf. }\end{array}$ & Interval] \\
\hline ExpCafe125kgOKconver & .613218 & .083349 & 7.36 & 0.000 & .4487057 & .7777321 \\
\hline BenPGCCosMedAntIPP & $-1.68 e-1$ & $1.23 e-1$ & -1.36 & 0.175 & $-4.11 e-1$ & $7.53 e-12$ \\
\hline GC15percent & $6.05 e-08$ & $2.62 \mathrm{e}-0$ & 2.31 & 0.022 & $8.76 \mathrm{e}-09$ & $1.12 \mathrm{e}-07$ \\
\hline PrecLibraCafConvCoITRMCon & -.0257 & .286582 & -0.09 & 0.929 & -.591348 & .539948 \\
\hline PromMenTRMCorriente & -.268669 & .641403 & -0.42 & 0.676 & -1.53465 & .9973146 \\
\hline
\end{tabular}

Fuente: Cálculo del investigador

En la Tabla 10 se observa que el valor "t" del beneficio de los cultivadores de esta categoría pasó de -1.63 a -1.36 con un p-valor de 0.175 , lo cual confirma que la garantía de compra también tiene una incidencia positiva en la producción. Sin embargo el margen de beneficios permanece aún de forma inelástica para los productores, ya que este incentivo entregado por la FNC aún no genera el beneficio deseado para ellos. En este caso se evidencia que por cada unidad en que aumenta el margen de beneficio la producción sube un $0.00000000000168 \%$. 
Tabla 11. Regresión lineal múltiple con cultivadores grandes simulando aumento de la garantía de compra al $10 \%$

\begin{tabular}{|c|c|c|c|c|c|c|}
\hline Source & SS & df & MS & & & $\begin{array}{l}\text { Number of } \\
\text { obs }=179\end{array}$ \\
\hline & & & & & & $\begin{array}{l}F(5,173)= \\
15.18\end{array}$ \\
\hline Model & 4.2208 & 5 & .84417 & & & $\begin{array}{l}\text { Prob }>F= \\
0.3049\end{array}$ \\
\hline Residual & 9.6108 & 173 & .05561 & & & $\begin{array}{l}\text { R-squared = } \\
0.3100\end{array}$ \\
\hline & & & & & & $\begin{array}{l}\text { Adj R- } \\
\text { squared = } \\
0.2849\end{array}$ \\
\hline Total & 13,841 & 178 & .07776 & & & $\begin{array}{l}\text { Root MSE = } \\
.23582\end{array}$ \\
\hline ProdCafe125kgOKconver & Coef. & Std. Err. & $\mathbf{t}$ & $P>t$ & \begin{tabular}{|l|}
{$[95 \%$} \\
Conf.
\end{tabular} & Interval] \\
\hline ExpCafe125kgOKconver & .68414 & .0816995 & 8.37 & 0.000 & .5228935 & .8454059 \\
\hline BenPGCCosBigAntIPP & .14948 & .1728406 & 0.86 & 0.388 & -.191660 & .4906348 \\
\hline GC10percent & .00107 & .0004546 & 2.38 & 0.019 & .0001826 & .0019771 \\
\hline PrecLibraCafConvColTRMCon & -.1954 & .3308837 & -0.59 & 0.556 & -.848496 & .4576813 \\
\hline PromMenTRMCorriente & -.4682 & .655488 & -0.71 & 0.476 & -1.76201 & .8255505 \\
\hline cons & .01376 & .0181879 & 0.76 & 0.450 & -.022131 & .0496658 \\
\hline
\end{tabular}

Fuente: Cálculo del investigador

En la Tabla 11 se expone la regresión lineal de los cultivadores grandes simulando un aumento de la garantía de compra al 10\%. En ella se pudo evidenciar que los valores "t" en variables como las exportaciones, margen de beneficios y la misma garantía de compra aumentan pasando de $8.33,0.81$ y 2.08 a $8.37,0.86$ y 2.38 , respectivamente. En cuanto a los p-valor de las variables de referencia, el incentivo que se le otorga a los caficultores ganó nivel de significancia a diferencia del reflejado en la Tabla 8 al pasar de 0.418 a 0.019 , lo cual quiere decir que los caficultores se ven estimulados a producir café cuando el incentivo económico logra, además de cubrir sus costos, les genera ganancias. 


\subsection{Análisis de resultados}

De acuerdo a los resultados observados en los modelos de estimación econométrica, en el numeral anterior se encuntró que la variable determinante en la producción para los caficultores grandes, medianos y pequeños de Antioquia entre los años 1999 a 2013 son las exportaciones. La mayor prueba del anterior juicio es el estadístico "t" de $8,33,8,03$ y 8,43 para cada uno de los estimadores beta que hicieron parte de los modelos econométricos y un p-valor de 0,000 que es al nivel de significancia menor al 0,05\%. Lo anterior también reafirma el hecho de que esta variable genera un grado de sensibilidad alto en la producción. No obstante cuando se simuló un aumento del $10 \%$ siguió teniendo una significancia estadística considerable.

Por otra parte con la prueba del estadístico $\mathrm{F}$, la validez del modelo se vuelve significativa ya que es igual a $0(0.0000)$. De igual manera al hacer una lectura a los coeficientes de regresión se encontró que las ventas hacia el exterior genera una alta sensibilidad para pequeños, medianos y grandes caficultores, ya que por cada unidad que aumentan las exportaciones la producción se incrementa en un $0,688 \%, 0,662 \%$ y $0,683 \%$, respectivamente.

La evidencia empírica para los tres tipos de caficultores estudiados que resultaron de los modelos, señala que la garantía de compra di dio lugar a una incidencia positiva en la producción. Mientras que para los grandes y medianos cultivadores del grano esa incidencia tenía una alta sensibilidad $(0,930$ y 0,937$)$ para los pequeños cultivadores la sensibilidad fue del 0,874 .

Asimismo, el estadístico "t" en este caso para los tres tipos de cafeteros (pequeños, medianos y grandes), del 0,043, 0,032 y 0,039 en un intervalo de confianza del $95 \%$, implica que se vuelven altamente significativa, lo cual refuerza el hecho de que este incentivo motiva de forma positiva la producción cafetera. Sin embargo, aun cuando 
para los caficultores grandes y medianos existe una relación positiva en la producción, se evidencia un margen de beneficio bajo para los pequeños

No obstante variables como el precio de la libra de café a nivel internacional (PrecLibraCafConvColTRMCon) y la TRM (PromMenTRMCorriente), si bien es cierto que son representativas en la conformación de la garantía de compra, no lo son en la producción. Prueba de esto son los estadísticos expuestos en las tablas 6,7 y 8 . El mismo comportamiento se repite en las regresiones que se realizaron simulando un aumento de la garantía de compra al 10\% para caficultores grandes, pequeños y $15 \%$ para los medianos. Lo anterior podría también llevar a la interpretación de que la garantía de compra que se entrega a los caficultores no compensa a los cultivadores del grano debido a los periodos de volatilidades al cual ha estado sometido este commodity.

Sin embargo el margen de beneficio para los grandes cultivadores es estadísticamente significativo ya que el resultado del "t" estadístico es 2,08 y un pvalor con nivel de significancia de 0,039. Entretanto, los estadísticos del margen de beneficios de los medianos y grandes cultivadores son de $-1,63,0,81$ y un $p$-valor de 0,104 y 0,418 , lo cual se puede inferir que dicho margen no tiene significancia estadística en este tipo de trabajadores y ellos no contribuyen al incentivo de la producción, pero en el caso de los productores medianos les genera una baja tasa de ganancia, en tanto que para los grandes dicha tasa es de baja sensibilidad para sus ingresos.

\subsection{Análisis de covarianza}

En este apartado del documento se mostrará la covarianza de las variables que se estudiaron en la sección 3.5 de este capítulo. Para este desarrollo vale la pena mencionar que según la literatura, la covarianza permite determinar de manera práctica la existencia de una relación lineal entre dos variables aleatorias de tipo cuantitativo. 
De acuerdo con Wooldridge (2001, p. 680) "la covarianza entre dos variables aleatorias $\mathrm{X}$ y $\mathrm{Y}$, a veces llamada covarianza poblacional para destacar que atañe a la relación entre dos variables que describen una población, se define como el valor esperado del producto $(X-\mu x)(Y-\mu y)$ " representado en la siguiente ecuación:

$$
(\operatorname{Cov}(\mathrm{X}, \mathrm{Y}) \equiv[(X-\mu x)(Y-\mu y)]
$$

10.

Para Wooldridge (2001), al estudiar las desviaciones de las observaciones con respecto a su media, asegura que la covarianza es positiva cuando las dos variables se mueven en la misma dirección, mientras que la covarianza es negativa cuando las variables se mueven en sentidos opuestos. Si la covarianza se ubica en cero, probablemente no indique una relación lineal y resulte en un nivel de asociación de otro tipo. El autor de referencia señala que la forma en que se midan las variables no influye en el grado de su relación, pero que la covarianza entre aquéllas depende de las unidades de medida. "El hecho de que la covarianza dependa de las unidades de medida es una deficiencia que se supera mediante el coeficiente de correlación" (Wooldridge 2001, p. 682). A continuación en la Figura 20 se evalúan las variables aleatorias que conforman la investigación.

(a) Exportaciones y producción cafetera

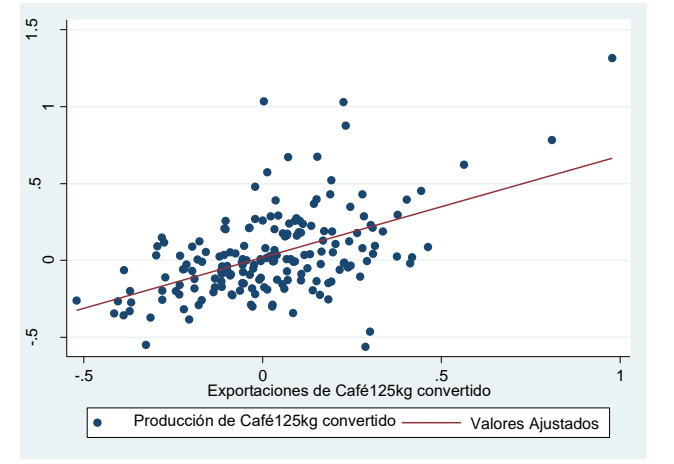

Stata: anova ProdCafe125kgOKconver c. ExpCafe125kgOKconver Number of obs $=179$ R-squared $=0.2713$ Root MSE $=.238707$ Adj R-squared $=0.2672$ (b) Beneficios caficultores pequeños y producción cafetera

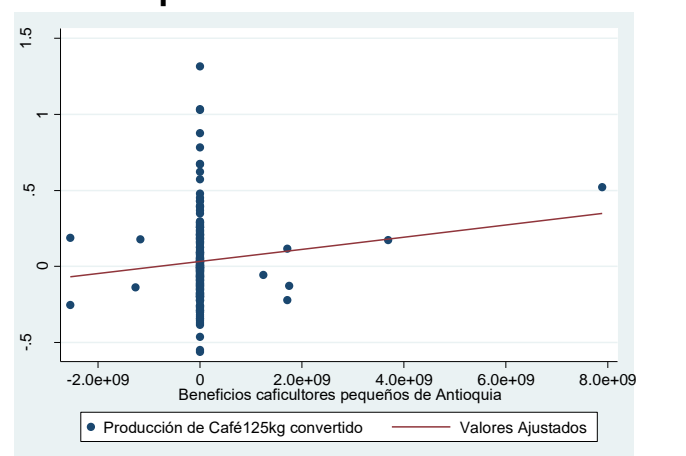

Stata: anova ProdCafe125kgOKconver c.BenPGCCosSmallAntIPP

Number of obs $=179 \mathrm{R}$-squared $=0.0117$ Root MSE $=.278002$ Adj R-squared $=-0.0061$ 


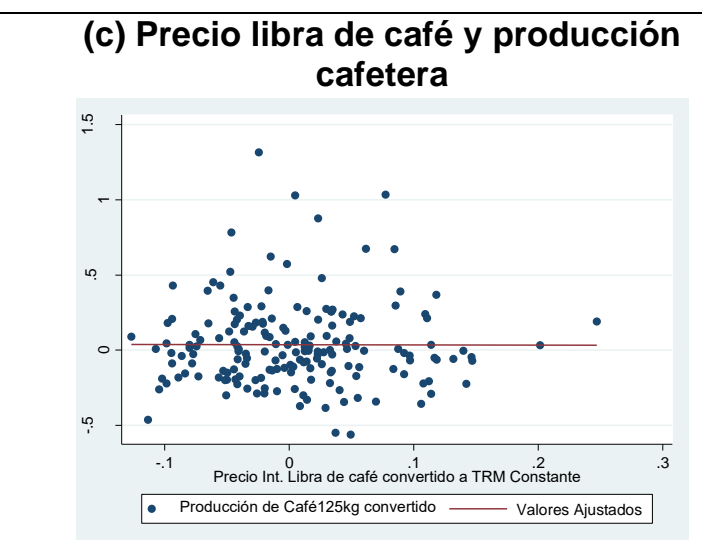

Stata: anova ProdCafe125kgOKconver c.PrecLibraCafConvColTRMCon Number of obs $=179$ R-squared $=0.0000$

Root MSE $=.279642$ Adj R-squared $=-0.0056$

(e) Garantía de compra y producción cafetera

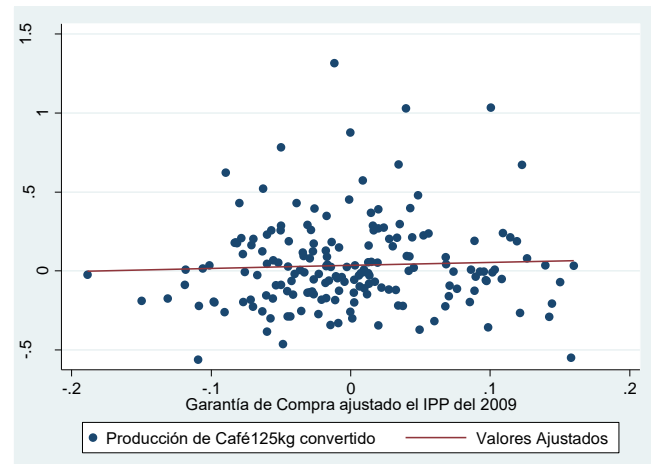

Stata: anova ProdCafe125kgOKconver c.GarCompraAdjustIPPmensual Number of obs $=179 \mathrm{R}$-squared $=0.0020$ Root MSE $=.279358$ Adj R-squared $=-.00036$ (d) Beneficios caficultores grandes y producción cafetera

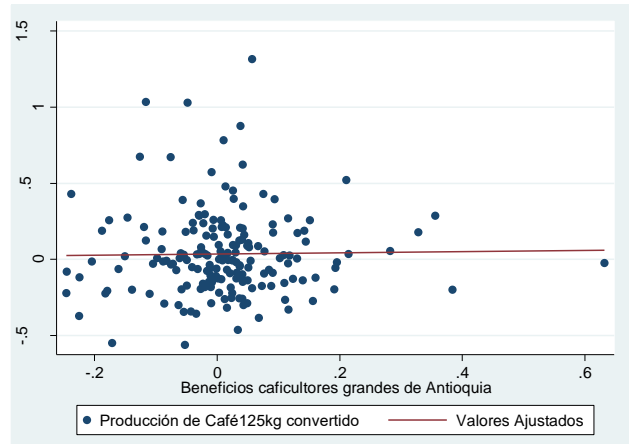

Stata: anova ProdCafe125kgOKconver c.BenPGCCosBigAntIPP

Number of obs $=179$ R-squared $=0.0003$

Root MSE $=.279605$ Adj R-squared $=-0.0054$

(f) Beneficios caficultores medianos y producción cafetera

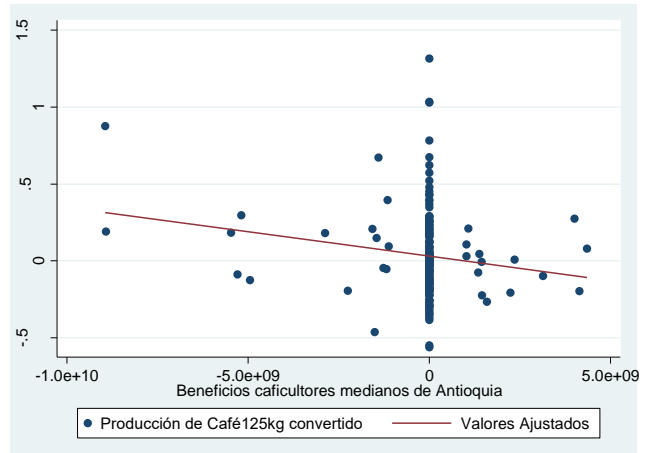

Stata: anova ProdCafe125kgOKconver c.BenPGCCosMedAntIPP

Number of obs $=179 \mathrm{R}$-squared $=0.0274$

Root MSE $=.275782$ Adj R-squared $=0.0219$

\section{(g) TRM corriente y producción cafetera}

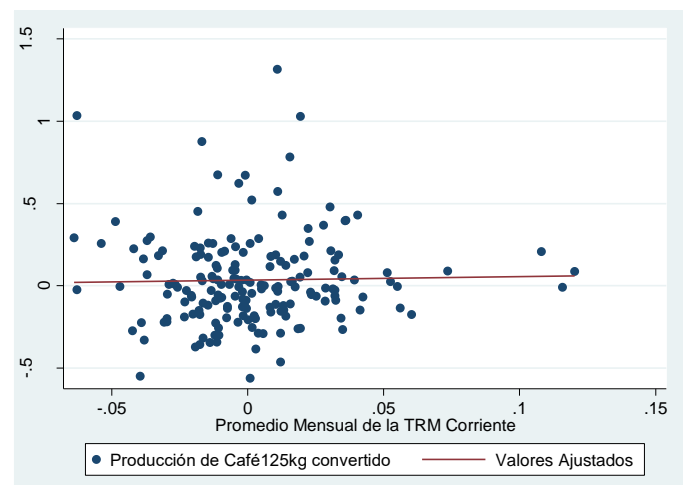

Stata: anova ProdCafe125kgOKconver c.PromMenTRMCorriente Number of obs $=179 \mathrm{R}$-squared $=0.0005$

Root MSE $=.279575$ Adj R-squared $=-0.0052$

Figura 20. Covarianzas en valores porcentuales con su coeficiente de correlación (paneles) Fuente: Cálculos del investigador con base en datos de la FNC. 
En la Figura 20 que se encuentra dividida por siete paneles se pudo evidenciar que las variables que guardan una alta correlación son la producción cafetera con las exportaciones (panel a), ya que tienen una covarianza de 0.2713 , lo cual significa que a medida que aumenta la producción las exportaciones responden en la misma proporción.

En el panel b de la Figura 20 en donde se realiza la covarianza entre la producción cafetera y el margen de beneficios su resultado fue, medido a través del coeficiente de correlación, de 0.0117 . Con esta cifra, se observa una correlación positiva pero con un bajo nivel de asociación entre las dos variables evaluadas; es decir a medida que la producción adopta una tendencia creciente los cultivadores pequeños están produciendo con muy bajos beneficios.

Por otra parte, en las gráficas en donde se evalúa la covarianza entre el precio internacional de la libra de café con la producción cafetera (panel c), los beneficios de los caficultores grandes con la misma producción cafetera (panel d), y la garantía de compra con la variable ya mencionada (panel e) anteriormente, sus resultados fueron de $0.0000,0.0000$ y 0.0020 , respectivamente. Lo anterior evidencia una correlación positiva con un bajo nivel de asociación.

Mientras en el panel c, los precios internacionales no son estimulados por la producción por la por su bajo nivel de asociación, en el d los grandes productores de café producen con muy bajos beneficios. De igual manara en el panel e si bien es cierto existe un nivel de correlación positivo se da un bajo nivel de asociación lo que significa que la producción no responde a la garantía de compra.

Entretanto en el panel $f$, que corresponde a los beneficios de los caficultores medianos y la producción cafetera, la covarianza fue de 0.0274 , resultado que también refleja un nivel bajo de asociación; cuando la producción adopta una tendencia decreciente los caficultores medianos están produciendo bajo márgenes de beneficios muy bajos. 
En cuanto al panel g, que relaciona a la Tasa Representativa del Mercado (TRM) y la producción cafetera y que presenta una covarianza de 0.0005 , se repite de forma similar las situaciones presentadas en los paneles c, d y g de la Figura 20. Aunque existe una correlación positiva hay un bajo nivel de asociación, lo cual permite inferir que la producción no responde a los precios de la TRM en una misma proporción.

\subsection{Respuesta de las variables estudiadas}

Después de efectuar la regresión lineal multivariada y examinar qué tan relevante era la garantía de compra en la producción cafetera y otras variables para los caficultores de Antioquia durante los años 1999 a 2013, a través de su significancia estadística, ahora se planea evaluar cómo interactúa de manera individual cada variable con la garantía de compra.

Para este procedimiento se usarán los Vectores Autorregresivos (VAR) y a través de esta herramienta se analizará cómo responden aquéllas con el incentivo entregado por el Gobierno, a través de la Función Impulso-Respuesta (FIR) que según Gujarati y Porter (2005, p. 789), valora el impacto de los choques entre las variables que interactúan para varios periodos en el futuro.

En este caso se quiso probar dentro de la función del impulso y respuesta como interactuaba la garantía de compra con las siguientes variables en variaciones porcentuales y que ya fueron explicadas anteriormente:

- ProdCafe125kgOKconver: Producción registrada - mensual Miles de sacos de $125 \mathrm{Kg}$ de café verde pergamino transformado.

- GarCompraAdjustIPPmensual: Garantía de compra del café. Este valor se encuentra deflactado con el Índice de Precios al Productor del año 2009.

- BenPGCCosBigAntIPP: Margen de beneficios de los grandes productores de Antioquia.

- BenPGCCosMedAntIPP: Margen de beneficios de los medianos productores de Antioquia. 
- BenPGCCosSmallAntIPP: Margen de beneficios de los pequeños productores de Antioquia.

- ExpCafe125kgOKconver: Volumen de las exportaciones colombianas de café - mensual.

- PromMenTRMCorriente: Promedio mensual de la Tasa Representativa del Mercado de 1999 a 2013.

- PrecLibraCafConvColTRMCon: Promedio del Precio mensual dados en centavos de dólar americano por libra Café, arábica suave.

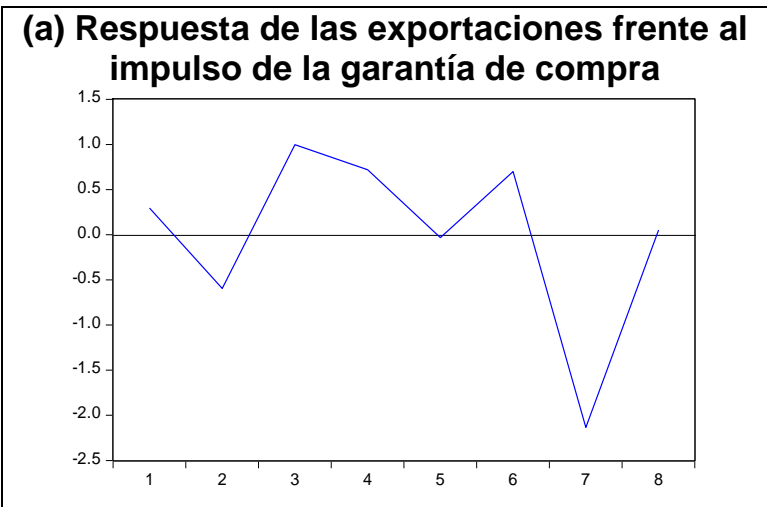

(c) Rta precio libra de café en precios ctes. frente al impulso la garantía de compra

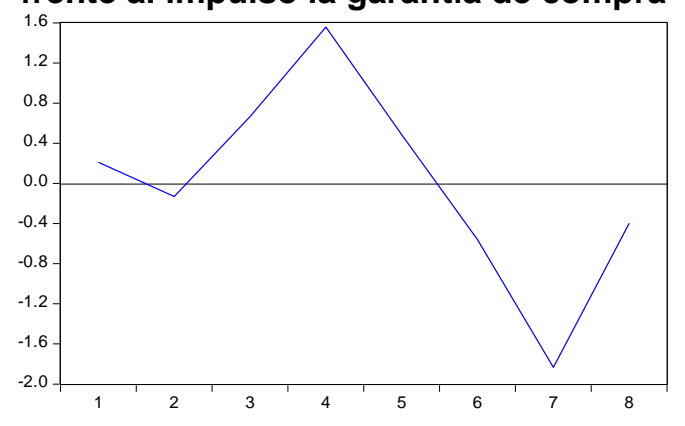

(e) Rta de la producción de café frente al impulso de la garantía de compra

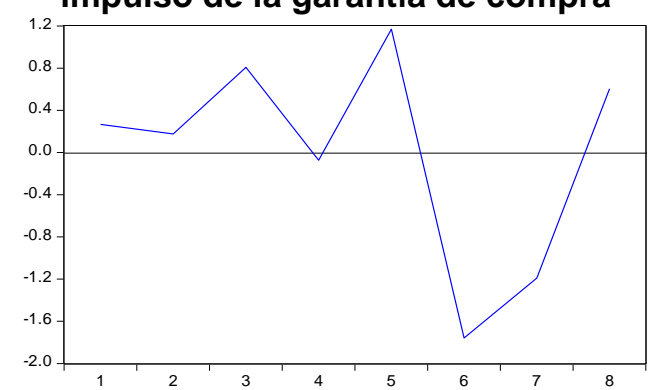

(b) Rta. beneficios caficultores pequeños frente al impulso de la garantía de compra

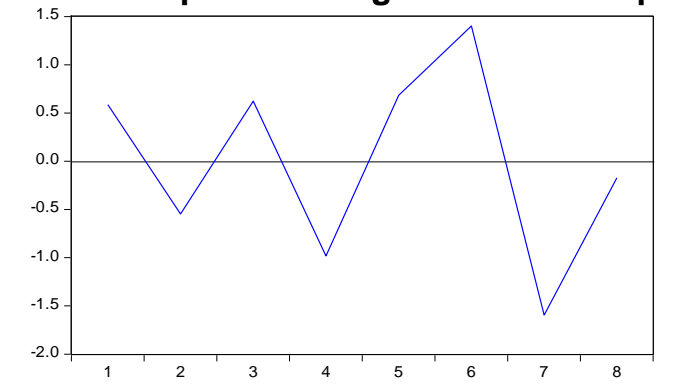

(d) Rta beneficios caficultores grandes con impulso de garantía de compra

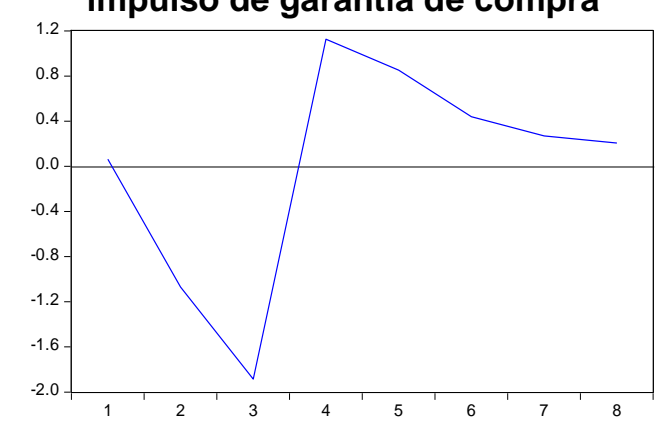

(f) Rta margen de beneficios de cafeteros medianos frente a la garantía de compra

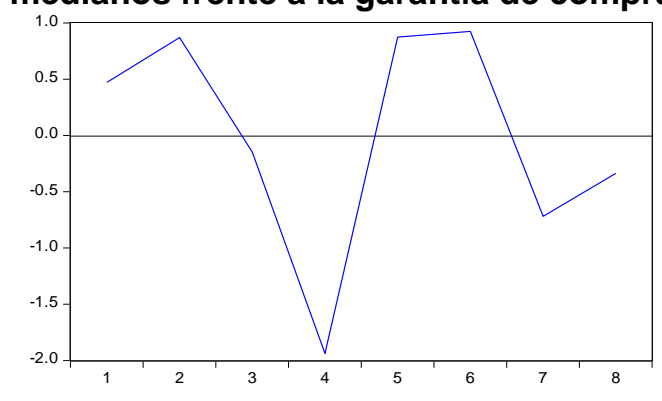

(g) Respuesta del promedio mensual de la TRM corriente frente a la garantía de compra 


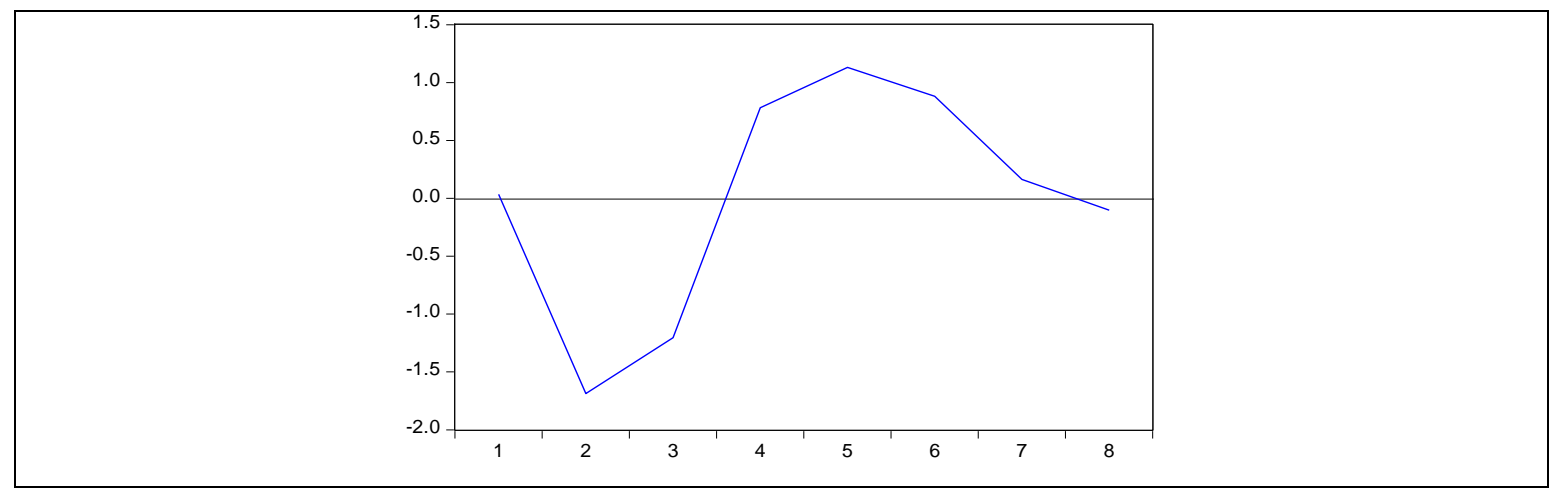

Figura 21. Análisis impulso-respuesta de la garantía de compra y distintas variables cafeteras (paneles)

Fuente: Cálculos del investigador con base en datos de la FNC.

En vista de que el análisis impulso-respuesta cobra importancia cuando se quiere valorar el nivel de sensibilidad de las variables que se especifican en el modelo, en la Figura 21, a través de la interacción de dos variables en Eviews se observa como la respuesta de las exportaciones en el panel a frente al impulso de la garantía de compra comienza con una reacción negativa, en donde vuelve a ser positiva al cabo del tercer periodo de rezago cayendo nuevamente hacia el quinto y mostrando un alto descenso en el séptimo periodo. El impacto positivo del choque entre exportaciones y la garantía de compra se dio únicamente durante el tercer y sexto periodo.

En el panel b que corresponde a la evaluación de la respuesta de los beneficios de los caficultores pequeños de Antioquia, frente al impulso de la garantía de compra se muestra como dicho impulso reacciona negativamente durante el segundo, cuarto y séptimo periodo de rezago. Lo anterior significa que, en los periodos que tarda en manifestarse los efectos positivos entre la interacción del margen de beneficio de estos cultivadores cuando reciben la garantía de compra se da durante el tercer, quinto y sexto mes, volviendo a estabilizarse en el octavo mes.

Entretanto en el panel c, el test que corresponde a la respuesta del precio de la libra de café en precios corrientes frente al impulso la garantía de compra, reflejó que la primera variable se comporta negativamente en el segundo mes, pero responde positivamente entre el tercer y el quinto mes, volviendo a terreno negativo entre el 
sexto y octavo mes, lo cual significa que a medida que los precios internacionales son bajos, los efectos de la garantía de compra no son de gran ayuda para compensar a dichos precios por largos periodos.

Por su parte al examinar los resultados del panel d en la Figura 21 en donde se valoran los beneficios de los caficultores grandes con el impulso de garantía de compra, claramente se puede evidenciar que en los periodos en donde tarda en manifestarse los efectos negativos entre la interacción del beneficio de estos cultivadores cuando reciben la garantía de compra por el rezago es entre el primer y el tercer periodo. Aunque se presenta una recuperación en el mismo periodo y regresa a terreno positivo en el cuarto y decrece nuevamente hasta al octavo, no logra compensar la incidencia negativa que tuvo en los tres primeros tres periodos de rezago. En otras palabras, los caficultores no obtienen los mismos márgenes de beneficios a lo largo del tiempo haciendo que se vuelva inestable incentivo al momento de obtener ingresos.

En cuanto a la panel e (respuesta de la producción de café frente al impulso de la garantía de compra), se evidenció que durante los cinco primeros periodos la producción responde de forma positiva al shock de la garantía de compra, obteniendo grandes picos en entre el segundo y el quinto mes, en tanto que en el mismo mes de referencia el efecto de la producción cafetera ante un impulso de la garantía de compra posee un comportamiento decreciente y se estabiliza en el octavo periodo. Lo anterior da lugar para que se pueda argumentar que la garantía de compra no incentiva de forma permanente la producción de café y muy probablemente los mismos caficultores recurran a exportadores privados, descartando el incentivo económico que entrega la FNC.

Siguiendo con el análisis de las variables, precisamente del impulso de garantía de compra con otras que conforman este documento, en el panel $f$ que corresponde a la repuesta del margen de beneficios de cafeteros medianos frente a la garantía de compra, se observa como el primer, segundo, el quinto y el sexto mes son los 
periodos de rezago en donde reaccionan de forma positiva los beneficios de este tipo de caficultores, mientras que el cuarto y el séptimo mes perciben una sensibilidad negativa. Lo anterior podría llevar a inferir que la garantía de compra no estabiliza los ingresos de los productores del grano por largos periodos de tiempo y mucho menos de forma regular.

De igual manera, al observar cómo se comporta la respuesta del promedio mensual de la Tasa Representativa del Mercado (TRM) en precios corrientes frente a la garantía de compra, en el panel g se puede observar que en los periodos en donde tarda en manifestarse los efectos negativos se refleja en los tres primeros periodos de rezago. No obstante a partir del tercer periodo, se evidencia como la interacción de estas variables genera efectos positivos hasta el quinto, experimentando luego una fase decreciente a partir del sexto periodo. Este comportamiento muestra cómo, esta herramienta de política fundamental en la institucionalidad cafetera, logra contrarrestar por algunos periodos los efectos de la revaluación del tipo de cambio. En el panel g dicha situación se manifiesta entre el primer mes, mientras que cuando no logra apaciguar dichos la volatilidad de la tasa de cambia se da partir del cuarto mes.

\subsection{Prueba de Jarque-Bera}

Con el fin de examinar si el conjunto de variables son significativas, se emplea el test de Jarque-Bera, un estadístico de gran importancia que examina qué tan dispersos se encuentran los coeficientes de asimetría y curtosis, dos insumos de vital importancia en la comprobación de que las variables siguen una distribución normal.

De acuerdo con Gujarati y Porter (2010, p. 131) la prueba de normalidad "JB es una prueba asintótica, o de muestras grandes. También se basa en los residuos de MCO. Esta prueba calcula primero la asimetría y la curtosis de los residuos de MCO, con el siguiente estadístico de prueba": 


$$
J B=n\left\{\frac{S^{2}}{6}+\frac{(K-3)^{2}}{24}\right\}
$$

11.

Según Gujarati y Porter en la ecuación anterior n representa el tamaño de la muestra, $\mathrm{S}$ corresponde al coeficiente de asimetría y $\mathrm{K}$ hace referencia al coeficiente de curtosis. El primer coeficiente examina que tan simétrica es su distribución de probabilidad; es decir si su coeficiente es mayor que cero se dice que dicha distribución se encuentra inclinada hacia la derecha permitiendo la mayor acumulación de datos hacia el lado izquierdo de la distribución, así como también el hecho de que si es menor que cero la distribución se encuentra hacia la izquierda y la acumulación de datos pasa a ubicarse hacia la derecha, lo cual establece que tan uniforme es la distribución de los datos en la media.

Por otra parte los autores señalan que el coeficiente de curtosis es otro valor fundamental el cual muestra el nivel de apuntalamiento de la distribución de probabilidad. La literatura especializada señala que si dicho valor del coeficiente es mayor a tres, la distribución es platicúrtica en donde reflejará un bajo grado de concentración alrededor de los valores centrales de la variable, mientras que si el coeficiente de curtosis es menor a 3 la distribución de probabilidad presentará un índice alto de concentración sobre los valores centrales de la variable.

Para el caso de las regresiones para caficultores pequeños, medianos y grandes se obtuvieron los siguientes resultados en Stata: ${ }^{26}$

Predict residual, resid

(6 missing values generated)

sum residual, $d$

${ }^{26}$ Los resultados de la regresión pueden observarse en la sección 3,5 de este capitulo 
Tabla 12. Prueba Jarque-Bera

\begin{tabular}{|l|l|}
\hline Obs & 179 \\
\hline $\begin{array}{l}\text { Sum of } \\
\text { Wgt. }\end{array}$ & 179 \\
\hline Mean & $6.71 \mathrm{e}-10$ \\
\hline Std. Dev. & .2323655 \\
\hline Variance & .0539937 \\
\hline Skewness & .7402664 \\
\hline Kurtosis & 5.326989 \\
\hline
\end{tabular}

Fuente: Elaboración propia

Basados en los datos anteriores se replica la Ecuación 11 en Stata de la siguiente manera:

scalar $\mathrm{JB}=(\mathrm{r}(\mathrm{N}) / 6){ }^{*}\left(\left(\mathrm{r}(\text { skewness })^{\wedge} 2\right)+\left((\mathrm{r}(\text { kurtosis })-3)^{\wedge} 2\right) / 24\right)$

di "JB" = JB

JB23.079491

Para el caso de los caficultores de referencia, al aplicar la prueba Jarque-Bera, se pudo evidenciar que con un nivel de significancia del $5 \%$ y un grado de libertad, se propuso como hipótesis nula el que el grupo de observaciones no sigue una distribución uniforme con un valor crítico de 3.841, mientras que la hipótesis alternativa es que el grupo de observaciones tiene una distribución uniforme con un valor crítico diferente de 3.841. Como el resultado de dicha prueba fue de 23,07 , es decir mayor que 3.841 se descarta la hipótesis nula, y se concluye que los datos explican suficientemente el modelo econométrico. 


\section{CONCLUSIONES}

El presente documento permitió lograr un acercamiento empírico sobre lo fundamental que se vuelve una herramienta económica de gran importancia en la industria cafetera, como lo es la garantía de compra para los caficultores. A través de este ejercicio se evaluó la incidencia de este incentivo para los pequeños, medianos y grandes caficultores del Departamento de Antioquia, con el fin de responder la siguiente pregunta: ¿La garantía de compra ha incentivado la producción cafetera y ha generado beneficios a los cultivadores?

Para resolver este interrogante a nivel econométrico se buscó, a través de un modelo de regresión lineal múltiple, responder si efectivamente la garantía de compra incidió en la producción cafetera y si además generó beneficios a los grandes, medianos y pequeños cultivadores de la zona referenciada.

A través de la investigación se comprobó que la garantía de compra se vuelve una medida importante que contribuye a la producción cafetera y es una esencial herramienta de política pública enmarcada dentro de la teoría del neoinstitucionalismo. A partir de los resultados obtenidos para una población de 91.355 productores (grandes, medianos pequeños) y bajo el supuesto de que todos recurrieron a la garantía de compra en el periodo de estudio, se evidenció que sí hubo una incidencia positiva en la producción, especialmente para los pequeños productores, ya que sus estadísticos demostraron ser lo suficientemente significativos para la generación de sus ingresos. Ellos aportan el $95 \%$ de la mano de obra para cultivos de 5 hectáreas (has) y son los que más dependen de este incentivo, mientras que los medianos constituyen el $3 \%$ para cultivos de 5,1 a 10 has y los grandes con cultivos de 10,1 has en adelante solo conforman en $2 \%$.

Pese a que la producción se ha visto fuertemente estimulada con la garantía de compra para los tres tipos de productores, el margen de beneficios no refleja el mismo comportamiento para cada clase de cultivador, ya que si la filosofía principal de la garantía de compra es transferir un mayor ingreso cuando los precios 
internacionales del café no compensan el costo de su producción, dicha garantía se vuelve insuficiente.

Prueba de lo anterior es el margen de beneficios obtenido por los pequeños productores, cuyo resultado fue de 4,92e-11. Aunque fue positivo, generó un nivel de sensibilidad muy bajo, situación que se repite y se hace aún más difícil con los caficultores medianos con -2,04e-11; en este caso la baja sensibilidad genera un margen negativo, lo cual permite inferir que sus costos son superiores a sus beneficios. Pese a que la ganancia recibida por los pequeños caficultores por cuenta de la garantía de compra los incentiva, sus beneficios son demasiados bajos. Dicho de otro modo los productores de café pequeños acuden a la garantía de compra para que cubran sus costos, sus pérdidas y permanezcan en el negocio.

Para el caso de los medianos, la garantía de compra otorgada por la Federación Nacional de Cafeteros, resultó estadísticamente significativo en la producción, pero no les generó a ellos una tasa de ganancia que cause retornos considerables, debido a que los caficultores de esta categoría manejan una estructura de costos más alta. En cuanto a los grandes productores del grano, pese a que les generó beneficios producir con la garantía de compra, esta variable no es significativa para la producción; probablemente este grupo puede cosechar sin depender de este incentivo institucional.

También se estimó una prueba de Modelo de Vectores Autorregresivos (VAR), a través de la herramienta de Impulsos y Respuesta, donde se pudo evidenciar que la garantía de compra en un lapso de ocho etapas, incide positivamente y provoca un efecto estabilizador en el tiempo, en variables como exportaciones, producción cafetera, el precio internacional de la libra del grano, precio corriente de la TRM y margen de beneficio de los caficultores de Antioquia. Sin embargo hay periodos en que dicho incentivo no contrarresta las situaciones de volatilidad que se originan en este tipo de mercados. En otras palabras, sus ganancias no se sostienen en el tiempo. 
Bajo esta situación los caficultores tendrían que optar por otra clase de ingresos mientras esperan los respectivos réditos para su cosecha. Mientras los beneficios se estabilizan en el mediano plazo para grandes productores de café, para los pequeños y los medianos se producen beneficios en periodos cortos; no es un estímulo suficiente porque no siempre aseguran utilidades a los productores del grano. Lo anterior se resume en que el efecto de la garantía de compra no genera de manera constante los beneficios a los caficultores; probablemente se presenten periodos en que reciban ganancias como en otros que no.

Por tal razón, siendo la garantía de compra un importante mecanismo estabilizador del precio, y dados los resultados de este trabajo se recomienda que este incentivo se fortalezca, con el fin que la Federación Nacional de Cafeteros y el Gobierno Nacional, realicen las gestiones necesarias para que esta herramienta importante en la política cafetera se incremente especialmente para que los productores obtengan un mayor margen de beneficios.

En vista de los argumentos anteriores se realizó una simulación aumentando el precio de la garantía de compra al $5 \%, 10 \%, 15 \%$ y $20 \%$, para analizar cuál de los porcentajes incidía positivamente el margen de beneficios de los cultivadores del grano. A través de esta simulación se pudo constatar que la garantía de compra aunque incentiva a la producción, aún es un estímulo insuficiente para generar ingresos, debido a que no certifica los beneficios a los productores del grano y la mejora de sus ingresos es marginal a largo plazo.

Teniendo como supuesto que los tres tipos de caficultores recibieron el incentivo para producir, los caficultores pequeños y grandes se beneficiarían con una propuesta de política de aumento de la garantía de compra en $10 \%$, en tanto que para los medianos el mejor resultado es con un aumento de la garantía de compra el $15 \%$. Sin embargo la garantía de compra no se puede aumentar de manera arbitraria, ya que este incentivo responde a unas fuerzas de mercado que se explicaron a los largo del documento. 
En caso de que los agentes del mercado que intervienen en la conformación de este incentivo a la producción consideren que esta herramienta sea insuficiente, el Gobierno y la Federación Nacional de Cafeteros deberán tomar acciones como aumentar los impuestos como la contribución cafetera (este aporte corresponde a un descuento aplicado a un caficultor que equivale a 6 USD\$/libra de café verde exportada), o reforzar aspectos como la distribución o comercialización que hace parte de la cadena de producción del grano, o reciban un subsidio cuando el precio interno se encuentre por debajo del precio internacional y la garantía de compra no alcance a afrontar estas externalidades. 


\section{BIBLIOGRAFÍA}

Federación Nacional de Cafeteros. (2012). Comportamiento de la Industria Cafetera Colombiana. Bogotá: Federación Nacional de Cafeteros.

Béjar, R. C. (26 de abril al 2 de mayo de 2004.). América Latina y el Consenso de Washington. Boletín Económico de ICE(2803.), 20pp.

Bohman, M., \& Jarvis, L. (Semestre Septiembre 1989-Abril 1990. 1989. No. 5 de 1990). El Acuerdo Internacional del Café: Análisis Económico del Mercado de los No Miembros. Ensayos sobre Economía Cafetera. Dirección Gerencia General Federación., 15pp.

Cáceres, R. G., \& Escobar, É. S. (2006). Caracterización de las cadenas de valor y abastecimiento del sector agroindustrial del café (Vols. 197-217). Bogotá: Cuadernos de Administración.

Cano, C. G., Vallejo, C., Caicedo, E., Amador, J. S., \& Tique, E. Y. (2012). El mercado mundial del café y su impacto en Colombia (Vol. 710). Bogotá: Banco de la República. Colección Borradores de economía.

Casas Pardo, J. (2007). Curso de economía (Nueva edición ampliada y revisada). Valencia. España: Ediciones Tyrant Lo Blanch.

Clavijo, S., \& Leibovich, J. (Enero-Diciembre de 1993 Año 6 No.9. 1). Concentración en las compras de café colombiano: Una medición del grado de oligopsonio. Ensayos sobre Economía Cafetera. Dirección Gerencia General Federación., 15pp.

Consejo Nacional de Política Económica y Social. (2013). CONPES 3763. Bogotá.

Echavarría, J. J., Esguerra, P., McAllister, D., \& Robayo, C. F. (2014). Informe de la misión de estudios para la competitividad de la Caficultura en Colombia (Informe preliminar). Bogotá.

Encinas, F. C. (Diciembre 2010 de 2010). Monopsonio-monopolio La perfecta competencia imperfecta. Tecsistecatl. Revista electrónica de ciencias sociales. , Vol 2, 14pp. .

Escobar, J. (2013). Caracterización de la cadena productiva del café en Antioquia. Revista de la Gobernación de Antioquia Secretaría de Productividad y Competitividad, 5.

Federación Nacional de Cafeteros. (2002). El comportamiento de la industria cafetera. Bogotá: Informes de gestión Federación Nacional de Cafeteros.

Federación Nacional de Cafeteros. (2010). Comportamiento de la Industria Cafetera Colombiana. Bogotá: Informes de gestión Federación Nacional de Cafeteros.

Federción Nacional de Cafeteros. (2007). El comportamiento de la industria cafetera durante 2007. Bogotá: Federción Nacional de Cafeteros.

Gómez, M. U., Ruiz, N. P., \& Castro, A. R. (2011). Sostenibilidad en Acción 19272010. Colombia: Federación Nacional de Cafeteros.

Gujarati, D., \& Porter, D. (2010). Econometría. Ciudad de México: Mc Graw Hill. Junguito, R., \& Pizano, D. (1993.). El comercio exterior y la política internacional del café. Bogotá.: Fondo Cultural Cafetero Fedesarrollo Primera Edición.

Mankiw, N. (2002). Principios de economía. Madrid: Mc Graw Hill.

Naciones Unidas. (2011). Políticas para la agricultura en América Latina y el Caribe: competitividad, sostenibilidad. En r. e. Memoria del seminario 
internacional sobre políticas agrícolas en América Latina y el Caribe (Ed.), Colombia: la experiencia de la Federación Nacional de Cafeteros (pág. 239). Santiago de Chile: Serie Seminarios y Conferencias.

North, D. (1995). Instituciones, cambio inctitucional y desempeño económico. Ciudad de México: Fondo de Cultura econímco.

Organización Internacional del Café. (Septiembre de 2002.). Convenio Internacional del Café de 2001. Londres 47pp.: OIC.

Perdomo, J. A., \& Hueth, D. (Agosto de 2010). Funciones de producción y eficiencia técnica en el eje cafetero colombiano: una aproximación con frontera estocástica. Documentos CEDE, edición electrónica(21), 36.

Pérez, J. A. (2013). Economía Cafetera y Desarrollo Económico en Colombia. (P. d. Internacionales, Ed.) Bogotá: Universidad Jorge Tadeo Lozano. Facultad de Ciencias Sociales.

Perfetti, J. J., Escobar, D., Castro, F., Cuervo, B., Rodríguez, M., \& Vargas, J. I. (2012). Costos de Produccio n de Doce Productos Agropecuarios. Informe final. Bogotá: Fedesarrollo.

Pindyck, R. S., \& Rubinfeld, D. L. (2009). Microeconomía. (S. edición, Ed.) Madrid: Pearson Educación.

Presidencia de la República. (1967). Decreto-Ley Número 444. Bogotá: Diario Oficial. Año Cll. N. 32189. 6, abril, 1967. .

Reina, M., Silva, G., \& Luis Fernando Samper, M. d. (2007). La Estrategia detrás de la marca. Bogotá: Ediciones B Grupo Zeta.

Samuelson, P., \& Nordhaus, W. (2006). Economía. Decimoctava edición. Ciudad de México, España: Ediciones McGraw Hill.

Schultz, T. W. (1967). Modernización de la agricultura. Título original: Transforming traditional Agriculture. Madrid: 46pp.

Silva, G., Valenzuela, L. R., Villegas, A., \& Villegas, L. (2002). El café, capital social estratégico. Informe final comisión de ajuste de la institucionalidad cafetera. Bogotá.: Federación Nacional de Cafeteros.

Silva, S. (2011). Instituciones, Garantía de Compra y beneficios para el caficultor en Colombia. Ensayos sobre Economía Cafetera. Dirección Gerencia General Federación Nacional de Cafeteros, 28.

Thomas, V. (1986). Macroeconomía y política agropecuaria. La experiencia colombiana. Bogotá.: Ediciones Banco de la República.

Varian, H. R. (2010). Intermediate Microeconomics. A Modern Approach (Eighth Edition ed.). New York, London: W. W. Norton \& Company.

Wooldridge, J. (2001). Introducción a la econometría. Ciudad de México: Thomson \& Learning. 


\section{ANEXOS}

Anexo A. Índice de Precios al Productor y serie costos totales para productores grandes de Antioquia

\begin{tabular}{|c|c|c|c|}
\hline FECHA & $\begin{array}{l}\text { INDICE DE PRECIOS } \\
\text { AL PRODUCTOR } \\
\text { **La serie histórica } \\
\text { de la sección } \\
\text { "Agricultura, } \\
\text { Ganadería, Caza, } \\
\text { Silvicultura Y Pesca" } \\
\text { en oferta interna es } \\
\text { construida } \\
\text { agregando las } \\
\text { antiguas secciones }\end{array}$ & $\begin{array}{l}\text { SERIE COSTOS TOTALES PARA } \\
\text { PRODUCTORES GRANDES DE } \\
\text { ANTIOQUIA Región: Antioquia } \\
\text { Cultivo: Café Tecnificado } \\
\text { Duración ciclo: } 5 \text { años } \\
\text { Tipo productor: Grande Mayor a } 20 \text { Has } \\
\text { Actualización: Septiembre 2009 VALOR } \\
\text { COSTOS DE PRODUCCIÓN POR } \\
\text { HECTÁREA: } \$ 5948780\end{array}$ & Variación \\
\hline ene-99 & 45,39 & 276179,7021 & \\
\hline feb-99 & 45,33 & 275817,5238 & $-0,001311386$ \\
\hline mar-99 & 44,04 & 267930,7787 & $-0,028594068$ \\
\hline abr-99 & 44,30 & 269541,8478 & 0,006013005 \\
\hline may-99 & 43,76 & 266251,0206 & $-0,012208966$ \\
\hline jun-99 & 44,22 & 269038,4671 & 0,010469242 \\
\hline jul-99 & 44,74 & 272202,194 & 0,011759385 \\
\hline ago-99 & 45,58 & 277312,8297 & 0,018775145 \\
\hline sep-99 & 45,42 & 276339,3753 & $-0,003510312$ \\
\hline oct-99 & 45,61 & 277495,3524 & 0,004183179 \\
\hline nov-99 & 46,47 & 282727,67 & 0,018855514 \\
\hline dic-99 & 47,68 & 290089,4191 & 0,026038304 \\
\hline ene-00 & 48,36 & 294226,6004 & 0,014261745 \\
\hline feb-00 & 50,35 & 306333,9398 & 0,041149711 \\
\hline mar-00 & 52,12 & 317102,7794 & 0,035153923 \\
\hline abr-00 & 53 & 322456,7788 & 0,016884114 \\
\hline may-00 & 51,55 & 313634,848 & $-0,027358491$ \\
\hline jun-00 & 50,37 & 306455,6216 & $-0,022890398$ \\
\hline jul-00 & 50,61 & 307915,8033 & 0,004764741 \\
\hline ago-00 & 50,58 & 307733,2806 & $-0,000592768$ \\
\hline sep-00 & 51,13 & 311079,5302 & 0,010873863 \\
\hline oct-00 & 50,75 & 308767,5759 & $-0,007432036$ \\
\hline nov-00 & 50,55 & 307550,7579 & $-0,003940887$ \\
\hline dic-00 & 50,55 & 307550,7579 & 0 \\
\hline ene-01 & 52,01 & 316433,5295 & 0,028882295 \\
\hline feb-01 & 53,7 & 326715,6419 & 0,032493751 \\
\hline mar-01 & 54,33 & 330548,6187 & 0,011731844 \\
\hline$a b r-01$ & 55,76 & 339248,8676 & 0,026320633 \\
\hline may-01 & 56,33 & 342716,799 & 0,010222382 \\
\hline
\end{tabular}




\begin{tabular}{|c|c|c|c|}
\hline jun-01 & 55,31 & 336511,027 & $-0,01810758$ \\
\hline jul-01 & 55,01 & 334685,8 & $-0,005423974$ \\
\hline ago-01 & 55,06 & 334990,0045 & 0,000908926 \\
\hline sep-01 & 54,62 & 332313,0048 & $-0,007991282$ \\
\hline oct- 01 & 53,87 & 327749,9372 & $-0,013731234$ \\
\hline nov-01 & 54,06 & 328905,9143 & 0,003527009 \\
\hline dic-01 & 54,37 & 330791,9823 & 0,005734369 \\
\hline ene-02 & 55,29 & 336389,3452 & 0,016921096 \\
\hline feb-02 & 55,14 & 335476,7317 & $-0,002712968$ \\
\hline mar-02 & 55,65 & 338579,6177 & 0,009249184 \\
\hline abr-02 & 55,74 & 339127,1858 & 0,001617251 \\
\hline may-02 & 56,79 & 345515,4805 & 0,01883746 \\
\hline jun-02 & 56,48 & 343629,4125 & $-0,005458708$ \\
\hline jul-02 & 56,28 & 342412,5945 & $-0,003541076$ \\
\hline ago-02 & 56,6 & 344359,5034 & 0,005685856 \\
\hline sep-02 & 58,34 & 354945,8202 & 0,030742049 \\
\hline oct-02 & 59,83 & 364011,1146 & 0,025539938 \\
\hline nov-02 & 60,03 & 365227,9326 & 0,003342805 \\
\hline dic-02 & 59,35 & 361090,7513 & $-0,011327669$ \\
\hline ene-03 & 58,73 & 357318,6154 & $-0,010446504$ \\
\hline feb-03 & 59,05 & 359265,5243 & 0,005448663 \\
\hline mar-03 & 60,02 & 365167,0917 & 0,016426757 \\
\hline abr-03 & 62,67 & 381289,9307 & 0,044151949 \\
\hline may-03 & 62,19 & 378369,5674 & $-0,007659167$ \\
\hline jun-03 & 61,37 & 373380,6134 & $-0,0131854$ \\
\hline jul-03 & 61,28 & 372833,0453 & $-0,001466515$ \\
\hline ago-03 & 60,44 & 367722,4096 & $-0,013707572$ \\
\hline sep-03 & 60,52 & 368209,1368 & 0,001323627 \\
\hline oct-03 & 59,51 & 362064,2057 & $-0,016688698$ \\
\hline nov-03 & 60,21 & 366323,0689 & 0,011762729 \\
\hline dic-03 & 60,88 & 370399,4093 & 0,01112772 \\
\hline ene-04 & 61,57 & 374597,4315 & 0,011333771 \\
\hline feb-04 & 62,96 & 383054,3168 & 0,02257593 \\
\hline mar-04 & 63,3 & 385122,9075 & 0,005400254 \\
\hline abr-04 & 63,5 & 386339,7255 & 0,003159558 \\
\hline may-04 & 64,22 & 390720,2704 & 0,011338583 \\
\hline jun-04 & 64,48 & 392302,1339 & 0,004048583 \\
\hline jul-04 & 63,29 & 385062,0666 & $-0,018455335$ \\
\hline ago-04 & 63,11 & 383966,9303 & $-0,002844051$ \\
\hline sep-04 & 63,91 & 388834,2025 & 0,01267628 \\
\hline oct-04 & 63,35 & 385427,112 & $-0,008762322$ \\
\hline
\end{tabular}




\begin{tabular}{|c|c|c|c|}
\hline nov-04 & 64,18 & 390476,9068 & 0,013101815 \\
\hline dic-04 & 64,61 & 393093,0656 & 0,006699907 \\
\hline ene-05 & 65,76 & 400089,7693 & 0,017799102 \\
\hline feb-05 & 67,4 & 410067,6771 & 0,024939173 \\
\hline mar-05 & 69,49 & 422783,4256 & 0,031008902 \\
\hline abr-05 & 68,89 & 419132,9715 & $-0,008634336$ \\
\hline may-05 & 68,91 & 419254,6533 & 0,000290318 \\
\hline jun-05 & 68,68 & 417855,3126 & $-0,003337687$ \\
\hline jul-05 & 68,27 & 415360,8356 & $-0,005969715$ \\
\hline ago-05 & 67,82 & 412622,995 & $-0,006591475$ \\
\hline sep-05 & 67,07 & 408059,9274 & $-0,011058685$ \\
\hline oct- 05 & 68,53 & 416942,699 & 0,021768302 \\
\hline nov-05 & 68,02 & 413839,813 & $-0,007441996$ \\
\hline dic-05 & 67,19 & 408790,0182 & $-0,012202293$ \\
\hline ene-06 & 68,26 & 415299,9947 & 0,015924989 \\
\hline feb-06 & 68,77 & 418402,8807 & 0,007471433 \\
\hline mar-06 & 70,33 & 427894,0613 & 0,02268431 \\
\hline abr-06 & 71,38 & 434282,356 & 0,014929618 \\
\hline may-06 & 70,77 & 430571,061 & $-0,008545811$ \\
\hline jun-06 & 70,74 & 430388,5383 & $-0,000423908$ \\
\hline jul-06 & 70,42 & 428441,6294 & $-0,004523608$ \\
\hline ago-06 & 71,31 & 433856,4697 & 0,012638455 \\
\hline sep-06 & 71,65 & 435925,0603 & 0,004767915 \\
\hline oct-06 & 71,56 & 435377,4922 & $-0,001256106$ \\
\hline nov-06 & 71,24 & 433430,5834 & $-0,004471772$ \\
\hline dic-06 & 71,08 & 432457,1289 & $-0,002245929$ \\
\hline ene-07 & 70,71 & 430206,0156 & $-0,005205402$ \\
\hline feb-07 & 71,75 & 436533,4694 & 0,014707962 \\
\hline mar-07 & 73,6 & 447789,0362 & 0,025783972 \\
\hline$a b r-07$ & 74,54 & 453508,0809 & 0,012771739 \\
\hline may-07 & 74,11 & 450891,9221 & $-0,005768715$ \\
\hline jun-07 & 73,31 & 446024,65 & $-0,010794765$ \\
\hline jul-07 & 72,64 & 441948,3096 & $-0,009139272$ \\
\hline ago-07 & 72,53 & 441279,0597 & $-0,001514317$ \\
\hline sep-07 & 72,41 & 440548,9689 & $-0,001654488$ \\
\hline oct- 07 & 72,42 & 440609,8098 & 0,000138102 \\
\hline nov-07 & 72,5 & 441096,537 & 0,001104667 \\
\hline dic-07 & 73,5 & 447180,6271 & 0,013793103 \\
\hline ene-08 & 75,25 & 457827,7849 & 0,023809524 \\
\hline feb-08 & 79,15 & 481555,7366 & 0,051827243 \\
\hline mar-08 & 74,88 & 455576,6716 & $-0,0539482$ \\
\hline
\end{tabular}




\begin{tabular}{|c|c|c|c|}
\hline abr-08 & 74,99 & 456245,9215 & 0,001469017 \\
\hline may-08 & 75,81 & 461234,8754 & 0,010934791 \\
\hline jun-08 & 79,38 & 482955,0773 & 0,047091413 \\
\hline jul-08 & 80,49 & 489708,4174 & 0,013983371 \\
\hline ago-08 & 77,85 & 473646,4194 & $-0,032799105$ \\
\hline sep-08 & 78,44 & 477236,0326 & 0,007578677 \\
\hline oct-08 & 79,7 & 484901,9862 & 0,016063233 \\
\hline nov-08 & 79,54 & 483928,5317 & $-0,002007528$ \\
\hline dic-08 & 80,22 & 488065,7131 & 0,008549158 \\
\hline ene-09 & 81,48 & $\$ 495.732$ & 0,015706806 \\
\hline feb-09 & 82,5 & 501937,4386 & 0,012518409 \\
\hline mar-09 & 85,67 & 521224,0045 & 0,038424242 \\
\hline abr-09 & 87,38 & 531627,7986 & 0,019960313 \\
\hline may-09 & 87,81 & 534243,9574 & 0,004921035 \\
\hline jun-09 & 82,4 & 501329,0296 & $-0,061610295$ \\
\hline jul-09 & 82,22 & 500233,8934 & $-0,002184466$ \\
\hline ago-09 & 81,38 & 495123,2577 & $-0,010216492$ \\
\hline sep-09 & 79,51 & 483746,009 & $-0,022978619$ \\
\hline oct-09 & 78,62 & 478331,1688 & $-0,011193561$ \\
\hline nov-09 & 78,44 & 477236,0326 & $-0,002289494$ \\
\hline dic-09 & 79,66 & 484658,6226 & 0,015553289 \\
\hline ene-10 & 83,79 & 509785,9149 & 0,051845343 \\
\hline feb-10 & 86,41 & 525726,2312 & 0,031268648 \\
\hline mar-10 & 87,84 & 534426,4801 & 0,016549011 \\
\hline$a b r-10$ & 87,47 & 532175,3668 & $-0,004212204$ \\
\hline may-10 & 86,97 & 529133,3217 & $-0,005716246$ \\
\hline jun-10 & 87,27 & 530958,5487 & 0,003449465 \\
\hline jul-10 & 87,24 & 530776,026 & $-0,000343761$ \\
\hline ago-10 & 86,7 & 527490,6173 & $-0,006189821$ \\
\hline sep-10 & 84,99 & 517086,8231 & $-0,019723183$ \\
\hline oct-10 & 82,63 & 502728,3704 & $-0,027767973$ \\
\hline nov-10 & 85,13 & 517938,5958 & 0,030255355 \\
\hline dic-10 & 88,63 & 539232,9113 & 0,041113591 \\
\hline ene-11 & 91,83 & 558701,9999 & 0,036105156 \\
\hline feb-11 & 93,09 & 566367,9535 & 0,013721006 \\
\hline mar-11 & 94,94 & 577623,5203 & 0,019873241 \\
\hline$a b r-11$ & 94,54 & 575189,8842 & $-0,004213187$ \\
\hline may-11 & 95,32 & 579935,4746 & 0,008250476 \\
\hline jun-11 & 95,5 & 581030,6108 & 0,001888376 \\
\hline jul-11 & 94,74 & 576406,7023 & $-0,007958115$ \\
\hline ago-11 & 93,91 & 571356,9074 & $-0,008760819$ \\
\hline
\end{tabular}




\begin{tabular}{|l|l|l|l|} 
sep-11 & 95,9 & 583464,2468 & 0,021190502 \\
\hline oct-11 & 98,17 & 597275,1315 & 0,02367049 \\
\hline nov-11 & 96,94 & 589791,7006 & $-0,012529286$ \\
\hline dic-11 & 97,05 & 590460,9505 & 0,001134723 \\
\hline ene-12 & 95,71 & 582308,2697 & $-0,013807316$ \\
\hline feb-12 & 96,4 & 586506,2919 & 0,007209278 \\
\hline mar-12 & 95,61 & 581699,8607 & $-0,008195021$ \\
\hline abr-12 & 95,02 & 578110,2475 & $-0,006170903$ \\
\hline may-12 & 93,89 & 571235,2256 & $-0,011892233$ \\
\hline jun-12 & 90,5 & 550610,16 & $-0,036106082$ \\
\hline jul-12 & 91,87 & 558945,3635 & 0,015138122 \\
\hline ago-12 & 91,48 & 556572,5683 & $-0,004245129$ \\
\hline sep-12 & 94,34 & 573973,0662 & 0,031263664 \\
\hline oct-12 & 93,12 & 566550,4762 & $-0,012931948$ \\
\hline nov-12 & 89,73 & 545925,4105 & $-0,036404639$ \\
\hline dic-12 & 87,64 & 533209,6621 & $-0,023292099$ \\
\hline ene-13 & 88,43 & 538016,0933 & 0,009014149 \\
\hline feb-13 & 88,08 & 535886,6618 & $-0,003957933$ \\
\hline mar-13 & 89,45 & 544221,8653 & 0,015554042 \\
\hline abr-13 & 89,23 & 542883,3654 & $-0,002459475$ \\
\hline may-13 & 90,19 & 548724,092 & 0,010758713 \\
\hline jun-13 & 89,32 & 543430,9336 & $-0,009646302$ \\
\hline jul-13 & 88,89 & 540814,7748 & $-0,004814151$ \\
\hline ago-13 & 88,63 & 539232,9113 & $-0,002924963$ \\
\hline sep-13 & 86,84 & 528342,39 & $-0,020196322$ \\
\hline oct-13 & 84,89 & 516478,4141 & $-0,02245509$ \\
\hline nov-13 & 83,55 & 508325,7333 & 0,000718785134 \\
\hline dic-13 & 83,61 & 508690,7787 & \\
\hline & & & \\
\hline
\end{tabular}

Fuente: Elaboración propia 
Anexo B. Serie costos totales para productores medianos y pequeños de Antioquia.

\begin{tabular}{|c|c|c|c|c|}
\hline FECHA & \begin{tabular}{|c} 
SERIE COSTOS \\
TOTALES PARA \\
PRODUCTORES \\
MEDIANOS DE \\
ANTIOQUIA Región: \\
Antioquia \\
Cultivo: Café \\
Tecnificado \\
Duración ciclo: 5 \\
años \\
Tipo productor: \\
Mediano Entre 5 - 20 \\
Has \\
Actualización: \\
Septiembre 2009 \\
VALOR COSTOS DE \\
PRODUCCIÓN POR \\
HECTÁREA: \\
7140976
\end{tabular} & Variación & $\begin{array}{c}\text { SERIE COSTOS } \\
\text { TOTALES PARA } \\
\text { PRODUCTORES } \\
\text { PEQUEÑOS DE } \\
\text { ANTIOQUIA } \\
\text { Región: Antioquia } \\
\text { Cultivo: Café } \\
\text { Tecnificado } \\
\text { Duración ciclo: } 5 \\
\text { años Tipo } \\
\text { productor: } \\
\text { Pequeño Menor a } 5 \\
\text { Has Actualización: } \\
\text { Septiembre 2009 } \\
\text { VALOR COSTOS } \\
\text { DE PRODUCCIÓN } \\
\text { POR HECTÁREA: } \\
\text { \$6604287 }\end{array}$ & Variación \\
\hline ene-99 & 331528,9227 & & 306612,451 & \\
\hline feb-99 & 331094,1601 & $-0,001311386$ & 306210,3636 & $-0,001311386$ \\
\hline mar-99 & 321626,8311 & $-0,028594068$ & 297454,5636 & $-0,028594068$ \\
\hline abr-99 & 323560,7748 & 0,006013005 & 299243,1593 & 0,006013005 \\
\hline may-99 & 319610,4324 & $-0,012208966$ & 295589,7099 & $-0,012208966$ \\
\hline jun-99 & 322956,5115 & 0,010469242 & 298684,3102 & 0,010469242 \\
\hline jul-99 & 326754,2815 & 0,011759385 & 302196,654 & 0,011759385 \\
\hline ago-99 & 332889,1406 & 0,018775145 & 307870,44 & 0,018775145 \\
\hline sep-99 & 331720,596 & $-0,003510312$ & 306789,7189 & $-0,003510312$ \\
\hline oct-99 & 333108,2427 & 0,004183179 & 308073,0753 & 0,004183179 \\
\hline nov-99 & 339389,1699 & 0,018855514 & 313881,9515 & 0,018855514 \\
\hline dic-99 & 348226,2883 & 0,026038304 & 322054,9053 & 0,026038304 \\
\hline ene-00 & 353192,6028 & 0,014261745 & 326647,9702 & 0,014261745 \\
\hline feb-00 & 367726,3762 & 0,041149711 & 340089,4396 & 0,041149711 \\
\hline mar-00 & 380653,4008 & 0,035153923 & 352044,9174 & 0,035153923 \\
\hline abr-00 & 387080,396 & 0,016884114 & 357988,8838 & 0,016884114 \\
\hline may-00 & 376490,4606 & $-0,027358491$ & 348194,8483 & $-0,027358491$ \\
\hline jun-00 & 367872,4443 & $-0,022890398$ & 340224,5297 & $-0,022890398$ \\
\hline jul-00 & 369625,2612 & 0,004764741 & 341845,6115 & 0,004764741 \\
\hline ago-00 & 369406,1591 & $-0,000592768$ & 341642,9763 & $-0,000592768$ \\
\hline sep-00 & 373423,0311 & 0,010873863 & 345357,9552 & 0,010873863 \\
\hline oct- 00 & 370647,7377 & $-0,007432036$ & 342791,2425 & $-0,007432036$ \\
\hline nov-00 & 369187,0569 & $-0,003940887$ & 341440,341 & $-0,003940887$ \\
\hline dic-00 & 369187,0569 & 0 & 341440,341 & 0 \\
\hline ene-01 & 379850,0263 & 0,028882295 & 351301,9216 & 0,028882295 \\
\hline feb-01 & 392192,7786 & 0,032493751 & 362717,0388 & 0,032493751 \\
\hline
\end{tabular}




\begin{tabular}{|c|c|c|c|c|}
\hline mar-01 & 396793,9229 & 0,011731844 & 366972,3784 & 0,011731844 \\
\hline abr-01 & 407237,7902 & 0,026320633 & 376631,3238 & 0,026320633 \\
\hline may-01 & 411400,7303 & 0,010222382 & 380481,3929 & 0,010222382 \\
\hline jun-01 & 403951,2586 & $-0,01810758$ & 373591,7955 & $-0,01810758$ \\
\hline jul-01 & 401760,2374 & $-0,005423974$ & 371565,4433 & $-0,005423974$ \\
\hline ago-01 & 402125,4076 & 0,000908926 & 371903,1687 & 0,000908926 \\
\hline sep-01 & 398911,91 & $-0,007991282$ & 368931,1855 & $-0,007991282$ \\
\hline oct-01 & 393434,3572 & $-0,013731234$ & 363865,3051 & $-0,013731234$ \\
\hline nov-01 & 394822,0039 & 0,003527009 & 365148,6615 & 0,003527009 \\
\hline dic-01 & 397086,0591 & 0,005734369 & 367242,5587 & 0,005734369 \\
\hline ene-02 & 403805,1905 & 0,016921096 & 373456,7054 & 0,016921096 \\
\hline feb-02 & 402709,6799 & $-0,002712968$ & 372443,5293 & $-0,002712968$ \\
\hline mar-02 & 406434,4158 & 0,009249184 & 375888,328 & 0,009249184 \\
\hline abr-02 & 407091,7221 & 0,001617251 & 376496,2336 & 0,001617251 \\
\hline may-02 & 414760,296 & 0,01883746 & 383588,4662 & 0,01883746 \\
\hline jun-02 & 412496,2409 & $-0,005458708$ & 381494,569 & $-0,005458708$ \\
\hline jul-02 & 411035,5601 & $-0,003541076$ & 380143,6675 & $-0,003541076$ \\
\hline ago-02 & 413372,6493 & 0,005685856 & 382305,1098 & 0,005685856 \\
\hline sep-02 & 426080,5718 & 0,030742049 & 394057,9524 & 0,030742049 \\
\hline oct-02 & 436962,6433 & 0,025539938 & 404122,1682 & 0,025539938 \\
\hline nov-02 & 438423,324 & 0,003342805 & 405473,0697 & 0,003342805 \\
\hline dic-02 & 433457,0095 & $-0,011327669$ & 400880,0048 & $-0,011327669$ \\
\hline ene-03 & 428928,8992 & $-0,010446504$ & 396692,2103 & $-0,010446504$ \\
\hline feb-03 & 431265,9884 & 0,005448663 & 398853,6526 & 0,005448663 \\
\hline mar-03 & 438350,29 & 0,016426757 & 405405,5246 & 0,016426757 \\
\hline abr-03 & 457704,3098 & 0,044151949 & 423304,9688 & 0,044151949 \\
\hline may-03 & 454198,676 & $-0,007659167$ & 420062,8053 & $-0,007659167$ \\
\hline jun-03 & 448209,885 & $-0,0131854$ & 414524,1094 & $-0,0131854$ \\
\hline jul-03 & 447552,5786 & $-0,001466515$ & 413916,2037 & $-0,001466515$ \\
\hline ago-03 & 441417,7195 & $-0,013707572$ & 408242,4176 & $-0,013707572$ \\
\hline sep-03 & 442001,9918 & 0,001323627 & 408782,7782 & 0,001323627 \\
\hline oct-03 & 434625,5541 & $-0,016688698$ & 401960,7259 & $-0,016688698$ \\
\hline nov-03 & 439737,9367 & 0,011762729 & 406688,881 & 0,011762729 \\
\hline dic-03 & 444631,2171 & 0,01112772 & 411214,4008 & 0,01112772 \\
\hline ene-04 & 449670,5657 & 0,011333771 & 415875,0108 & 0,011333771 \\
\hline feb-04 & 459822,2968 & 0,02257593 & 425263,7759 & 0,02257593 \\
\hline mar-04 & 462305,4541 & 0,005400254 & 427560,3084 & 0,005400254 \\
\hline abr-04 & 463766,1348 & 0,003159558 & 428911,2098 & 0,003159558 \\
\hline may-04 & 469024,5855 & 0,011338583 & 433774,455 & 0,011338583 \\
\hline jun-04 & 470923,4705 & 0,004048583 & 435530,6269 & 0,004048583 \\
\hline jul-04 & 462232,4201 & $-0,018455335$ & 427492,7633 & $-0,018455335$ \\
\hline
\end{tabular}




\begin{tabular}{|c|c|c|c|c|}
\hline ago-04 & 460917,8074 & $-0,002844051$ & 426276,952 & $-0,002844051$ \\
\hline sep-04 & 466760,5304 & 0,01267628 & 431680,5578 & 0,01267628 \\
\hline oct-04 & 462670,6243 & $-0,008762322$ & 427898,0337 & $-0,008762322$ \\
\hline nov-04 & 468732,4494 & 0,013101815 & 433504,2747 & 0,013101815 \\
\hline dic-04 & 471872,9129 & 0,006699907 & 436408,7128 & 0,006699907 \\
\hline ene-05 & 480271,8272 & 0,017799102 & 444176,3962 & 0,017799102 \\
\hline feb-05 & 492249,4093 & 0,024939173 & 455253,788 & 0,024939173 \\
\hline mar-05 & 507513,523 & 0,031008902 & 469370,7082 & 0,031008902 \\
\hline abr-05 & 503131,4808 & $-0,008634336$ & 465318,0038 & $-0,008634336$ \\
\hline may-05 & 503277,5488 & 0,000290318 & 465453,094 & 0,000290318 \\
\hline jun-05 & 501597,766 & $-0,003337687$ & 463899,5573 & $-0,003337687$ \\
\hline jul-05 & 498603,3705 & $-0,005969715$ & 461130,2093 & $-0,005969715$ \\
\hline ago-05 & 495316,8388 & $-0,006591475$ & 458090,6811 & $-0,006591475$ \\
\hline sep-05 & 489839,286 & $-0,011058685$ & 453024,8007 & $-0,011058685$ \\
\hline oct-05 & 500502,2554 & 0,021768302 & 462886,3812 & 0,021768302 \\
\hline nov-05 & 496777,5196 & $-0,007441996$ & 459441,5825 & $-0,007441996$ \\
\hline dic-05 & 490715,6945 & $-0,012202293$ & 453835,3415 & $-0,012202293$ \\
\hline ene-06 & 498530,3364 & 0,015924989 & 461062,6643 & 0,015924989 \\
\hline feb-06 & 502255,0723 & 0,007471433 & 464507,463 & 0,007471433 \\
\hline mar-06 & 513648,3821 & 0,02268431 & 475044,4943 & 0,02268431 \\
\hline abr-06 & 521316,956 & 0,014929618 & 482136,7269 & 0,014929618 \\
\hline may-06 & 516861,8797 & $-0,008545811$ & 478016,4774 & $-0,008545811$ \\
\hline jun-06 & 516642,7776 & $-0,000423908$ & 477813,8422 & $-0,000423908$ \\
\hline jul-06 & 514305,6884 & $-0,004523608$ & 475652,3999 & $-0,004523608$ \\
\hline ago-06 & 520805,7177 & 0,012638455 & 481663,9114 & 0,012638455 \\
\hline sep-06 & 523288,875 & 0,004767915 & 483960,4438 & 0,004767915 \\
\hline oct-06 & 522631,5686 & $-0,001256106$ & 483352,5382 & $-0,001256106$ \\
\hline nov-06 & 520294,4795 & $-0,004471772$ & 481191,0959 & $-0,004471772$ \\
\hline dic-06 & 519125,9349 & $-0,002245929$ & 480110,3747 & $-0,002245929$ \\
\hline ene-07 & 516423,6755 & $-0,005205402$ & 477611,207 & $-0,005205402$ \\
\hline feb-07 & 524019,2153 & 0,014707962 & 484635,8945 & 0,014707962 \\
\hline mar-07 & 537530,5122 & 0,025783972 & 497131,7329 & 0,025783972 \\
\hline$a b r-07$ & 544395,7117 & 0,012771739 & 503480,9697 & 0,012771739 \\
\hline may-07 & 541255,2481 & $-0,005768715$ & 500576,5316 & $-0,005768715$ \\
\hline jun-07 & 535412,5251 & $-0,010794765$ & 495172,9258 & $-0,010794765$ \\
\hline jul-07 & 530519,2446 & $-0,009139272$ & 490647,406 & $-0,009139272$ \\
\hline ago-07 & 529715,8702 & $-0,001514317$ & 489904,4102 & $-0,001514317$ \\
\hline sep-07 & 528839,4618 & $-0,001654488$ & 489093,8693 & $-0,001654488$ \\
\hline oct- 07 & 528912,4958 & 0,000138102 & 489161,4144 & 0,000138102 \\
\hline nov-07 & 529496,7681 & 0,001104667 & 489701,775 & 0,001104667 \\
\hline dic-07 & 536800,1718 & 0,013793103 & 496456,2822 & 0,013793103 \\
\hline
\end{tabular}




\begin{tabular}{|c|c|c|c|c|}
\hline ene-08 & 549581,1283 & 0,023809524 & 508276,6699 & 0,023809524 \\
\hline feb-08 & 578064,4027 & 0,051827243 & 534619,2481 & 0,051827243 \\
\hline mar-08 & 546878,8689 & $-0,0539482$ & 505777,5022 & $-0,0539482$ \\
\hline abr-08 & 547682,2433 & 0,001469017 & 506520,498 & 0,001469017 \\
\hline may-08 & 553671,0344 & 0,010934791 & 512059,1939 & 0,010934791 \\
\hline jun-08 & 579744,1856 & 0,047091413 & 536172,7848 & 0,047091413 \\
\hline jul-08 & 587850,9637 & 0,013983371 & 543670,2878 & 0,013983371 \\
\hline ago-08 & 568569,9779 & $-0,032799105$ & 525838,3887 & $-0,032799105$ \\
\hline sep-08 & 572878,9861 & 0,007578677 & 529823,548 & 0,007578677 \\
\hline oct-08 & 582081,2748 & 0,016063233 & 538334,2271 & 0,016063233 \\
\hline nov-08 & 580912,7302 & $-0,002007528$ & 537253,506 & $-0,002007528$ \\
\hline dic-08 & 585879,0447 & 0,008549158 & 541846,5709 & 0,008549158 \\
\hline ene-09 & 595081,3333 & 0,015706806 & 550357,25 & 0,015706806 \\
\hline feb-09 & 602530,8051 & 0,012518409 & 557246,8474 & 0,012518409 \\
\hline mar-09 & 625682,5948 & 0,038424242 & 578658,6353 & 0,038424242 \\
\hline abr-09 & 638171,4152 & 0,019960313 & 590208,8427 & 0,019960313 \\
\hline may-09 & 641311,8787 & 0,004921035 & 593113,2808 & 0,004921035 \\
\hline jun-09 & 601800,4647 & $-0,061610295$ & 556571,3967 & $-0,061610295$ \\
\hline jul-09 & 600485,8521 & $-0,002184466$ & 555355,5854 & $-0,002184466$ \\
\hline ago-09 & 594350,993 & $-0,010216492$ & 549681,7993 & $-0,010216492$ \\
\hline sep-09 & 580693,628 & $-0,022978619$ & 537050,8707 & $-0,022978619$ \\
\hline oct-09 & 574193,5988 & $-0,011193561$ & 531039,3593 & $-0,011193561$ \\
\hline nov-09 & 572878,9861 & $-0,002289494$ & 529823,548 & $-0,002289494$ \\
\hline dic-09 & 581789,1386 & 0,015553289 & 538064,0468 & 0,015553289 \\
\hline ene-10 & 611952,1959 & 0,051845343 & 565960,1617 & 0,051845343 \\
\hline feb-10 & 631087,1136 & 0,031268648 & 583656,9707 & 0,031268648 \\
\hline mar-10 & 641530,9809 & 0,016549011 & 593315,9161 & 0,016549011 \\
\hline$a b r-10$ & 638828,7215 & $-0,004212204$ & 590816,7484 & $-0,004212204$ \\
\hline may-10 & 635177,0196 & $-0,005716246$ & 587439,4948 & $-0,005716246$ \\
\hline jun-10 & 637368,0407 & 0,003449465 & 589465,8469 & 0,003449465 \\
\hline jul-10 & 637148,9386 & $-0,000343761$ & 589263,2117 & $-0,000343761$ \\
\hline ago-10 & 633205,1006 & $-0,006189821$ & 585615,7778 & $-0,006189821$ \\
\hline sep-10 & 620716,2803 & $-0,019723183$ & 574065,5704 & $-0,019723183$ \\
\hline oct-10 & 603480,2476 & $-0,027767973$ & 558124,9333 & $-0,027767973$ \\
\hline nov-10 & 621738,7568 & 0,030255355 & 575011,2014 & 0,030255355 \\
\hline dic-10 & 647300,6698 & 0,041113591 & 598651,9768 & 0,041113591 \\
\hline ene-11 & 670671,5616 & 0,036105156 & 620266,3999 & 0,036105156 \\
\hline feb-11 & 679873,8503 & 0,013721006 & 628777,0791 & 0,013721006 \\
\hline mar-11 & 693385,1471 & 0,019873241 & 641272,9175 & 0,019873241 \\
\hline$a b r-11$ & 690463,7856 & $-0,004213187$ & 638571,1146 & $-0,004213187$ \\
\hline may-11 & 696160,4405 & 0,008250476 & 643839,6302 & 0,008250476 \\
\hline
\end{tabular}




\begin{tabular}{|c|c|c|c|c|}
\hline jun-11 & 697475,0532 & 0,001888376 & 645055,4415 & 0,001888376 \\
\hline jul-11 & 691924,4664 & $-0,007958115$ & 639922,016 & $-0,007958115$ \\
\hline ago-11 & 685862,6413 & $-0,008760819$ & 634315,775 & $-0,008760819$ \\
\hline sep-11 & 700396,4147 & 0,021190502 & 647757,2444 & 0,021190502 \\
\hline oct- 11 & 716975,1411 & 0,02367049 & 663089,9759 & 0,02367049 \\
\hline nov-11 & 707991,9545 & $-0,012529286$ & 654781,9319 & $-0,012529286$ \\
\hline dic-11 & 708795,3289 & 0,001134723 & 655524,9277 & 0,001134723 \\
\hline ene-12 & 699008,768 & $-0,013807316$ & 646473,888 & $-0,013807316$ \\
\hline feb-12 & 704048,1165 & 0,007209278 & 651134,498 & 0,007209278 \\
\hline mar-12 & 698278,4276 & $-0,008195021$ & 645798,4373 & $-0,008195021$ \\
\hline$a b r-12$ & 693969,4194 & $-0,006170903$ & 641813,278 & $-0,006170903$ \\
\hline may-12 & 685716,5732 & $-0,011892233$ & 634180,6849 & $-0,011892233$ \\
\hline jun-12 & 660958,0347 & $-0,036106082$ & 611282,9053 & $-0,036106082$ \\
\hline jul-12 & 670963,6978 & 0,015138122 & 620536,5802 & 0,015138122 \\
\hline ago-12 & 668115,3703 & $-0,004245129$ & 617902,3224 & $-0,004245129$ \\
\hline sep-12 & 689003,1049 & 0,031263664 & 637220,2131 & 0,031263664 \\
\hline oct-12 & 680092,9524 & $-0,012931948$ & 628979,7143 & $-0,012931948$ \\
\hline nov-12 & 655334,4138 & $-0,036404639$ & 606081,9347 & $-0,036404639$ \\
\hline dic-12 & 640070,3001 & $-0,023292099$ & 591965,0146 & $-0,023292099$ \\
\hline ene-13 & 645839,989 & 0,009014149 & 597301,0753 & 0,009014149 \\
\hline feb-13 & 643283,7977 & $-0,003957933$ & 594936,9978 & $-0,003957933$ \\
\hline mar-13 & 653289,4608 & 0,015554042 & 604190,6727 & 0,015554042 \\
\hline$a b r-13$ & 651682,712 & $-0,002459475$ & 602704,6811 & $-0,002459475$ \\
\hline may-13 & 658693,9795 & 0,010758713 & 609189,0081 & 0,010758713 \\
\hline jun-13 & 652340,0183 & $-0,009646302$ & 603312,5868 & $-0,009646302$ \\
\hline jul-13 & 649199,5547 & $-0,004814151$ & 600408,1487 & $-0,004814151$ \\
\hline ago-13 & 647300,6698 & $-0,002924963$ & 598651,9768 & $-0,002924963$ \\
\hline sep-13 & 634227,5772 & $-0,020196322$ & 586561,4088 & $-0,020196322$ \\
\hline oct-13 & 619985,9399 & $-0,02245509$ & 573390,1197 & $-0,02245509$ \\
\hline nov-13 & 610199,379 & $-0,015785134$ & 564339,08 & $-0,015785134$ \\
\hline dic-13 & 610637,5832 & 0,000718133 & 564744,3504 & 0,000718133 \\
\hline
\end{tabular}

Fuente: Elaboración propia 
Anexo C. Garantía de compra deflactada con el Índice de Precios al Productor de 2009 y margen de beneficios de productores grandes de café

\begin{tabular}{|c|c|c|c|c|}
\hline FECHA & $\begin{array}{l}\text { GARANTIA DE } \\
\text { COMPRA: } \\
\text { DEFLACTADA } \\
\text { CON EL IPP de } \\
2009\end{array}$ & Variaciones & $\begin{array}{l}\text { Precio de Garantía } \\
\text { de Compra-COSTO } \\
\text { = MARGEN DE } \\
\text { BENEFICIO } \\
\text { PRODUCTORES } \\
\text { GRANDES DE } \\
\text { ANTIOQUIA } \\
\text { (DEFLACTADA } \\
\text { CON IPP) } \\
\end{array}$ & Variación \\
\hline ene-99 & 308952,9035 & & 393290,087 & \\
\hline feb-99 & 312640,7386 & 0,011936561 & 363212,4285 & $-0,076477032$ \\
\hline mar-99 & 311867,0669 & $-0,002474635$ & 372684,4625 & 0,026078496 \\
\hline abr-99 & 312778,2803 & 0,0029218 & 369207,0964 & $-0,00933059$ \\
\hline may-99 & 313147,9234 & 0,001181806 & 383615,7477 & 0,039025933 \\
\hline jun-99 & 315119,7181 & 0,006296688 & 400468,5323 & 0,04393142 \\
\hline jul-99 & 320553,9189 & 0,017244877 & 385954,966 & $-0,036241465$ \\
\hline ago-99 & 325604,5291 & 0,015755884 & 370635,3344 & $-0,039692796$ \\
\hline sep-99 & 330335,4805 & 0,014529747 & 362329,0977 & $-0,022410806$ \\
\hline oct-99 & 333468,1374 & 0,009483259 & 355173,3592 & $-0,019749279$ \\
\hline nov-99 & 336536,8626 & 0,009202454 & 406174,3057 & 0,143594516 \\
\hline dic-99 & 338646,6112 & 0,006268997 & 469995,5347 & 0,157127686 \\
\hline ene-00 & 343377,5625 & 0,013970172 & 397218,1957 & $-0,154846873$ \\
\hline feb-00 & 349770,74 & 0,018618507 & 341256,9942 & $-0,140882775$ \\
\hline mar-00 & 354501,6913 & 0,013525864 & 332159,6191 & $-0,026658428$ \\
\hline$a b r-00$ & 360255,5511 & 0,016230839 & 294292,1121 & $-0,114003945$ \\
\hline may-00 & 362109,5725 & 0,005146406 & 310923,7678 & 0,056514106 \\
\hline jun-00 & 364411,1164 & 0,006355932 & 292997,01 & $-0,057656441$ \\
\hline jul-00 & 368247,0229 & 0,010526316 & 291372,3912 & $-0,005544831$ \\
\hline ago-00 & 370101,0444 & 0,005034722 & 262508,5574 & $-0,099061664$ \\
\hline sep-00 & 373105,8378 & 0,008118846 & 254376,2615 & $-0,030979165$ \\
\hline oct-00 & 373169,7696 & 0,00017135 & 256591,3414 & 0,008707888 \\
\hline nov-00 & 373617,292 & 0,001199246 & 257130,967 & 0,002103055 \\
\hline dic-00 & 376046,6995 & 0,006502396 & 253482,9042 & $-0,014187567$ \\
\hline ene-01 & 382759,5358 & 0,017851071 & 220848,9158 & $-0,128742364$ \\
\hline feb-01 & 389536,3039 & 0,017705028 & 151746,5278 & $-0,312894395$ \\
\hline mar-01 & 393244,3469 & 0,00951912 & 152535,4327 & 0,005198833 \\
\hline$a b r-01$ & 398934,2748 & 0,014469192 & 162914,5939 & 0,068044264 \\
\hline may-01 & 402194,7954 & 0,008173077 & 197667,8775 & 0,213322102 \\
\hline jun-01 & 401235,8187 & $-0,002384359$ & 133049,2024 & $-0,326905291$ \\
\hline jul-01 & 401491,5458 & 0,000637349 & 111430,442 & $-0,162486959$ \\
\hline ago-01 & 402706,2496 & 0,003025478 & 115414,8217 & 0,035756653 \\
\hline
\end{tabular}




\begin{tabular}{|c|c|c|c|c|}
\hline sep-01 & 403025,9084 & 0,000793777 & 123846,5764 & $\mid 0,073056082$ \\
\hline oct-01 & 401427,6141 & $-0,003965736$ & 87574,15899 & $-0,292881874$ \\
\hline nov-01 & 400916,1599 & $-0,001274088$ & 109561,6347 & 0,251072645 \\
\hline dic-01 & 402066,9318 & 0,002870356 & 98471,81164 & $-0,101219949$ \\
\hline ene-02 & 403793,0897 & 0,00429321 & 101356,0632 & 0,029290124 \\
\hline feb-02 & 405007,7934 & 0,003008233 & 92242,2896 & $-0,089918386$ \\
\hline mar-02 & 407245,4056 & 0,005524862 & 127447,0699 & 0,381655534 \\
\hline abr-02 & 408779,7682 & 0,003767661 & 142405,5011 & 0,117369754 \\
\hline may-02 & 411592,7663 & 0,006881451 & 96336,02619 & $-0,323509096$ \\
\hline jun-02 & 413063,1971 & 0,003572538 & 86451,07036 & $-0,10260913$ \\
\hline jul-02 & 416899,1036 & 0,009286488 & 63695,3644 & $-0,263220639$ \\
\hline ago-02 & 421949,7138 & 0,012114706 & 49860,19362 & $-0,217208441$ \\
\hline sep-02 & 430260,8445 & 0,01969697 & 94236,9435 & 0,890023617 \\
\hline oct-02 & 437293,3397 & 0,016344725 & 91722,80354 & $-0,026678921$ \\
\hline nov-02 & 437037,6126 & $-0,000584795$ & 106564,051 & 0,161805428 \\
\hline dic-02 & 439403,0883 & 0,005412522 & 54585,08166 & $-0,487772085$ \\
\hline ene-03 & 444325,835 & 0,011203259 & 108811,208 & 0,99342393 \\
\hline feb-03 & 449887,8994 & 0,012517986 & 94487,85076 & $-0,131634944$ \\
\hline mar-03 & 453979,533 & 0,009094785 & 56009,33548 & $-0,407232411$ \\
\hline abr-03 & 458902,2796 & 0,010843543 & 54384,73182 & $-0,029005944$ \\
\hline may-03 & 459158,0067 & 0,000557258 & 60076,6112 & 0,10465951 \\
\hline jun-03 & 458262,9619 & $-0,001949318$ & 31220,19172 & $-0,480327017$ \\
\hline jul-03 & 459221,9385 & 0,002092634 & 70363,14858 & 1,253770547 \\
\hline ago-03 & 459989,1198 & 0,001670611 & 48836,70885 & $-0,305933435$ \\
\hline sep-03 & 459797,3245 & $-0,000416956$ & 59902,27487 & 0,226582959 \\
\hline oct-03 & 460564,5058 & 0,001668521 & 49474,9754 & $-0,174071844$ \\
\hline nov-03 & 462929,9814 & 0,005136036 & 46517,00849 & $-0,059787133$ \\
\hline dic-03 & 464528,2758 & 0,003452562 & 48571,01882 & 0,044156114 \\
\hline ene-04 & 467724,8645 & 0,006881365 & 84933,98162 & 0,74865555 \\
\hline feb-04 & 472200,0888 & 0,00956807 & 69829,51748 & $-0,177837702$ \\
\hline mar-04 & 474757,3598 & 0,005415651 & 76518,91504 & 0,09579613 \\
\hline abr-04 & 477826,085 & 0,006463776 & 50591,63656 & $-0,338834894$ \\
\hline may-04 & 483452,0811 & 0,01177415 & 67310,79972 & 0,330472867 \\
\hline jun-04 & 485178,2391 & 0,003570484 & 106386,159 & 0,580521394 \\
\hline jul-04 & 483260,2858 & $-0,00395309$ & 38868,16712 & $-0,634650151$ \\
\hline ago-04 & 483707,8082 & 0,000926048 & 38084,17149 & $-0,020170635$ \\
\hline sep-04 & 485178,2391 & 0,003039915 & 74807,85123 & 0,964276714 \\
\hline oct- 04 & 487287,9876 & 0,004348399 & 72801,57441 & $-0,026819068$ \\
\hline nov-04 & 488310,896 & 0,002099187 & 117814,4712 & 0,618295651 \\
\hline dic-04 & 486073,2839 & $-0,004582351$ & 162244,0725 & 0,377114974 \\
\hline ene-05 & 488438,7596 & 0,0048665 & 145425,6882 & $-0,103661009$ \\
\hline
\end{tabular}




\begin{tabular}{|c|c|c|c|c|}
\hline feb-05 & 492530,3932 & 0,008376963 & 217358,0108 & 0,49463285 \\
\hline mar-05 & 498156,3894 & 0,011422638 & 293998,2792 & 0,352599235 \\
\hline abr-05 & 497644,9352 & $-0,001026694$ & 247634,6348 & $-0,157700394$ \\
\hline may-05 & 497964,594 & 0,000642343 & 224988,6852 & $-0,09144904$ \\
\hline jun-05 & 498476,0482 & 0,001027089 & 177405,6853 & $-0,211490635$ \\
\hline jul-05 & 497964,594 & $-0,001026036$ & 115172,1505 & $-0,35079786$ \\
\hline ago-05 & 497836,7305 & $-0,000256772$ & 113455,8655 & $-0,01490191$ \\
\hline sep-05 & 495854,8455 & $-0,003980994$ & 86461,90908 & $-0,237924732$ \\
\hline oct-05 & 498092,4576 & 0,004512635 & 138314,8937 & 0,599720561 \\
\hline nov-05 & 497069,5492 & $-0,002053652$ & 163783,6889 & 0,184136318 \\
\hline dic-05 & 496174,5043 & $-0,001800643$ & 170073,1203 & 0,038400841 \\
\hline ene-06 & 499818,6155 & 0,007344414 & 256147,3064 & 0,506101058 \\
\hline feb-06 & 500649,7286 & 0,001662829 & 187067,3658 & $-0,269688335$ \\
\hline mar-06 & 505380,6799 & 0,009449623 & 130929,4681 & $-0,300094554$ \\
\hline$a b r-06$ & 514139,3331 & 0,017330803 & 148152,0509 & 0,131540921 \\
\hline may-06 & 517911,3078 & 0,007336483 & 136817,2915 & $-0,07650761$ \\
\hline jun-06 & 522258,6685 & 0,008394025 & 120356,2396 & $-0,120314119$ \\
\hline jul-06 & 524240,5535 & 0,003794834 & 122901,2858 & 0,021145943 \\
\hline ago-06 & 524240,5535 & 0 & 128484,4635 & 0,045428147 \\
\hline sep-06 & 525455,2572 & 0,002317073 & 102142,947 & $-0,205017134$ \\
\hline oct-06 & 524368,417 & $-0,002068378$ & 87423,21048 & $-0,144109182$ \\
\hline nov-06 & 523089,7815 & $-0,00243843$ & 149237,024 & 0,707064099 \\
\hline dic-06 & 523665,1675 & 0,001099976 & 190024,8635 & 0,273309118 \\
\hline ene-07 & 524688,0759 & 0,001953363 & 152819,6094 & $-0,195791505$ \\
\hline feb-07 & 525391,3254 & 0,001340319 & 136674,7322 & $-0,105646633$ \\
\hline mar-07 & 526861,7562 & 0,002798734 & 85320,08563 & $-0,375743531$ \\
\hline abr-07 & 526030,6432 & $-0,001577478$ & 61913,997 & $-0,27433269$ \\
\hline may-07 & 521235,7601 & $-0,009115216$ & 48624,12689 & $-0,214650495$ \\
\hline jun-07 & 517016,2629 & $-0,00809518$ & 79495,43807 & 0,634896977 \\
\hline jul-07 & 514522,9237 & $-0,004822555$ & 77682,48517 & $-0,022805748$ \\
\hline ago-07 & 515673,6956 & 0,002236581 & 116651,9767 & 0,501650937 \\
\hline sep-07 & 520660,3741 & 0,009670221 & 156976,817 & 0,345685015 \\
\hline oct- 07 & 521235,7601 & 0,001105108 & 166815,3045 & 0,06267478 \\
\hline nov-07 & 525135,5983 & 0,007481908 & 155805,6478 & $-0,065999081$ \\
\hline dic-07 & 530314,0721 & 0,009861213 & 162954,5662 & 0,045883564 \\
\hline ene-08 & 536451,5225 & 0,011573237 & 141539,8087 & $-0,13141551$ \\
\hline feb-08 & 545849,4934 & 0,01751877 & 158454,191 & 0,119502651 \\
\hline mar-08 & 544570,8579 & $-0,002342469$ & 121925,8721 & $-0,230529207$ \\
\hline abr-08 & 545849,4934 & 0,002347969 & 60015,60452 & $-0,507769733$ \\
\hline may-08 & 549365,741 & 0,00644179 & 45698,62224 & $-0,238554329$ \\
\hline jun-08 & 558188,3259 & 0,016059583 & 36022,18487 & $-0,211744619$ \\
\hline
\end{tabular}




\begin{tabular}{|c|c|c|c|c|}
\hline jul-08 & 563942,1856 & 0,010308098 & 35347,89584 & $-0,018718715$ \\
\hline ago-08 & 562088,1642 & $-0,003287609$ & 96230,41672 & 1,722380341 \\
\hline sep-08 & 571613,9986 & 0,016947225 & 131457,575 & 0,366070932 \\
\hline oct-08 & 582802,0592 & 0,019572755 & 76113,52406 & $-0,421003133$ \\
\hline nov-08 & 582674,1957 & $-0,000219394$ & 82418,57161 & 0,082837415 \\
\hline dic-08 & 578007,1761 & $-0,008009655$ & 70578,96361 & $-0,143652186$ \\
\hline ene-09 & 569568,1818 & $-0,014600155$ & 143586,0815 & 1,034403371 \\
\hline feb-09 & 579797,2658 & 0,017959367 & 202309,1707 & 0,408974802 \\
\hline mar-09 & 581587,3555 & 0,003087441 & 202341,2068 & 0,000158352 \\
\hline abr-09 & 581651,2873 & 0,000109926 & 306149,9847 & 0,513038246 \\
\hline may-09 & 578454,6985 & $-0,005495713$ & 387618,5431 & 0,266106688 \\
\hline jun-09 & 573468,0201 & $-0,00862069$ & 246542,6639 & $-0,363955445$ \\
\hline jul-09 & 571741,8622 & $-0,003010033$ & 216758,7508 & $-0,120806325$ \\
\hline ago-09 & 567778,0921 & $-0,006932797$ & 264819,0483 & 0,221722524 \\
\hline sep-09 & 563047,1408 & $-0,008332395$ & 214155,7117 & $-0,191313038$ \\
\hline oct-09 & 559019,439 & $-0,007153401$ & 169970,5238 & $-0,206322715$ \\
\hline nov-09 & 560106,2791 & 0,00194419 & 198812,3637 & 0,169687304 \\
\hline dic-09 & 565348,6847 & 0,009359662 & 276856,7003 & 0,392552732 \\
\hline ene-10 & 572317,2481 & 0,012326134 & 289296,9716 & 0,044933972 \\
\hline feb-10 & 577239,9948 & 0,00860143 & 227852,2382 & $-0,212393282$ \\
\hline mar-10 & 580564,4471 & 0,00575922 & 223509,8705 & $-0,019057823$ \\
\hline$a b r-10$ & 583313,5134 & 0,004735161 & 191596,0054 & $-0,142785037$ \\
\hline may-10 & 586190,4433 & 0,004932047 & 208912,5783 & 0,090380657 \\
\hline jun-10 & 585678,9891 & $-0,000872505$ & 286991,4567 & 0,37373948 \\
\hline jul-10 & 582162,7415 & $-0,006003711$ & 357611,7503 & 0,246071065 \\
\hline ago-10 & 579030,0845 & $-0,005381067$ & 391173,4998 & 0,093849683 \\
\hline sep-10 & 575833,4957 & $-0,005520592$ & 373091,9267 & $-0,046223921$ \\
\hline oct- 10 & 573851,6107 & $-0,003441768$ & 331619,8917 & $-0,111157685$ \\
\hline nov-10 & 580564,4471 & 0,011697861 & 353092,0777 & 0,064749391 \\
\hline dic-10 & 590090,2815 & 0,016407885 & 435495,0551 & 0,233375322 \\
\hline ene-11 & 597058,845 & 0,011809317 & 452559,0202 & 0,039182914 \\
\hline feb-11 & 603835,6131 & 0,011350252 & 516151,8983 & 0,140518419 \\
\hline mar-11 & 609461,6093 & 0,009317099 & 553732,5472 & 0,072809282 \\
\hline$a b r-11$ & 610740,2448 & 0,002097975 & 546085,407 & $-0,013810169$ \\
\hline may-11 & 614448,2877 & 0,006071391 & 485330,414 & $-0,111255478$ \\
\hline jun-11 & 613361,4476 & $-0,001768807$ & 422934,9359 & $-0,128562885$ \\
\hline jul-11 & 609909,1317 & $-0,005628518$ & 400407,7632 & $-0,05326392$ \\
\hline ago-11 & 610228,7906 & 0,000524109 & 437076,8275 & 0,091579304 \\
\hline sep-11 & 614384,356 & 0,006809848 & 432239,0925 & $-0,011068386$ \\
\hline oct-11 & 620841,4652 & 0,010509886 & 337293,4235 & $-0,219660069$ \\
\hline nov-11 & 621736,5101 & 0,001441664 & 359605,3548 & 0,066149915 \\
\hline
\end{tabular}




\begin{tabular}{|l|l|l|l|l|} 
dic-11 & 622631,5549 & 0,001439589 & 332812,6262 & $-0,074505922$ \\
\hline ene-12 & 619498,8979 & $-0,005031317$ & 319494,6199 & $-0,04001653$ \\
\hline feb-12 & 620330,011 & 0,001341589 & 265126,4873 & $-0,170169165$ \\
\hline mar-12 & 618987,4437 & $-0,002164279$ & 169142,8465 & $-0,362029618$ \\
\hline abr-12 & 620266,0792 & 0,002065689 & 145513,2567 & $-0,139701975$ \\
\hline may-12 & 619371,0344 & $-0,001443001$ & 120246,6166 & $-0,173638064$ \\
\hline jun-12 & 609078,0187 & $-0,016618497$ & 70806,66541 & $-0,411154613$ \\
\hline jul-12 & 607991,1785 & $-0,001784402$ & 123010,2335 & 0,737269123 \\
\hline ago-12 & 610995,9719 & 0,004942166 & 84000,46943 & $-0,317126169$ \\
\hline sep-12 & 615023,6737 & 0,006592027 & 75052,40158 & $-0,106524022$ \\
\hline oct-12 & 613808,97 & $-0,001975052$ & 49956,1377 & $-0,334383222$ \\
\hline nov-12 & 608694,428 & $-0,008332465$ & 19272,57287 & $-0,61421011$ \\
\hline dic-12 & 604219,2038 & $-0,007352169$ & 17065,94493 & $-0,114495763$ \\
\hline ene-13 & 603899,5449 & $-0,000529045$ & 19690,64246 & 0,153797375 \\
\hline feb-13 & 604986,3851 & 0,001799704 & $-3464,332686$ & $-1,175938022$ \\
\hline mar-13 & 607223,9972 & 0,003698616 & $-5104,607515$ & 0,473474974 \\
\hline abr-13 & 605306,0439 & $-0,00315856$ & 856,0726598 & $-1,167705873$ \\
\hline may-13 & 606456,8159 & 0,001901141 & $-10757,38592$ & $-13,56597299$ \\
\hline jun-13 & 607863,3149 & 0,002319207 & $-41445,76318$ & 2,852772735 \\
\hline jul-13 & 607863,3149 & 0 & $-47843,18108$ & 0,154356378 \\
\hline ago-13 & 607863,3149 & 0 & $-63789,98291$ & 0,333313995 \\
\hline sep-13 & 606904,3383 & $-0,001577619$ & $-69225,8981$ & 0,085215812 \\
\hline oct-13 & 602173,387 & $-0,007795218$ & $-84955,8672$ & 0,227226653 \\
\hline nov-13 & 600639,0244 & $-0,002548041$ & $-99160,52385$ & 0,16720042 \\
\hline dic-13 & 601278,3421 & 0,001064396 & $-82460,77534$ & $-0,168411257$ \\
\hline
\end{tabular}

Fuente: Elaboración propia 
Anexo D. Margen de beneficios de productores medianos y pequeños de café.

\begin{tabular}{|c|c|c|c|c|}
\hline FECHA & $\begin{array}{l}\text { Precio de Garantía } \\
\text { de Compra-COSTO } \\
\text { = MARGEN DE } \\
\text { BENEFICIO } \\
\text { PRODUCTORES } \\
\text { MEDIANOS DE } \\
\text { ANTIOQUIA } \\
\text { (DEFLACTADA } \\
\text { CON IPP) }\end{array}$ & Variación & $\begin{array}{l}\text { Precio de Garantía de } \\
\text { Compra-COSTO = } \\
\text { MARGEN DE } \\
\text { BENEFICIO } \\
\text { PRODUCTORES } \\
\text { PEQUEÑOS DE } \\
\text { ANTIOQUIA } \\
\text { (DEFLACTADA CON } \\
\text { IPP) }\end{array}$ & Variación \\
\hline ene-99 & 337940,8665 & & 362857,3381 & \\
\hline feb-99 & 307935,7921 & $-0,088787943$ & 332819,5887 & $-0,082781155$ \\
\hline mar-99 & 318988,4101 & 0,035892606 & 343160,6776 & 0,031071155 \\
\hline abr-99 & 315188,1694 & $-0,011913413$ & 339505,7849 & $-0,010650675$ \\
\hline may-99 & 330256,3359 & 0,047806891 & 354277,0584 & 0,043508165 \\
\hline jun-99 & 346550,4879 & 0,049337894 & 370822,6892 & 0,046702518 \\
\hline jul-99 & 331402,8785 & $-0,043709675$ & 355960,506 & $-0,040078948$ \\
\hline ago-99 & 315059,0236 & $-0,049317178$ & 340077,7241 & $-0,044619506$ \\
\hline sep-99 & 306947,877 & $-0,025744848$ & 331878,7541 & $-0,024109106$ \\
\hline oct-99 & 299560,469 & $-0,024067305$ & 324595,6364 & $-0,021945116$ \\
\hline nov-99 & 349512,8058 & 0,166752099 & 375020,0242 & 0,155345242 \\
\hline dic-99 & 411858,6654 & 0,178379328 & 438030,0485 & 0,16801776 \\
\hline ene-00 & 338252,1933 & $-0,178717794$ & 364796,826 & $-0,167187669$ \\
\hline feb-00 & 279864,5578 & $-0,172615689$ & 307501,4944 & $-0,157060938$ \\
\hline mar-00 & 268608,9978 & $-0,040217883$ & 297217,4812 & $-0,033443783$ \\
\hline abr-00 & 229668,4949 & $-0,144970955$ & 258760,0071 & $-0,129391696$ \\
\hline may-00 & 248068,1552 & 0,080113994 & 276363,7675 & 0,068031226 \\
\hline jun-00 & 231580,1873 & $-0,066465475$ & 259228,1018 & $-0,062004024$ \\
\hline jul-00 & 229662,9333 & $-0,008279007$ & 257442,583 & $-0,006887829$ \\
\hline ago-00 & 200835,6789 & $-0,125519839$ & 228598,8617 & $-0,112039434$ \\
\hline sep-00 & 192032,7605 & $-0,043831447$ & 220097,8364 & $-0,037187522$ \\
\hline oct-00 & 194711,1796 & 0,013947719 & 222567,6748 & 0,011221548 \\
\hline nov-00 & 195494,6679 & 0,004023849 & 223241,3838 & 0,003026985 \\
\hline dic-00 & 191846,6051 & $-0,018660677$ & 219593,321 & $-0,016341338$ \\
\hline ene-01 & 157432,419 & $-0,179383868$ & 185980,5237 & $-0,153068395$ \\
\hline feb-01 & 86269,39111 & $-0,452022705$ & 115745,1309 & $-0,377649183$ \\
\hline mar-01 & 86290,12845 & 0,000240379 & 116111,673 & 0,003166804 \\
\hline$a b r-01$ & 94925,67132 & 0,100075675 & 125532,1378 & 0,081132797 \\
\hline may-01 & 128983,9462 & 0,358788876 & 159903,2836 & 0,273803557 \\
\hline jun-01 & 65608,9709 & $-0,491340025$ & 95968,43394 & $-0,399834501$ \\
\hline jul-01 & 44356,0046 & $-0,323933846$ & 74550,79871 & $-0,223173749$ \\
\hline ago-01 & 48279,41854 & 0,088452826 & 78501,65747 & 0,052995526 \\
\hline sep-01 & 57247,67122 & 0,185757264 & 87228,39571 & 0,111166293 \\
\hline
\end{tabular}




\begin{tabular}{|c|c|c|c|c|}
\hline oct-01 & 21889,73897 & $-0,617630927$ & 51458,79112 & $-0,410068353$ \\
\hline nov-01 & 43645,54511 & 0,993881479 & 73318,88758 & 0,424807812 \\
\hline dic-01 & 32177,73485 & $-0,2627487$ & 62021,23523 & $-0,154089249$ \\
\hline ene-02 & 33940,21801 & 0,054773376 & 64288,70313 & 0,036559541 \\
\hline feb-02 & 25009,34139 & $-0,263135511$ & 55275,49204 & $-0,140198988$ \\
\hline mar-02 & 59592,27179 & 1,382800525 & 90138,35963 & 0,630711122 \\
\hline$a b r-02$ & 74440,96475 & 0,249171453 & 105036,4533 & 0,165280284 \\
\hline may-02 & 27091,21066 & $-0,636071204$ & 58263,04046 & $-0,445306476$ \\
\hline jun-02 & 17584,24202 & $-0,350924466$ & 48585,91392 & $-0,166093744$ \\
\hline jul-02 & $-4927,601235$ & $-1,280228242$ & 25964,29138 & $-0,465600433$ \\
\hline ago-02 & $-19152,95235$ & 2,886871408 & 11914,58713 & $-0,541116414$ \\
\hline sep-02 & 23102,19199 & $-2,206194824$ & 55124,8113 & 3,626665676 \\
\hline oct-02 & 18771,27486 & $-0,187467801$ & 51611,7499 & $-0,063729223$ \\
\hline nov-02 & 33368,65961 & 0,777644825 & 66318,91394 & 0,284957671 \\
\hline dic-02 & $-17781,17652$ & $-1,532870566$ & 14795,82821 & $-0,776898816$ \\
\hline ene-03 & 37200,92422 & $-3,092152011$ & 69437,61315 & 3,693053484 \\
\hline feb-03 & 22487,38664 & $-0,395515377$ & 54899,72243 & $-0,209366222$ \\
\hline mar-03 & $-17173,86277$ & $-1,763710922$ & 15770,90259 & $-0,712732562$ \\
\hline abr-03 & $-22029,64729$ & 0,282742711 & 12369,69368 & $-0,215663554$ \\
\hline may-03 & $-15752,49742$ & $-0,284941007$ & 18383,37326 & 0,486162368 \\
\hline jun-03 & $-43609,0798$ & 1,76839149 & $-9923,304217$ & $-1,539797788$ \\
\hline jul-03 & $-4356,384717$ & $-0,900103723$ & 29279,99018 & $-3,950629099$ \\
\hline ago-03 & $-24858,60109$ & 4,706245592 & 8316,700787 & $-0,715959577$ \\
\hline sep-03 & $-13890,58015$ & $-0,441216338$ & 19328,63344 & 1,324074647 \\
\hline oct-03 & $-23086,37295$ & 0,662016468 & 9578,455217 & $-0,504442192$ \\
\hline nov-03 & $-26897,85933$ & 0,165096804 & 6151,196354 & $-0,357809144$ \\
\hline dic-03 & $-25660,78907$ & $-0,045991402$ & 7756,027246 & 0,26089736 \\
\hline ene-04 & 9860,847391 & $-1,384276858$ & 43656,40226 & 4,628706666 \\
\hline feb-04 & $-6938,462561$ & $-1,703637556$ & 27620,05839 & $-0,367330862$ \\
\hline mar-04 & $-663,6315954$ & $-0,904354662$ & 34081,51415 & 0,233940699 \\
\hline abr-04 & $-26834,77278$ & 39,43624952 & 8020,152249 & $-0,764677349$ \\
\hline may-04 & $-10993,51536$ & $-0,590325752$ & 24256,61512 & 2,024458185 \\
\hline jun-04 & 27764,8224 & $-3,525563615$ & 63157,66596 & 1,603729566 \\
\hline jul-04 & $-38302,18639$ & $-2,37952211$ & $-3562,529609$ & $-1,056406923$ \\
\hline ago-04 & $-38866,70558$ & 0,014738563 & $-4225,850163$ & 0,186193696 \\
\hline sep-04 & $-3118,476665$ & $-0,919764832$ & 31961,49592 & $-8,563329196$ \\
\hline oct-04 & $-4441,9379$ & 0,424393503 & 30330,65266 & $-0,051025248$ \\
\hline nov-04 & 39558,92868 & $-9,90578157$ & 74787,10331 & 1,465726806 \\
\hline dic-04 & 83464,22514 & 1,109870715 & 118928,4252 & 0,590226389 \\
\hline ene-05 & 65243,6303 & $-0,218304247$ & 101339,0613 & $-0,147898737$ \\
\hline feb-05 & 135176,2787 & 1,071869362 & 172171,8999 & 0,698968765 \\
\hline
\end{tabular}




\begin{tabular}{|c|c|c|c|c|}
\hline mar-05 & 209268,1818 & 0,548113203 & 247410,9966 & 0,436999863 \\
\hline abr-05 & 163636,1256 & $-0,218055396$ & 201449,6025 & $-0,185769407$ \\
\hline may-05 & 140965,7897 & $-0,138541143$ & 178790,2445 & $-0,112481522$ \\
\hline jun-05 & 93663,23182 & $-0,335560549$ & 131361,4405 & $-0,265276241$ \\
\hline jul-05 & 31929,6156 & $-0,659101923$ & 69402,77673 & $-0,471665532$ \\
\hline ago-05 & 30762,02172 & $-0,03656774$ & 67988,17944 & $-0,020382431$ \\
\hline sep-05 & 4682,550425 & $-0,847781447$ & 41497,03581 & $-0,389643374$ \\
\hline oct-05 & 54755,33726 & 10,69348588 & 92371,21148 & 1,225971318 \\
\hline nov-05 & 80845,98235 & 0,476495012 & 118181,9194 & 0,279423724 \\
\hline dic-05 & 88147,44405 & 0,090313229 & 125027,797 & 0,057926607 \\
\hline ene-06 & 172916,9647 & 0,961678714 & 210384,6368 & 0,682702902 \\
\hline feb-06 & 103215,1741 & $-0,403093998$ & 140962,7835 & $-0,329975869$ \\
\hline mar-06 & 45175,14731 & $-0,562320679$ & 83779,03515 & $-0,405665573$ \\
\hline abr-06 & 61117,45088 & 0,352899869 & 100297,68 & 0,197169194 \\
\hline may-06 & 50526,47276 & $-0,173288937$ & 89371,87504 & $-0,108933776$ \\
\hline jun-06 & 34102,00032 & $-0,325066674$ & 72930,9357 & $-0,183960998$ \\
\hline jul-06 & 37037,22678 & 0,086071974 & 75690,5153 & 0,037838259 \\
\hline ago-06 & 41535,21547 & 0,121445072 & 80677,02183 & 0,065880203 \\
\hline sep-06 & 14779,13237 & $-0,644178267$ & 54107,56353 & $-0,329331174$ \\
\hline oct-06 & 169,1340644 & $-0,988555887$ & 39448,16454 & $-0,27093068$ \\
\hline nov-06 & 62373,12792 & 367,7792175 & 101476,5115 & 1,572401345 \\
\hline dic-06 & 103356,0576 & 0,657060677 & 142371,6177 & 0,40300071 \\
\hline ene-07 & 66601,94949 & $-0,355606715$ & 105414,418 & $-0,259582636$ \\
\hline feb-07 & 49188,98616 & $-0,261448253$ & 88572,30696 & $-0,159770469$ \\
\hline mar-07 & $-4421,390394$ & $-1,08988578$ & 35977,38886 & $-0,593807703$ \\
\hline$a b r-07$ & $-28973,63375$ & 5,553059368 & 11941,10817 & $-0,668094085$ \\
\hline may-07 & $-41739,19904$ & 0,440592485 & $-1060,482593$ & $-1,088809395$ \\
\hline jun-07 & $-9892,437029$ & $-0,762994086$ & 30347,16225 & $-29,61636999$ \\
\hline jul-07 & $-10888,44986$ & 0,100684273 & 28983,38879 & $-0,044939077$ \\
\hline ago-07 & 28215,16611 & $-3,591293201$ & 68026,62615 & 1,347090144 \\
\hline sep-07 & 68686,32406 & 1,43437603 & 108431,9165 & 0,593962874 \\
\hline oct-07 & 78512,61843 & 0,14306042 & 118263,6999 & 0,090672411 \\
\hline nov-07 & 67405,41662 & $-0,141470276$ & 107200,4098 & $-0,093547641$ \\
\hline dic-07 & 73335,0215 & 0,087969264 & 113678,9111 & 0,06043355 \\
\hline ene-08 & 49786,46535 & $-0,321109283$ & 91090,92375 & $-0,198699892$ \\
\hline feb-08 & 61945,52489 & 0,244224197 & 105390,6795 & 0,156983321 \\
\hline mar-08 & 30623,67471 & $-0,505635399$ & 71725,04142 & $-0,319436578$ \\
\hline abr-08 & $-31420,71732$ & $-2,026027008$ & 9741,028006 & $-0,864189301$ \\
\hline may-08 & $-46737,5367$ & 0,487475166 & $-5125,696276$ & $-1,526196647$ \\
\hline jun-08 & $-60766,92338$ & 0,300173857 & $-17195,5226$ & 2,354768148 \\
\hline jul-08 & $-62794,65043$ & 0,033368927 & $-18613,97459$ & 0,082489612 \\
\hline
\end{tabular}




\begin{tabular}{|c|c|c|c|c|}
\hline ago-08 & 1306,858176 & $-1,020811616$ & 44038,44737 & $-3,365880923$ \\
\hline sep-08 & 35814,6215 & 26,40513252 & 78870,0596 & 0,790936427 \\
\hline oct-08 & $-21065,76452$ & $-1,588188947$ & 22681,28312 & $-0,712422138$ \\
\hline nov-08 & $-14565,6268$ & $-0,308564055$ & 29093,59741 & 0,282713912 \\
\hline dic-08 & $-27234,36801$ & 0,869769724 & 16798,10579 & $-0,42261847$ \\
\hline ene-09 & 44236,41481 & $-2,624286446$ & 88960,49814 & 4,295864858 \\
\hline feb-09 & 101715,8042 & 1,299368171 & 146999,7619 & 0,652416129 \\
\hline mar-09 & 97882,61648 & $-0,037685272$ & 144906,576 & $-0,014239383$ \\
\hline abr-09 & 199606,3682 & 1,039242261 & 247568,9406 & 0,708472779 \\
\hline may-09 & 280550,6218 & 0,405519395 & 328749,2197 & 0,327909789 \\
\hline jun-09 & 146071,2288 & $-0,479340919$ & 191300,2969 & $-0,418096575$ \\
\hline jul-09 & 116506,7922 & $-0,202397398$ & 161637,0589 & $-0,155061118$ \\
\hline ago-09 & 165591,313 & 0,421301796 & 210260,5067 & 0,300818687 \\
\hline sep-09 & 117208,0927 & $-0,292184532$ & 160850,85 & $-0,234992569$ \\
\hline oct-09 & 74108,09383 & $-0,367722039$ & 117262,3333 & $-0,27098717$ \\
\hline nov-09 & 103169,4102 & 0,392147671 & 146224,8483 & 0,246989073 \\
\hline dic-09 & 179726,1843 & 0,742049159 & 223451,276 & 0,528134777 \\
\hline ene-10 & 187130,6906 & 0,041198818 & 233122,7248 & 0,043282137 \\
\hline feb-10 & 122491,3558 & $-0,345423482$ & 169921,4987 & $-0,271107101$ \\
\hline mar-10 & 116405,3698 & $-0,049685025$ & 164620,4346 & $-0,031197136$ \\
\hline$a b r-10$ & 84942,65072 & $-0,270285805$ & 132954,6238 & $-0,192356501$ \\
\hline may-10 & 102868,8804 & 0,211039207 & 150606,4053 & 0,132765457 \\
\hline jun-10 & 180581,9647 & 0,755457667 & 228484,1585 & 0,517094563 \\
\hline jul-10 & 251238,8377 & 0,391273143 & 299124,5646 & 0,309169819 \\
\hline ago-10 & 285459,0165 & 0,136205768 & 333048,3394 & 0,113410194 \\
\hline sep-10 & 269462,4695 & $-0,056037981$ & 316113,1794 & $-0,050848955$ \\
\hline oct- 10 & 230868,0144 & $-0,143227571$ & 276223,3287 & $-0,126188509$ \\
\hline nov-10 & 249291,9166 & 0,079802749 & 296019,472 & 0,071667167 \\
\hline dic-10 & 327427,2967 & 0,313429257 & 376075,9897 & 0,270443418 \\
\hline ene-11 & 340589,4585 & 0,040198731 & 390994,6202 & 0,039669192 \\
\hline feb-11 & 402646,0015 & 0,182203358 & 453742,7727 & 0,160483417 \\
\hline mar-11 & 437970,9204 & 0,08773195 & 490083,15 & 0,080090261 \\
\hline$a b r-11$ & 430811,5056 & $-0,016346781$ & 482704,1767 & $-0,015056574$ \\
\hline may-11 & 369105,448 & $-0,143232149$ & 421426,2583 & $-0,126947148$ \\
\hline jun-11 & 306490,4935 & $-0,169639746$ & 358910,1051 & $-0,148344229$ \\
\hline jul-11 & 284889,999 & $-0,070476882$ & 336892,4494 & $-0,061345879$ \\
\hline ago-11 & 322571,0936 & 0,132265417 & 374117,9599 & 0,11049672 \\
\hline sep-11 & 315306,9247 & $-0,022519591$ & 367946,0949 & $-0,01649711$ \\
\hline oct-11 & 217593,414 & $-0,309899666$ & 271478,5792 & $-0,262178393$ \\
\hline nov-11 & 241405,1009 & 0,10943202 & 294615,1234 & 0,085224198 \\
\hline dic-11 & 214478,2478 & $-0,111542188$ & 267748,649 & $-0,09119177$ \\
\hline
\end{tabular}




\begin{tabular}{|l|l|l|l|l|} 
ene-12 & 202794,1216 & $-0,054476975$ & 255329,0015 & $-0,046385472$ \\
\hline feb-12 & 147584,6627 & $-0,272243882$ & 200498,2812 & $-0,214745368$ \\
\hline mar-12 & 52564,27959 & $-0,643836435$ & 105044,2699 & $-0,476083938$ \\
\hline abr-12 & 29654,08483 & $-0,435851018$ & 81810,22619 & $-0,221183352$ \\
\hline may-12 & 5765,268943 & $-0,805582638$ & 57301,15731 & $-0,299584417$ \\
\hline jun-12 & $-39541,20933$ & $-7,858519476$ & 10133,92005 & $-0,823146329$ \\
\hline jul-12 & 10991,89922 & $-1,277985914$ & 61419,01674 & 5,060736265 \\
\hline ago-12 & $-27542,33257$ & $-3,505693695$ & 22670,71534 & $-0,630884431$ \\
\hline sep-12 & $-39977,63712$ & 0,451497872 & 11805,25466 & $-0,479272953$ \\
\hline oct-12 & $-63586,33849$ & 0,590547693 & $-12473,10039$ & $-2,056571904$ \\
\hline nov-12 & $-90136,43044$ & 0,417543966 & $-40883,95133$ & 2,277769765 \\
\hline dic-12 & $-89794,6931$ & $-0,003791334$ & $-41689,40759$ & 0,019701037 \\
\hline ene-13 & $-88133,25327$ & $-0,018502651$ & $-39594,33955$ & $-0,050254205$ \\
\hline feb-13 & $-110861,4687$ & 0,257884675 & $-62514,66872$ & 0,578878936 \\
\hline mar-13 & $-114172,203$ & 0,029863707 & $-65073,41494$ & 0,040930333 \\
\hline abr-13 & $-107943,2739$ & $-0,054557318$ & $-58965,24301$ & $-0,093865858$ \\
\hline may-13 & $-120727,2735$ & 0,118432572 & $-71222,30199$ & 0,207869218 \\
\hline jun-13 & $-150354,8479$ & 0,245409125 & $-101327,4164$ & 0,422692241 \\
\hline jul-13 & $-156227,961$ & 0,039061681 & $-107436,5549$ & 0,060291072 \\
\hline ago-13 & $-171857,7413$ & 0,100044705 & $-123209,0483$ & 0,146807513 \\
\hline sep-13 & $-175111,0853$ & 0,018930448 & $-127444,917$ & 0,034379526 \\
\hline oct-13 & $-188463,393$ & 0,076250499 & $-141867,5728$ & 0,11316776 \\
\hline nov-13 & $-201034,1695$ & 0,066701423 & $-155173,8705$ & 0,093793793 \\
\hline dic-13 & $-184407,5798$ & $-0,082705292$ & $-138514,347$ & $-0,107360366$ \\
\hline
\end{tabular}

Fuente: Elaboración propia 
Anexo E. Producción registrada y volumen de las exportaciones colombianas de café mensuales

\begin{tabular}{|c|c|c|c|c|}
\hline FECHA & $\begin{array}{l}\text { Producción } \\
\text { registrada - mensual } \\
\text { Miles de sacos de } \\
125 \mathrm{Kg} \text { de café verde } \\
\text { pergamino } \\
\text { transformado } \\
\text { (Producción de } \\
\text { sacos } 60 \mathrm{~kg}^{\star} \mathrm{kilos} \text { de } \\
\left.\text { café verde }{ }^{\star} 60\right)^{\star} \\
\text { factor de conversión } \\
(0,80) / 125) 12\end{array}$ & Variación & $\begin{array}{l}\text { Volumen de las } \\
\text { exportaciones } \\
\text { colombianas de café - } \\
\text { mensual (Miles de } \\
\text { sacos de } 60 \mathrm{Kg} \text { de café } \\
\text { verde equivalente) } \\
\text { Producción de sacos } \\
60 \mathrm{~kg}^{\star} \text { kilos de café } \\
\text { verde }\left({ }^{*} 60\right)^{\star} \text { factor de } \\
\text { conversión }(0,80) / 125 \\
12\end{array}$ & Variación \\
\hline ene-99 & 1016,25 & & 316,416 & \\
\hline feb-99 & 887,50 & $-0,126691267$ & 338,688 & 0,07038835 \\
\hline mar-99 & 837,5 & $-0,056338028$ & 264,576 & $-0,218820862$ \\
\hline abr-99 & 858,75 & 0,025373134 & 364,032 & 0,375907112 \\
\hline may-99 & 800 & $-0,068413392$ & 292,224 & $-0,197257384$ \\
\hline jun-99 & 925 & 0,15625 & 310,656 & 0,063074901 \\
\hline jul-99 & 1007,5 & 0,089189189 & 249,6 & $-0,196538937$ \\
\hline ago-99 & 946,25 & $-0,060794045$ & 303,36 & 0,215384615 \\
\hline sep-99 & 970 & 0,025099075 & 266,88 & $-0,120253165$ \\
\hline oct-99 & 926,25 & $-0,045103093$ & 330,624 & 0,238848921 \\
\hline nov-99 & 1102,5 & 0,190283401 & 387,456 & 0,171893148 \\
\hline dic-99 & 1112,5 & 0,009070295 & 413,568 & 0,067393459 \\
\hline ene-00 & 822,5 & $-0,260674157$ & \begin{tabular}{|l|}
198,528 \\
\end{tabular} & $-0,51996286$ \\
\hline feb-00 & 925 & 0,124620061 & 246,528 & 0,241779497 \\
\hline mar-00 & 740 & $-0,2$ & 155,136 & $-0,370716511$ \\
\hline abr-00 & 1318,75 & 0,782094595 & 280,704 & 0,809405941 \\
\hline may-00 & 1392,5 & 0,055924171 & 236,16 & $-0,158686731$ \\
\hline jun-00 & 1365 & $-0,019748654$ & 333,696 & 0,41300813 \\
\hline jul-00 & 1013,75 & $-0,257326007$ & 276,864 & $-0,170310702$ \\
\hline ago-00 & 545 & $-0,462392109$ & 360,192 & 0,300970874 \\
\hline sep-00 & 626,25 & 0,149082569 & \begin{tabular}{|l|}
258,816 \\
\end{tabular} & $-0,281449893$ \\
\hline oct- 00 & 1175 & 0,876247505 & 319,104 & 0,232937685 \\
\hline nov-00 & 1707,5 & 0,453191489 & 460,8 & 0,444043321 \\
\hline dic- 00 & 1642,5 & $-0,03806735$ & 408,576 & $-0,113333333$ \\
\hline ene-01 & 1538,75 & $-0,063165906$ & 249,984 & $-0,388157895$ \\
\hline feb-01 & 676,25 & $-0,560519903$ & 321,792 & 0,287250384 \\
\hline mar-01 & 602,5 & $-0,109057301$ & 234,24 & $-0,272076372$ \\
\hline$a b r-01$ & 1222,5 & 1,029045643 & 287,232 & 0,226229508 \\
\hline may-01 & 1086,25 & $-0,111451943$ & 285,696 & $-0,005347594$ \\
\hline jun-01 & 897,5 & $-0,173762946$ & \begin{tabular}{|l|}
286,848 \\
\end{tabular} & 0,004032258 \\
\hline jul-01 & 817,5 & $-0,08913649$ & 254,208 & $-0,113788487$ \\
\hline
\end{tabular}




\begin{tabular}{|c|c|c|c|c|}
\hline ago-01 & 825 & 0,009174312 & 252,672 & $-0,006042296$ \\
\hline sep-01 & 957,5 & 0,160606061 & 276,864 & 0,095744681 \\
\hline oct-01 & 1553,75 & 0,622715405 & 432,768 & 0,563106796 \\
\hline nov-01 & 1921,25 & 0,236524537 & 481,536 & 0,112688554 \\
\hline dic-01 & 1571,25 & $-0,182173064$ & 467,328 & $-0,029505582$ \\
\hline ene-02 & 1030 & $-0,344470963$ & 273,408 & $-0,414954807$ \\
\hline feb-02 & 1010 & $-0,019417476$ & 335,616 & 0,22752809 \\
\hline mar-02 & 972,5 & $-0,037128713$ & 302,208 & $-0,099542334$ \\
\hline abr-02 & 1177,5 & 0,210796915 & 290,688 & $-0,038119441$ \\
\hline may-02 & 1390 & 0,180467091 & 321,792 & 0,107001321 \\
\hline jun-02 & 1315 & $-0,053956835$ & 313,344 & $-0,026252983$ \\
\hline jul-02 & 1085 & $-0,174904943$ & 271,488 & $-0,133578431$ \\
\hline ago-02 & 938,75 & $-0,134792627$ & 312,576 & 0,151343706 \\
\hline sep-02 & 972,5 & 0,035952064 & 278,784 & $-0,108108108$ \\
\hline oct-02 & 1330 & 0,367609254 & 318,72 & 0,143250689 \\
\hline nov-02 & 1725 & 0,296992481 & 439,296 & 0,378313253 \\
\hline dic-02 & 1571,25 & $-0,089130435$ & 486,912 & 0,108391608 \\
\hline ene-03 & 1155 & $-0,264916468$ & 289,92 & $-0,404574132$ \\
\hline feb-03 & 985 & $-0,147186147$ & 343,296 & 0,18410596 \\
\hline mar-03 & 805 & $-0,182741117$ & 278,016 & $-0,1901566$ \\
\hline abr-03 & 1347,5 & 0,673913043 & 320,64 & 0,153314917 \\
\hline may-03 & 1215 & $-0,098330241$ & 291,456 & $-0,091017964$ \\
\hline jun-03 & 1346,25 & 0,108024691 & 350,976 & 0,204216074 \\
\hline jul-03 & 1340 & $-0,004642526$ & 349,056 & $-0,00547046$ \\
\hline ago-03 & 826,25 & $-0,383395522$ & 277,248 & $-0,205720572$ \\
\hline sep-03 & 993,75 & 0,202723147 & 286,464 & 0,033240997 \\
\hline oct-03 & 1421,25 & 0,430188679 & 340,608 & 0,189008043 \\
\hline nov-03 & 1470 & 0,034300792 & 380,544 & 0,117249154 \\
\hline dic-03 & 1555 & \begin{tabular}{|l}
0,057823129 \\
\end{tabular} & 443,136 & 0,164480323 \\
\hline ene-04 & 1463,75 & $-0,058681672$ & 344,448 & $-0,22270364$ \\
\hline feb-04 & 962,5 & $-0,342442357$ & 373,632 & 0,084726867 \\
\hline mar-04 & 1013,75 & 0,053246753 & 339,84 & $-0,090441932$ \\
\hline abr-04 & 922,5 & $-0,09001233$ & 309,504 & $-0,089265537$ \\
\hline may-04 & 1363,75 & 0,478319783 & 302,976 & $-0,021091811$ \\
\hline jun-04 & 1192,5 & $-0,125572869$ & 315,264 & 0,040557668 \\
\hline jul-04 & 967,5 & $-0,188679245$ & 319,488 & 0,013398295 \\
\hline ago-04 & 902,5 & $-0,067183463$ & 282,24 & $-0,116586538$ \\
\hline sep-04 & 581,25 & $-0,355955679$ & 172,416 & $-0,389115646$ \\
\hline oct- 04 & 1346,25 & 1,316129032 & 340,992 & 0,977728285 \\
\hline nov-04 & 1671,25 & 0,241411328 & 366,336 & 0,074324324 \\
\hline dic-04 & 1662,5 & $-0,005235602$ & 473,472 & 0,29245283 \\
\hline
\end{tabular}




\begin{tabular}{|c|c|c|c|c|}
\hline ene-05 & 1375 & $-0,172932331$ & 419,328 & $-0,114355231$ \\
\hline feb-05 & 1278,75 & $-0,07$ & 448,128 & 0,068681319 \\
\hline mar-05 & 907,5 & $-0,290322581$ & 367,872 & $-0,179091688$ \\
\hline$a b r-05$ & 1091,25 & 0,202479339 & 329,856 & $-0,103340292$ \\
\hline may-05 & 1193,75 & 0,093928981 & 312,96 & $-0,051222352$ \\
\hline jun-05 & 1185 & $-0,007329843$ & 322,176 & 0,029447853 \\
\hline jul-05 & 922,5 & $-0,221518987$ & 294,144 & $-0,087008343$ \\
\hline ago-05 & 807,5 & $-0,124661247$ & 291,456 & $-0,009138381$ \\
\hline sep-05 & 845 & 0,046439628 & 269,184 & $-0,076416337$ \\
\hline oct-05 & 1413,75 & 0,673076923 & 288,384 & 0,071326676 \\
\hline nov-05 & 1546,25 & 0,09372237 & 379,008 & 0,31424767 \\
\hline dic-05 & 1332,5 & $-0,138237672$ & 451,968 & 0,192502533 \\
\hline ene-06 & 1377,5 & 0,033771107 & 317,568 & $-0,297366185$ \\
\hline feb-06 & 1110 & $-0,194192377$ & 362,112 & 0,140266022 \\
\hline mar-06 & 891,25 & $-0,197072072$ & 339,072 & $-0,063626723$ \\
\hline abr-06 & 973,125 & 0,091865358 & 239,232 & $-0,294450736$ \\
\hline may-06 & 1358,75 & 0,396274888 & 335,616 & 0,402889246 \\
\hline jun-06 & 1467,5 & 0,080036799 & 338,304 & 0,008009153 \\
\hline jul-06 & 1025,625 & $-0,301107325$ & 347,52 & 0,027241771 \\
\hline ago-06 & 1427,5 & 0,391834247 & 360,192 & 0,036464088 \\
\hline sep-06 & 1016,25 & $-0,288091068$ & 370,176 & 0,02771855 \\
\hline oct-06 & 1280 & 0,259532595 & 370,176 & 0 \\
\hline nov-06 & 1552,5 & 0,212890625 & 356,736 & $-0,036307054$ \\
\hline dic-06 & 1617,5 & 0,041867955 & 466,944 & 0,308934338 \\
\hline ene-07 & 1203,75 & $-0,255795981$ & 335,616 & $-0,28125$ \\
\hline feb-07 & 1251,25 & 0,039460021 & 380,16 & 0,132723112 \\
\hline mar-07 & 970 & $-0,224775225$ & 347,904 & $-0,084848485$ \\
\hline$a b r-07$ & 961,25 & $-0,009020619$ & 289,152 & $-0,168874172$ \\
\hline may-07 & 1242,5 & 0,292587776 & 301,824 & 0,043824701 \\
\hline jun-07 & 1523,75 & 0,226358149 & 342,912 & 0,136132316 \\
\hline jul-07 & 1243,75 & $-0,183757178$ & 363,648 & 0,060470325 \\
\hline ago-07 & 1237,5 & $-0,005025126$ & 375,168 & 0,031678986 \\
\hline sep-07 & 1121,25 & $-0,093939394$ & 361,728 & $-0,035823951$ \\
\hline oct- 07 & 1411,25 & 0,258639911 & 324,096 & $-0,10403397$ \\
\hline nov-07 & 1902,5 & 0,34809566 & 403,584 & 0,245260664 \\
\hline dic-07 & 1703,75 & $-0,104467806$ & 513,792 & 0,273073264 \\
\hline ene-08 & 1755 & 0,030080704 & 395,136 & $-0,230941704$ \\
\hline feb-08 & 1362,5 & $-0,223646724$ & 458,496 & 0,160349854 \\
\hline mar-08 & 1090 & $-0,2$ & 347,136 & $-0,242881072$ \\
\hline abr-08 & 1107,5 & 0,016055046 & 350,976 & 0,011061947 \\
\hline may-08 & 1025 & $-0,074492099$ & 331,776 & $-0,054704595$ \\
\hline
\end{tabular}




\begin{tabular}{|c|c|c|c|c|}
\hline jun-08 & 1307,5 & 0,275609756 & 363,264 & 0,094907407 \\
\hline jul-08 & 1113,75 & $-0,148183556$ & 342,528 & $-0,057082452$ \\
\hline ago-08 & 893,75 & $-0,197530864$ & 246,528 & $-0,280269058$ \\
\hline sep-08 & 971,25 & 0,086713287 & 360,576 & 0,462616822 \\
\hline oct-08 & 1173,75 & 0,208494208 & 322,176 & $-0,106496273$ \\
\hline nov-08 & 1166,25 & $-0,006389776$ & 351,36 & 0,090584029 \\
\hline dic-08 & 1381,25 & 0,184351554 & 386,688 & 0,100546448 \\
\hline ene-09 & 1095 & $-0,207239819$ & 333,312 & $-0,138033764$ \\
\hline feb-09 & 1085 & $-0,00913242$ & 362,112 & 0,08640553 \\
\hline mar-09 & 956,25 & $-0,118663594$ & 313,728 & $-0,133616119$ \\
\hline abr-09 & 431,25 & $-0,549019608$ & 211,2 & $-0,326805386$ \\
\hline may-09 & 877,5 & 1,034782609 & \begin{tabular}{|l|}
211,968 \\
\end{tabular} & 0,003636364 \\
\hline jun-09 & 856,25 & $-0,024216524$ & 246,528 & 0,163043478 \\
\hline jul-09 & 727,5 & $-0,150364964$ & 233,472 & $-0,052959502$ \\
\hline ago-09 & 496,25 & $-0,317869416$ & 182,016 & $-0,220394737$ \\
\hline sep-09 & 583,75 & 0,176322418 & 192,384 & 0,056962025 \\
\hline oct-09 & 680 & 0,164882227 & 205,44 & 0,067864271 \\
\hline nov-09 & 950 & 0,397058824 & 236,544 & 0,151401869 \\
\hline dic-09 & 1026,25 & 0,080263158 & 302,592 & 0,279220779 \\
\hline ene-10 & 643,75 & $-0,3727162$ & 207,8208 & $-0,31319797$ \\
\hline feb-10 & 810 & 0,258252427 & 226,56 & 0,090169993 \\
\hline mar-10 & 786,25 & $-0,029320988$ & 221,184 & $-0,023728814$ \\
\hline$a b r-10$ & 808,75 & 0,028616852 & 225,792 & 0,020833333 \\
\hline may-10 & 1027,5 & 0,270479134 & 221,184 & $-0,020408163$ \\
\hline jun-10 & 975 & $-0,051094891$ & 248,832 & 0,125 \\
\hline jul-10 & 983,75 & 0,008974359 & 235,008 & $-0,055555556$ \\
\hline ago-10 & 768,75 & $-0,218551461$ & 230,016 & $-0,02124183$ \\
\hline sep-10 & 662,5 & $-0,138211382$ & 203,52 & $-0,115191987$ \\
\hline oct-10 & 1008,75 & 0,522641509 & 242,688 & 0,19245283 \\
\hline nov-10 & 1223,75 & 0,213135068 & 317,4528 & 0,30806962 \\
\hline dic-10 & 1455 & 0,188968335 & 424,4352 & 0,33700254 \\
\hline ene-11 & 1135 & $-0,219931271$ & 325,5168 & $-0,233058898$ \\
\hline feb-11 & 955 & $-0,158590308$ & 250,0608 & $-0,231803704$ \\
\hline mar-11 & 973,75 & 0,019633508 & 354,6624 & 0,418304668 \\
\hline abr-11 & 653,75 & $-0,328626444$ & 222,72 & $-0,372022521$ \\
\hline may-11 & 841,25 & 0,286806883 & 227,712 & 0,022413793 \\
\hline jun-11 & 588,75 & $-0,300148588$ & 221,184 & $-0,028667791$ \\
\hline jul-11 & 662,5 & 0,125265393 & 182,016 & $-0,177083333$ \\
\hline ago-11 & 582,5 & $-0,120754717$ & 147,3024 & $-0,1907173$ \\
\hline sep-11 & 573,75 & $-0,015021459$ & 180,864 & 0,227841502 \\
\hline oct-11 & 820 & 0,4291939 & 231,4368 & 0,279617834 \\
\hline
\end{tabular}




\begin{tabular}{|l|l|l|l|r|} 
nov-11 & 1056,25 & 0,288109756 & 297,1008 & 0,283723245 \\
\hline dic-11 & 918,75 & $-0,130177515$ & 329,1072 & 0,107729094 \\
\hline ene-12 & 668,75 & $-0,272108844$ & 207,96288 & $-0,368099877$ \\
\hline feb-12 & 713,75 & 0,06728972 & 214,9056 & 0,033384419 \\
\hline mar-12 & 720 & 0,008756567 & 231,936 & 0,079245957 \\
\hline abr-12 & 725 & 0,006944444 & 189,5808 & $-0,182615894$ \\
\hline may-12 & 861,25 & 0,187931034 & 226,486272 & 0,194668827 \\
\hline jun-12 & 892,5 & 0,03628447 & 235,392 & 0,039321271 \\
\hline jul-12 & 835 & $-0,06442577$ & 212,03136 & $-0,099241436$ \\
\hline ago-12 & 706,25 & $-0,154191617$ & 223,872 & 0,055843815 \\
\hline sep-12 & 648,75 & $-0,081415929$ & 202,368 & $-0,096054889$ \\
\hline oct-12 & 816,25 & 0,258188825 & 223,513728 & 0,104491461 \\
\hline nov-12 & 962,5 & 0,179173047 & 282,564096 & 0,264191236 \\
\hline dic-12 & 1130 & 0,174025974 & 302,068608 & 0,069026859 \\
\hline ene-13 & 1096,25 & $-0,029867257$ & 285,351936 & $-0,055340646$ \\
\hline feb-13 & 781,25 & $-0,287343216$ & 275,91936 & $-0,033055938$ \\
\hline mar-13 & 771,25 & $-0,0128$ & 259,814784 & $-0,058366966$ \\
\hline abr-13 & 1212,5 & 0,572123177 & 263,290368 & 0,01337716 \\
\hline may-13 & 1171,25 & $-0,034020619$ & 328,232448 & 0,246655738 \\
\hline jun-13 & 1141,25 & $-0,025613661$ & 258,323712 & $-0,212985451$ \\
\hline jul-13 & 1288,75 & 0,12924425 & 301,956864 & 0,168908815 \\
\hline ago-13 & 962,5 & $-0,253152279$ & 357,315456 & 0,183332782 \\
\hline sep-13 & 1075 & 0,116883117 & 258,758784 & $-0,275825382$ \\
\hline oct-13 & 1322,5 & 0,230232558 & 336,953088 & 0,30218995 \\
\hline nov-13 & 1391,25 & 0,051984877 & 403,299072 & 0,196899765 \\
\hline dic-13 & 1393,75 & 0,001796945 & 384,822528 & $-0,045813505$ \\
\hline
\end{tabular}

Fuente: Elaboración propia 
Anexo F. Promedio mensual de la Tasa Representativa del Mercado de 1999 a 2013 en valores corrientes e Índice de tasa de cambio real.

\begin{tabular}{|c|c|c|c|c|}
\hline FECHA & \begin{tabular}{|c|} 
Promedio mensual de \\
la Tasa Representativa \\
del Mercado de 1999 a \\
2013 VALORES \\
CORRIENTES
\end{tabular} & Variación & $\begin{array}{c}\text { ITCRIPC: ITCRIPC (T): } \\
\text { Índice de tasa de cambio } \\
\text { real, utiliza las } \\
\text { ponderaciones totales y el } \\
\text { IPC como deflactor. Para la } \\
\text { estructura de } \\
\text { ponderaciones }\end{array}$ & Variación \\
\hline ene-99 & 1570,01 & & 119,39 & \\
\hline feb-99 & 1567,07 & $-0,0018726$ & 115,48 & $-0,032720886$ \\
\hline mar-99 & 1550,15 & $-0,01079722$ & 111,72 & $-0,032536986$ \\
\hline abr-99 & 1574,67 & 0,015817824 & 114,35 & 0,023524136 \\
\hline may-99 & 1641,33 & 0,042332679 & 118,70 & 0,038018946 \\
\hline jun-99 & 1693,99 & 0,032083737 & 120,77 & 0,017468031 \\
\hline jul-99 & 1818,63 & 0,073577766 & 129,44 & 0,071781893 \\
\hline ago-99 & 1876,93 & 0,032057098 & 134,44 & 0,03863614 \\
\hline sep-99 & 1975,64 & 0,052591199 & 141,40 & 0,051731857 \\
\hline oct-99 & 1978,71 & 0,001553927 & 140,51 & $-0,006267927$ \\
\hline nov-99 & 1944,64 & $-0,017218289$ & 136,92 & $-0,025525935$ \\
\hline dic-99 & 1888,46 & $-0,028889666$ & 132,51 & $-0,03225301$ \\
\hline ene-00 & 1923,57 & 0,018591869 & 133,15 & 0,004889938 \\
\hline feb-00 & 1950,64 & 0,014072792 & 132,12 & $-0,007757106$ \\
\hline mar-00 & 1956,25 & 0,002875979 & 131,25 & $-0,006624552$ \\
\hline abr-00 & 1986,77 & 0,015601278 & 132,09 & 0,006407133 \\
\hline may-00 & 2055,69 & 0,034689471 & 134,84 & 0,020813321 \\
\hline jun-00 & 2120,17 & 0,031366597 & 140,80 & 0,044195987 \\
\hline jul-00 & 2161,34 & 0,019418254 & 143,86 & 0,021749389 \\
\hline ago-00 & 2187,38 & 0,012048081 & 144,52 & 0,004630329 \\
\hline sep-00 & 2213,76 & 0,01206009 & 145,60 & 0,007460929 \\
\hline oct-00 & 2176,61 & $-0,016781404$ & 142,82 & $-0,019120143$ \\
\hline nov-00 & 2136,63 & $-0,018368013$ & 139,63 & $-0,022353607$ \\
\hline dic-00 & 2186,21 & 0,023204766 & 143,14 & 0,025176389 \\
\hline ene-01 & 2241,4 & 0,025244601 & 146,58 & 0,024017216 \\
\hline feb-01 & 2243,42 & 0,000901222 & 144,02 & $-0,017461423$ \\
\hline mar-01 & 2278,78 & 0,01576165 & 143,60 & $-0,002884583$ \\
\hline$a b r-01$ & 2323,1 & 0,019449003 & 144,76 & 0,008079775 \\
\hline may-01 & 2346,93 & 0,010257845 & 145,71 & 0,006514671 \\
\hline jun-01 & 2305,66 & $-0,017584674$ & 142,61 & $-0,021280994$ \\
\hline jul-01 & 2304,28 & $-0,000598527$ & 141,94 & $-0,004681941$ \\
\hline ago-01 & 2288,9 & $-0,006674536$ & 141,73 & $-0,001461032$ \\
\hline sep-01 & 2328,23 & 0,017182926 & 144,13 & 0,016923469 \\
\hline
\end{tabular}




\begin{tabular}{|c|c|c|c|c|}
\hline oct-01 & 2320,65 & $-0,003255692$ & 142,84 & $-0,008918412$ \\
\hline nov-01 & 2310,47 & $-0,004386702$ & 142,24 & $-0,00422878$ \\
\hline dic-01 & 2306,9 & $-0,00154514$ & 141,95 & $-0,002045828$ \\
\hline ene-02 & 2274,96 & $-0,01384542$ & 138,28 & $-0,025824487$ \\
\hline feb-02 & 2286,7 & 0,00516053 & 134,31 & $-0,028770543$ \\
\hline mar-02 & 2282,33 & $-0,001911051$ & 134,07 & $-0,001748032$ \\
\hline abr-02 & 2263,11 & $-0,008421219$ & 133,60 & $-0,003473659$ \\
\hline may-02 & 2310,24 & 0,020825324 & 134,27 & 0,0049675 \\
\hline jun-02 & 2364,25 & 0,023378523 & 134,28 & 0,00012118 \\
\hline jul-02 & 2506,72 & 0,060260125 & 142,73 & 0,062900741 \\
\hline ago-02 & 2647,22 & 0,056049339 & 149,74 & 0,049099537 \\
\hline sep-02 & 2751,23 & 0,039290274 & 154,63 & 0,032686286 \\
\hline oct-02 & 2827,86 & 0,027852997 & 158,11 & 0,022486369 \\
\hline nov-02 & 2726,66 & $-0,035786779$ & 153,88 & $-0,026760828$ \\
\hline dic-02 & 2814,89 & 0,03235827 & 159,59 & 0,037139065 \\
\hline ene-03 & 2913 & 0,034853937 & 162,09 & 0,015662387 \\
\hline feb-03 & 2951,86 & 0,013340199 & 164,76 & 0,016414228 \\
\hline mar-03 & 2959,01 & 0,002422202 & 165,37 & 0,003749202 \\
\hline abr-03 & 2926,62 & $-0,010946229$ & 163,20 & $-0,013164858$ \\
\hline may-03 & 2858,94 & $-0,023125653$ & 161,39 & $-0,011077741$ \\
\hline jun-03 & 2826,95 & $-0,011189462$ & 159,96 & $-0,008820548$ \\
\hline jul-03 & 2858,82 & 0,011273634 & 161,78 & 0,011375494 \\
\hline ago-03 & 2867,29 & 0,002962761 & 160,98 & $-0,004980603$ \\
\hline sep-03 & 2840,08 & $-0,009489797$ & 160,51 & $-0,002895554$ \\
\hline oct-03 & 2876,2 & 0,012717952 & 164,40 & 0,024193685 \\
\hline nov-03 & 2844,55 & $-0,011004103$ & 162,22 & $-0,013223822$ \\
\hline dic-03 & 2807,2 & $-0,013130372$ & 160,50 & $-0,010612928$ \\
\hline ene-04 & 2749,14 & $-0,020682531$ & 157,81 & $-0,016743679$ \\
\hline feb-04 & 2717,94 & $-0,011349004$ & 153,33 & $-0,028426375$ \\
\hline mar-04 & 2670,8 & $-0,017344018$ & 148,72 & $-0,030043263$ \\
\hline abr-04 & 2639,6 & $-0,011681893$ & 146,16 & $-0,01718678$ \\
\hline may-04 & 2719,43 & 0,030243219 & 149,66 & 0,023908458 \\
\hline jun-04 & 2716,56 & $-0,001055368$ & 149,51 & $-0,001017778$ \\
\hline jul-04 & 2653,32 & $-0,023279442$ & 146,42 & $-0,02061892$ \\
\hline ago-04 & 2598,59 & $-0,020626988$ & 143,47 & $-0,020166081$ \\
\hline sep-04 & 2552,78 & $-0,017628791$ & 141,04 & $-0,016916294$ \\
\hline oct-04 & 2580,7 & 0,010937096 & 144,03 & 0,021205351 \\
\hline nov-04 & 2530,19 & $-0,019572209$ & 142,77 & $-0,00876751$ \\
\hline dic-04 & 2411,37 & $-0,0469609$ & 136,79 & $-0,041911495$ \\
\hline ene-05 & 2362,96 & $-0,020075725$ & 132,82 & $-0,02899907$ \\
\hline feb-05 & 2340,49 & $-0,00950926$ & 130,89 & $-0,014528978$ \\
\hline
\end{tabular}




\begin{tabular}{|c|c|c|c|c|}
\hline mar-05 & 2353,71 & 0,00564839 & 130,21 & $-0,005194121$ \\
\hline abr-05 & 2350,01 & $-0,001571986$ & 129,77 & $-0,00341135$ \\
\hline may-05 & 2339,22 & $-0,00459147$ & 128,94 & $-0,006403049$ \\
\hline jun-05 & 2331,79 & $-0,003176272$ & 127,43 & $-0,01169517$ \\
\hline jul-05 & 2323,38 & $-0,003606671$ & 127,33 & $-0,000740924$ \\
\hline ago-05 & 2306,19 & $-0,007398704$ & 127,61 & 0,002202066 \\
\hline sep-05 & 2294,52 & $-0,005060294$ & 127,53 & $-0,000668078$ \\
\hline oct- 05 & 2292,55 & $-0,000858567$ & 126,95 & $-0,004507926$ \\
\hline nov-05 & 2279,85 & $-0,005539683$ & 125,70 & $-0,009887427$ \\
\hline dic-05 & 2278,91 & $-0,000412308$ & 125,65 & $-0,000354875$ \\
\hline ene-06 & 2273,66 & $-0,002303733$ & 125,94 & 0,002263334 \\
\hline feb-06 & 2256,24 & $-0,007661656$ & 124,47 & $-0,011691744$ \\
\hline mar-06 & 2262,36 & 0,002712477 & 124,39 & $-0,00059565$ \\
\hline abr-06 & 2334,29 & 0,031794233 & 128,98 & 0,036874169 \\
\hline may-06 & 2417,99 & 0,035856727 & 134,57 & 0,043312208 \\
\hline jun-06 & 2542,24 & 0,051385655 & 140,54 & 0,044417897 \\
\hline jul-06 & 2511,74 & $-0,011997294$ & 139,42 & $-0,008020068$ \\
\hline ago-06 & 2389,65 & $-0,048607738$ & 132,85 & $-0,047069938$ \\
\hline sep-06 & 2398,88 & 0,00386249 & 132,71 & $-0,001098059$ \\
\hline oct-06 & 2364,29 & $-0,014419229$ & 130,81 & $-0,014307291$ \\
\hline nov-06 & 2290,46 & $-0,031227134$ & 127,12 & $-0,028232734$ \\
\hline dic-06 & 2261,335263 & $-0,012715671$ & 126,21 & $-0,007100994$ \\
\hline ene-07 & 2237,06 & $-0,010734924$ & 123,74 & $-0,019620503$ \\
\hline feb-07 & 2227,63 & $-0,004215354$ & 122,43 & $-0,01058283$ \\
\hline mar-07 & 2201,39 & $-0,011779335$ & 120,32 & $-0,017203318$ \\
\hline abr-07 & 2144,6 & $-0,025797337$ & 117,49 & $-0,023527188$ \\
\hline may-07 & 2007,91 & $-0,063736827$ & 110,50 & $-0,059499722$ \\
\hline jun-07 & 1923,76 & $-0,041909249$ & 106,12 & $-0,039657866$ \\
\hline jul-07 & 1950,87 & 0,014092194 & 108,39 & 0,021404498 \\
\hline ago-07 & 2058,28 & 0,055057487 & 114,19 & 0,053552514 \\
\hline sep-07 & 2117,05 & 0,028552967 & 118,53 & 0,037983224 \\
\hline oct- 07 & 2003,26 & $-0,053749321$ & 114,01 & $-0,038178277$ \\
\hline nov-07 & 2047,72 & 0,022193824 & 118,15 & 0,036328394 \\
\hline dic-07 & 2014,2015 & $-0,016368693$ & 116,15 & $-0,01686616$ \\
\hline ene-08 & 1980,59 & $-0,016687258$ & 114,50 & 0,014239033 \\
\hline feb-08 & 1903,27 & $-0,039038872$ & 109,61 & $-0,042744685$ \\
\hline mar-08 & 1846,9 & $-0,029617448$ & 104,96 & $-0,042419033$ \\
\hline abr-08 & 1796,13 & $-0,027489306$ & 103,24 & $-0,016391888$ \\
\hline may-08 & 1778,01 & $-0,010088357$ & 102,26 & $-0,009468606$ \\
\hline jun-08 & 1712,28 & $-0,036968296$ & 98,59 & $-0,035840978$ \\
\hline jul-08 & 1783,09 & 0,041354218 & 103,43 & 0,049072215 \\
\hline
\end{tabular}




\begin{tabular}{|c|c|c|c|c|}
\hline ago-08 & 1844,29 & 0,03432244 & 105,44 & 0,019433415 \\
\hline sep-08 & 2066,04 & 0,120235972 & 115,73 & 0,097545893 \\
\hline oct-08 & 2289,17 & 0,107998877 & 122,28 & 0,056592448 \\
\hline nov-08 & 2329,16 & 0,017469214 & 121,90 & $-0,003084606$ \\
\hline dic-08 & 2252,72 & $-0,032818699$ & 117,66 & $-0,034760273$ \\
\hline ene-09 & 2252,98 & 0,000115416 & 115,80 & $-0,015823997$ \\
\hline feb-09 & 2513,74 & 0,115740042 & 126,80 & 0,094959959 \\
\hline mar-09 & 2477,21 & $-0,014532131$ & 124,73 & $-0,01633883$ \\
\hline abr-09 & 2379,36 & $-0,039500083$ & 121,66 & $-0,024562$ \\
\hline may-09 & 2229,95 & $-0,062794197$ & 116,09 & $-0,045828057$ \\
\hline jun-09 & 2090,04 & $-0,062741317$ & 110,31 & $-0,049727099$ \\
\hline jul-09 & 2052,68 & $-0,017875256$ & 108,61 & $-0,015416687$ \\
\hline ago-09 & 2018,97 & $-0,016422433$ & 108,07 & $-0,005004723$ \\
\hline sep-09 & 1980,77 & $-0,018920539$ & 107,43 & $-0,00589648$ \\
\hline oct-09 & 1904,86 & $-0,03832348$ & 104,19 & $-0,030206847$ \\
\hline nov-09 & 1973,57 & 0,036070892 & 108,52 & 0,041632163 \\
\hline dic-09 & 2017,05 & 0,022031142 & 109,74 & 0,011155494 \\
\hline ene-10 & 1978,19 & $-0,019265759$ & 105,70 & $-0,036771448$ \\
\hline feb-10 & 1952,89 & $-0,012789469$ & 101,95 & $-0,035478058$ \\
\hline mar-10 & 1909,1 & $-0,022423178$ & 100,19 & $-0,017276167$ \\
\hline$a b r-10$ & 1940,36 & 0,016374208 & 101,98 & 0,017928574 \\
\hline may-10 & 1984,36 & 0,022676204 & 102,54 & 0,005469937 \\
\hline jun-10 & 1925,9 & $-0,02946038$ & 99,09 & $-0,033683472$ \\
\hline jul-10 & 1874,52 & $-0,026678436$ & 97,75 & $-0,013498441$ \\
\hline ago-10 & 1819,06 & $-0,029586241$ & 95,23 & $-0,025760127$ \\
\hline sep-10 & 1805,6 & $-0,007399426$ & 95,39 & 0,001685097 \\
\hline oct-10 & 1808,46 & 0,001583961 & 97,48 & 0,02184114 \\
\hline nov-10 & 1863,67 & 0,030528737 & 100,33 & 0,029313541 \\
\hline dic-10 & 1925,86 & 0,033369642 & 102,91 & 0,025696048 \\
\hline ene-11 & 1866,64 & $-0,030749899$ & 99,75 & $-0,03074086$ \\
\hline feb-11 & 1882,61 & 0,008555479 & 100,90 & 0,011544327 \\
\hline mar-11 & 1884,38 & 0,000940184 & 101,97 & 0,010554596 \\
\hline$a b r-11$ & 1812,77 & $-0,038001889$ & 99,41 & $-0,025032433$ \\
\hline may-11 & 1801,65 & $-0,006134259$ & 98,95 & $-0,004695083$ \\
\hline jun-11 & 1782,54 & $-0,010606944$ & 97,75 & $-0,012109084$ \\
\hline jul-11 & 1761,75 & $-0,011663132$ & 97,14 & $-0,006175564$ \\
\hline ago-11 & 1785,04 & 0,01321981 & 98,36 & 0,012502069 \\
\hline sep-11 & 1836,15 & 0,028632412 & 99,19 & 0,008407312 \\
\hline oct-11 & 1910,38 & 0,04042698 & 102,65 & 0,034873945 \\
\hline nov-11 & 1918,21 & 0,004098661 & 102,80 & 0,001507279 \\
\hline dic-11 & 1934,08 & 0,008273338 & 102,62 & $-0,001796536$ \\
\hline
\end{tabular}




\begin{tabular}{|l|l|l|l|r|} 
ene-12 & 1852,12 & $-0,042376737$ & 98,32 & $-0,041860402$ \\
\hline feb-12 & 1783,56 & $-0,03701704$ & 95,45 & $-0,02921949$ \\
\hline mar-12 & 1766,34 & $-0,009654848$ & 94,78 & 0,007032011 \\
\hline abr-12 & 1775,06 & 0,004936762 & 95,10 & 0,003389349 \\
\hline may-12 & 1793,28 & 0,010264442 & 94,62 & $-0,005031948$ \\
\hline jun-12 & 1792,63 & $-0,000362464$ & 93,69 & $-0,009772553$ \\
\hline jul-12 & 1784,43 & $-0,004574285$ & 93,69 & $1,28979 \mathrm{E}-05$ \\
\hline ago-12 & 1806,34 & 0,012278431 & 95,48 & 0,019004372 \\
\hline sep-12 & 1803,18 & $-0,001749394$ & 96,15 & 0,007048905 \\
\hline oct-12 & 1804,97 & 0,000992691 & 96,59 & 0,004631881 \\
\hline nov-12 & 1820,29 & 0,008487676 & 97,10 & 0,005244713 \\
\hline dic-12 & 1793,94 & $-0,014475715$ & 96,08 & $-0,010478021$ \\
\hline ene-13 & 1770,01 & $-0,013339354$ & 95,12 & $-0,010069819$ \\
\hline feb-13 & 1791,48 & 0,012129875 & 95,55 & 0,004610134 \\
\hline mar-13 & 1809,89 & 0,010276419 & 96,03 & 0,004963606 \\
\hline abr-13 & 1829,96 & 0,011089072 & 97,23 & 0,012512301 \\
\hline may-13 & 1850,12 & 0,011016634 & 97,86 & 0,006450559 \\
\hline jun-13 & 1909,5 & 0,032095215 & 100,36 & 0,02562357 \\
\hline jul-13 & 1900,59 & $-0,004666143$ & 99,89 & $-0,00470481$ \\
\hline ago-13 & 1903,66 & 0,001615288 & 99,99 & 0,000995018 \\
\hline sep-13 & 1919,4 & 0,008268283 & 100,68 & 0,006846696 \\
\hline oct-13 & 1885,91 & $-0,017448161$ & 99,92 & $-0,007481913$ \\
\hline nov-13 & 1922,14 & 0,019210885 & 101,52 & 0,015936742 \\
\hline dic-13 & 1934,08 & 0,006211826 & 102,12 & 0,005970104 \\
\hline
\end{tabular}

Fuente: Elaboración propia 
Anexo G. Promedio mensual de la Tasa Representativa del Mercado de 1999 a 2013, deflactado Con ITCRIP IPC del Año 2009 y Promedio mensual de la Tasa Representativa del Mercado de 1999 a 2013 deflactado con el ITCRIP IPC de 1999.

\begin{tabular}{|c|c|c|c|c|}
\hline FECHA & $\begin{array}{c}\text { Promedio mensual } \\
\text { de la Tasa } \\
\text { Representativa del } \\
\text { Mercado de 1999 a } \\
\text { 2013: DEFLACTADO } \\
\text { CON el ITCRIP IPC } \\
\text { DEL AÑO } 2009\end{array}$ & Variación & $\begin{array}{l}\text { Promedio mensual de la } \\
\text { Tasa Representativa del } \\
\text { Mercado de } 1999 \text { a } 2013 \text { : } \\
\text { DEFLACTADO CON el } \\
\text { ITCRIP IPC de } 1999\end{array}$ & Variación \\
\hline ene-99 & 2329,193267 & & 1315,078202 & \\
\hline feb-99 & 2328,750524 & $-0,000190084$ & 1357,018432 & 0,031891815 \\
\hline mar-99 & 2201,198703 & $-0,054772643$ & 1387,51186 & 0,022470901 \\
\hline abr-99 & 2170,461347 & $-0,013963917$ & 1377,065014 & $-0,007529194$ \\
\hline may-99 & 2214,30053 & 0,020198094 & 1382,787734 & 0,004155737 \\
\hline jun-99 & 2102,088134 & $-0,050676227$ & 1402,651177 & 0,014364782 \\
\hline jul-99 & 2169,171583 & 0,031912767 & 1405,001453 & 0,001675595 \\
\hline ago-99 & 2142,161982 & $-0,012451574$ & 1396,10174 & $-0,006334309$ \\
\hline sep-99 & 2267,190586 & 0,058365616 & 1397,242457 & 0,000817073 \\
\hline oct-99 & 2311,995856 & 0,019762463 & 1408,240419 & 0,00787119 \\
\hline nov-99 & 2328,067174 & 0,006951275 & 1420,246037 & 0,008525262 \\
\hline dic-99 & 2242,016678 & $-0,036962205$ & 1425,182013 & 0,003475437 \\
\hline ene-00 & 2270,593232 & 0,012745915 & 1444,614733 & 0,013635255 \\
\hline feb-00 & 2268,004513 & $-0,001140107$ & 1476,397064 & 0,022000558 \\
\hline mar-00 & 2238,636756 & $-0,012948721$ & 1490,517159 & 0,009563887 \\
\hline$a b r-00$ & 2207,044082 & $-0,014112461$ & 1504,133945 & 0,009135612 \\
\hline may-00 & 2157,621777 & $-0,022392985$ & 1524,579982 & 0,013593229 \\
\hline jun-00 & 2205,022117 & 0,02196879 & 1505,848412 & $-0,012286381$ \\
\hline jul-00 & 2242,596043 & 0,017040159 & 1502,412799 & $-0,002281513$ \\
\hline ago-00 & 2236,29516 & $-0,002809638$ & 1513,505961 & 0,007383564 \\
\hline sep-00 & 2296,896999 & 0,027099213 & 1520,415268 & 0,004565101 \\
\hline oct-00 & 2304,493747 & 0,003307396 & 1524,040437 & 0,002384328 \\
\hline nov-00 & 2197,651081 & $-0,046362749$ & 1530,253528 & 0,004076723 \\
\hline dic-00 & 2200,138791 & 0,001131986 & 1527,310539 & $-0,001923204$ \\
\hline ene-01 & 2293,01938 & 0,042215786 & 1529,141171 & 0,001198598 \\
\hline feb-01 & 2259,497708 & $-0,01461901$ & 1557,719262 & 0,018688981 \\
\hline mar-01 & 2234,922331 & $-0,010876478$ & 1586,848884 & 0,018700174 \\
\hline abr-01 & 2238,397577 & 0,001554974 & 1604,74553 & 0,011278104 \\
\hline may-01 & 2301,968171 & 0,028400046 & 1610,713494 & 0,003718947 \\
\hline jun-01 & 2263,577938 & $-0,016677134$ & 1616,796661 & 0,003776691 \\
\hline jul-01 & 2256,276492 & $-0,003225622$ & 1623,429767 & 0,004102622 \\
\hline ago-01 & 2215,486286 & $-0,018078549$ & 1614,953625 & $-0,005221132$ \\
\hline sep-01 & 2273,253813 & 0,026074423 & 1615,365664 & 0,000255139 \\
\hline
\end{tabular}




\begin{tabular}{|c|c|c|c|c|}
\hline oct-01 & 2262,547817 & $-0,004709547$ & 1624,59534 & 0,005713676 \\
\hline nov-01 & 2257,598658 & $-0,002187427$ & 1624,337691 & $-0,000158593$ \\
\hline dic-01 & 2312,704406 & 0,02440901 & 1625,152644 & 0,000501714 \\
\hline ene-02 & 2319,719593 & 0,003033326 & 1645,136531 & 0,012296621 \\
\hline feb-02 & 2256,925177 & $-0,027069831$ & 1702,611361 & 0,034936207 \\
\hline mar-02 & 2260,833363 & 0,001731642 & 1702,333317 & $-0,000163305$ \\
\hline abr-02 & 2241,843642 & $-0,008399434$ & 1693,881562 & $-0,004964806$ \\
\hline may-02 & 2252,707018 & 0,004845733 & 1720,610064 & 0,01577944 \\
\hline jun-02 & 2119,652299 & $-0,059064369$ & 1760,622036 & 0,023254526 \\
\hline jul-02 & 2147,536931 & 0,013155286 & 1756,248036 & $-0,002484349$ \\
\hline ago-02 & 2181,669332 & 0,015893743 & 1767,882372 & 0,00662454 \\
\hline sep-02 & 2203,432798 & 0,009975603 & 1779,18791 & 0,006394961 \\
\hline oct-02 & 2314,929429 & 0,05060133 & 1788,526166 & 0,005248606 \\
\hline nov-02 & 2172,302709 & $-0,061611692$ & 1771,939134 & $-0,009274134$ \\
\hline dic-02 & 2218,237112 & 0,021145489 & 1763,771206 & $-0,004609599$ \\
\hline ene-03 & 2216,596282 & $-0,0007397$ & 1797,098722 & 0,0188956 \\
\hline feb-03 & 2244,564674 & 0,01261772 & 1791,663601 & $-0,003024386$ \\
\hline mar-03 & 2283,035842 & 0,017139701 & 1789,294944 & $-0,001322044$ \\
\hline abr-03 & 2278,217504 & $-0,002110496$ & 1793,317684 & 0,002248227 \\
\hline may-03 & 2273,029366 & $-0,002277279$ & 1771,469926 & $-0,012182871$ \\
\hline jun-03 & 2227,6395 & $-0,019968886$ & 1767,236123 & $-0,002389994$ \\
\hline jul-03 & 2264,257368 & 0,016437968 & 1767,058137 & $-0,000100714$ \\
\hline ago-03 & 2259,52257 & $-0,002091104$ & 1781,164783 & 0,007983125 \\
\hline sep-03 & 2199,759707 & $-0,026449332$ & 1769,385242 & $-0,006613392$ \\
\hline oct-03 & 2283,172264 & 0,03791894 & 1749,559897 & $-0,011204651$ \\
\hline nov-03 & 2277,1472 & $-0,0026389$ & 1753,495473 & 0,002249466 \\
\hline dic-03 & 2291,345556 & 0,006235151 & 1749,033795 & $-0,002544448$ \\
\hline ene-04 & 2318,897861 & 0,012024509 & 1742,027297 & $-0,004005925$ \\
\hline feb-04 & 2322,763391 & 0,001666968 & 1772,646951 & 0,017577023 \\
\hline mar-04 & 2292,378608 & $-0,013081308$ & 1795,855488 & 0,013092589 \\
\hline abr-04 & 2200,372486 & $-0,040135657$ & 1805,91435 & 0,005601153 \\
\hline may-04 & 2255,27537 & 0,024951632 & 1817,087258 & 0,006186843 \\
\hline jun-04 & 2300,412011 & 0,020013805 & 1817,018884 & -3,76282E-05 \\
\hline jul-04 & 2299,348855 & $-0,000462159$ & 1812,082891 & $-0,002716534$ \\
\hline ago-04 & 2291,747881 & $-0,003305707$ & 1811,230499 & $-0,000470393$ \\
\hline sep-04 & 2206,196823 & $-0,037330048$ & 1809,917797 & $-0,000724757$ \\
\hline oct-04 & 2272,907741 & 0,030237972 & 1791,719012 & $-0,010055034$ \\
\hline nov-04 & 2351,536406 & 0,034593865 & 1772,188795 & $-0,010900267$ \\
\hline dic-04 & 2320,265542 & $-0,013298056$ & 1762,848844 & $-0,005270291$ \\
\hline ene-05 & 2286,196094 & $-0,014683426$ & 1779,049146 & 0,009189842 \\
\hline feb-05 & 2264,74335 & $-0,009383597$ & 1788,111134 & 0,005093725 \\
\hline
\end{tabular}




\begin{tabular}{|c|c|c|c|c|}
\hline mar-05 & 2260,692011 & $-0,001788873$ & | 1807,599975 & 0,010899122 \\
\hline abr-05 & 2267,498906 & 0,003010978 & 1810,93619 & 0,00184566 \\
\hline may-05 & 2279,640786 & 0,005354746 & 1814,237985 & 0,001823253 \\
\hline jun-05 & 2254,650524 & $-0,010962368$ & 1829,876184 & 0,008619706 \\
\hline jul-05 & 2248,029691 & $-0,002936523$ & 1824,628332 & $-0,002867873$ \\
\hline ago-05 & 2254,486172 & 0,002872062 & 1807,148987 & $-0,009579674$ \\
\hline sep-05 & 2263,182258 & 0,003857236 & 1799,206291 & $-0,004395153$ \\
\hline oct-05 & 2275,478628 & 0,005433221 & 1805,801973 & 0,003665884 \\
\hline nov-05 & 2253,779809 & $-0,009535936$ & 1813,731541 & 0,004391161 \\
\hline dic-05 & 2247,892269 & $-0,002612296$ & 1813,627335 & $-5,74537 \mathrm{E}-05$ \\
\hline ene-06 & 2279,632884 & 0,014120167 & 1805,363083 & $-0,004556753$ \\
\hline feb-06 & 2254,322787 & $-0,011102708$ & 1812,724928 & 0,004077765 \\
\hline mar-06 & 2172,857678 & $-0,036137287$ & 1818,725227 & 0,003310099 \\
\hline$a b r-06$ & 2159,449474 & $-0,006170769$ & 1809,814783 & $-0,00489928$ \\
\hline may-06 & 2157,16334 & $-0,001058665$ & 1796,881895 & $-0,007145973$ \\
\hline jun-06 & 2271,19514 & 0,052861922 & 1808,869661 & 0,006671427 \\
\hline jul-06 & 2364,265848 & 0,040978737 & 1801,617214 & $-0,004009381$ \\
\hline ago-06 & 2255,456624 & $-0,046022415$ & 1798,709837 & $-0,001613759$ \\
\hline sep-06 & 2285,681916 & 0,013400964 & 1807,642234 & 0,004966002 \\
\hline oct-06 & 2318,435781 & 0,014330019 & 1807,436953 & $-0,000113563$ \\
\hline nov-06 & 2269,092814 & $-0,02128287$ & 1801,867524 & $-0,003081396$ \\
\hline dic-06 & 2298,069276 & 0,012770065 & 1791,678265 & $-0,005654833$ \\
\hline ene-07 & 2277,077928 & $-0,009134341$ & 1807,916975 & 0,009063407 \\
\hline feb-07 & 2292,417181 & 0,006736376 & 1819,551973 & 0,006435582 \\
\hline mar-07 & 2307,26342 & 0,006476238 & 1829,593947 & 0,005518927 \\
\hline$a b r-07$ & 2395,512316 & 0,038248297 & 1825,340422 & $-0,002324846$ \\
\hline may-07 & 2346,01807 & $-0,020661237$ & 1817,116969 & $-0,004505161$ \\
\hline jun-07 & 2205,766671 & $-0,059782744$ & 1812,857002 & $-0,002344355$ \\
\hline jul-07 & 2138,460086 & $-0,030513919$ & 1799,878636 & $-0,007159068$ \\
\hline ago-07 & 2170,536044 & 0,014999559 & 1802,449717 & 0,001428475 \\
\hline sep-07 & 2342,409144 & 0,079184633 & 1786,074149 & $-0,009085173$ \\
\hline oct- 07 & 2174,001999 & $-0,071894846$ & 1757,159185 & $-0,016189117$ \\
\hline nov-07 & 2291,631015 & 0,054107133 & 1733,193144 & $-0,013639084$ \\
\hline dic-07 & 2285,523646 & $-0,002665075$ & 1734,070142 & 0,000506001 \\
\hline ene-08 & 2353,583171 & 0,029778526 & 1729,763425 & $-0,002483589$ \\
\hline feb-08 & 2352,782769 & $-0,000340078$ & 1736,459841 & 0,00387129 \\
\hline mar-08 & 2290,526046 & $-0,026460889$ & 1759,674 & 0,013368671 \\
\hline abr-08 & 2274,516501 & $-0,006989462$ & 1739,820729 & $-0,011282358$ \\
\hline may-08 & 2336,730714 & 0,02735272 & 1738,732167 & $-0,000625675$ \\
\hline jun-08 & 2147,592862 & $-0,080941228$ & 1736,699199 & $-0,001169224$ \\
\hline jul-08 & 2210,031541 & 0,029073797 & 1723,922348 & $-0,007356974$ \\
\hline
\end{tabular}




\begin{tabular}{|c|c|c|c|c|}
\hline ago-08 & 2052,743321 & $-0,071170125$ & 1749,100573 & 0,014605197 \\
\hline sep-08 & 2132,307498 & 0,038759925 & 1785,260547 & 0,020673467 \\
\hline oct-08 & 2259,951059 & 0,059861704 & 1872,118889 & 0,048653034 \\
\hline nov-08 & 2334,114455 & 0,032816373 & 1910,717144 & 0,020617416 \\
\hline dic-08 & 2289,204363 & $-0,019240741$ & 1914,56054 & 0,002011494 \\
\hline ene-09 & 2252,98 & $-0,015823997$ & 1945,568176 & 0,016195694 \\
\hline feb-09 & 2466,922889 & 0,094959959 & 1982,49105 & 0,018977939 \\
\hline mar-09 & 2216,168943 & $-0,101646446$ & 1986,132307 & 0,001836708 \\
\hline abr-09 & 2197,642305 & $-0,008359759$ & 1955,716219 & $-0,015314231$ \\
\hline may-09 & 2149,730304 & $-0,021801546$ & 1920,941611 & $-0,017781009$ \\
\hline jun-09 & 2140,945841 & $-0,00408631$ & 1894,633849 & $-0,013695243$ \\
\hline jul-09 & 2218,246513 & 0,036105851 & 1889,902824 & $-0,002497066$ \\
\hline ago-09 & 2241,70446 & 0,010574995 & 1868,215924 & $-0,01147514$ \\
\hline sep-09 & 2239,695348 & $-0,000896243$ & 1843,739848 & $-0,01310131$ \\
\hline oct-09 & 2184,924578 & $-0,024454563$ & 1828,308763 & $-0,008369448$ \\
\hline nov-09 & 2346,77643 & 0,074076631 & 1818,547429 & $-0,005338996$ \\
\hline dic-09 & 2278,113104 & $-0,029258571$ & 1838,107113 & 0,010755663 \\
\hline ene-10 & 2170,134663 & $-0,047398192$ & 1871,51282 & 0,018173972 \\
\hline feb-10 & 2173,048644 & 0,001342765 & 1915,536687 & 0,023523145 \\
\hline mar-10 & 2214,057142 & 0,018871413 & 1905,504073 & $-0,005237495$ \\
\hline$a b r-10$ & 2293,37272 & 0,035823636 & 1902,594388 & $-0,00152699$ \\
\hline may-10 & 2265,303659 & $-0,012239206$ & 1935,152843 & 0,017112662 \\
\hline jun-10 & 2177,091811 & $-0,038940408$ & 1943,610038 & 0,004370299 \\
\hline jul-10 & 2222,568282 & 0,020888632 & 1917,64275 & $-0,013360338$ \\
\hline ago-10 & 2194,942949 & $-0,012429464$ & 1910,111628 & $-0,003927281$ \\
\hline sep-10 & 2256,776489 & 0,02817091 & 1892,788367 & $-0,00906924$ \\
\hline oct- 10 & 2302,187651 & 0,020122135 & 1855,26536 & $-0,019824196$ \\
\hline nov-10 & 2319,022821 & 0,007312684 & 1857,455667 & 0,001180589 \\
\hline dic-10 & 2310,872683 & $-0,003514471$ & 1871,351947 & 0,007481352 \\
\hline ene-11 & 2183,721458 & $-0,055023033$ & 1871,334495 & $-9,32591 \mathrm{E}-06$ \\
\hline feb-11 & 2278,989137 & 0,043626296 & 1865,805194 & $-0,002954737$ \\
\hline mar-11 & 2276,759293 & $-0,000978436$ & 1848,053932 & $-0,009513995$ \\
\hline$a b r-11$ & 2196,582428 & $-0,035215346$ & 1823,47029 & $-0,013302448$ \\
\hline may-11 & 2242,402072 & 0,020859515 & 1820,833616 & $-0,001445965$ \\
\hline jun-11 & 2225,698476 & $-0,007448975$ & 1823,60229 & 0,001520553 \\
\hline jul-11 & 2239,066577 & 0,00600625 & 1813,532965 & $-0,005521668$ \\
\hline ago-11 & 2281,146912 & 0,018793695 & 1814,818539 & 0,000708878 \\
\hline sep-11 & 2271,921505 & $-0,004044196$ & 1851,217408 & 0,020056479 \\
\hline oct-11 & 2331,550301 & 0,026245975 & 1861,150865 & 0,005365905 \\
\hline nov-11 & 2256,375868 & $-0,032242252$ & 1865,96656 & 0,002587482 \\
\hline dic-11 & 2248,932441 & $-0,003298842$ & 1884,790425 & 0,010087997 \\
\hline
\end{tabular}




\begin{tabular}{|l|l|l|l|l|} 
ene-12 & 2158,669352 & $-0,040135972$ & 1883,774723 & $-0,000538894$ \\
\hline feb-12 & 2187,149074 & 0,013193184 & 1868,643777 & $-0,008032248$ \\
\hline mar-12 & 2237,137019 & 0,022855299 & 1863,707922 & $-0,002641411$ \\
\hline abr-12 & 2260,616136 & 0,010495163 & 1866,582105 & 0,001542186 \\
\hline may-12 & 2241,643123 & $-0,008392851$ & 1895,27847 & 0,015373749 \\
\hline jun-12 & 2230,962633 & $-0,004764581$ & 1913,28922 & 0,009502957 \\
\hline jul-12 & 2253,009059 & 0,009882024 & 1904,512726 & $-0,004587123$ \\
\hline ago-12 & 2295,79647 & 0,018991229 & 1891,941985 & $-0,006600503$ \\
\hline sep-12 & 2268,861043 & $-0,011732498$ & 1875,412627 & $-0,008736715$ \\
\hline oct-12 & 2263,415536 & $-0,002400106$ & 1868,61911 & $-0,003622412$ \\
\hline nov-12 & 2264,796234 & 0,000610006 & 1874,647355 & 0,003226043 \\
\hline dic-12 & 2229,373227 & $-0,015640704$ & 1867,073732 & $-0,004040025$ \\
\hline ene-13 & 2230,2929 & 0,000412525 & 1860,907173 & $-0,003302793$ \\
\hline feb-13 & 2263,366541 & 0,014829281 & 1874,836496 & 0,007485233 \\
\hline mar-13 & 2264,162906 & 0,00035185 & 1884,747956 & 0,005286573 \\
\hline abr-13 & 2281,169964 & 0,007511411 & 1882,098676 & $-0,001405641$ \\
\hline may-13 & 2267,51298 & $-0,005986833$ & 1890,637401 & 0,00453681 \\
\hline jun-13 & 2310,709392 & 0,019050127 & 1902,56725 & 0,006309961 \\
\hline jul-13 & 2242,380156 & $-0,029570674$ & 1902,641165 & $3,88501 \mathrm{E}-05$ \\
\hline ago-13 & 2255,221756 & 0,005726772 & 1903,820142 & 0,000619653 \\
\hline sep-13 & 2268,405469 & 0,005845861 & 1906,508184 & 0,00141192 \\
\hline oct-13 & 2236,1234 & $-0,014231172$ & 1887,364218 & $-0,010041377$ \\
\hline nov-13 & 2288,885161 & 0,023595192 & 1893,446781 & 0,003222782 \\
\hline dic-13 & 2266,430524 & $-0,009810294$ & 1893,901754 & 0,000240288 \\
\hline
\end{tabular}

Fuente: Elaboración propia 
Anexo H. Precio Mensual por de libra café arábica suave, precio mensual por libra de café, arábica suave convertido a TRM de Colombia deflactado con el ITCRIP IPC de 1999. Precio Mensual por libra de café arábica suave convertido a TRM y deflactado con el ITCRIP IPC de 2009.

\begin{tabular}{|c|c|c|c|c|c|}
\hline FECHA & $\begin{array}{l}\text { Precio } \\
\text { Mensual - } \\
\text { centavos } \\
\text { de dólar } \\
\text { americano } \\
\text { por libra } \\
\text { Café, } \\
\text { arábica } \\
\text { suave }\end{array}$ & $\begin{array}{l}\text { Precio Mensual - } \\
\text { centavos de dólar } \\
\text { americano por } \\
\text { libra Café, } \\
\text { arábica suave } \\
\text { convertido a TRM } \\
\text { de Colombia } \\
\text { DEFLACTADO } \\
\text { CON el ITCRIP } \\
\text { IPC con el dólar } \\
\text { de dic-99-13 }\end{array}$ & Variación & $\begin{array}{l}\text { Precio Mensual - } \\
\text { centavos de dólar } \\
\text { americano por libra } \\
\text { Café, arábica suave } \\
\text { convertido a TRM de } \\
\text { Colombia } \\
\text { DEFLACTADO CON } \\
\text { el ITCRIP IPC DEL } \\
\text { AÑO } 2009\end{array}$ & Variación \\
\hline ene-99 & 111,48 & 1466,04918 & & 2596,584654 & \\
\hline feb-99 & 103,24 & 1400,98583 & $-0,04438006$ & 2404,202041 & $-0,074090638$ \\
\hline mar-99 & 103,23 & 1432,328493 & 0,022371863 & 2272,297421 & $-0,054864199$ \\
\hline abr-99 & 99,69 & 1372,796113 & $-0,041563357$ & 2163,732917 & $-0,047777418$ \\
\hline may-99 & 108,91 & 1505,994121 & 0,097026796 & 2411,594707 & 0,114552858 \\
\hline jun-99 & 104,21 & 1461,702792 & $-0,029410028$ & 2190,586044 & $-0,091644198$ \\
\hline jul-99 & 90,85 & 1276,44382 & $-0,126741888$ & 1970,692383 & $-0,100381203$ \\
\hline ago-99 & 87,64 & 1223,543565 & $-0,041443466$ & 1877,390761 & $-0,04734459$ \\
\hline sep-99 & 81,06 & 1132,604736 & $-0,074324145$ & 1837,784689 & $-0,021096339$ \\
\hline oct-99 & 92,2 & 1298,397666 & 0,146381985 & 2131,660179 & 0,159907465 \\
\hline nov-99 & 114,02 & 1619,364531 & 0,247202281 & 2654,462192 & 0,245255795 \\
\hline dic-99 & 123,56 & 1760,954895 & 0,087435757 & 2770,235807 & 0,043614716 \\
\hline ene-00 & 109,17 & 1577,085904 & $-0,104414367$ & 2478,806631 & $-0,105200133$ \\
\hline feb-00 & 101,65 & 1500,757615 & $-0,048398308$ & 2305,426588 & $-0,069944965$ \\
\hline mar-00 & 97,95 & 1459,961557 & $-0,027183642$ & 2192,744703 & $-0,048876805$ \\
\hline abr-00 & 92,56 & 1392,226379 & $-0,046395179$ & 2042,840002 & $-0,068363955$ \\
\hline may-00 & 91,76 & 1398,954592 & 0,0048327 & 1979,833742 & $-0,030842484$ \\
\hline jun-00 & 84,1 & 1266,418514 & $-0,09473937$ & 1854,4236 & $-0,063343774$ \\
\hline jul-00 & 84,67 & 1272,092917 & 0,004480669 & 1898,80607 & 0,023933296 \\
\hline ago-00 & 74,52 & 1127,864642 & $-0,113378727$ & 1666,487153 & $-0,122349997$ \\
\hline sep-00 & 73,83 & 1122,522592 & $-0,004736428$ & 1695,799055 & 0,017589035 \\
\hline oct- 00 & 75,37 & 1148,669277 & 0,023292792 & 1736,896937 & 0,024235113 \\
\hline nov-00 & \begin{tabular}{|l|}
70,47 \\
\end{tabular} & 1078,369661 & $-0,061200919$ & 1548,684717 & $-0,108361191$ \\
\hline dic- 00 & 64,5 & 985,1152978 & $-0,086477177$ & \begin{tabular}{|l|}
1419,08952 \\
\end{tabular} & $-0,083680813$ \\
\hline ene-01 & 64,98 & 993,635933 & 0,008649379 & 1490,003993 & 0,049971811 \\
\hline feb-01 & 66,94 & 1042,737274 & 0,049415826 & 1512,507766 & 0,015103162 \\
\hline mar-01 & 65,93 & 1046,209469 & 0,003329885 & 1473,484293 & $-0,025800511$ \\
\hline$a b r-01$ & 65,51 & 1051,268797 & 0,004835865 & 1466,374253 & $-0,004825324$ \\
\hline may-01 & 68,94 & 1110,425882 & 0,056272084 & 1586,976857 & 0,082245446 \\
\hline
\end{tabular}




\begin{tabular}{|c|c|c|c|c|c|}
\hline jun-01 & 63,67 & 1029,414434 & $-0,072955295$ & 1441,220073 & $-0,091845564$ \\
\hline jul-01 & 58,47 & 949,2193848 & $-0,07790356$ & 1319,244865 & $-0,084633298$ \\
\hline ago-01 & 59,68 & 963,8043236 & 0,015365193 & 1322,202216 & 0,0022417 \\
\hline sep-01 & 57,71 & 932,2275244 & $-0,032762666$ & 1311,894775 & $-0,007795661$ \\
\hline oct-01 & 56,53 & 918,3837458 & $-0,014850214$ & 1279,018281 & $-0,025060314$ \\
\hline nov-01 & 58,96 & 957,7095028 & 0,042820615 & 1331,080169 & 0,040704569 \\
\hline dic-01 & 55,6 & 903,5848702 & $-0,056514666$ & 1285,86365 & $-0,033969794$ \\
\hline ene-02 & 57,34 & 943,3212866 & 0,043976407 & 1330,127215 & 0,034423218 \\
\hline feb-02 & 60,51 & 1030,250135 & 0,092151899 & 1365,665424 & 0,026717903 \\
\hline mar-02 & 66,38 & 1130,008856 & 0,096829612 & 1500,741186 & 0,098908385 \\
\hline abr-02 & 65,78 & 1114,235291 & $-0,013958797$ & 1474,684747 & $-0,01736238$ \\
\hline may-02 & 58,43 & 1005,352461 & $-0,097719783$ & 1316,256711 & $-0,1074318$ \\
\hline jun-02 & 55,16 & 971,159115 & $-0,034011302$ & 1169,200208 & $-0,111723269$ \\
\hline jul-02 & 53,09 & 932,3920822 & $-0,039918312$ & 1140,127356 & $-0,024865589$ \\
\hline ago-02 & 52,02 & 919,6524097 & $-0,013663428$ & 1134,904386 & $-0,004581041$ \\
\hline sep-02 & 57,58 & 1024,456398 & 0,113960435 & 1268,736605 & 0,117923783 \\
\hline oct-02 & 64,05 & 1145,551009 & 0,118203772 & 1482,712299 & 0,168652574 \\
\hline nov-02 & 70,18 & 1243,546884 & 0,085544751 & 1524,522041 & 0,028198149 \\
\hline dic-02 & 63,86 & 1126,344292 & $-0,094248632$ & 1416,56622 & $-0,070812896$ \\
\hline ene-03 & 65,22 & 1172,067786 & 0,040594598 & 1445,664095 & 0,020541133 \\
\hline feb-03 & 67,6 & 1211,164594 & 0,033357122 & 1517,32572 & 0,049570038 \\
\hline mar-03 & 61,66 & 1103,279262 & $-0,089075698$ & 1407,7199 & $-0,072236184$ \\
\hline abr-03 & 65,32 & 1171,395111 & 0,061739445 & 1488,131673 & 0,057121998 \\
\hline may-03 & 66,18 & 1172,358797 & 0,000822682 & 1504,290834 & 0,01085869 \\
\hline jun-03 & 61,34 & 1084,022638 & $-0,075349082$ & 1366,43407 & $-0,091642362$ \\
\hline jul-03 & 62,29 & 1100,700514 & 0,015385173 & 1410,405915 & 0,032179998 \\
\hline ago-03 & 63,6 & 1132,820802 & 0,029181679 & 1437,056355 & 0,018895582 \\
\hline sep-03 & 65,51 & 1159,124272 & 0,023219445 & 1441,062584 & 0,002787802 \\
\hline oct-03 & 62,58 & 1094,874584 & $-0,055429508$ & 1428,809203 & $-0,008503018$ \\
\hline nov-03 & 62,36 & 1093,479777 & $-0,001273942$ & 1420,028994 & $-0,006145124$ \\
\hline dic-03 & 64,88 & 1134,773126 & 0,037763249 & 1486,624996 & 0,046897636 \\
\hline ene-04 & 73,73 & 1284,396726 & 0,131853316 & 1709,723393 & 0,150070392 \\
\hline feb-04 & 77,51 & 1373,978651 & 0,069746305 & 1800,373904 & 0,053020571 \\
\hline mar-04 & 77,47 & 1391,249247 & 0,01256977 & 1775,905708 & $-0,013590619$ \\
\hline abr-04 & 74,34 & 1342,516728 & $-0,035027885$ & 1635,756906 & $-0,078916803$ \\
\hline may-04 & 75,81 & 1377,53385 & 0,026083193 & 1709,724258 & 0,045219037 \\
\hline jun-04 & 82,16 & 1492,862715 & 0,083721257 & 1890,018508 & 0,105452238 \\
\hline jul-04 & 73,96 & 1340,216506 & $-0,102250667$ & 1700,598413 & $-0,100221291$ \\
\hline ago-04 & 73,17 & 1325,277356 & $-0,011146818$ & 1676,871924 & $-0,013951847$ \\
\hline sep-04 & 80,99 & 1465,852424 & 0,106072187 & 1786,798807 & 0,065554728 \\
\hline oct-04 & 79,81 & 1429,970943 & $-0,024478235$ & 1814,007668 & 0,015227714 \\
\hline
\end{tabular}




\begin{tabular}{|c|c|c|c|c|c|}
\hline nov-04 & 89,51 & 1586,286191 & 0,109313583 & 2104,860237 & 0,160337012 \\
\hline dic-04 & 102,57 & 1808,154059 & 0,13986623 & 2379,896366 & 0,13066717 \\
\hline ene-05 & 107,11 & \begin{tabular}{|l|}
1905,53954 \\
\end{tabular} & 0,053859062 & 2448,744636 & 0,028929104 \\
\hline feb-05 & 122,23 & 2185,608239 & 0,146976062 & 2768,195797 & 0,130455074 \\
\hline mar-05 & 134,69 & 2434,656407 & 0,113949135 & 3044,92607 & 0,099967738 \\
\hline$a b r-05$ & 128,79 & 2332,304719 & $-0,042039479$ & 2920,311841 & $-0,040925207$ \\
\hline may-05 & 126,16 & 2288,842642 & $-0,018634819$ & 2875,994816 & $-0,015175443$ \\
\hline jun-05 & 119,98 & 2195,485446 & $-0,040787949$ & 2705,129698 & $-0,059410788$ \\
\hline jul-05 & 108,45 & 1978,809426 & $-0,098691622$ & 2437,9882 & $-0,098753675$ \\
\hline ago-05 & 108,43 & 1959,491647 & $-0,009762324$ & 2444,539356 & 0,002687116 \\
\hline sep-05 & 98,17 & 1766,280816 & $-0,098602528$ & 2221,766023 & $-0,091131007$ \\
\hline oct-05 & 106,09 & 1915,775313 & 0,084638012 & 2414,055277 & 0,086547931 \\
\hline nov-05 & 108,81 & 1973,521289 & 0,030142353 & 2452,33781 & 0,015858184 \\
\hline dic-05 & 103,03 & 1868,580243 & $-0,053174519$ & 2316,003405 & $-0,055593648$ \\
\hline ene-06 & 124,36 & 2245,14953 & 0,201526955 & 2834,951455 & 0,224070504 \\
\hline feb-06 & 118,52 & 2148,441585 & $-0,043074166$ & 2671,823367 & $-0,057541757$ \\
\hline mar-06 & 112,2 & 2040,609705 & $-0,050190743$ & 2437,946315 & $-0,087534624$ \\
\hline abr-06 & 114,71 & 2076,038538 & 0,017361886 & 2477,104492 & 0,016061952 \\
\hline may-06 & 107,96 & 1939,913694 & $-0,065569517$ & 2328,873542 & $-0,059840411$ \\
\hline jun-06 & 101,21 & 1830,756984 & $-0,056268848$ & 2298,676601 & $-0,012966329$ \\
\hline jul-06 & 102,77 & 1851,522011 & 0,011342317 & 2429,756012 & 0,057023859 \\
\hline ago-06 & 112,13 & 2016,893341 & 0,089316427 & 2529,043512 & 0,040863157 \\
\hline sep-06 & 109,36 & 1976,837547 & $-0,019860145$ & 2499,621743 & $-0,011633556$ \\
\hline oct-06 & 110,91 & 2004,628325 & 0,0140582 & 2571,377125 & 0,028706496 \\
\hline nov-06 & 123,57 & 2226,5677 & 0,110713479 & 2803,91799 & 0,090434368 \\
\hline dic-06 & 129,95 & 2328,285905 & 0,045683859 & 2986,341024 & 0,065060046 \\
\hline ene-07 & 124,46 & 2250,133467 & $-0,033566513$ & 2834,051189 & $-0,05099546$ \\
\hline feb-07 & 122,34 & 2226,039884 & $-0,010707624$ & 2804,54318 & $-0,010411953$ \\
\hline mar-07 & 116,61 & 2133,489502 & $-0,041576246$ & 2690,499874 & $-0,040663772$ \\
\hline abr-07 & 114,59 & 2091,65759 & $-0,019607273$ & 2745,017563 & 0,020263034 \\
\hline may-07 & 112,52 & 2044,620014 & $-0,022488182$ & 2639,739532 & $-0,038352407$ \\
\hline jun-07 & 118,67 & 2151,317404 & 0,052184459 & 2617,583309 & $-0,008393337$ \\
\hline jul-07 & 116,8 & 2102,258247 & $-0,022804239$ & 2497,72138 & $-0,045791065$ \\
\hline ago-07 & 123,63 & 2228,368585 & 0,059988033 & 2683,433711 & 0,074352701 \\
\hline sep-07 & 128,04 & 2286,88934 & 0,026261704 & 2999,220668 & 0,117680178 \\
\hline oct- 07 & 134,57 & 2364,609116 & 0,033984931 & 2925,554491 & $-0,024561773$ \\
\hline nov-07 & 130,33 & 2258,870625 & $-0,044717112$ & 2986,682702 & 0,020894573 \\
\hline dic- 07 & 136,47 & 2366,485523 & 0,047641019 & 3119,05412 & 0,044320549 \\
\hline ene-08 & 139,05 & 2405,236042 & 0,016374712 & 3272,6574 & 0,04924675 \\
\hline feb-08 & 158,21 & 2747,253114 & 0,142196884 & 3722,337618 & 0,137405223 \\
\hline mar-08 & 148,07 & 2605,549292 & $-0,051580184$ & 3391,581916 & $-0,088856986$ \\
\hline
\end{tabular}




\begin{tabular}{|c|c|c|c|c|c|}
\hline abr-08 & 137,74 & 2396,429072 & $-0,080259553$ & 3132,919029 & $-0,076266148$ \\
\hline may-08 & 139,74 & 2429,70433 & 0,013885351 & 3265,3475 & 0,042269995 \\
\hline jun-08 & 144,08 & 2502,236206 & 0,029852141 & 3094,251795 & $-0,052397396$ \\
\hline jul-08 & 145,35 & 2505,721133 & 0,001392725 & 3212,280845 & 0,038144617 \\
\hline ago-08 & 145,77 & 2549,663906 & 0,017536977 & 2992,283938 & $-0,068486199$ \\
\hline sep-08 & 140,56 & 2509,362225 & $-0,015806664$ & 2997,171419 & 0,001633361 \\
\hline oct-08 & 121,41 & 2272,939544 & $-0,094216243$ & 2743,80658 & $-0,084534651$ \\
\hline nov-08 & 120,44 & 2301,267728 & 0,012463237 & 2811,207449 & 0,02456473 \\
\hline dic-08 & 116,97 & 2239,461464 & $-0,026857485$ & 2677,682344 & $-0,047497422$ \\
\hline ene-09 & 128,03 & 2490,910936 & 0,112281223 & 2884,490294 & 0,077233937 \\
\hline feb-09 & 128,51 & 2547,699248 & 0,022798211 & 3170,242604 & 0,099065097 \\
\hline mar-09 & 127,76 & 2537,482635 & $-0,004010133$ & 2831,377442 & $-0,106889347$ \\
\hline abr-09 & 134,58 & 2632,002887 & 0,037249615 & 2957,587014 & 0,044575326 \\
\hline may-09 & 147,64 & 2836,078194 & 0,077536126 & 3173,861822 & 0,073125425 \\
\hline jun-09 & 144,46 & 2736,988058 & $-0,034939141$ & 3092,810361 & $-0,025537174$ \\
\hline jul-09 & 137,6 & 2600,506285 & $-0,049865681$ & 3052,307202 & $-0,013095908$ \\
\hline ago-09 & 146,87 & 2743,848727 & 0,055120975 & 3292,39134 & 0,07865661 \\
\hline sep-09 & 145,67 & 2685,775836 & $-0,021164757$ & 3262,564214 & $-0,009059411$ \\
\hline oct-09 & 151,95 & 2778,115165 & 0,034380877 & 3319,992896 & 0,017602315 \\
\hline nov-09 & 150,23 & 2732,003803 & $-0,016598074$ & 3525,56223 & 0,061918607 \\
\hline dic-09 & 155,86 & 2864,873746 & 0,048634611 & 3550,667084 & 0,007120809 \\
\hline ene-10 & 154,41 & 2889,802945 & 0,008701675 & 3350,904933 & $-0,056260457$ \\
\hline feb-10 & 155,92 & 2986,704803 & 0,033532341 & 3388,217446 & 0,011135056 \\
\hline mar-10 & 162,15 & 3089,774855 & 0,034509622 & 3590,093655 & 0,059581834 \\
\hline$a b r-10$ & 171,07 & 3254,768219 & 0,053399802 & 3923,272712 & 0,092805116 \\
\hline may-10 & 174,03 & 3367,746492 & 0,034711619 & 3942,307958 & 0,004851879 \\
\hline jun-10 & 193,52 & 3761,274146 & 0,116851923 & 4213,108073 & 0,068690756 \\
\hline jul-10 & 205,25 & 3935,961745 & 0,046443729 & 4561,821398 & 0,082768664 \\
\hline ago-10 & 212,8 & 4064,717545 & 0,032712665 & 4670,838596 & 0,023897735 \\
\hline sep-10 & 222,1 & 4203,882964 & 0,034237414 & 5012,300582 & 0,073105071 \\
\hline oct-10 & 215,84 & 4004,404754 & $-0,047450943$ & 4969,041825 & $-0,008630519$ \\
\hline nov-10 & 227,96 & 4234,255938 & 0,057399588 & 5286,444423 & 0,063876016 \\
\hline dic-10 & 237,33 & 4441,279576 & 0,048892566 & 5484,394137 & 0,037444774 \\
\hline ene-11 & 262,94 & 4920,486921 & 0,107898487 & 5741,877202 & 0,046948315 \\
\hline feb-11 & 288,08 & 5375,011602 & 0,092373923 & 6565,311907 & 0,143408623 \\
\hline mar-11 & 294,48 & 5442,149218 & 0,012490692 & 6704,600767 & 0,021215879 \\
\hline abr-11 & 302,71 & 5519,826914 & 0,014273349 & 6649,274668 & $-0,00825196$ \\
\hline may-11 & 293,06 & 5336,134995 & $-0,033278565$ & 6571,583513 & $-0,011684155$ \\
\hline jun-11 & 277,78 & 5065,602442 & $-0,050698221$ & 6182,545225 & $-0,059200083$ \\
\hline jul-11 & 269,18 & 4881,668034 & $-0,03631047$ & 6027,119413 & $-0,025139454$ \\
\hline ago-11 & 273,54 & 4964,254631 & 0,0169177 & 6239,849262 & 0,035295443 \\
\hline
\end{tabular}




\begin{tabular}{|l|l|l|l|l|l|} 
sep-11 & 275,58 & 5101,584934 & 0,027663831 & 6260,961284 & 0,003383419 \\
\hline oct-11 & 248,49 & 4624,773785 & $-0,093463336$ & 5793,669343 & $-0,074635814$ \\
\hline nov-11 & 249,5 & 4655,586568 & 0,006662549 & 5629,657792 & $-0,028308752$ \\
\hline dic-11 & 243,14 & 4582,679441 & $-0,015660138$ & 5468,054338 & $-0,028705733$ \\
\hline ene-12 & 240,89 & 4537,824931 & $-0,009787835$ & 5200,018603 & $-0,049018484$ \\
\hline feb-12 & 225,49 & 4213,604853 & $-0,071448344$ & 4931,802446 & $-0,051579846$ \\
\hline mar-12 & 201,85 & 3761,89444 & $-0,107202841$ & 4515,661072 & $-0,084379165$ \\
\hline abr-12 & 193,35 & 3609,0365 & $-0,040633235$ & 4370,9013 & $-0,032057271$ \\
\hline may-12 & 186,35 & 3531,851429 & $-0,021386614$ & 4177,301959 & $-0,044292773$ \\
\hline jun-12 & 169,79 & 3248,573767 & $-0,080206562$ & 3787,951455 & $-0,093206215$ \\
\hline jul-12 & 190,77 & 3633,238928 & 0,118410475 & 4298,065381 & 0,134667493 \\
\hline ago-12 & 175,97 & 3329,250311 & $-0,083668766$ & 4039,913048 & $-0,060062449$ \\
\hline sep-12 & 179,6 & 3368,241079 & 0,011711576 & 4074,874432 & 0,008653994 \\
\hline oct-12 & 172,37 & 3220,93876 & $-0,043732712$ & 3901,449359 & $-0,042559612$ \\
\hline nov-12 & 160,64 & 3011,433512 & $-0,065044779$ & 3638,16867 & $-0,06748279$ \\
\hline dic-12 & 154,22 & 2879,40111 & $-0,043843705$ & 3438,139391 & $-0,05498076$ \\
\hline ene-13 & 158,27 & 2945,257783 & 0,022871657 & 3529,884573 & 0,026684544 \\
\hline feb-13 & 153 & 2868,49984 & $-0,026061537$ & 3462,950807 & $-0,018962027$ \\
\hline mar-13 & 153,01 & 2883,852847 & 0,005352278 & 3464,395662 & 0,000417232 \\
\hline abr-13 & 152,96 & 2878,858135 & $-0,001731958$ & 3489,277576 & 0,00718218 \\
\hline may-13 & 151,43 & 2862,992216 & $-0,005511185$ & 3433,694906 & $-0,015929564$ \\
\hline jun-13 & 138,86 & 2641,904883 & $-0,077222471$ & 3208,651061 & $-0,065539849$ \\
\hline jul-13 & 138,44 & 2634,016428 & $-0,002985896$ & 3104,351089 & $-0,032505863$ \\
\hline ago-13 & 135,63 & 2582,151258 & $-0,019690526$ & 3058,757268 & $-0,01468707$ \\
\hline sep-13 & 132,78 & 2531,461567 & $-0,019630799$ & 3011,988782 & $-0,015290029$ \\
\hline oct-13 & 128,83 & 2431,491322 & $-0,039491117$ & 2880,797776 & $-0,043556273$ \\
\hline nov-13 & 122,75 & 2324,205924 & $-0,04412329$ & 2809,606535 & $-0,024712335$ \\
\hline dic-13 & 126,74 & 2400,331083 & 0,03275319 & 2872,474046 & 0,022375913 \\
\hline
\end{tabular}

Fuente: Elaboración propia 
Anexo I. Costo de producción por hectárea (pequeños)

\begin{tabular}{|l|l|}
\hline Región: & Antioquia \\
\hline Cultivo: & Café Tecnificado \\
\hline Duración ciclo: & 5 años \\
\hline Tipo productor: & Pequeño Menor a 5 Has \\
\hline Actualización: & sep-09 \\
\hline
\end{tabular}

\begin{tabular}{|l|l|l|l|l|}
\hline & \multicolumn{4}{|c|}{ Año 1 } \\
\hline ITEM & V.Total \% & Par. & Jornales & Hr/Maq \\
\hline COSTO DIRECTO & 5.419 .398 & 82,1 & & \\
\hline Adecuación Terreno & 220.000 & 3,3 & 11 & \\
\hline Adecuación & 220.000 & 3,3 & 11 & \\
\hline Siembra & 753.333 & 11,4 & 38 & \\
\hline Mantenimiento Cultivo & 1.013 .333 & 15,3 & 51 & \\
\hline Labores culturales & 673.333 & 10,2 & 34 & \\
\hline Aplicación insumos & 340.000 & 5,1 & 17 & \\
\hline Insumos & 3.432 .731 & 52 & \multicolumn{1}{|c|}{ Unid. Empleadas } \\
\hline Material propagación & 1.407 .400 & 21,3 & 7.037 & Unidades \\
\hline Enmienda & 446.546 & 6,8 & $2.116,30$ & Kg - Lt \\
\hline Fertilizantes edáficos & 1.162 .558 & 17,6 & 942 & Kg - Lt \\
\hline Fertilizantes foliares & 13.982 & 0,2 & 0,9 & Kg - Lt \\
\hline Fungicidas & 168.545 & 2,6 & 1,8 & Kg - Lt \\
\hline Insecticidas & 112.823 & 1,7 & 3,7 & Kg - Lt \\
\hline Herbicidas & 89.610 & 1,4 & 6,3 & Kg - Lt \\
\hline Coadyuvantes & 31.267 & 0,5 & 1,3 & Kg - Lt \\
\hline & & & & \\
\hline COSTO INDIRECTO & 1.184 .889 & 17,9 & & \\
\hline Arriendo & 441.881 & 6,7 & & \\
\hline Asistencia técnica & 309.456 & 4,7 & & \\
\hline Administración ${ }^{27}$ & 162.582 & 2,5 & & \\
\hline Imprevistos ${ }^{28}$ & 270.970 & 4,1 & & \\
\hline COSTO TOTAL $^{29}$ & 6.604 .287 & 100 & & \\
\hline & & & & \\
\hline
\end{tabular}

Fuente: Sistema de Información de Precios de Insumos y Factores. Ministerio de Agricultura y Desarrollo Rural - Corporación Colombia Internacional. Cálculos Corporación Colombia Internacional.

\footnotetext{
$273 \%$ sobre costos directos.

28 5\% sobre costos directos

29 Costo y rendimiento en café pergamino.
} 


\section{Anexo J. Costo de producción por hectárea (medianos)}

\begin{tabular}{|l|l|}
\hline Región: & Antioquia \\
\hline Cultivo: & Café Tecnificado \\
\hline Duración ciclo: & 5 años \\
\hline Tipo productor: & Mediano Entre 5 - 20 Has \\
\hline Actualización: & sep-09 \\
\hline
\end{tabular}

\begin{tabular}{|c|c|c|c|c|}
\hline & \multicolumn{4}{|c|}{ Año 1} \\
\hline ITEM & V.Total \% & \% Par. & Jornales & $\mathrm{Hr} / \mathrm{Maq}$ \\
\hline COSTO DIRECTO & 5.500 .936 & 77 & & \\
\hline Adecuación Terreno & 206.667 & 2,9 & 10 & \\
\hline Adecuación & 206.667 & 2,9 & 10 & \\
\hline Siembra & 933.333 & 13,1 & 47 & \\
\hline Mantenimiento Cultivo & 1.413 .333 & 19,8 & 71 & \\
\hline Labores culturales & 946.667 & 13,3 & 47 & \\
\hline Aplicación insumos & 466.667 & 6,5 & 23 & \\
\hline Insumos & 2.947 .602 & 41,3 & \multicolumn{2}{|c|}{ Unid. Empleadas } \\
\hline Material propagación & 1.191 .400 & 16,7 & 5.957 & Unidades \\
\hline Enmienda & 321.494 & 4,5 & $1.523,70$ & $\mathrm{Kg}-\mathrm{Lt}$ \\
\hline $\begin{array}{l}\text { Abono orgánico y } \\
\text { acondicionadores }\end{array}$ & 231.136 & 3,2 & 992 & $\mathrm{Kg}-\mathrm{Lt}$ \\
\hline Fertilizantes edáficos & 1.033 .867 & 14,5 & $1.040,00$ & $\mathrm{Kg}-\mathrm{Lt}$ \\
\hline Fertilizantes foliares & 13.315 & 0,2 & 0,7 & $\mathrm{Kg}-\mathrm{Lt}$ \\
\hline Fungicidas & 57.708 & 0,8 & 0,8 & $\mathrm{Kg}-\mathrm{Lt}$ \\
\hline Insecticidas & 42.466 & 0,6 & 1,4 & $\mathrm{Kg}-\mathrm{Lt}$ \\
\hline Herbicidas & 49.250 & 0,7 & 3,7 & $\mathrm{Kg}-\mathrm{Lt}$ \\
\hline Coadyuvantes & 6.967 & 0,1 & 0,3 & $\mathrm{Kg}-\mathrm{Lt}$ \\
\hline COSTO INDIRECTO & 1.640 .041 & 23 & & \\
\hline Arriendo & 1.001 .596 & 14,0 & & \\
\hline Asistencia técnica & 198.369 & 2,8 & & \\
\hline Administración ${ }^{30}$ & 165.028 & 2,3 & & \\
\hline Imprevistos ${ }^{31}$ & 275.047 & 3,9 & & \\
\hline COSTO TOTAL ${ }^{32}$ & 7.140 .976 & 100 & & \\
\hline
\end{tabular}

Fuente: Sistema de Información de Precios de Insumos y Factores. Ministerio de Agricultura y Desarrollo Rural - Corporación Colombia Internacional. Cálculos Corporación Colombia Internacional.

\footnotetext{
30 3\% sobre costos directos.

$315 \%$ sobre costos directos.

32 Costo y rendimiento en café pergamino.
} 
Anexo K. Costo de producción por hectárea (grandes)

\begin{tabular}{|l|l|}
\hline Región: & Antioquia \\
\hline Cultivo: & Café Tecnificado \\
\hline Duración ciclo: & 5 años \\
\hline Tipo productor: & $\begin{array}{l}\text { Grande Mayor a 20 } \\
\text { Has }\end{array}$ \\
\hline Actualización: & sep-09 \\
\hline
\end{tabular}

\begin{tabular}{|c|c|c|c|c|}
\hline & \multicolumn{4}{|c|}{ Año 1} \\
\hline ITEM & V.Total \% & \% Par. & Jornales & $\mathrm{Hr} / \mathrm{Maq}$ \\
\hline COSTO DIRECTO & 4.823 .468 & 81,1 & & \\
\hline Adecuación Terreno & 40.000 & 0,7 & 2 & \\
\hline Adecuación & 40.000 & 0,7 & 2 & \\
\hline Siembra & 816.767 & 13,7 & 41 & \\
\hline Mantenimiento Cultivo & 886.667 & 14,9 & 44 & \\
\hline Labores culturales & 633.333 & 10,6 & 32 & \\
\hline Aplicación insumos & 253.333 & 4,3 & 13 & \\
\hline Insumos & 3.080 .034 & 51,8 & Unid. & leadas \\
\hline Material propagación & 1.394 .733 & 23,4 & 6.974 & Unidades \\
\hline Enmienda & 172.117 & 2,9 & 533,30 & $\mathrm{Kg}-\mathrm{Lt}$ \\
\hline Fertilizantes edáficos & 1.286 .431 & 21,6 & $1.058,30$ & $\mathrm{Kg}-\mathrm{Lt}$ \\
\hline Fertilizantes foliares & 3.800 & 0,1 & 1 & $\mathrm{Kg}-\mathrm{Lt}$ \\
\hline Fungicidas & 83.521 & 1,4 & 0,8 & $\mathrm{Kg}-\mathrm{Lt}$ \\
\hline Insecticidas & 73.715 & 1,2 & 2,6 & $\mathrm{Kg}-\mathrm{Lt}$ \\
\hline Herbicidas & 59.583 & 1 & 4,3 & $\mathrm{Kg}-\mathrm{Lt}$ \\
\hline Coadyuvantes & 6.133 & 0,1 & 0,7 & $\mathrm{Kg}-\mathrm{Lt}$ \\
\hline COSTO INDIRECTO & 1.125 .312 & 18,9 & & \\
\hline Arriendo & $441.8817,4$ & 14,0 & & \\
\hline Asistencia técnica & 297.554 & 5 & & \\
\hline Administración ${ }^{33}$ & 144.704 & 2,4 & & \\
\hline Imprevistos $^{34}$ & 241.173 & 4,1 & & \\
\hline COSTO TOTAL ${ }^{35}$ & 5.948 .780 & 100 & & \\
\hline
\end{tabular}

Fuente: Sistema de Información de Precios de Insumos y Factores. Ministerio de Agricultura y Desarrollo Rural - Corporación Colombia Internacional. Cálculos Corporación Colombia Internacional.

\footnotetext{
33 3\% sobre costos directos.

$345 \%$ sobre costos directos.

35 Costo y rendimiento en café pergamino.
} 